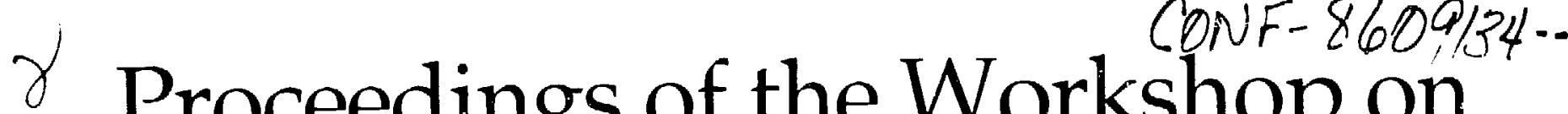

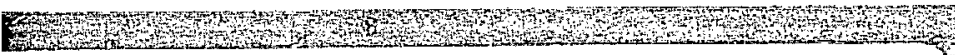
Received hy 0STI

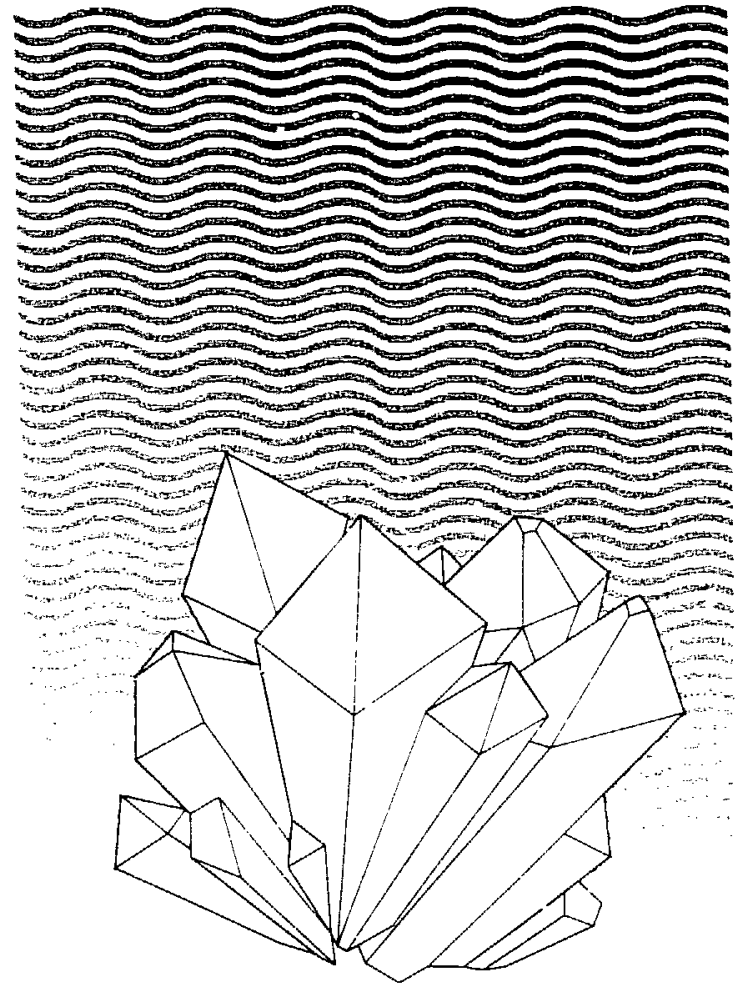

September 14-17, 1986 Failen Leaf Lake, California

Sponsored by the Office of Civilian Radioactive Waste Management Program at the Lawrence Livermore National Laboratory

Technical Organizers: 


\section{DISCL AIMER}

This document was prepared as an account of work sponsored by an agenat of the L nited States Covernment Veither the Lnited States Government nor the Lniversity of California nor any of their employees, makes any warranty: express or implied, or jssumes any legal liability or responsibility tor the accuracy. completeness, or usefulness of any information, apparatus, product, or process disclosed, or represents that its use would not intringe privately owned rights. Reference herein to any specific commercial products, process, or service hy trade name, trademark, manutacturer, or otherwise, does not necessarily constitute or imply its endorsement, recommendation, or tasoring bv the Lnited States Government or the Lniversity of Culifornis. The views and opinions of authors expressed herein do not necessarily state or reflect those ot the L'nited States Government or the Lniversity of California, and shall not be used for advertising or product endorsement purposes. 


\title{
Proceedings of the Workshop on Geochemical Modeling
}

\author{
Kenneth J. Jackson \\ and \\ William L. Bourcier \\ Technical Organizers
}

Fallen Leaf Lake, California

September 14-17, 1986

Lawrence Livermore National Laboratory

Livermore, California 


\section{IVR(I)) ( II)}

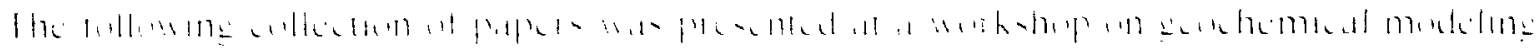

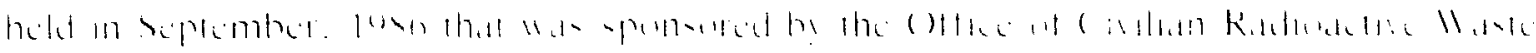

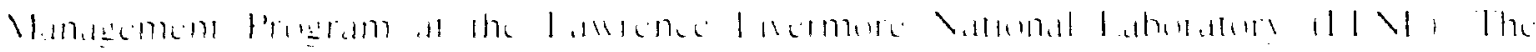

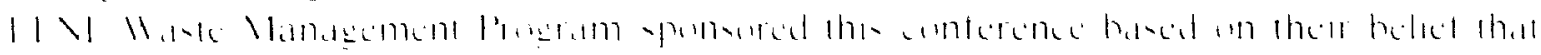

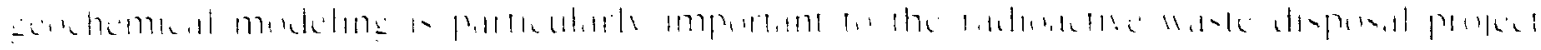

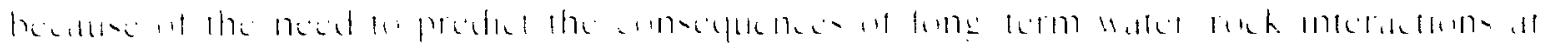

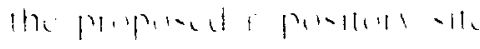

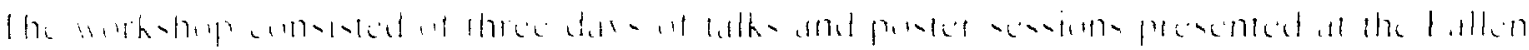

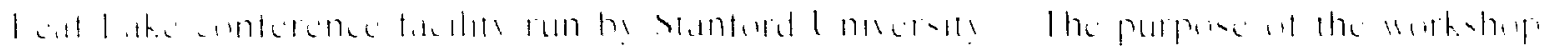

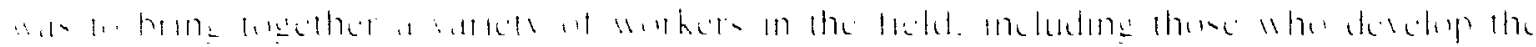

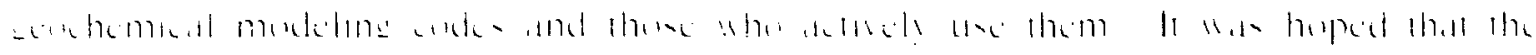

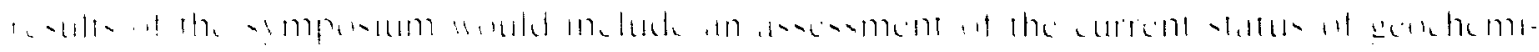

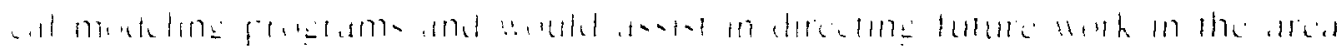

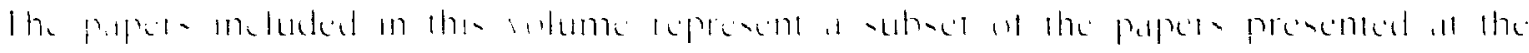

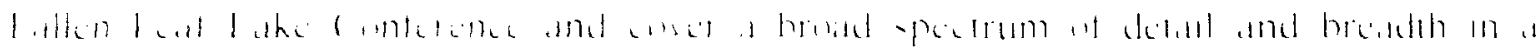
-

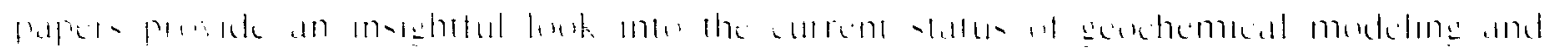

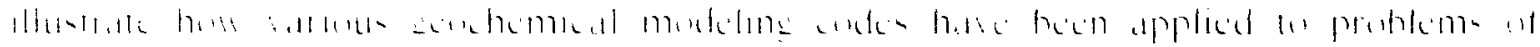

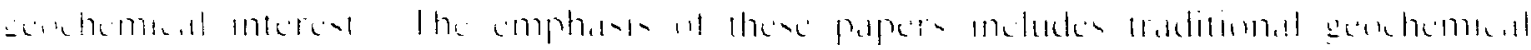

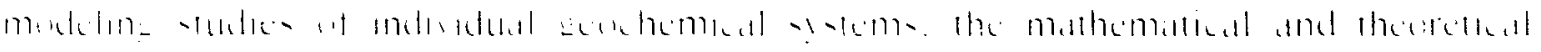

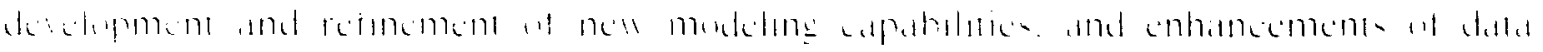

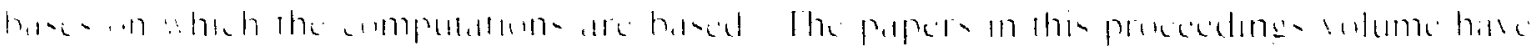

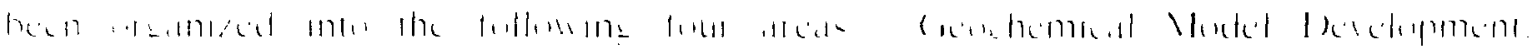

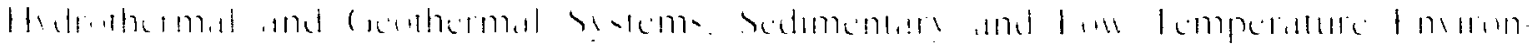

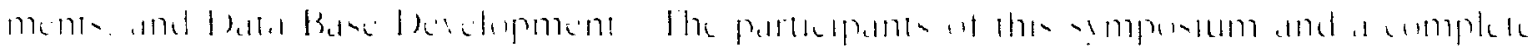

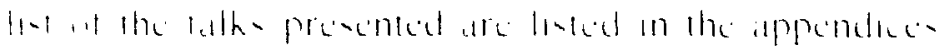

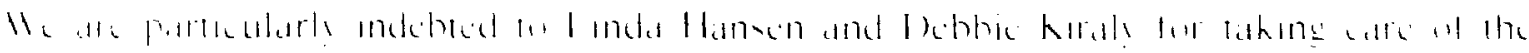

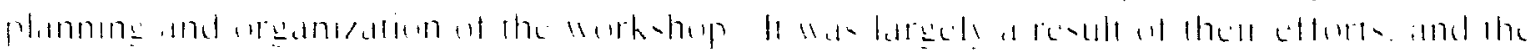

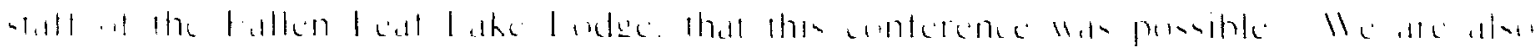

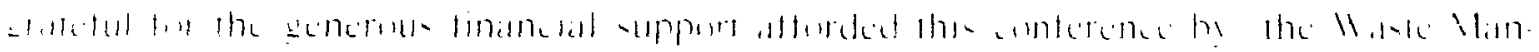

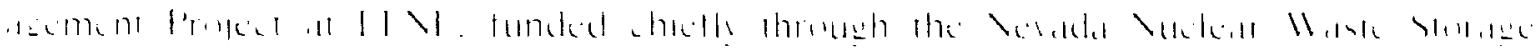

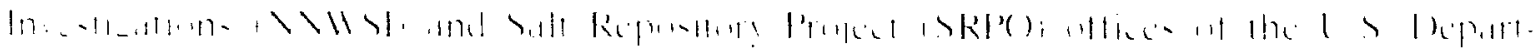

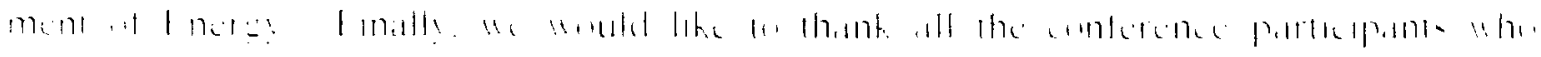

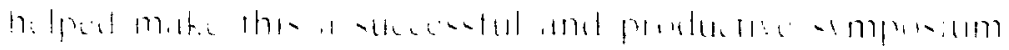

\section{hemnelh I. Iachumn and II illiam I. Bunteiel}

\section{Iechnical Greaniser}




\section{Contents}

\section{Geochemical Model Development}

Multiple Reaction Path Model Describing Mass Transfer in Geochemical Systems

Petter C. Lichtrt'r ................................................................ .

EQ3/6 - Status and Future Development

Thumas I. Wulery ................................................................. 10

A Theoretical Basis for the Coupling of Chemical Reactions to Open System

Processes

E. H. Perkins

Calculations of Geochemical Mass Transfer as a Function of Temperature and Time

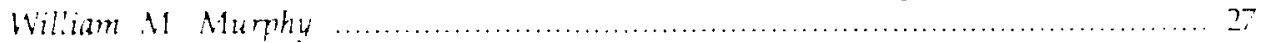

Development and Application of Stable Isotope Mass T:ansfer Reaction Path Models

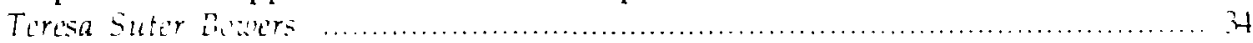

Improvements in the Solid Solution Modeling Capabilities of EQ3/6

Hilliam L. Bourcier

\section{Hydrothermal and Geothermal Systems}

Preliminary Chemical Modeling of Epithermal Processes at Creede, Colorado:

The Role of Fluid Mixiri: is an Ore Deposition Mechanism

Geoffrey 5. Plumlee and Daniel O. Hayba

Boiling of Geothermal Waters: Precipitation of Base and Precious Metals, Speciation

of Arsenic and Antimony, and the Role of Gas Phase Metal Transport

Niculas F. Spycher and Mark H. Reed 58

Progressive Mineral Alteration and Coupled ${ }^{18} \mathrm{O}$ Depietions in the Lake City

Hydrothermal System (23 Ma), Colorado

Peter B. Larson (x)

Application of EQ3/6 to Modeling the Chemical Evolution in Hydrothermal

Systems: An Example at the Valles Caldera, N.M.

Art $F$. White and Nancy I. Chuma

Serpentinization Reaction Pathways: Implicstions for Modeling Approach

D. R. Janicky

Predicted Reaction Paths During the Hydrothermal Alteration of Columbia River

Basalt: A Sensitivity Analysis of Variability in the Composition of the Mesostasis

R. C Arthur

\section{Sedimentary and Low Temperature Environments}

Chemical Equilibrium in Mineral Formation and Diagenesis in the Carbonate

Evaporite System: An Assessment of Chemical Model Application to

Site Performance

John H. Weare. Vancy Noller. lerry Gréthers. and Andrew Folmy

Modelling Mass Transfer Reaction Rates: Calcite Precipitation and $\mathrm{CO}_{2}$

Outgassing in a Karst Stream

lanet 5 . Herman and Wichille' 11. Irrah

Predicting Mineral Dissolution and Precipitation During Burial: Synthetic

Diagenetic Sequences 
Modelling Interaction of Deep Groundwaters with Bentonite

Hans Vianner

Evaluation of an Equilibrium Speciation Model for the Acid Aqueous Iron Sulfate

System at $25^{\circ} \mathrm{C}$

Susan L. Stipp

Thermodynamic and Kinetic Modeling of Glass Leaching in a Waste Pachage

Environment

B. Grambou

Computer Modeling of the Aqueous Geochemistry of the Archean Hydrosphere and the Formation of Banded Iron Formations

William E. Glassley, Kenneth I. Jackson, and Willium L. Bunritir

\section{Database Development}

The NEA Thermocherical Data Base

Hans Wanner

EQ3/6 Data Base - Ongoing Development at Lawrence Livermore National

Laboratory

Joan M. Delany

A Consistent Set of Thermodynamic Constants for Americium (II) Species

with Hydroxyl and Carbonate

lerry F. Kerrisk and Robert I. Silva

Software for the Computation and Graphical Display of Intensive Variable

Phase Diagrams

E. H. Perkins, R. Berman, and T. H. Brown

Chlorite Solubility Between $200^{\circ} \mathrm{C}$ and $350^{\circ} \mathrm{C}$ : An Experimental and Theoretical

Modeling Study

Edward C. Thornton, William E. Seyfried, Jr., and Jeffrey Secwald

Appendices

A. Agenda

B. List of Attendees 
Geochemical Model Development 


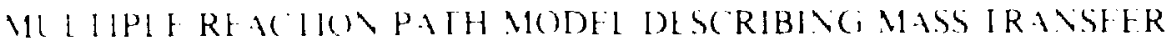

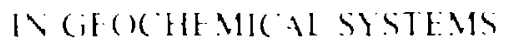

\author{
Peter C. Luhtner \\ Departrant of Geologe and Geophesks \\ Lnsersitl of California \\ Berkeles. California 44720
}

Ahatrat

Cickemeal reactun path models tor open sustems approximate interacting continua modek describing thiwng ststems hior sufficient! lurge Peclet numbers and surface controlled mineral dissolullun rates Two distunct tume scales characterize mass transter for such systems. related to fluid transfort and mineral reaction rates along the flow path. The reaction path formulation is valid when the tunce reutred for a packet of fluid to traverse a characteristic distance along the flow path is much shurter than the lime characterizing changes in mineral volume fraction. porosity. permeability and mineral surface ared. The upen system reaction path model results in a steady state regime in which the tluid compositun and mineral reation rates are constant in time, hut may vary with distance. Mineral alteration zones are stationary throughout the steady state regime despite a constant fluid how rate. Whencer a mineral in an alteration zone completely dissolves. or significant changes occur in reacting surface area. porosity or permeability. a new reaction path is formed. By considering a conrecullice sertes of such paths. the time evolution of a geochemical system can be predicted ovel geologi: time spans. It is suggested that a multiple reaction path approach may be applicable to the descriptun of metasomatic processes and weathering phenomena including the formation of bauxite depusts The sssue of mudel verification and validation in light of this new interpretation of reaction puth models is hriefly discussed.

Introduction

Compututionall!. geochemical reaction path models have advanced considerably since the pionering work of Helgeson and co-workers (Helgeson et al. 1966: Helgeson. 1968: Helgeson e! al.. 1ytiy). However. the development of a conceptual and quantitative framework which incorporates a spatial representation of mineral alteration products and fluid composition in response to fluid flow: within the reaction path approach has received relatively little attention. Previous applications of the open s!stem reaction path formulation to geochemical systems have been limited to a description of the change in mineral and fluid composition with time or reaction progress. but not as a function of distance along the flow path. The rapid approach to equilibrium exhibited by both open and closed reaction path calculations involving the dissolution of feldspar has been interpreted as implying that quasi-equilibrium conditions are established instantaneously on a geologic time scale (Helgeson and Murph: 19831. However. as demonstrated below. when interpreted spatially these results imply that conditions far from equilibrium may persist in flowing systems over geologic time.

Although in open system option for product mineral assemblages is incorporated in the computer code EQ3it (Moler! 1987). Woler dismissed its applicability to circulating hydrothermal systems in favor of the closed sıctem path model (Wolery. 1980). Bowers and Taylor (1985) combined both upen and closed variations of the reaction path approach in an attempt to describe isotopic changes in the miducean ridge hydrothermal st stem resulting from seawater-hasalt interaction and flurd tlow in the presence of a thermal gradient. The present contribution proposes that the open rather than the closed system reaction path model is the appropriate description for flowing systems. regardless of whether fluds are curul.ting or not. or whether the system contains variations in 


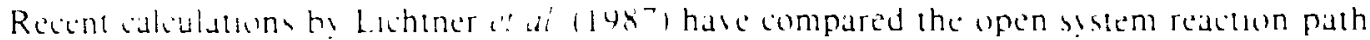
model whh d tramsent. ume-space contunum model. Following a hrief transtent period. excellent agreenient helween the wo models was found throughout a spallal region in which a steads state fivrmed These result appl! 6 s!stems sharacterized hy large Peilet numbers and surface controlled moneral discolutun rates. It thus appears that the open ststem reatun path model has greater generalli! than presously acknowledged. This contrihutun outlines the basis for a conceptual framework that combines fluid flow with chemical reactions by generalizang the open system reaction path rinodel to incorporate multiple reation paths hased on a mised Lagrangian-Eulerian description of flund flow in porous media. Further details of this approach and numerical examples can be found in Lichtner $\left(148{ }^{-1}\right)$.

Reinterpretatun of the Open Sistem Reaction Path Model for Flowing Sistems

The open compostuon of a single packet of thid as it traverses the flow path and reacts with minerals with which it comes in contact. The packet is presumed closed with respect to transter of matter within the aqueous phase. but open with respect to minerals. Mineral products precipitated from the packet are left behind as the packet advances along the flow path and do not hack react with the fluid in the packet. One difficulty in interpreting the results of reaction path calculations in terms of a space courdinate is relating the amount of reacted rock to distance along the flow path. The incorporation of reaction kinetics into these models (Helgeson and Aagaard. 1979: Helgeson and Murphy. 1983). has ben of primary significance for nierging fluid flow with geochemical reaction path calculations by providing an absolute scale of time with which to correlate fluid flow rates with mineral reaction rates.

Incurporating kinetics into the reaction path model allows the chemical composition of the fluid in the packet to be parameterized by a single parameter 1 . equal to the time the packet is in contact with the rock along the flow path. Conservation of mass requires that the composition of the fluid packet satisty equations of the form developed by Helgeson and Murphy (1983) and, for example. solved by more recent bersiuns of the computer code EQ3/6 which incorporate dissolution and precipitation kinetics of the reacting host rock (Wolery. 1987). A solution to these equations yields the concentration and mineral reaction rates as a function of elapsed time of the packet along the flow path. Also obiained are the times of appearance and disappearance of product minerals.

Equivalently. for fluid flow in a one-dimensional porous medium with constant porosity and permeability. time can be related to the distance $x$ along the flow path by multiplying by the average pore velocity according to

$$
x=\frac{y}{\phi},
$$

where 1 denotes the Darcy reiocity and $\phi$ designates the porosity. This formulation is equivalent to the Lagrangian representation of fluid flow (Bear. 1972). Transforming the time-dependent functions $($ ( $/$ ). I $/(/)$ representing the concentration of the $/$ th species and reaction rate of the $\pi$ th mineral. respectwely. according to Eqr. 11 ) yields an equivalent spatial representation in terms of functions $\left({ }^{\prime}(x)\right.$ and $I \prime-(x)$. These functions have the form

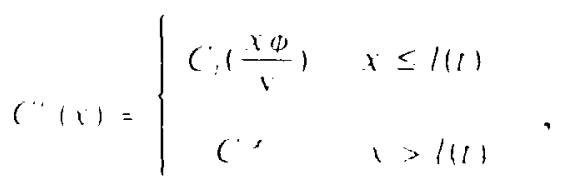

and

$$
I_{-1}(x)=\left\{\begin{array}{ccc}
I_{-1}\left(\begin{array}{l}
1 \\
1
\end{array}\right) & x \leq l(1) \\
0 & x>/ 11) \\
4 &
\end{array} .\right.
$$




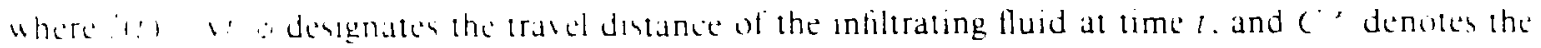
inclad solute concentration which is assumed wo be in equilibrium with the host rock.

Thu interpretutun of the uper system reaction path model impies that at any given point along the this path wthan a distance! ! ) of the inlet. the concentration and reactun rates are constant in

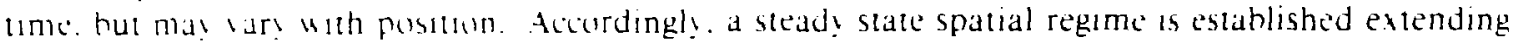
from the inled $\omega / / /$ ). Furthermore. zones of secondary mineralization within the steady state regime are statunary in lime despite a continuous fluid flow rate. The width of a particular reaction zone $\Delta /$, can be determined hy noung the tumes of a. 'peararive and disappearance of the corresponding mineral. denoted by is and respectively. and multiplying the difference in these times by the flow rate

$$
l_{-\pi}=\frac{1}{\omega}\left(T^{5}-i j\right)
$$

flthough not immediately apparent from Eqn.(4). $\Delta / \pi$ is independent of the porosity for $\phi \ll 1$. This is because the ume - is directly proportional to the porosity as can be seen by noting that the surface ared in contact with the tluid packet and hence the reaction rate are inversely proportional to the porosity. The leading boundary of the reaction zone farthest downstream advances linearly with time. its position conciding with the front of infiltrating fluid according to Eqns.(2) and (3).

The first packet of fluid determines the sequence of mineral reaction zones and their widths. During the duration of the steady state subsequent packets repeat the behavior of the first packet and merel! alter the amounts of reacting minerals precipitated or dissolved. It is this first reaction path that is computed by computer codes such as EQ6. Before considering how long such a steady state may last and how the first reaction path ma! become modified with time. it is necessary to first ascertain whether the forination of a stead state is a reasonable assumption in the first place.

\section{Comparison with Time-Space Continuum Models}

The formation of a steady state requires that the characteristic time for complete dissolution of minerals in the reacting host rock, or for significant changes to occur in redcting surface area. porosity and permetahility of the porous medium. be much laiger than the time required to attain steady state. An immediate question which arises is whether a steady state condition is consistent with an exact. transient description of fluid flow coupled to fluid/rock interactions. One means of answering this question is from calculations using so-called interacting continua models based on the Eulerian representation of fluid flow in porous media. In the Eulerian description. mass conservation equations are formulated relative io a fixed reference volume of rock referred to as a representative elemental volume (REV). The resulting set of nonlinear, partial differential equations must generally be solved numerically using finite difference techniques. Calculations performed for the reaction of microcline and quariz at $100 \mathrm{C}$ in a porous medium of porosit! 0.2 demonstrated that a steady state regime was acheved after only approximatel $5 \times 10^{\circ} \mathrm{sec}$ had elapsed (Lichtner el al. 1987). A flou rate of $1 \mathrm{~m}: \mathrm{r}$ and a diffusion coefficient of $10^{\mathrm{t}} \mathrm{cm}^{2} / \mathrm{sec}$ were used in the calculation. After a brief transient period during which reactions zones of secondary minerals phyrophyllite. gibbsite. kaolinite and muscovite were formed. a steady state was reached consisting of the mineral zones gibbsite and muscovite. The gibbsite-muscrite boundary remained stationary while the leading muscovite boundar adianced at a slightly retarded rate. Within the steady state regime the position of the gibbsitemuscowle houndar! as well as solute concentration and mineral reaction rates agreed with that obtained from the open system reaction path model. Lichtner (' al (1987) further demonstrated that for sıstems with large Peclet numbers. the open sistem reaction path model and the Eulerian formulatun of the transport equizitons are identical in the steady state limit. 
The condition of steady state cannot last indefinitely. A measure of the duration of steady state is given by the time required for a mineral grain in the host rock to completely dissolve. The characteristic time $r$, for the $r$ th minera! to dissolve can be estimated for conditions of far from equilibrium surface controlled reaction using the rate law of Helgeson 't al. (1984). The following expression is obrained:

$$
\tau_{r}^{I)}=\frac{a \phi_{r}^{0}}{\overline{\Gamma_{r} k_{r} s_{r}{ }^{0}}},
$$

where $\varphi^{\prime \prime}$ denotes the initial mineral volume fraction, $\bar{r}$, denotes the corresponding molar volume. $k_{r}$ denotes the rate constant, and $s_{r}^{\prime \prime}$ denotes the initial surface area per unit volume of bulk porous medium. The coefficient $a$ has the value one for constant surface area. ard three for variable surface area. taken to be proportional to the mineral volume fraction raised to the irvi-inirds power. The results for $1 \mathrm{~mm}$ sized grains of microcline in a porous medium with a porosity of 0.1 are shown in the accompanying figure as a function of temperature. Both $\mathrm{pH}$-dependent and $\mathrm{pH}$-independent forms of the rate law. the former for $\mathrm{pH} 4$, are illustrated. Solid lines correspond to variable surface area and crosses to constant surface area. The dissolution time ranges from approximately $10^{5}$ years at $25^{\circ} \mathrm{C}$ to $10^{4}$ years or $3 \times 10^{3} \mathrm{sec}$ at $600^{\circ} \mathrm{C}$.

The mineral dissolution time $\tau_{r}^{I \prime}$ can be compared with the time $\tau_{d}$ required for a packet of fluid to iravel a characteristic distance $d$ given by

$$
\tau_{d}=\frac{\phi d}{\mathrm{v}} .
$$

When

$$
\tau^{i} \gg \tau_{d},
$$

then many fluid packets traverse the flow path before significant changes occur in porosity. permeability and surface area. For example. according to the figure with a Darcy flow rate of $1 \mathrm{~m} \operatorname{year}^{-1}$ and a distance $d$ of $1 \mathrm{~m} . \tau_{d}=10^{-1}$ years. and condition (7) is satisfied for temperatures up to $600^{\circ} \mathrm{C}$ for the $\mathrm{pH}$-independent rate law and for temperatures less than approximately $200{ }^{\circ} \mathrm{C}$ for the $\mathrm{pH}$-dependent form of the rate law. For temperatures higher than these local equilibrium conditions are approached and a chromatographic description applies.

\section{Multiple Reaction Path Model}

As time progresses and additional packets of fluid traverse the flow path. several feedback inechanisms operate to alter the steady state pattern. At first, only the amounts of minerals present along the flow path change while the positions of the reaction zones remained fixed. Eventually, however. after sufficient time has elapsed, the mineral volume fractions become altered enough to effect the porosity and permeability of the porous medium and surface area of the reacting minerals, thereby perturbing the steady state reaction path. As the surface area and hence dissolution rate of the dissolving minerals decrease. where previously a secondary mineral was precipitating, for the new path it may be dissolving. A new steady state path is formed which persists until the surface area, permeability or porosity is again sufficiently altered to disturb the path. When one of the minerals in the host rock completely dissolves in some region of space, the various secondary minerals in the region and those downstream must readjust their zone boundaries to accommodate the new situation.

The multiple reaction path model consists of accounting for changes in the reaction path with time. while keeping track of the amount of each mineral precipitated or dissolved along the flow path. In this model subsequent packets of fluid react not only with the initial host 1ock, but also with secondary minerals deposited by preceding fluid packets. The change in mineral volume fraction with 
MICROCLINE

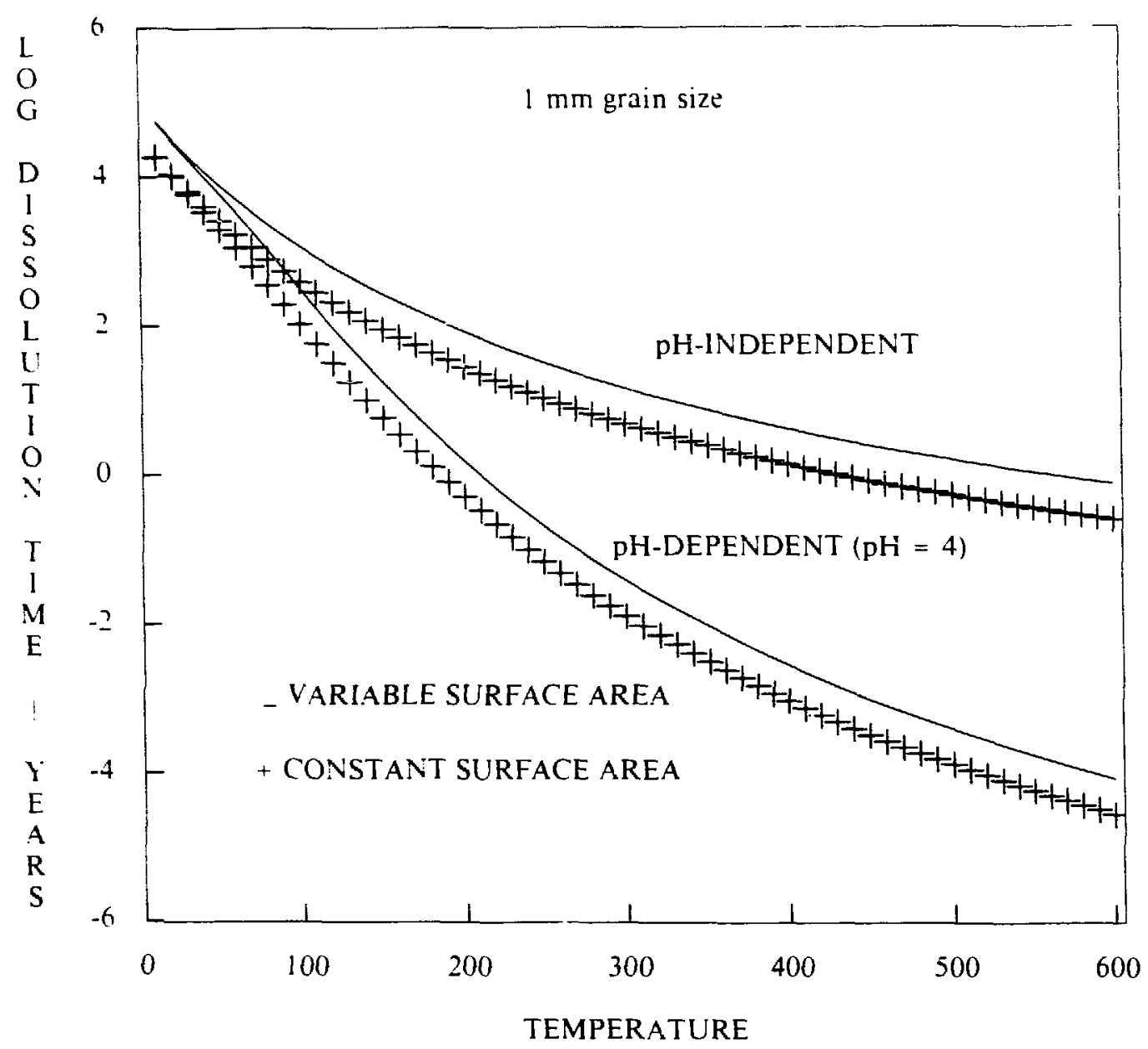

Logarithm of the dissolution tıme in years for $1 \mathrm{~mm}$ sized grains of microcline in a porous medium of porosity 0.1 plotted as a function of temperature. Rate laws for $\mathrm{pH}$-dependent and $\mathrm{pH}$-independent dissolution of microcline were taken from Helgeson et al. (1984).

time at a fixed position along the flow path can be computed by noting that for each path the reaction rates are constant in time. Thus the transport process consists of a series of steady state reaction paths. For the multiple reaction path model to be valid, each steady state path must be separated in time by an interval which is long compared to the time required to reach steady state, but short compared to the time for a mineral to completely dissolve.

Preliminary calculations for the dissolution of microcline at $25^{\circ} \mathrm{C}$ in response to infiltrating rainwater, indicate that the first reaction path lasts for several thousand years (Lichtner, 1987). During this time. according to the model calculations, secondary minerals gibbsite and kaolinite precipitate within stationary reaction zones. The second path results in gibbsite dissolving at the inlet end of the initial gibbsite zune and precipitating further downstream. Succeeding reaction paths generally exist for periods of time on the order of tens to hundreds of years as the mineral alteration zones slowly migrate downsteam. Such a model may account for the formation of bauxite deposits by chemical weathering. a process probably requiring on the order of hundreds of thousands of years 
(Butt! and Chapallaz. 1984).

Model Verification and Validation

A complete and rigorous formulation of reaction path models for flowing systems also has important consequences for model verification and validation. Model verification here refers to establishing that the model in question solves equations which are believed to represent physical reality as well as ensuring that the model was correctly programmed, while model validation refers to demonstrating that the model agrees with physical reality. Clearly model validation represents a much more difficult task.

Modis can be divided into two categories: those which are complete and those which are incomplete. Completeness of a model signifies whether or not the model provides a complete description within its range of applicability of the processes it attempts to explain. In principle an incomplete model is cannot be validated. The open system reaction path model represents an incomplete model since it only accounts for the first of many reaction paths that are necessary to describe coupled fluid flow and fluid/rock interaction. Hence in principle this model cannot be validated for situations in which more than one reaction path is important. The reaction path model may be partially validated however. if it can be demonstrated that the first reaction path correctly predicts the observed mineral assemblages. and that subsequent paths do not alter the mineralogy but only the amounts and location of minerals deposited along the flow path.

\section{Concluding Remarks}

There appears to be little fundamental basis for applying the closed system reaction path model or some combination of closed and open systems to flowing sỵstems. This is true for circuläing hydrothermal systems as well as flow in the presence of a temperature gradient. The physical basis for the validity of the multiple reaction path model is the existence of two distinct characteristic time scales related to fluid transport and mineral reaction rates. The multiple reaction path model applicable to systems characterized by large Pećlet numbers at a much reduced computational effort ccmpared to time-space continuum models based on an Eulerian formulation. Finally the model may lead to a qualitatively new understanding of the formation of mineral reaction zones and their propagation in time.

Acknowledgements

I am greatly indebted to Hal Helgeson, Bill Murphy, Eric Oelkers, Barbara Ransom. Everett Shock. J. K. Bohlke and Charlie Aipers for helpful discussions during the course of this work. In addition I want to thank Ken Jackson for reviewing the manuscript. Financial support was provided by a grant to Professor H. C. Helgeson by the Department of Energy (DOE Grant DE-AT03-83ER13100).

References

Bear J. (1972) Dynamics of Fluids in Porous Media. Elsevier. 764 pp.

Butty D. L. and Chapallaz C. A. (1984) Ba!nxite genesis. In. Bauxite, Proceedings of the 1984 Bauxite Simporium. Ed. Leonard Jacob. Jr.. Los Angeles. California.

Bowers T. S. and Taylor H. P. Jr. (1985) An integrated chemical and stable-isotope model of the origin of midocean ridge hot spring systems. Jour. Geophys. Res. 90, 12583-12606.

Helgeson H. C.. Garrels R. M. and MacKenzie F. T. (1966) Evaluation of irreversible reactions involving minerals and aqueous solutions (abstract): 1966 Annual Meeting. Geological Society of 
America. (iS.t Spetial Paper $\# 1011.93$.

Helgeson H. C. (1968) Evaluation of irreversible reactions in geochemical processes involving minerals and aqueous solutions I. Thermodynamic relations. Gerhim. Cosmochim. Acta 33. $853-877$.

Helgeson H. C. Garrels R. M. and Mackenzie F. T. (1969) Evaluation of irreversible reactions in geochemical processes involving minerals and aqueous solutions II. Applications. Geochim. Cosmochim. tetu 33. 455-481.

Helgeson H. C. and Aagaard P. (1979) A retroactive clock for geochemical processes, Geological Society of America Abstracts with Programs, 11. 442.

Helgernn H. C. and Murphy W. M. (1983) Calculation of mass transfer among minerals and aqueous solutions as a function of time and surface area in geochemical processes. I. Computational Approach. Wath. Geol. 15. 109-130.

Helgeson H. C.. Murph! W. M. and Aagaard P. (1984) Thermodynamic and kinetic constraints on reaction rates among minerals and aqueous solutions. II. Rate constants. effective surface area. and the hydrolysis of feldspar. Geochim. Cosmochim. Acta 48. 2405-2432.

Lichtner P. C. (1985) Continuum model for simultaneous chemical reactions and mass transport in hydrothermal systems. Geochim. Cosmochim. Acta 49. 779-800.

L.ichtner P. C.. Helgeson H. C. and Murphy W. M. (1987) Lagrangian and Eulerian descriptions of metasomatic alteration processes. In. Proceedings of the Natu Conference on Metamorphic Reactions and Me'lasomatism. Ed. ii. C. Helgeson. In Press.

Lichtner P. C. (1987) A mixed Lagrangian-Eulerian formulation of fluid-rock interaction coupled to fluid flow: In preparation.

Wolen. T. J. (1979) Calculation of chemical equilibrium between aqueous solutions and minerals: The EQ3/EQ6 software package. UCRL-52658.

Woler. T. J. (1980) Chemical modeling of geologic disposal of nuclear waste: progress report and a perspective. Lawrence Livermore National Laboratory, Livermore. CA. UCRL-52748.

Wolery T. J. (1987) EQ6, a computer code for reaction-path modeling of aqueous geochemical systems: user's guide and documentation. Lawrence Livermore National Laboratory. Livermore. CA. UCRL report in preparation. 


\author{
Thomas 3 . Wolery \\ Earth Sciences Department and \\ Nuclear Waste Management Program \\ Lawrence Livermore National Laboratory \\ Livermore, CA 94550
}

\title{
Abstract
}

EQ3/6 is a software package for geochemical modeling of aqueous systems, focused on speciation-solubility and reaction-path modeling. It includes a large thermodynamic data base and a collection of data base handling programs. EQ3/6 is being developed primarily for applications related to the disposal of high level nuclear waste, but the software is much more widely applicable in aqueous geochemistry. Recent work has focused on growth and improvement in the data base, creation of data base management software, the introduction of precipitation growth kinetics into reaction-path modeling, an option to compute reaction paths at fixed gas fugacities, improvements in the treatment of solid solutions, and inclusion of equations to represent activity coefficients in concentrated aqueous salt solutions. In addition, the coding has changed from FORTRAN 66 to FORTRAN 77 , and a set of coding standards has been developed in order to assist code portability and future development.

\section{Introduction}

EQ3/6 is a software package for geochemical modeling of aqueous geochemical systems, first developed to allow reaction-path modeling of seawater and basalt under hydrothermal conditions (WOLERY, 1978). It consists of the following elements:

o EQ3NR - speciation-solubility code (WOLERY, 1983)

- EQ6 - reaction-path code (WOLERY, 1978; WOLERY, 1987a)

- MCRT - thermodynamic data processing code (WOLERY et al., 1987)

- EQLIB - supporting code library

- DATAO - the EQ3/6 main data file

- MDAS - the MCRT master data file (see DELANY, 1986, this volume)

- Special data bases to support the use of Pitzer's equatioris (WOLERY, 1987b)

- Various data base manipulation codes and preprocessors (see DELANY, 1986, this voiume)

There have been five previous major public releases of EQ3/6: version 2020, Feb. 1979; version 2055, Nov. 1979; version 3015, Dec. 1980; version 3175, Dec., 1981; and version 3230. Aug. 1983. Since the release of the latter, the code package has been self-contained (older versions required math routines from the IMSL library, a proprietary software package). Recent work has focused on the preparation of version 3245 (estimated release in Jan. or Feb., 1987).

Current EQ3/6 development is funded by the three major DOE projects for the geologic disposal of high level nuclear waste, each of which is 
investigating a candidate site for the nation's first high-level waste repository. The Nevada Nuclear Waste Storage Investigations (NNWSI) is investigating a site in tuff at Yucca Mountain. Nevada; the Salt Repository Project (SRP), a site in bedded salt in Deaf Smith County, Texas; and the Basalt Waste Isolation Project (BWIP), the Hanford site in the Columbia basalt near Richland, Washington. The proposed repository at the Nevada site would be situated in a thick hydrologically unsaturated zone (in which water is present in the pores with a gas phase that is very similar to air), whereas the proposed repositories at the other two sites would be located below the groundwater table.

Performance requirements for a high-level waste repository have been mandated by the Nuclear Regulatory Commission (10CFR60) and the Environmental Protection Agency (4OCFR191). The NRC requirements apply to both near-field and far-field behavior (the near-field comprises the immediate zone of the repository itself); the EPA requirements limit the eventual exposure of human beings to radiation released from the repository. Release and transport of radionuclides is expected to be effected principally by groundwater. The relevant geochemical processes include rock-water interactions and processes analogous to rock-water interactions (e.g., container corrosion and deposition of insoluble phases of waste form elements).

Most software products developed for the high-level waste disposal projects appear to have a single well-defined function that falls into a single project niche. In contrast, EQ3/6 can be used to make several kinds of related but dissimilar geochemical calculations, and can be applied in more than one of the traditional lines of waste project organization. In the remainder of this paper, I review the various kinds of geochemical calculations that can be made, how EQ3/6 usage fits into the waste projects, some examples of usage outside the waste projects, the current status of the code package, and plans for future oevelopment.

\section{Types of EQ3/6 Calculations}

Aqueous speciation (distribution of dissolved components among free ions, ion pairs, and complexes) and saturation indices ( $\log Q / K$ ) for minerals and other solids can be calculated from analytical data using the EQ3NR code (WOLERY, 1983). This provides a userul means of screening analytical data by means of rigorous charge balance calculations, and has already been useful in detecting problems in NNWSI work in at least two instances (see KERRISK., 1983, and DELANY, 1984). This code has also been used to calculate temperature corrections to the $\mathrm{pH}$ of standard buffer solutions used in dissolution rate experiments (KNAUSS and WOLERY, 1986). More recently, it has been used design custom $\mathrm{pH}$ buffer compositions for solubility and dissolution rate experiments at desired temperatures.

It is also possible to use EQ3NR to compute the solubilities of various solids from thermodynamic data, if a sufficient set of solution parameters is constrained; otherwise, the EQ6 code must be used. Solubility is generally affected by solution composition, either directly through mass action effects, or indirectly by ion pairing or complexing or by effects on the activity coefficients. All of these effects are taken into account in both codes. Which code must be used depends upon exactly how the problem is posed, because solubility problems come in different forms. If the form of the question is, "how much of a mineral will dissolve in a water of known initial composition," 
then EQ6 is usually called for. In such a situation, dissolution of the mineral might change, for example, the $\mathrm{pH}$. If the solubility depends directly or indirectly on the $\mathrm{pH}$, it is necessary to calculate not only the solubility, but also the $\mathrm{pH}$ of the equilibrated solution, because one knows in advance only the initial $\mathrm{pH}$.

The function of the EQ6 code (WOLERY, 1987a) is generally to answer the question, "what happens when an aqueous solution of known composition reacts with specified materials." As such materials react, many phenomena of interest may occur: reaction rates may speed up or slow down; new phases may begin to form; with further reaction, some newly formed phases may disappear; and the solution composition changes. The goal of reaction path modeling is to predict such effects. Originally, the process modeled by EQ6 had no kinetic framework, but followed a non-kinetic formalism laid down by HELGESON (1968); in essence, the water was "titrated" with reactant solids according to specified "relative reaction rates." Overall progress was measured not in terms of time, but of a "reaction progress variable." More recently, the development of increased understanding of controls on the rates of mineral growth ard dissolution have permitted an expansion of reaction-path modeling to include a time framework (see HELGESON and MURPHY, 1983, and DELANY et al., 1987). This was included in the EQ6 code, for the case of mineral dissolution only, in version 3230 . The case of mineral growth has since been added to version 3245 (DELANY et al., 1987).

EQ6 treats chemical processes in considerable detail, using a variety of coupled submodels for such things as rate laws and activity coefficients. Some of these are the targets of ongoing research in the field of aqueous geochemistry. In some cases, a large number of specific submodels already exist, with others under current development. Our response to this situation has been to offer within EQ6 a menu of the most adequate or useful specific submodels. This has been done partly with a viewpoint on doing comparative analysis of such submodels: aird partly with an eye on providing a computational superstructure for the testing of new specific submodels. The basic type of system the code models is a closed one with a homogeneous aqueous fluid phase. The code does not offer a general model combining the processes of chemistry and fluid transport, a topic of much current interest. It does allow modeling of a flow-through system which is focused on the evolution of a packet of fluid flowing through a reactive medium (which can be visualized as a pipe, fracture, or porous medium). However, this model does not solve any transport equations, and it only follows what happens to what may be thought of as trie first of possibly many packets of water. It has been described as "pseudo-one dimensional."

\section{Us agges of EQ3/6 on the High Level. Waste Projects}

In order to obtain a license for a repository from the NRC, the U.S. Department of Energy must present a strong case that the NRC and EPA performance requirements will be satisfied at the proposed site. The job of making this case is unusual in that it focuses on the behavior of a large underground engineered structure, and unprecedented in terms of the time scale involved (thousands of years).

One major strategy for dealing with geochemical effects, which actually precedes the current requirements by many years, has been to conduct various 
kinds of "applications level" experiments and to pipe the results, which may reflect the lumped effects of many detailed processes, directly into a computer code containing a model for fluid transport. Such coupling is generally at the level of dimensional analysis, and the applicability of the experimental results to behavior of an actual repository in the field at even short times, let alone long time periods, is merely assumed without any proof or check. In general, this approach ignores any theoretical framework for treating geochemical interactions, and makes little or no attempt to relate any of the results to known fundamental data, such as thermodynamic data.

There has actually been at least one attempt to claim credit for the results of thermodynamic modeling calculations, made with an unchecked data base. Such calculations can be wholly off the mark because of bad and/or incomplete supporting data and/or lack of provision for important detailed processes. Premature efforts in this direction tended to give "geochemical modeling" a bad name, and emphasis was again placed upon "applications level" experiments .

The present strategy for applying EQ3/6 and other geochemical modeling tools on the waste projects is to provide the critical link between the results of "applications level" experiments on the one hand and concepts from detailed modeling and known fundamental data on the other (MCKENZIE et al., 1986). This creates a focus on modeling the experiments before any serious attempt is made to model the repository. It becomes possible to demonstrate consistency (or inconsistency) between the results of "application"

experiments and fundamental data. It also provides a means to identify and isolate any artifactual effects in the experiments (e.g., interactions with vessel walls, effects of finely ground materials and other artificially prepared surfaces, presence or absence of air) that would not apply to behavior in an actual repository and may also point out critical errors or omissions in the measurements. Finaily, detailed modeling should point to a wetter methodology for including chemical effects in a larger model of repositcry performance, providing a conceptual basis for the degree of extrapolation that will of necessity be required in this process.

In order to realistically apply this strategy, it is necessary to address the current limitations of geochemical models and geochemical modeling codes, and the scope and quality of existing fundamental data. The current plan for developing EQ3/6 is discussed in detail by MCKENZIE et al. (1986) and will be touched upon later in this paper. It focuses on three types of inadequacies which must be addressed before EQ3/6 can be fully utilized for all of the intended purposes. The code package presently lacks consideration of certain processes and phenomena, such as sorption on mineral surfaces. This requires code development. Some of the specif:ic submodels, such as sets of equations for describing activity coefficients, are not adequate under all anticipated conditions. This requires submodel development. The data base is inadequate for some key intended purposes. This requires data base development.

Development of new specific submodels and of the supporting base of fundamental data can only partially be addressed by culling the existing literature. It is possible in only rare instances to extract fundamental data from "applications level" experiments. In general, a new category of experiments is required. Although experimental activity of this kind is called for in the EQ3/6 development plan (MCKENZIE et al., 1986), adequate funding is developing slowly. 
The present and anticipated usages of EQ3/6 on the waste projects overlap the traditional waste project organizational lines of site evaluation, waste package design, and performance assessment. This has probably caused more problems in gaining acceptance of the code package by the waste projects than it has heiped.

Site evaluation requires, or at least is aided, by speciation-solubility calculations of the groundwaters present at a candidate site. This allows an assessment of the degree of equilibration between a groundwater and coexisting minerals. The use of charge balance calculations to screen analytical data has been mentioned earlier, but is particularly useful in site work. Reaction-path modeling may also be useful in elucidating patterns of groundwater evolution along a flow path (e.g., see KERRISK, 1983). Such modeling has also been used to infer the direction of groundwater flow in an area of the Hanford site in which the hydraulic head is too small for this to be determined by conventional hydrologic testing (SOLOMON, 1986, this volume).

Waste package design requires a detailed understanding of the geochemical interactions that will occur in the so-called near-field environment. While several exact definitions of this have been proposed, the operative concept is based on the fact that young radioactive waste produces a lot of heat, and rock (of all the types of interest here) is a poor heat conductor. Within about the first 600 years, significantly elevated temperatures will prevail about the immediate vicinity of the waste canisters, producing a localized hydrotinermal environment. At the NNWSI site, this scenario is expected to be a bit different than it would at the other two sites. Here high temperatures in the hydrologically unsaturated zone are expected at first to drive off water. As the waste eventually cools, however, a hydrothermal environment will eventually be established.

\section{Important near-field chemical processes therefore include both} hydrothermal rock/water interactions and also reactions between water, rock, and materials introduced in the construction of the repository, in both the hydrothermal and post-hydrothermal phases. For the most part, such processes must be investigated by means of labcratory "applications level" experiments. The connections with geochemical modeling are several. First, speciationsolubility modeling of fluid samples are essential to determine the degree of thermodynamic stability (or instability) during these experiments. This process normally begins with EQ3NR calculations on analyses of quenched fluid samples. Screening of the analytical data by means of a charge balance calculation is as useful here as in site evaluation. The pH value available generally pertains to the quenched sample and is generally not identical to the value at elevated temperatures. The "in situ" $\mathrm{pH}$ can be calculated by feeding the EQ3NR output into the EQ6 code. This then also yields the pertinent calculation of the "in situ" species distribution and saturation indices.

The methodology given above describes how EQ3/6 can be used to analyze the results of a hydrothermal experiment. However, using appropriate assumptions concerning rate laws, it is possible to use the EQ6 code to compute a reaction-path model that is an attempt to predict the experimental results. DELANY (1984) has used this approach to mcdel Dickson gold-bag hydrothermal experiments in which devitrified tuff from the Nevada site has been reacted with J-13 well water (a proxy for Yucca Mountain groundwater) at various 
temperatures. The initial attempt used rate law formulations and rate constant values taken from single-mineral dissolution rate experiments reported in the literature, though some runs were made with slightly altered rate constant values in order to see if better fits were ubtainable.

It was found that reasonably good matches to the experimental data could be obtained in the case of experiments at $150^{\circ} \mathrm{C}$, if the formation of a significant number of possible product minerals was suppressed in the face of supersaturation in the fluid. Such suppressed phases were not found in the reaction vessel after the completion of the experiments. It is very clear that the fluids were highly supersaturated with respect to a number of potential product phases, which simply did not form on the time scale of the experiments (about three months). At present, there is no way to include such information into reaction-path models without doing the experiments, though as more work of this kind is done, useful rules of thumb may emerge.

To the extent that such "applications level" experiments can be successfuliy modeled, the results can be extrapolated to conditions more like those exnected to occur in an actual repository. For example, it is possible to run kinetic reaction path models out to times exceeding the length of the experiments, although this requires choosing some assumptions from among various possibilities. It is also possible to extrapolate an experiment to different physicochemical conditions, such as lower temperatures likely to be of greater significance in the hydrothermal period, or a system in which thi gas phase of the unsaturated zone at Yucca Mountain is present (che experimental system modeled by DELANY, 1984, did not include provision for the presence of such a phase).

On the other hand, DELANY (1984) found that modeling of experiments at $250^{\circ} \mathrm{C}$ was generally unsatisfactory, because of the formation in the experiments of significant amounts of dachiardite, a zeolite mineral which was not represented in the EQ3/6 data base. This, and similar problems in geochemical modeling, require new experiments designed to extract fundamental data which is presently unavailable.

There is presently increasing interest in applying geochemical modeling techniques to systems including the artificial components of the repository, such as the waste radionuclide elements, the original waste form itself, and the canister metal. Attempts are underway to extend the kinetic rock/water modeling described above to include leaching of waste forms. It may be possible to extend it as well to canister corrosion. However, there is now an increased emphasis in the waste projects to call upon solubility limitations in order to demonstrate compliance with the NRC near-field release requirements. The feasibility of developing geochemical modeling tools such as EQ3/6 to deal with this subject is currently more obvious. However, actually doing the work will require a number of new "fundamental data" experiments to complement "applications level" experiments.

Both site evaluation and waste package design activities feed into performance assessment, as it is defined in the broad sense. However, one of the special needs of performance assessment is to integrate detailed modeling into a grand model that shows that the repository will or will not meet the performance requirements. Such integration inevitably requires simplification of these detailed models. One way EQ3/6 can assist in this is to identify the essential features in genchemical models for specific reaction scenarios. In 
addition to simplifying the detailed models, EQ3/6 may be used, in scaled down form, to run the simplified models directly for a grand model code. There are no specific plans for this yet, however.

\section{Improvements to the 3245 Version of EQ3/6}

A number of major improvements have been made to the EQ3/6 :-singe since the release of the 3230 version. Some of these affect both EQ3NR and EQ6. An option was created to allow the use of Pitzer's equations (PITZER, 1973, 1975) for the activity coefficients of aqueous spar: - (WOLERY, 1987b; see also JACKSON and WOLERY, 1986, this volume). $\therefore$ special data file of virial coefficients is required. This allews calculations to be made in highly concentrated solitions, but is currently applicable to only a limited set of components, mostly strong electrolytes and "sea salts." A simplex algorithm was implementer to calculate the "maximum" hypothetical saturation index of solid sol: ons (BOURCIER, 1985). The previous algorithm for treating this wa?

Other code improvements pertained to the EQ6 code. Its capability to model dissolution kinetics was extended to include precipitation growth kinetics (DELANY et al., 1986), and some new rate law forms were added for both dissolution and precipitation. An option was created to allow the fugacities of selected gases to be fixed at chosen values during reaction path runs, simulating the effect of the presence of a large gas reservoir (DELANY and WOLERY, 1984). This was done primarily in order to make such calculations, taking into account the gas phase in the unsaturated zone at Yucca Mountain; however, it is also useful in treating many other settings, including some experimental configurations. Sample calculations have shown that fixed fugacities of $\mathrm{CO}_{2}$ can introduce major changes in reaction paths. Two faster calculational modes ("economy" and "super-economy") were developed in the EQ6 code. These allow greater step sizes in reaction-path runs which do not involve kinetics.

Substantial changes have been made to the thermodynamic data base which supports EQ3/6 calculations (see DELANY, 1986, this volume). A two-tier structure has been adopted, with DATAO, the EQ3/6 operational data base being supported by MDAS, the "MCRT data base." MCRT (WOLERY et al., 1987) for processing thermodynamic data, including making temperature extrapolations. It produces data blocks that can be inserted into DATAO. Neaily all of the data in DATAO is now documented as to the source, and the size of this data base has increased significantly. New data base management software has also been written.

The entire EQ3/6 package was adapted to run on 32-bit UNIX-based computers (Ridge $32 \mathrm{C}$ and $32 \mathrm{~S}$; the code package was originally written on $\mathrm{CDC} 6600$ and 7600 computers, with some work also being done on Cray-l machines by the time of the 3230 release). The EQ3/6 codes were originally written in FORTRAN 66; much it has since been rewritten in FORTRAN 77. A set of coding standards has been developed to increase portability and ease of future development. Much of this has been implemented. 
Plans for the 3270 version, which will succeed the 3245 version, include adding additional activity coefficient models (see JACKSON and WOLERY, 1986, this volume): the model of HELGESON et al. (1981) as modified by WOLERY and JACKSON (1987), and a model based upon hydration theory, under development at LLNL. Plans also call for adding pressure corrections to the thermodynamic data, increasing the temperature range of the data base from $0-300^{\circ} \mathrm{C}$ to $0-500^{\circ} \mathrm{C}$, some algorithmic improvements designed to increase computational speed, and a partial code rewrite to more implement FORTRAN 77 structures and our own recently adopted coding standards. The 3270 version may also see some extension of the solid solution modeling capabilities. The data base is expected to be larger and still further improved.

\section{Other Future Improvements}

A number of other future improvements are planned (MCKENZIE et al., 1986). These include the development of site-mixing models for solid solutions, EQ6 options for dealing with redox disequilibrium, inclusion of some sorption models to allow treatment of chemical processes on mineral surfaces, the addition of a gas phase, and the development of a "leaching cell" flow-through model. This model would be centered at a fixed location as opposed to following a particular packet of water. The data base will continue to be maintained, and it will continue to be expanded as necessary to meet the needs of the waste projects. Other improvements and enhancements are also possible as project needs arise.

\section{Availabilitu of EQ3/6 Outside the Waste Projects}

LLNL's Nuclear Waste Management Program desires to enhance the credibility and usefulness of EQ3/6, and is willing to provide the code package to "informal collaborators" for non-commercial applications, in return for useful feedback. In addition, changes in LLNL regulations regarding software distribution now make possible direct transfers to industry.

\section{Acknowledgments}

Prepared by Nevada Nuclear Waste Storage Investigations (NNWSI) Project participants as part of the Civilian Radioactive Waste Management Program. The NNWSI Project is managed by the Waste Management Project Office of the U.S. Department of Energy. Nevada Operations Office. NNWSI Project work is sponsored by the Office of Geologic Repositories of the DOE Office of Civilian Radioactive Waste Management.

\section{References}

BOURCIER, W.L. (1985) Improvements in the Solid Solution Modeling Capabilities of the EQ3/6 Geochemical Code. UCID-20587, Lawrence Livermore National Laboratory, Livermore, California.

DELANY, J.M. (1985) Reaction of Topopah Spring Tuff with J-13 Water: A Geochemical Modeling Approach Using the EQ3/6 Reaction Path Code. UCRL-53631, Lawrence Livermore National Laboratory, Livermore, Cal ifornia. 
DELANY, J.M. (1986) EQ3/6 data base - ongoing development at Lawrence Livermore Nationa! Laboratory. Pp.162-166, this volume.

DELANY, J.M., PUIGDOMENECH, I., and WOLERY, T.J. (1987) Precipitation Kinetics Option for the EQ6 Geochemical Reaction Path Code, Report in preparation, Lawrence Livermore National Laboratory, Livermore, California.

DELANY, J.M., and WOLERY, T.J. (1984) Fixed-Fugacity Option for the EQ6 Geochemical Reaction Path Code. UCRL-53598, Lawrence Livermore National Laboratory, Livermore, California.

HELGESON, H.C. (1968) Evaluation of irreversible reactions in geochemical processes involving minerals and aqueous solutions - I. Thermodynamic relations. Geochim. Cosmochim. Acta 32, 853-877.

HELGESON, H.C., and MURPHY, W.M. (1983) Calculation of mass transfer among minerals and aqueous solutions as a function of time and surface area in geochemical processes. I. Computational approach. Math. Geol. 15, 109-130.

HELGESON, H.C., KIRKHAM, D.H., and FLOWERS, G.C. (1981) Theoretical prediction of the thermodynamic behavior of aqueous electrolytes at high pressures and temperatures: IV. Calculation of activity coefficients, osmotic coefficients, and apparent molal and standard and relative partial molal properties to $600^{\circ} \mathrm{C}$ and $5 \mathrm{~Kb}$. Amer. Jour. Sci. 281, 1249-1516.

JACKSON, K.J., and WOLERY, T.J., 1986, this volume.

KERRISK, J.F. (1983) Reaction-Path Calculations of Groundwater Chemistry and Mineral Formation at Rainier Mesa, Nevada. LA-9912-MS, Los Alamos National Laboratory, Los Alamivs, New Mexico.

KNAUSS, K.G., and WOLERY, T.J. (1986) Dependence of albite dissolution kinetics on $\mathrm{pH}$ and time at $25^{\circ} \mathrm{C}$ and $70^{\circ} \mathrm{C}$. Geochim. Cosmochim. Acta 50, 2481-2497.

MCKENZIE, W.F., WOLERY, T.J., DELANY, J.M., SILVA, R.J., JACKSON, K.J., BOURCIER, W.L., and EMERSON, D.0. (1986) Geochemical Modeling (EQ3/6) Plan Office of Civilian Radioactive Waste Management Program. UCID-20864, Lawrence Livermore National Laboratory, Livermore, California.

PITZER, K.S. (1973) Thermodynamics of electrolytes I: Theoretical basis and general equations. J. Phys. Chem. 77, 268-277.

PITZER, K.S. (1975) Thermodynamics of e?ectrolytes V: Effects of higher order electrostatic terms. J. Solution Chem. 4 , 249-265.

SOLOMON, C. (1986) this volume

WOLERY T.J. (1983) EQ3NR, A Computer Program for Geochemical Aqueous Speciation-Sclubility Calculations: User's Guide and Documentation. UCRL-53414, Lawrence Livermore National Laboratory, Livermore, California. 
WOLERY, T.J., ISHERWOOD, D.J., JACKSON, K.J., DELANY, J.M., and PUIGDOMENECH, I. (1984) EQ3/6: Status and Applications. Pp. 54-65 in JACOBS, G.K., and WHATLEY, S.K., eds., Proceedings of the Conference on the Application of Geochemical Models to High-Level Nucleai Waste Repository Assessment, NUREG/CP-0062, U.S. Nuclear Regulatory Commission, Washington, D.C., and ORNL/TM-9585, Oak Ridge National Laboratory, Oak Ridge, Tennessee.

WOLERY T.J. (1987a) EQ6, A Computer Program for Reaction-Path Modeling of Aqueous Geochemical Systems: User's Guide and Documentation. Report in preparation, Lawrence Livermore National Laboratory, Livermore, Cal ifornia.

WOLERY T.J. (1987b) EQ3/6 Modifications for Geochemical Modeling of Brines. I. Pitzer's Equations. Report in preparation, Lawrence Livermore National Laboratory, Livermore, California.

WOLERY T.J., BOURCIER, W.L., AND MOORE, R.M., (1987) MCRT, A Data Base Building Code for the EQ3/6 Geochemical Modeling Software Package: User's Guide and Documentation. Report in preparation, Lawrence Livermore National Laboratory, Livermore, California.

WOLERY, T.J., and JACKSON, K.J. (1987) Activity coefficients in aqueous salt solutions. I. The ion size problem. Ms. in preparation. 
A Theoretical Basis for the Coupling of Chemical Reactions 10 Open System P'rocesses

\author{
E.ll. Perkins \\ Alberta Rescarch Council, Oil sands Research lopartinent, \\ Po Box 8330 . Postal sitation F. \\ Edmonton, Alberta, Canda. T6H $5 \times 2$
}

\begin{abstract}
In order 10 understand the processes involved in natural and industrial geological phenomenon involving an aqueous fluid and solid phases, the chemical interactions between the fluid and surrounding minerals must be known as functions of pressure, cemperature. composition, and time. In addition to the boundary conditions, these processes are also dependent upon external sources of work, energy and mass ffor example, injet tion wells).

Equations have been derived which allow the chemical reactions between a fluid and solid phases to be evaluated in any open system. They are based on derivatives of the mass action and mass balance equations taken with respect to time and can be used to predict the distribution of mass at future times. These equations are coupled to modified version of the flow, heat transport and solute transport equations through the derivatives of the volume and number of moles of each of the solid phase, through derivatives of the molalities and partial molal volumes of the aqueous species. through the derivative of the total number of moles of water and through the amount of heat generated consumed by the process. Lising these equations. a computer program has been writen and used to model wrious systems.
\end{abstract}

\title{
Introduction
}

In any regional or local How systein, the fluid can react with the surrounding media. These reactions are manifested by the spatial and temporal distribution of phases and by the spatial and temporal variation in the composition of the phases and the fluid. (icological eximples are abundant: weathering. hydrothermal alteration, diagensis, mostasomatisin and ore deposition are familiar results of these processes. Industrial camples include in-situ mining. waste disposal and secondary crotanced oil recovery.

Beninging in the late sixties. a munber of authors began wo mathematically model chenical reactions as function of temperalure. pressure and composition in closed

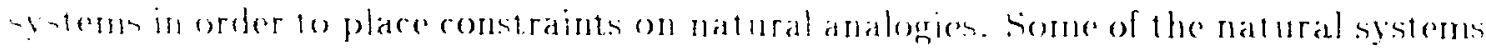

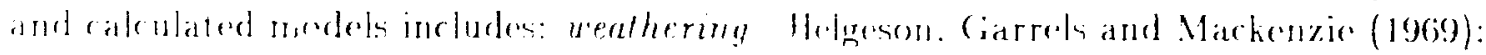


ore Af position Villas and Sorton(1977): reaction of a vaull fluid with different rock types Wolery (1980): supergene alteration Kwong. Brown and. Circenwood (1982): fothe rmal areas (apuano and cole (1952). The success of these modele has show that many processes can be modelled using a mathematical, geochenical approach. lading a a better understanding of rock-water interaction.

Hecause of the increasing problem of chemical and nuclear waste disposal and the potential problem of contaminating existing flow systems. considerable attention has been paid to the migration of dissolved material in ground water. In general, authors modelling the transport of dissolved material in a fluid have generally restricted themselves 10 near-surface conditions where the aqueous species and the solid phases are inert or where a retardation factor can be used to approximate the chemical reactions between the aqueous species and the surrounding matrix. A notable exception is lichtner (1985). whose model is completely coupled.

The coupling of chemical reactions to open system process can be most clearly illustrated by first examining the partial differential equations constraining fluid How, heat transfort and solute transport. Using implicit summation, commonly accepted forms of these equations can be written as:

$$
\begin{aligned}
& \frac{\partial \rho q}{\partial x_{i}} \quad \rho Q \cdot \partial \rho \partial
\end{aligned}
$$

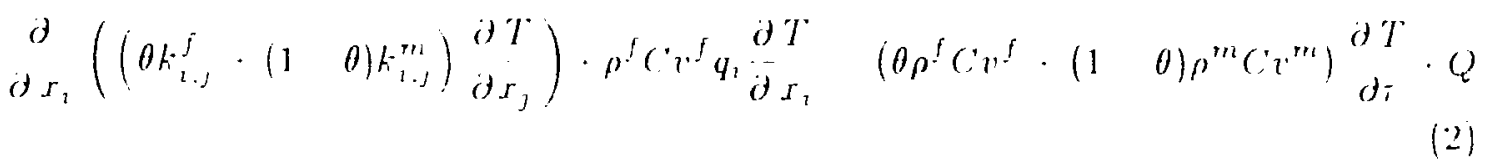

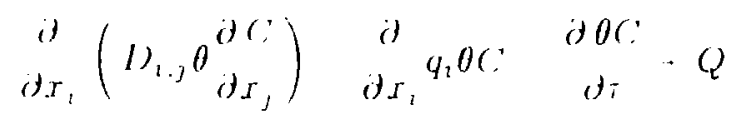

p. 0. Q. k. T. q. ( U. I) and ('are the density, porosity soureo/sink terme thermal conductivit. temperature. velecity. heat capacity at comstant volume. coefficient of dispersion and comentration of a component in the fluid. respectively ats and d

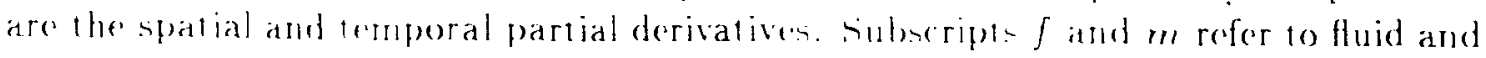
matrig (mimerals). resperelively. Most of these terme are direcely related to the chemical

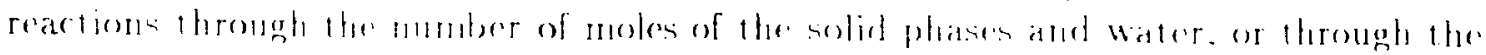

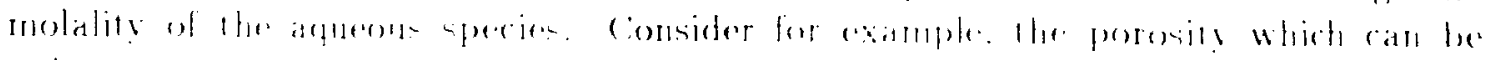
writhel:

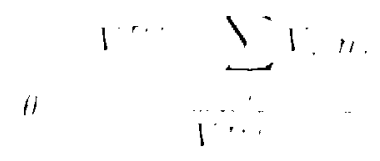




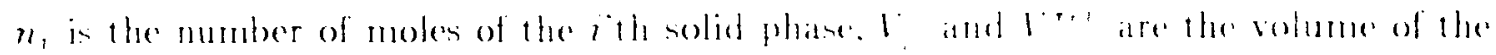

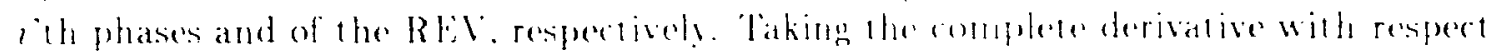
wo time yields:

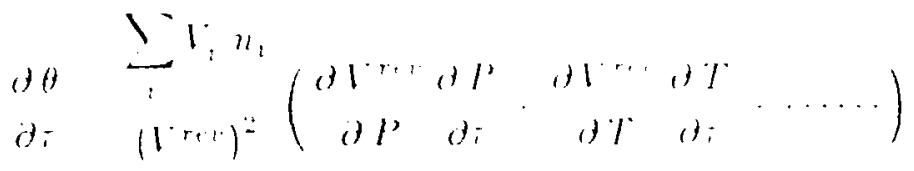

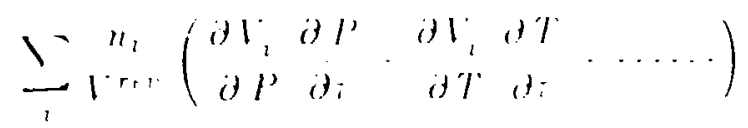

$$
\begin{aligned}
& \frac{l_{i} l_{i} \quad \partial n_{i}}{\partial i}
\end{aligned}
$$

The first termsi on the right hand side describe the effects of the process on the REV itself. the second on the molar volume of the phases. and the last is the result of the changing number of moles of minerals. If enough is known or assumed about the process, this equation can often be simplified down to the last term. Simitiar expansion an be mats for almost all of the other parameters. including the source sink terms.

At any point in time. the distribution of mass in any chemical system is completely specified and can be solved using the mass action fonc for cach non-component species and phase) and mass balance equations (one for each component). Any set of components which completely span the compositional space of all of the minerals, aqueous species and gases can be used. However. if the components are choosen such that $n p$ components have the same compositional vector and themodynamic properties as the np equilibrium phases in the ststem. one has the same compositional vector and thermodynamic properties as water. and the remaining ne np l components bave the same compositional vector and hermodynamie properties as the most abundant independent aqueous speries. mumerical accuracy is improved. speed of solution is increased. and the form of the cquation is charer. The component basis shoulet be dynamic as it changes when new phases precipitate from solution or existing phases completely dissolve into solution. The compenent batis can be changerd by simple matrix erehniques.

The mass balance requation for the rih componom in a system composed of cquilibrimplases. aqueous species and reactant phases can he written as:

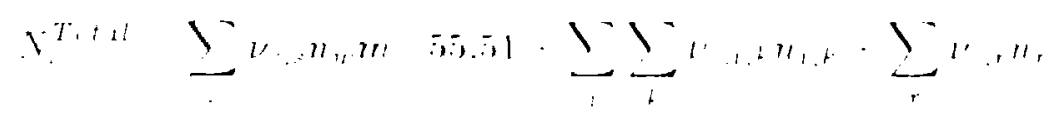

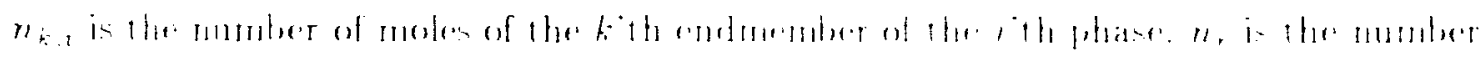

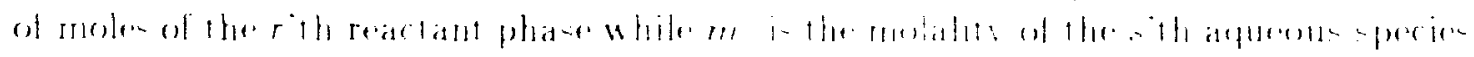

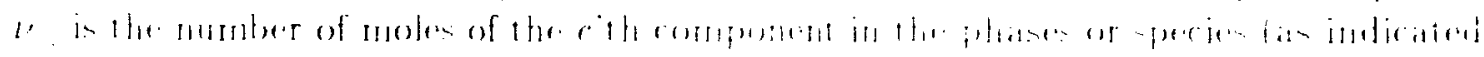
h Hetherenteript-l. 


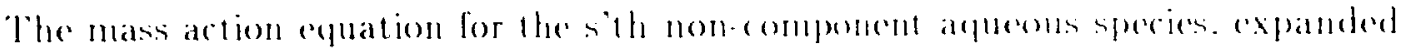

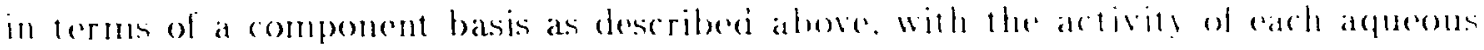

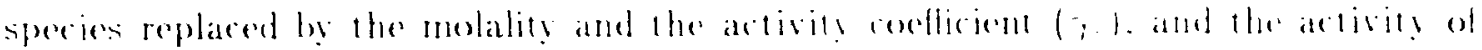
rach of the entmembers of the solid solution phanen replated hes the mumber of moles: and activity coefficient $\left(\lambda_{k, 1}\right)$ of the condmembers, can he writent:

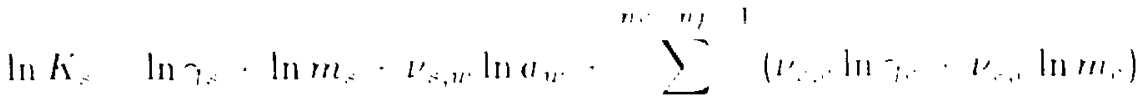

$$
\begin{aligned}
& \sum_{2}^{n} \sum_{k} \nu_{\cdots, k}\left(\ln \lambda_{1, k} \cdot \ln n_{1, k} \ln \left(\frac{y}{j} n_{1,1}\right)\right)
\end{aligned}
$$

The subseript "w" indicates water. The derivative of both the mass balance and mass action equations can now be taken with respect to time. Through the relationship, $\partial \ln \mathrm{K}^{\circ} \mathrm{X}^{1} \partial \mathrm{K}$, all derivatives of the number of moles of each of the solid phases and of the molality of each of the aqueous species in the mass action equation can be writen as normal derivatives. The derivative of the activity coefliciont of the $k$ 'th endmember of a solid phase can be expanded in terms of the derivative of number of moles of all of the endmembers of that solid solution phase. In a similar fashion, the derivative of the activity coefficient of each of the aqueous species could be reduced to the derivative of the molalities of all of the aqueous species. However. by leaving this derivative in terms of ionic strength, a faster numerical method of solution can be employed. For the identical reason. the derivative of the activity of water has not been expanded. Therefore, two new equations must be introduced. These are the derivative of the ionic strength cquation and of the (iibbs-l)uhemequation (which constrains the activity of water).

In order. ihe derivaive of the mass batance equation (one for cach component). the derivative of the ionic strenghte equation. the derivative of the Githbs-l)uhem equation and the derivative of the mass action equation fone for each non-component species in the system) are shown in figure 1. The coctlicients A. . Z are constants and depend on the specific models used for the activity coefficients of aqueous speries and of solid solution phases. and used for the gibbs frecenergy of solid phases and of aqueous species. $D$ is the only term which contains the change in the total number of cach component. due to mass fhux while $k$ and $z$ are the only tesms which eontain derivatives with respect to temperature and pressure.

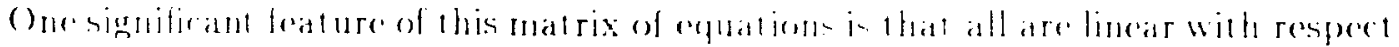

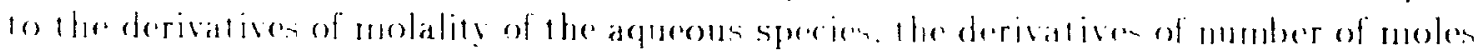

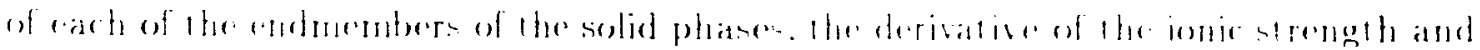

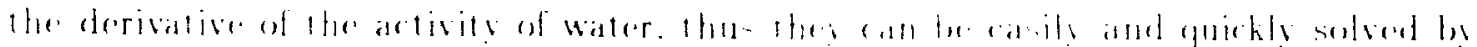

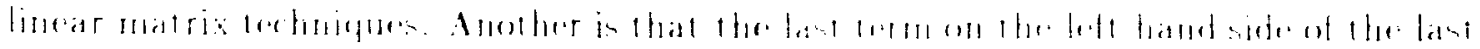

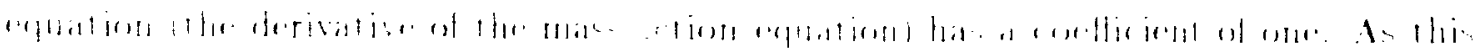


Figure 1 - Tabular Forms of the Constraining (homical Equations

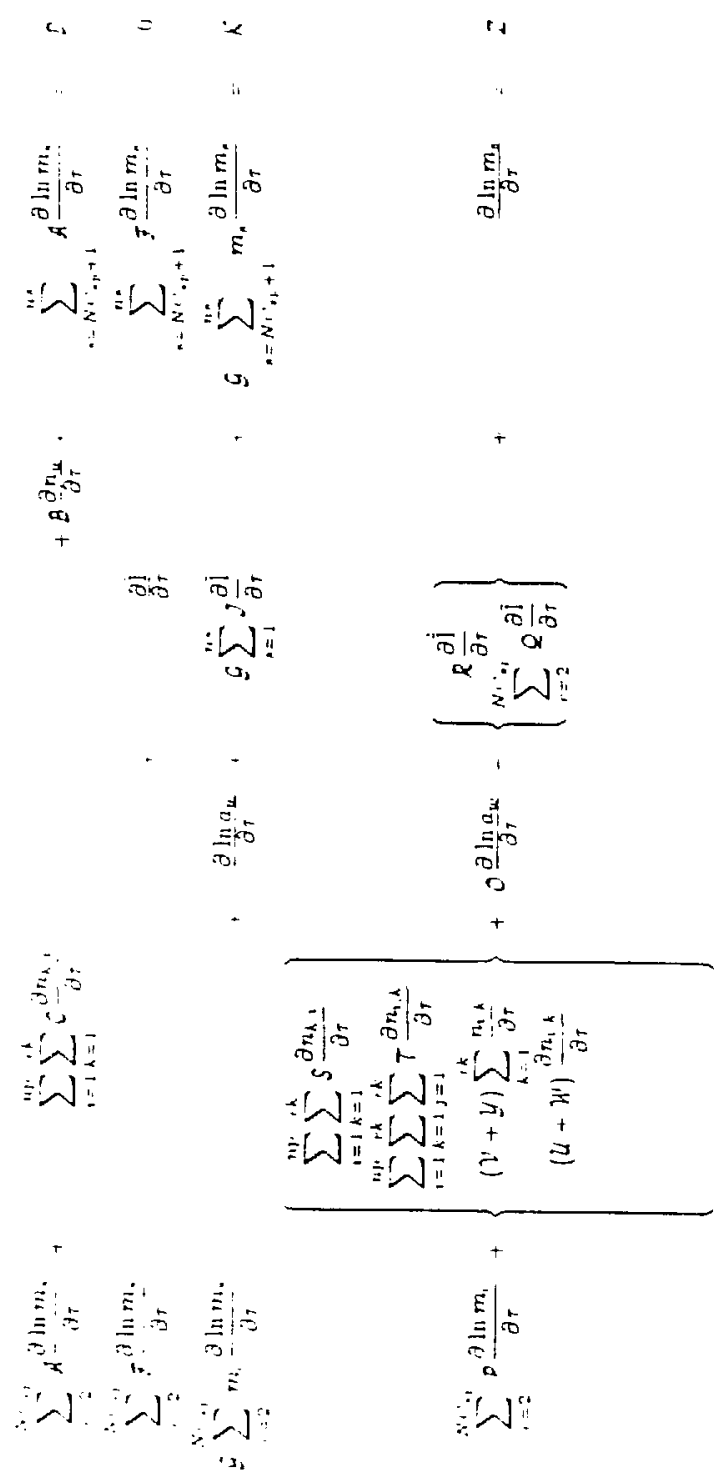

Although it was not done in the text. the first there equations have had the sums of the logs molatities of the species separated inter component and non-component froms. 


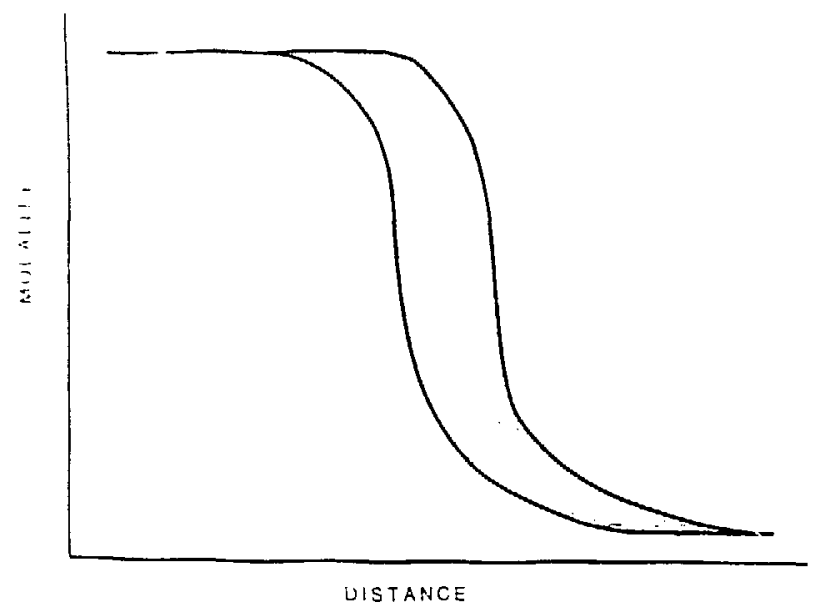

equation is repeated for every non-component species phase in the system, an identity $m^{-} \quad \mathrm{x}$ is developed. This allows very efficient numerical techniques to be used.

This set of equations is repeated for every $\mathrm{REV}$ in the system. To keep the size of the prograin small, it is usually easiest to solve these equations separately from the flow. heat transport and solute transport equations, and iterate between them.

Although suitable for inclusion in the flow, heat transport and mass transport equations, the first derivative is rarely sufficient to calculate the number of moles of solid phases or molality of aqueous species at a future time. Successive derivatives of the mass action and mass balance equations can be taken, and the higher order derivatives solved for. All of these derivatives can then be used in a series expansion such as a Taylor's expansion. It is worth noting that the left hand side of the equations in figure one do not change. only the constant terms on the left hand side must be modified. Thus once the first derivative is obtained, it takes only minor computational effort to obtain any number of higher order derivative's.

Mordel Results

A large number of simulations have been made in the silica-water system. The initial conditions were of the form: for torre zero. for all $x_{1}$. isothermal and isobarie.

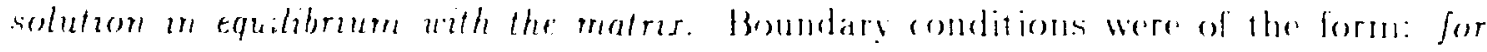
terese greater than acero. the temperature and pressure were elerated at the first reate.

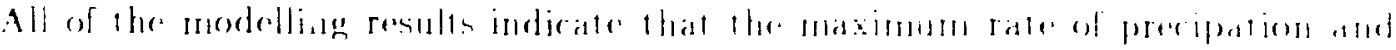

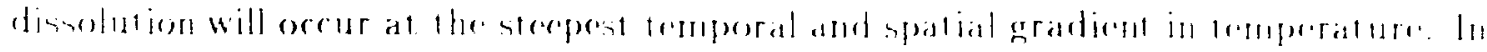




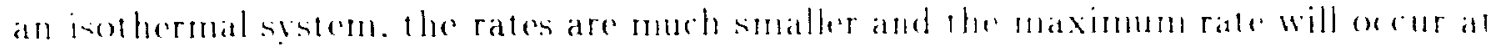
the -leepest temporal and spatial gradient in presente. This is shown schematioally in

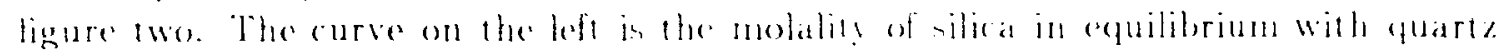
al the temperature and pressure of the matrix. The socomd in the the molatily whet would he expected if no sitica precipitated during the time shep. The shaded areat

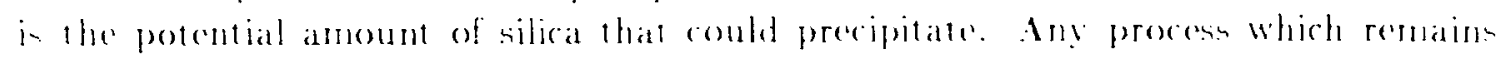

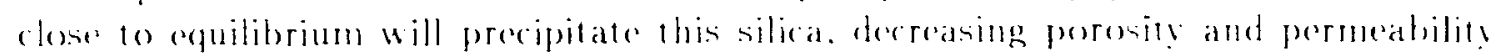
unt il advection is slower than conduction. These results are comsistent with the raphid dissolution and subsequent precipitation of silied in the vicinity of a injection well during a stoam flood into a heary oil ficld.

If the flow system is to remain open. Chere must be sufficiem mechanical encrg! avalable to hydraulically re-fracture the formation or other compensating reactions must be oceurring to create new void space.

\section{References}

Capmano. R.M1. and Cole, D.R. I982. Fuid-mineral Fquilibria in a Hydrothermal

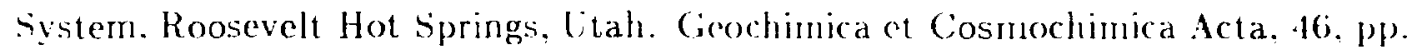
$1353-1364$.

Helgeson, H.C., Garrels. R.M. and Mackenzic, F. 1969. Evaluation of irreversible reactions in geochemical processes involving minerals and aqueous solutions 11. Applications. Ceochimica et Cosmochimica Acta. 33. pp. 155481.

Kwong. Y.T.J.. Brown. T.H. and Greenwood, J.H. 1982. A thermodynamic approach 10) the understanding of the supergene alteration at the Afton copper minc. southcentral British Columbia. Canadian Journal of Earth Sciences. 19. pp. 2:37s 2:3x6.

lichtner. P.( : lgxi). Continum model for simultaneous chemical reactions and maszansport in hydrothermal systems. Ceochimica eq Cosmochinica Acta. 19. pp. $7 \pi 9800$.

Villas. R.X. and Vorton. 1). 197z. Irreversible Mass Transfer Betwern Circulating Hydrothermal Fludes and the Mayflower Stock. Feonomic Geologs. T2. ph. 1.71 1504.

Holery. 'T.J. l9k0. Chemical modelling of geological disposal of muclear waste: progress report and a perspective. I C:R L-527.18. Iniversity of California. Lawrence Livermore laboratory. Livermore. (aliformia. Gif pages. 


\title{
CALCULATIONS OF GEOCHEMICAL MASS TRANSFER AS A FUNCTION OF TEMPERATURE AND TIME
}

\author{
William M. Muphy ${ }^{1}$ \\ University of California, Berkeley \\ Berkeley, CA 94720 USA
}

\section{Abstract}

Consideration of the temperature dependence of the rates of mineral dissolution permits kinetic calculations of geochemical mass transfer and transport in nonisothermal systems. Computations performed using a modified version of EQ6 show that differences in the variation of temperature with time significantly affect reaction paths. Nonisothermal kinetic reaction path models may be particularly useful in the understanding of the geochemical consequences of aqueous solutions ilowing in thermal gradients.

\section{Introduction}

Irreversible mass transfer in geochemical systems results from perturbations to quasistatic states such as those accompanying variations in temperature. The rates of chemical reactions occurring in response to these perturbations exert a control on the temporal and, in dynamic systems, spatial distribution and composition of reactants and products, including aqueous solutions. Prediction of these phenomena for many geochemical systems is permitted by recent experimental and theoretical advances in the field of mineral dissolution kinetics and the generation of a data base of rate parameters for silicate mineral dissolution. The object of the present communication is to illustrate a means of computing time-temperature-reaction path relations for water-rock systems using a modified version of computer programs in the EQ3/6 software package.

\section{A Nonisothermal Kinetic Reaction Path Model}

The rapid rates of most homogeneous reactions in the aqueous phase and of precipitation of secondary minerals relative to the rates of irreversible dissolution of primary minerals permits many water-rock systems to be considered in partial equilibrium (e.g., Helgeson, 1979). Under such circumstances the rate of mass transfer and the direction of the reaction path can be calculated by taking explicit account of the rates of dissolution of the primary minerals. In contrast, for systems of more than one mineral reactant, partial equilibrium models calculated using arbitrary kinetics generally provide inaccurate predictions of the reaction path because variations in the relative rates of reaction of the dissolving minerals are neglected. This underscores the advantage of kinetic calculations even if the time of reaction is not of primary interest.

Transition state theory and irreversible thermodynamics have been used to interpret the rates of mineral dissolution in numerous recent publications (e.g., Aagaard and Helgeson, 1982; Lasaga, 1984). An operational rate equation consistent with transition state theory is (Aagaard and Helgeson, 1982)

$$
d \xi_{i} / d t=k_{i} s_{i} a_{H} H^{-n} i\left(1-\exp \left(-A_{i} / \sigma_{i} R T\right)\right)
$$

\footnotetext{
1Present address: Rockwell Hanford Operations, P.O. Box 800, Richland, WA 99352 USA
} 
where $\xi_{j}$ denotes the reaction progress variable for the ith dissolution reaction, $t$ stands for time, $k_{i}$ refers to the operational rate constant corresponding to the ith dissolution reaction, $s_{j}$ signifies the total surface area of the dissolving mineral, $\mathrm{a}_{\mathrm{H}}+$ represents the activity of the aqueous hydrogen ion, $-n_{j}$ corresponds to the order of the ith dissolution reaction with respect to the aqueous hydrogen ion, $A_{i}$ denotes the chemical affinity for the ith dissolution reaction, $\sigma_{i}$ is a coefficient relating the stoichiometry of the activated complex to that of the dissolving mineral $\left(\sigma_{i}=1\right.$ for all applications in this paper), $R$ refers to the gas constant, and $T$ signifies the temperature in $K$. The variation of the operational rate constant with temperature is given by (Helgeson, Murphy and Aagaard, 1984)

$$
\left[\frac{\partial \ln \left(k_{i} / T\right)}{\partial(1 / T)}\right]_{P}=\frac{-\Delta H_{i}^{\dagger}}{R}
$$

where $\Delta \mathrm{H}_{i}^{\dagger}$ denotes the operational standard state activation enthalpy and $P$ refers to pressure. For constant pressure, or for rate constants that are pressure independent, eq 2 can be integrated from $\mathrm{T}^{\circ}$ to $\mathrm{T}$ to give

$$
k_{i}=\left(T k_{i} / T^{\circ}\right) \exp \left(\left(-\Delta H_{i}^{\dagger} / R\right)\left(1 / T-1 / T^{\circ}\right)\right)
$$

where $\mathrm{k}_{i}^{\circ}=\mathrm{k}_{i}$ at $\mathrm{T}^{\circ}$, and $\Delta \mathrm{H}_{i}^{\dagger}$ has been taken to be temperature independent, which is warranted by the experimental data for silicate mineral dissolution. A tabulation of kinetic parameters for silicate mineral dissolution consistent with eqs 1-3 is given in Murphy (1985) (see also Murphy and Helgeson, 1986a,b).

For nonisothermal reaction path modeling the manner in which $T$ varies must be specified. This may be accomplished by establishing a relation between temperature and reaction progress or between temperature and time. The former relation may be relevant, for instance, to certain adiabatic systems. The latter relation, which probably has greater geochemical applicability, could be used, for instance, to model a static closed system subjected to a thermal event or a fluid centered open system in which the fluid flows in a thermal gradient. In the second case, the rate of temperature change with time is given by the product of the thermal gradient and the rate of fluid flow (given in units of distance per time). The specific time-temperature $(t-T)$ or reaction progress-temperature $(\xi-T)$ relation will depend on the physical characteristics of the system being modeled, and in principle it may vary as the system evolves as a result of changes in permeability. porosity, heat capacity, etc.

\section{Computational Strategy}

In the reaction path computation using a modified version of EQ6, temperature is calculated at each step of reaction progress using a given $\mathrm{t}-\mathrm{T}$ or $\xi-\mathrm{T}$ relation. Parameters in rate expressions for the rate limiting steps are then calculated as a function of $T$. Calculation of the $\mathrm{k}_{j}$ array requires a supporting data base of activation enthalpies and rate constants at the reference temperature (i.e. $\Delta \mathrm{H}_{i}{ }^{\dagger}$ and $\mathrm{k}_{i}{ }^{\circ}$ in eq 3 ). Rates of individual irreversible dissolution reactions are then calculated with eq 1 . The rate of dissolution, $d_{5 m}^{E} / d t$, of each primary mineral $m$ is given by the sum of the rates of parallel dissolution reactions for that mineral. Fractional rates of reaction for each primary reactant are then calculated by dividing each $\mathrm{d} \xi_{m} / \mathrm{dt}$ by the overall rate of reaction which is given by $\mathrm{d} \xi / \mathrm{dt}=\Sigma_{\mathrm{m}}\left(\mathrm{d}_{\mathrm{m}} / \mathrm{dt}\right)$ where $\xi$ is the overall reaction progress variable. Following Wolery $(1979,1984)$ and the coding in EQ6, prediction of the fractional rates of reaction over a succeeding reaction progress step is made by extrapolating a truncated Taylor's series approximation for the fractional rates as a function of the overall reaction progress. Integration of this expression yields the masses of each reactant to be added to the system in the succeeding step. In a similar manner, integration of a truncated Taylor's series approximation to the inverse of 
the overall rate of reaction over the same step gives the time interval for that step. This enables calculation of the total time at the succeeding step and, !rom the time-temperature relation (if applicable), the estimated temperature at that time. After calculation of the new state of the system, and verification that the estimated fractional rates, time and temperature were sufficiently accurate, the sequence of calculations is repeated for the following step (see Wolery, 1984).

\section{Example}

Some results of a simple time-temperature-reaction path computation are shown in figures 1 and 2. Primary mineral reactants are albite, microcline, and quartz. Rate parameters for these minerals taken from Helgeson, Murphy and Aagaard (1984) and Murphy (1985) are presented in table 1. For albite and microcline rate parameters are given for parallel $\mathrm{pH}$ dependent and $\mathrm{pH}$-independent rate mechanisms. The rate of quartz dissolution was assumed to be $\mathrm{pH}$-independent. Total surface areas per kilogram of $\mathrm{H}_{2} \mathrm{O}$ for each reactant given in table 1 were taken to be independent of time. The sum of the total surface areas corresponds approximately to the surface area of a fractured medium with a fracture width of $2 \mathrm{~mm}$.

A $10^{-2}$ molal $\mathrm{NaCl}$ solution with $\mathrm{pH} 6$ in equilibrium with muscovite and quartz and approximately saturated with respect to kaolinite was chosen as the starting fluid. The initial temperature was taken to be $50^{\circ} \mathrm{C}(323 \mathrm{~K})$, and a linear time-temperature relation was imposed on the system according to the equation

$$
\mathrm{T}=323 \mathrm{~K}+\mathrm{at}
$$

in which a is a constant which was taken to be $1 \%$ year.

A fluid centered open system model was calculated in which precipitated minerals were not permitted to redissolve in the solution. One possible application of the linear $t-T$ relation (eq 4 ) in the open system is to a fluid flowing at a constant velocity $v$ (in units of meters/year) along a constant tinermal gradient given by $\mathrm{av}^{-1}$.

In fig 1 the logarithm of the rate of dissolution of the primary minerals is plott $€ J$ versus the logarithm o! time. Because of the linear $\mathrm{t}-\mathrm{T}$ relation, temperature is also given on the abscissa on a log scale. Microcline is seen to dissolve at the outset of the path, then it precipitates at equilibrium from about $10^{-1.7}$ to $10^{0.7}$ years, then it dissolves again. (The horizontal line labeled PPT in fig 1 denotes precipitation at equilibrium.) Quartz follows a roughly complementary pattern; initially at equilibrium and precipitating, it dissolves through an intermediate period, then precipitates again, and then dissolves at the end of the reaction path. Albite dissolves throughout the reaction path except that it comes to equilibrium at the end of the simulation. Muscovite was predicted to

TABLE 1: Rate parameters for primary mineral reactants.

\begin{tabular}{lllll}
\hline $\begin{array}{l}\text { Reactant } \\
25^{\circ} \mathrm{C} \text { Rate } \\
\text { Constant } \\
\text { mole }\end{array}$ & $\begin{array}{l}\text { Hydrogen } \\
\text { lon } \\
\mathrm{cm}^{2} \mathrm{sec}\end{array}$ & $\begin{array}{l}\mathrm{BH}_{\mathrm{i}}^{\dagger} \\
\left(-\mathrm{n}_{\mathrm{i}}\right)\end{array}$ & $\begin{array}{l}\text { Surface } \\
\mathrm{kcal} \\
\mathrm{mole}\end{array}$ & $\begin{array}{l}\text { Area } \\
\mathrm{cm}^{2}\end{array}$ \\
\hline ALBITE & $1.9 \mathrm{E}-13$ & 1 & 20.6 & 8000 \\
& $3.0 \mathrm{E}-16$ & 0 & 8.5 & \\
MICRO & $2.2 \mathrm{E}-13$ & 1 & 19.0 & 16000 \\
CLINE & $3.0 \mathrm{E}-16$ & 0 & 8.5 & \\
QUARTZ & $1.6 \mathrm{E}-18$ & 0 & 18.0 & 16000
\end{tabular}




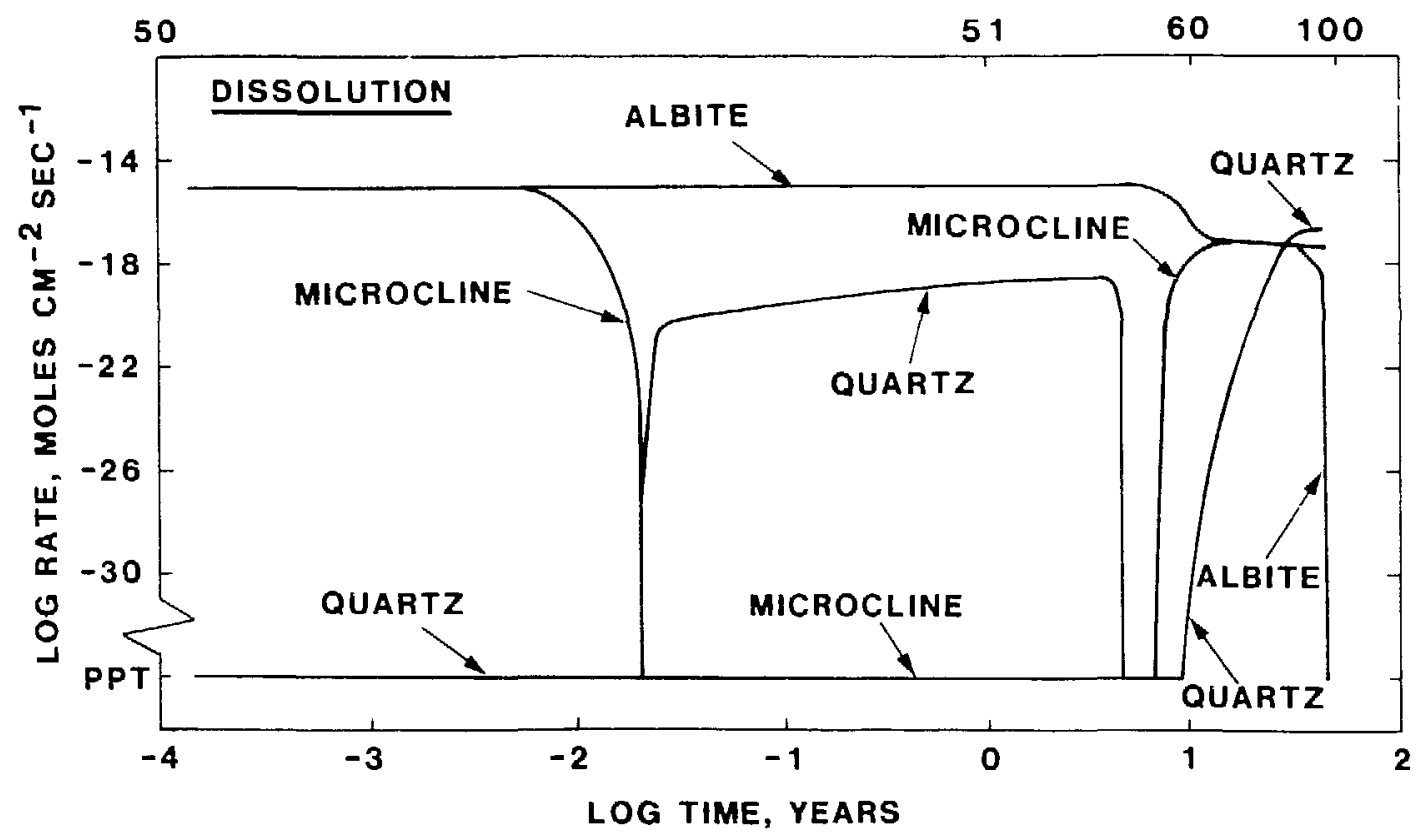

Figure 1. The logarithm of mineral dissolution rates as a function of the logarithm of time. Temperature is given at the top on the abscissa. (See text for discussion.)

precipitate at equilibrium throughout the reaction path and no other secondary phases (including gibbsite, kaolinite, and the EQ6 phyllosilicates) were predicted to come to equilibrium with the aqueous solution. It can be seen clearly in fig 1 that in this simple model the absolute and relative rates of reaction varied widely and affected significantly the sequence and timing of mass transfer events.

If we interpret the linear $t-T$ relation as the consequence of the movement of a fluid at $a$ constant rate in a constant thermal gradient, then the abscissa in fig 1 also corresponds to log distance, as well as to log time and log temperature. One can thus read from this figure the spatial regions over which each mineral dissolves or precipitates. Note also that the integral of the rate of dissolution over time gives the quantity of material dissolved. Therefore, imagining fig 1 to be transformed to a linear coordinate system, the areas under the curves would give the numbers of moles of minerals dissolved as a function of time, temperature, or distance.

A diagram analogous to fig 1 could be generated for the precipitated phases showing rates of precipitation as a function of time, temperature or distance. In this model the rates of precipitation are controlled by the overall rate of mass transfer and equilibrium constraints among the aqueous solution and the precipitating minerals.

Figure 2 is an illustration of the variation of solution composition for the same reaction path. Aqueous silica can be seen to follow closely quartz solubility. $\mathrm{Na}^{+}$increases as albite dissolves. Initially $\mathrm{pH}$ and $\mathrm{Al}(\mathrm{OH})_{4}{ }^{-}$increase as the two feldspars dissolve, then level off as microcline precipitates. Then, where microcline, muscovite and quartz are all in equilibrium with the aqueous phase, $\mathrm{pH}$ and $\mathrm{Al}(\mathrm{OH})_{4}{ }^{-}$increase dramatically, and this is accompanied by a large decrease in $\mathrm{K}^{+}$. Finally, as temperature increases from $60^{\circ}$ io $100^{\circ} \mathrm{C}$ during a period of relatively little dissolution, the $\mathrm{pH}$ declines. 
TEMPERA TURE, ${ }^{\circ} \mathrm{C}$

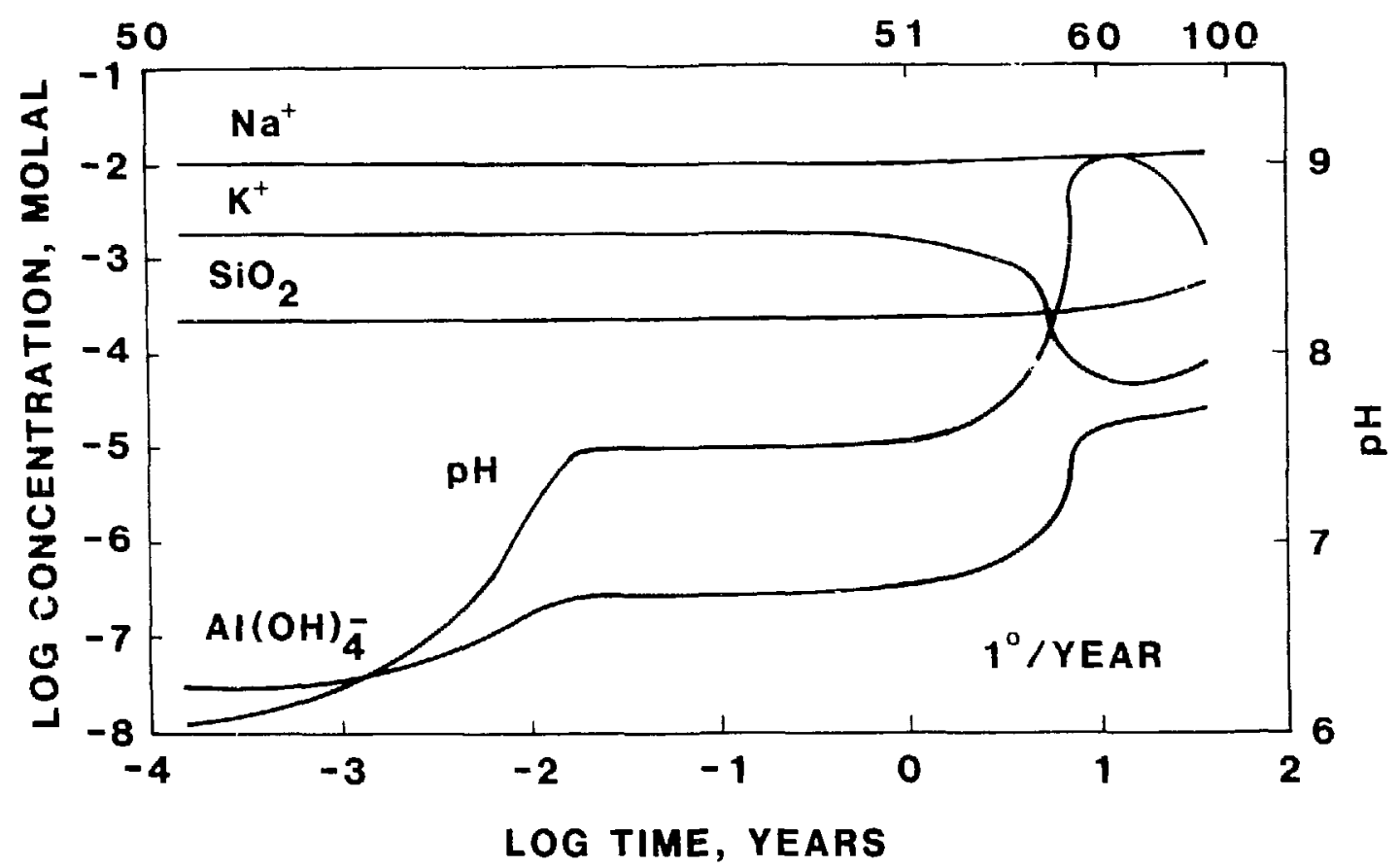

Figure 2. The logarithm of the molal concentration of principal aqueous species and $\mathrm{pH}$ (right scale) as a function of the iogarithm of time. Temperature is given at the top on the abscissa. (See text for discussion.)

The computations used to generate figs 1 and 2 have all been made for a unique $\mathrm{t}-\mathrm{T}$ relation, 1\%year. From these results it is difficult to appreciate which effects are a consequence of the variation in temperature and which are simply a result of the irreversible dissolution. This can be clarified by performing calculations for sther $t-T$ relations as illustrated in fig 3 . In this figure the logarithm of the change of temperature, $\log \Delta T=\log \left(T-T^{\circ}\right)$, is plotted against log time. Time in years is given on a log scale at the top of the figure, and temperatue in ${ }^{\circ} \mathrm{C}$ on a log scale is shown at the right. The dotted lines in this figure represent different linear $t-T$ relations of $2^{\circ}, 1^{\circ}, 0.5^{\circ}$, and $0.25 \%$ year as indicated, with the initial temperature in each case being $50^{\circ} \mathrm{C}$. Reaction paths with the same set of initial conditions as those described above have been calculated for each of these rates of lemperature change. In fig 3 the fields in time-temperature space delineateo by solid and dashed curves are labelled with symbols representing the primary mineral reactants that are out of equilibrium with the aqueous solution and dissolving in that space. The remaining primary minerals together with muscovite are predicted to be precipitating at equilibrium with the aqueous phase along reaction paths traversing the fields.

It can be seen in fig 3 that differences in the time-temperature relations significantly affect the reaction paths. If temperature variation was not important, the lines separating fields in this diagram would he vertical such as that separating the $A B+M /$ disequilibrium field from the $A B+Q$ disequilibrium field. Furthermore, the difference between $t-T$ relations is not simply that events always occur sooner at higher temperatures and later at lower temperatures. This relation is observed for the transitio from the $A B+M I+Q$ disequilibrium field to the $M I+Q$ disequilibrium field. However, the transition from the $A B+Q$ disequilibrium field to the $A B$ disequilibrium field occurs sooner at lower temperalures and later at higher temperatures. In fact, for the lowest rate of temperature increase shown here, $0.25 \%$ year, this transition does not occur at all. In this case there is a direct transition from the $A B+M I$ disequilibrium field to the $A B$ disequilibrium field, and there is no intermediate period or zone of quartz dissolution. 


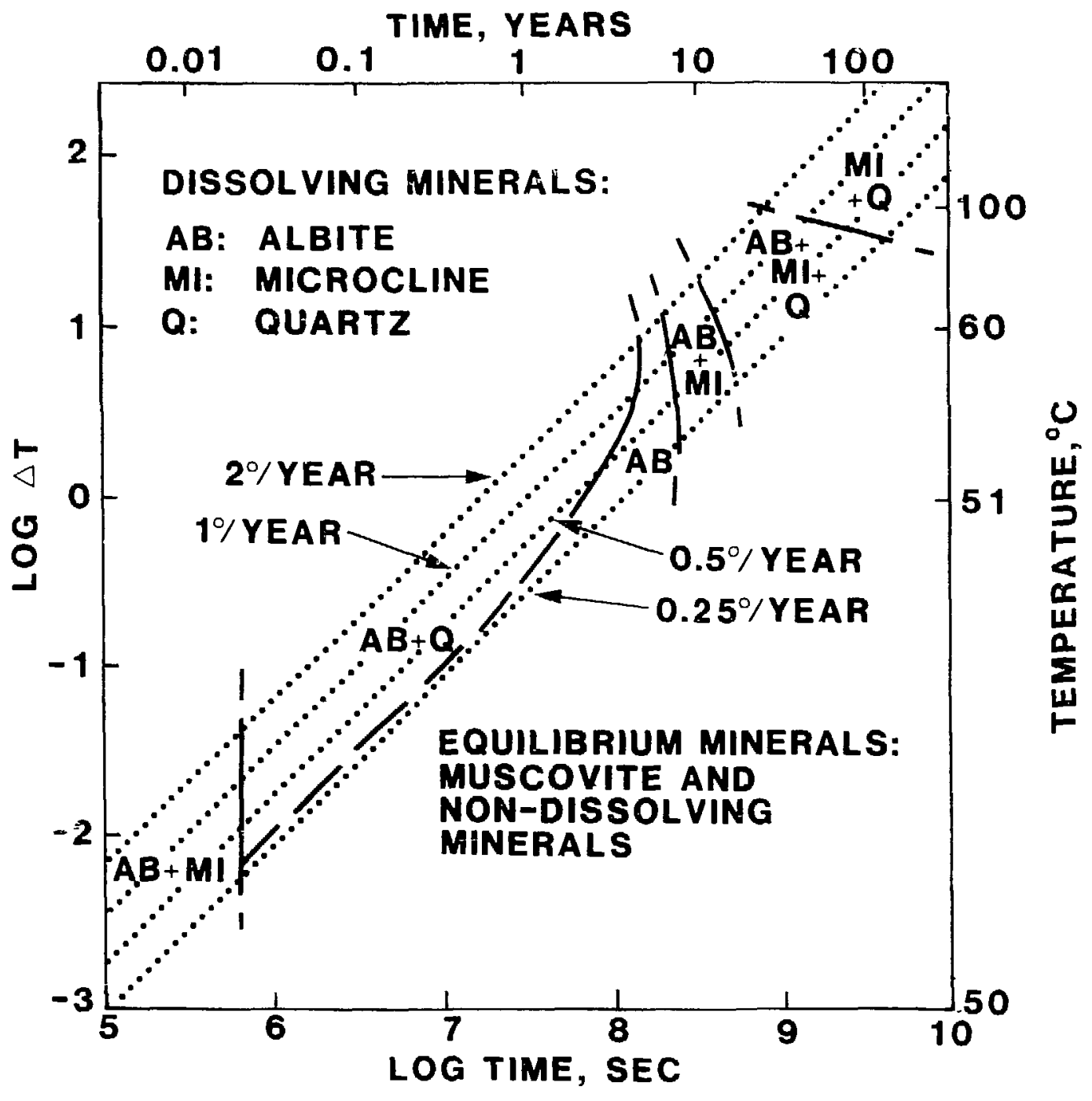

Figure 3. Time- temperature-reaction path diagram for the dissolution of albite, microcline and quartz in aqueous solutions initially at $50^{\circ} \mathrm{C}$ with temperature increasing as a function of time at rates from $0.25^{\circ}$ to $2.0^{\circ}$ / year. (See texi for discussion.)

In summary, figure 3 is a time-temperature-transformation diagram for a class of irreversibie water-rock interaction paths each with the same set of initial conditions but with different regimes of time-temperature evolution. The generation of this diagram requires a kinetic model for waterrock reactions as a function of temperature.

\section{Concluding Remarks}

Under far from equilibrium conditions rates of water-rock interactions are generally fast on a geologic time scale. Hence, most hydrothermal systems remain relatively close to equilibrium in quasistatic states (Helgeson and Murphy, 1983). Mass transfer will be induced in such systems by physical perturbations, among which variations in temperature are particularly important. It follows that kinetic modeling of nonisothermal water-rock systems provides a valuable means of predicting geoct amical mass transfer. Calculations such as those summarized above and their representation in, time-temperature-reaction path diagrams such as fig 3 should prove to be useful 
in understanding the evoiution of nonisothermal systems, and shouid be particularly relevant for predictions of the geochemical consequences of aqueous solutions flowing in thermal gradients.

\section{Reterences}

AAGAARD P. and HELGESON H. C. (1982) Thermodyriamic and kinetic constraints on reaction rates among minerals and aqueous solutions. I. Theoretical considerations. Am. J. Sci. 282 , 237-285.

HELGESON H. C. (1979) Mass transfer among minerals and hydrothermal solutions. In Geochemistry of Hydrothermal Ore Deposits (ed. H. L. BARNES) Wiley.

HELGESON H. C. and MURPHY W. M. (1983) Calculation of mass transfer among minerals and aqueous solutions as a function of time and surface area in geochemical processes. I. Computational approach. Math. Geo. 15, 109-130.

HELGESUN H. C., MURPHY W. M. and AAGAARD P. (1984) Thermodynamic and kinetic constraints on reaction rates among minerals and aqueous solutions. II. Rate constants, effective surface area, and the hycirolysis of feldspar. Geochim. Cosmochim. Acta 48, 24052432

LASAGA A. C. (1984) Chemical kinetics of water-rock interactions. J. Geophy. Res. 89, 40094025.

MURPHY W. M. (1985) Thermodynamic and Kinetic Constraints on Reaction Rates Among Minerals and Aqueous Solutions. Ph.D. Dissertation, Univ. California, Berkeley.

MURPHY W. M. and HELGESON H. C. (1986a) Thermodynamic and kinetic constraints on reaction rates among minerals and aqueous solutions. III. Activated complexes and the $\mathrm{pH}$ dependence of the rates of feldspar, pyroxene, wollastonite, and olivine hydrolysis. Geochim. Cosmochim. Acta (in review).

MURPHY W. M. and HELGESON H. C. (1986b) Thermodynamic and kinetic constraints on reaction rates among minerals and aqueous solutions. IV. Retrieval of rate constants and activation parameters for the hydrolysis of pyroxene, wollastonite, olivine, andalusite, and quartz. Am. J. Sci. (in review).

WOLERY T. J. (1979) Calculation of chemical equilibrium between aqueous solutions and minerals: The EQ3/6 software package. LLNL doc. UCRL-52748.

WOLERY T. J. (1984) EQ6, A computer program for reaction-path modeling of aqueous geochemical systems: User's guide and documentation. LLNL doc. UCRL-51 (draft). 
DEVELOPMENT AND APPLICATION OF STABLE ISOTOPE

MASS TRANSFER REACTION PATH MODELS

\author{
Teresa Suter Bowers \\ Departmert of Earth, Atmospheric and Planetary Sciences \\ Massachusetts Institute of Technology \\ Cambridge, MA 02139
}

\title{
Abstract
}

Modifications to EQ3/6 for the inclusion of oxygen, hydrogen and sulfur isotopes allow simultaneous calculation of the chemical and stable isotopic consequences of mass transfer in geologic systems. Additiun of isotopes to the computer programs provides further constraints that can be used to evaluate water-rock interaction models. An application to mid-ocean ridge hydrothermal systems is included where chemical and isotopic changes attending seawater-basalt interaction are calculated for an evolutionary path of seawater to hydrothermal endmember such as that exiting from mid-ocean ridge hot sp rings.

\section{Introduction}

The use of stable isotopes to demonstrate the presence of hydrothermal activity has become widespread in recent years (Taylor, 1983, 1974 and references therein). Isotopic ratios have been used to indicate mineral alteration, type or source of infiltrating fluids and water-rock ratios. In fact, at times they give evidence of water-rock interaction when mineralogical or chemical evidence is scant (Gregory and Taylor, 1981). As a result, it seemed desirable to incorporate stable isotope systematics into existing geochemical mass transfer computer codes in order to develop integrated chemical and isotopic models describing hydrothetmal systems. Computer models of this sort are important for (at least) two reasons: 1) they allow explicit accounting of the effect that formation of secondary mineral phases nay have on isotopic ratios of the fluid, and 2) each element for which stable isotopes are included provides an additional constraint that must be met when attempting to model a geologic problem. One of the criticisms of geochemical models is that they often cannot be shown to provide a unique path. However, additional constraints, such as isotopes, that result in the rejection of some paths will further the utility of sucil models.

\section{Computer Programs}

An integrated chemical and oxygen and hydrogen isotope computer model based on EQ3/6 (volery, 1978, 1979, 1983) was developed by Bower:s and Taylor (1985) to address hydrothermal circulation of seavater through basalt at rid-ocean tidges. A sumary of the calculational scheme used by EQ3/6 for isotopes is presented here. hovever, details ol the procedure are given in Bowers and Taylor (1985). The equations are: presented here in terms of oygen, but hold $t \%$ other etements as wo 11 . Iasses of each isotope can be conserved in a similar manner as are the. 
elements in EQ6. A $\delta^{18} \mathrm{O}$ for the system $\left(\delta^{18_{\mathrm{O}_{\mathrm{S}}}}\right.$ ) at a reaction progress of $(\xi)$ can be defined by

$$
\delta^{18} \mathrm{O}_{\mathrm{s}}(\xi)=\frac{\mathrm{n}_{\mathrm{O}}^{\mathrm{H}_{\mathrm{O}} \mathrm{O}}}{\mathrm{n}_{\mathrm{O}}^{\prime}} \delta^{18} \mathrm{O}_{\mathrm{H}_{2} \mathrm{O}}(\xi)+\frac{1}{\mathrm{n}_{\mathrm{O}}^{\prime}} \sum_{\mathrm{r}} \mathrm{n}_{\mathrm{O}}^{r} \delta^{18} \mathrm{O}_{\mathrm{r}}
$$

where

$$
\mathrm{n}_{0}^{3}-\mathrm{n}_{0}^{\mathrm{H}_{0} \mathrm{O}}+\sum_{\mathrm{r}}^{\mathrm{n}} \mathrm{n}^{5}
$$

where $\mathrm{n}_{0} \mathrm{H}_{2} \mathrm{O}$ represents the moles of oxygen in the fluid phase, $\mathrm{n}_{0}{ }^{\mathrm{r}}$ is the moles of oxygen in reactant phase $r$, and ${ }^{n}{ }^{s}$ denotes moles of oxygen in the system. $\xi$ represents one $\xi$-step before the present value of $\xi$; at the first step this is the initial state of the system prior to any dissolution of reactants. When products begin to form $\delta^{18} 0_{s}$ must be redistibuted between the fluid and these product phases according to

$$
\delta^{18} \mathrm{O}_{s}(\xi)=\frac{\mathrm{n}_{\mathrm{O}}^{\mathrm{H}_{2} \mathrm{O}}}{\mathrm{n}_{\mathrm{O}}^{\delta}} \delta^{18} \mathrm{O}_{\mathrm{H}_{i} \mathrm{O}}(\xi)+\frac{1}{\mathrm{n}_{\mathrm{O}}^{\delta}} \sum_{\mathrm{p}} \mathrm{n} B \delta^{18} \mathrm{O}_{\mathrm{p}}(\xi)
$$

where $\mathrm{n}_{\mathrm{O}} \mathrm{r}$ has the same value as in (1) but ${ }^{n} \mathrm{H}_{2} \mathrm{O}$ has been modified by the precipitation of products, and $\delta^{18} \mathrm{O}_{\mathrm{H}, \mathrm{l}}$ and $\delta^{18} \mathrm{O}_{\mathrm{p}}$ at $\xi$ must be calculated from equilibrium fractionation curves for the product minerals and $\mathrm{H}_{2} \mathrm{O}$, expressed by

$$
\alpha_{\mathrm{p}-\mathrm{H}_{2} \mathrm{O}}=\frac{1000+\delta^{18} \mathrm{O}_{\mathrm{p}}}{1000+\delta^{18} \mathrm{O}_{\mathrm{H}_{2} \mathrm{U}}}
$$

This procedure is followed for each $\xi$-step.

The distribution of sulfur isotopes between fluid and rock present a more complex situation because equilibrium between sulfate and sulfide in solution cannot always be assumed, for example, below approximately $250^{\circ} \mathrm{C}$ (Shanks et al., 1981). In this case, separate accounting must be taken of the sulfur assigned to either sulfate or sulfide and the interchange of isotopes between oxidation states not allowed.

The fractionation factors $(\alpha)$ for $O, H$, and $S$ isotopes are included in additional databases attached to EQ6. The fractionation curves have: either been determined experiment. Ly or are known empirically for a large number of geologically important systems and are summarized elsewhere (Bowers and Taylor, 1985; Barnes, 1979; and Taylor, 1974). 


\section{Applications}

Chemical and isotopic changes accompanying seawater-basalt interaction in axial mid-ocean ridge hydrothermal systems can now be assessed through the use of the above-described computer code. The illustrations here are meant to serve merely as an example of use of tho modified computer codes and for details of the development c.f the geologic model the reader should refer to Bowers and Taylor (1985). Th: model is constrained by the chemical and stable-isotope compositions of both the starting solution (seawater) and the final hydrothermal endmember $\left(21^{\circ} \mathrm{N}\right.$ ) (Von Damm et a1., 1985; Craig et al., 1980), as well as petrologic observations of the alteration mineralogy of the basalt (Humphris and Thompson, 1978, Stakes and O'Neil, 1982).

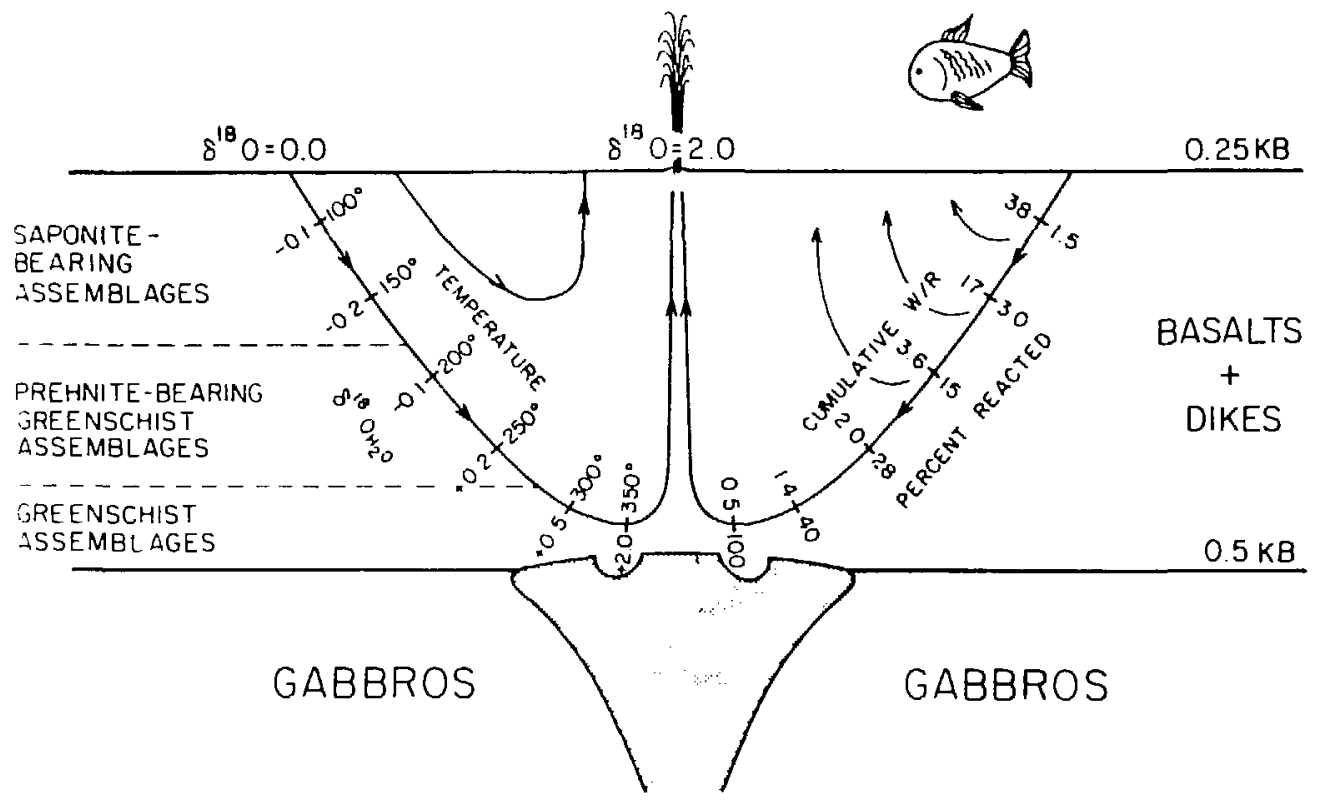

Fig. 1. Schematic illustration of seawater-basalt interaction at mid-ocean ridges

Fig. 1 is a schematic illustration of the mode1, where a hypothetical path shows the penetration of seawater through seafloor basalts at low temperature, circulation of the evolving fiuid downward to the magma-chamber contact, and eventual exit of the hydrothermal endmember at $350^{\circ} \mathrm{C}$ from mid-ocean ridge hot springs. Cumulative rater-rock ratio, percent reaction progress and $\delta^{18} \mathrm{O} \mathrm{H}_{2}$ ! are shown alon: the two syinetrical path-1ines at $50^{\circ} \mathrm{C}$ intervals. The increasing temperatures and decreasing water-rock ratio with depth provide i sharply increasing grade of hydrothermal metanorphism downward. The: mineral assemblages listed at the left of the figure correspond to thos;. found in nature and are essentially reproduced by the computer model. 
Examples of the isotopic alteration of the system during development of secondary mineral phases as a function of reaction progress at $250^{\circ} \mathrm{C}$ and $350^{\circ} \mathrm{C}$ are shown in Fig. 2.
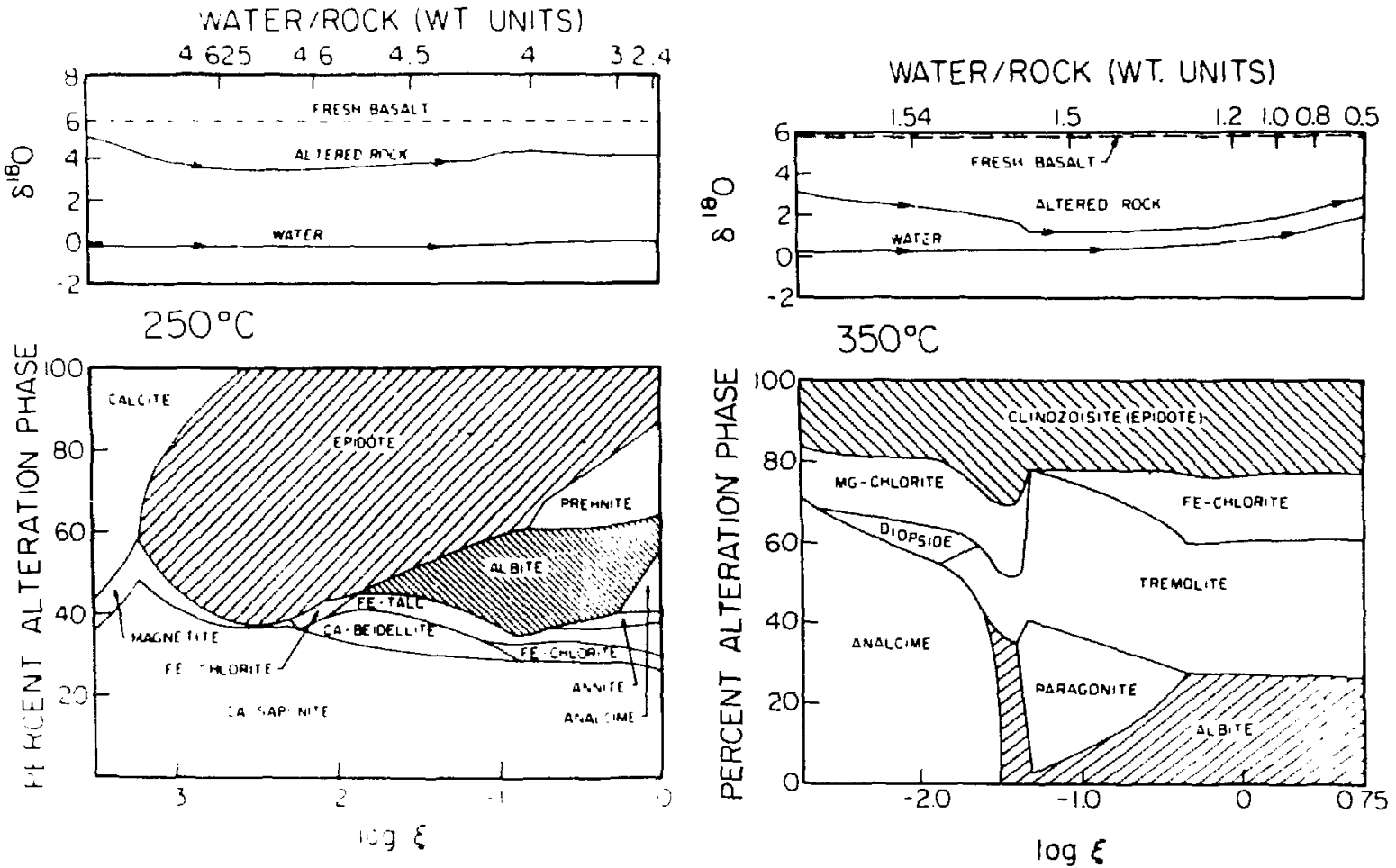

Fig. 2. Summary of predicted alteration phases and $\delta^{18} 0$ values as a function of reaction progress at $250^{\circ}$ and $350^{\circ}$

The reactant is fresh basalt, with $\delta^{18} \mathrm{O}=+5.8 \mathrm{o} / 00$. At $250^{\circ} \mathrm{C}$ the water-rock ratio is sufficiently high such that changes to $\delta^{18} \mathrm{O}_{\mathrm{H}} \mathrm{O}$ ) are slight and the major controls on $\delta^{18} 0$ of the altered rock are temperature and the identity of the alteration phases being produced. At $350^{\circ} \mathrm{C}$ the system has evolved to sufficiently low water-rock ratios so that $\delta^{18} \mathrm{O}$ of both the altered rock and the fluid vary as a function of reaction progress, or the quantity of fresh basalt that has been altered (right side of diagram).

Hydrogen and sulfur isotopes can be followed in a similar mannerand yield more information concerning potential paths of the evolving fluid. 


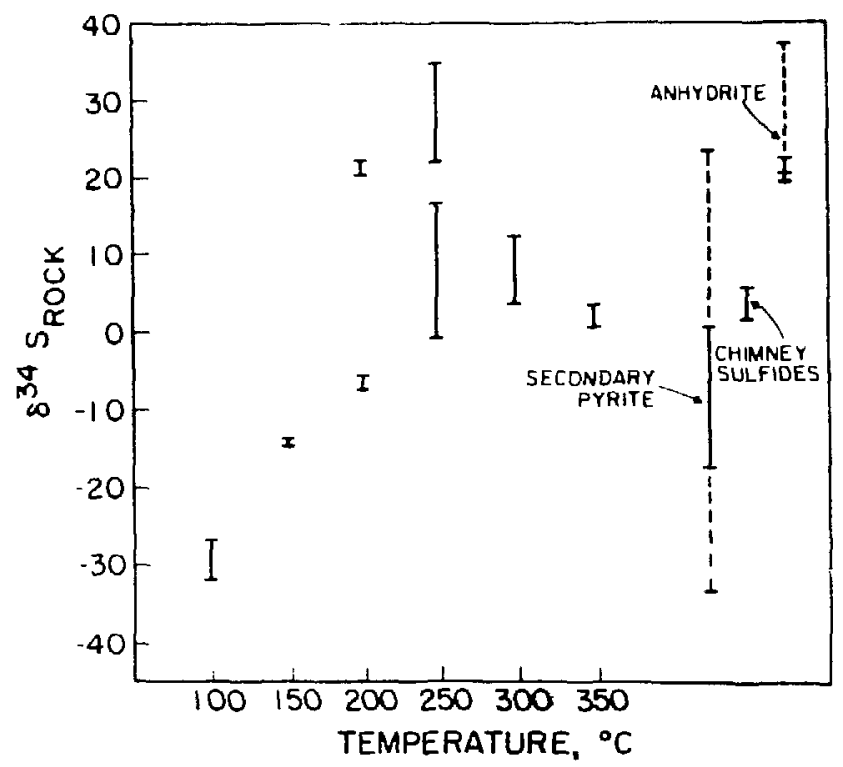

Fig. 3. Calculated $8^{34} \mathrm{~s}$ of predicted sulfides and anhydrite at discrete temperature steps together with ranges observed in natural samples

Fig. 3 illustrates some preliminary results of sulfur isotope modeling where equilibrium between sulfate and sulfide were assumed at all temperatures. The vertical bars at each temperature represent the range of $\delta^{34} \mathrm{~S}$ values of secondary sulfides (upper bars at $200^{\circ}$ and $250^{\circ} \mathrm{C}$ are for anhydrite) calculated to form during alteration of basalt. Also shown in Fig. 3 for comparison are ranges typical of samples taken from DSDP cores, dredged basalts and chimney pieces (Alt et al., 1985; Styrt et al., 1981; Andrews, 1979). The solid portion of the bars are where most samples fall; the dashed portions are extensions to include observations outside the normal range. The agreement between the low temperature calculated sulfide $\delta^{34} \mathrm{~S}$ values and the low observed $\delta^{34} \mathrm{~S}$ values for pyrite is coincidental and is not indicative of sulfate-sulfide equilibrium at $100^{\circ} \mathrm{C}$. However, at internediate temperatures calculated sulfide and anhydrite $\delta^{34}$ s values agree reasonably well with observation and at $350^{\circ} \mathrm{C}$ there is good agreement between the calculations and chimney sulfide values.

Tracking of the stable isotopes of oxygen, hydrogen and sulfur (or carbon) as a function of reaction progress in mass transfer computer codes such as EQ3/6 can yield additional information about water-rock interaction processes that may be of considerable use in determining, relative closeness of fit of diverse models. This can lead to rejection of potential paths that fit the chemical data adequately, but not the isotopic. 
ALT J.C., SALTZMAN E.S. and PRICE D.A. (1935) Anhydrite in hydrothermally altered basalts: Deep sea drilling project hole 504B Leg 83. Init. Repts. DSDP, 83 Washington, U. S. Govt. Printing office, 283-288.

ANDREWS A.J. (1979) On the effect of low-temperature seawater-basalt interaction on the distribution of sulfur in oceanic crust, layer 2. Earth Planet. Sci. Lett. 46 , 68-80.

BARNES H.L. (1979) Geochemistry of Hydrothermal Ore Deposits. Wiley.

BOWERS T.S. and TAYLOR H.P., Jr. (1985) An integrated chemical and stable-isotope model of the origin of mid-ocean ridge hot spring systems. J. Geophys. Res. 90, 12, 583-12,606.

CRAIG H., WELHAN J.A., KIM K., POREDA R. and LUPTON J.E. (1980) Geochemical studies of the $21^{\circ} \mathrm{N}$ EPR hydrothermal fluids. EOS, Trans. Amer. Geophys. Union 61, abstract, 992.

GREGORY R.T. and TAYLOR H.P., Jr.(1981) An oxygen isotope profile in a section of Cretaceous oceanic crust, Samail ophiolite, Oman: Evidence for $\delta^{18} \mathrm{O}$ buffering of the oceans by deep ( $\left.>5 \mathrm{~km}\right)$ seawater-hydrothermal circulation at mid-ocean ridges. J. Geophys. Res. 16 , 2737-2755.

HUMPHRIS S.E. and THOMPSON G. (1978) Hydrothermal alteration of oceanjc basalts by seawater. Geochim. Cosmochim. Acta. 42, 107-125.

SHANKS W.C., III, BISCHOFF J.L. and ROSENBAUER R.J. (1981) Seawater sulfate reduction and sulfur isotope fractionation in basaltic systems: Interaction of seawater with fayalite and magnetite at $200-300^{\circ} \mathrm{C}$. Geochim. Cosmochim. Acta $4 \underline{5}, 1977-1995$.

STAKES D.S. and O'NEIL J.R. (1982) Mineralogy and stable isotope geochemistry of hydrothermally altered oceanic rocks. Earth Planet. Sci. Lett. 57, 285-304.

STIRT M.M., BRACKMAN A.J., HOLLAND H.D., CLARK B.C., PISUTHA-ARNOLD V., ELDRIDGE C.S. and OHMOTO H. (1981) The mineralogy and the isotopic: composition of sulfur in hydrothermal sulfide/sulfate deposits on the East Pacific Rise, $21^{\circ} \mathrm{N}$ latitude. Earth Planet. Sci. Lett. 53. $382-390$.

TAYLOR H.P., Jr. (1983) Oxygen and hydrogen isotope studies of hydrothermal interactions at submarine and subaerial spreading centers. NATO Symposium Vol, on Hydrothermal Processes at Seafluef Spreading Centers, P.A. Rona, K. Bostrom, L. Laubier, and K. L. Smith, eds. Plenum Press, New York, 83-139. 
TAYLOR H.P., Jr. (1974) The applicaison of oxygen and hydrogen isotope studies to problems of hydrothermal alteration and ore deposition. Econ. Geol. 69, 843-883.

VON DAMM K.L., EDMOND J.M., GRANT B., MEASURES C.I., WALDEN B. and WEISS R. (1985) Chemistry of submarine hydrothermal solutions at $21^{\circ} \mathrm{N}$ East Pacific Rise. Geochim. Cosmochim. Acta. 49, 2197-2220.

HOLERY T.J. (1982) EQ3NR, A computer program for geochemical aqueous speciation-solubility calculations. UCRL-5, Distribution Category UC-70, Lawrence Livermore National Laboratory.

WOLERY T.J. (1979) Calculation of chemical equilibrium between aqueous solution and minerals: the EQ3/6 software package. Lawlence Livermore Laboratory Report UCRL-52658, 41p.

WOLERY T.J. (1978) Some chemical aspects of hydrothermal processes at mid-oceanic ridges - a theoretical study. I. Basalt-seawater reaction and chemical cycling between the ocean crust and the oceans. II. Calculation of chemical equilibrium between aqueous solutions and minerals. Ph.D. Dissertation, Northwestern

University. 


\title{
IMPROVEMENTS IN THE SOLID SOLUTION MODELING CAPABILITIES OF EQ3/6
}

\author{
William L. Bourcier \\ Lawrence Livermore National Laboratory \\ Livermore, California 94550
}

\section{ABSTRACT}

The EQ3/6 geochemical modeling codes have been expanded to include provision for the precipitation and dissolution of solid solution mineral phases in the calculation of water-rock reactions for both ideal and non-ideal solid solution models. The solid solution option can be used in both closed and open system modeling. In closed systems, the solid solution precipitates are assumed to completely re-equilibrate with the system at each step during the reaction. In open systems, a finite amount of solid solution which is precipitated at each step of reaction progress is removed from the system and not allowed to back-react with the fluid. The open system treatment can be used to model the zoning of solid solutions, which is commonly observed in nature.

Sample calculations using the solid solution option in the simulation of the diagenetic changes in an arkosic sandstone show that including solid solutions as product phases results in increased stability of clays and carbonates during burial.

\section{INTRODUCTION}

The EQ3/6 geochemical modeling codes (Wolery. 1988) have been expanded to take into account compositional variability of solid solution phases. In simulations of waterrock interactions. product phases can now continually change in composition in response to the evolving solution composition. This capability enables more accurate simulation of real systems in which solid solution phases are common and whose changing compositions record the progress of water-rock interaction.

This paper describes how solid solutions are handled in the EQ3/6 code package. describes the current database, provides instructions on how a user can add additional solid solution models to the database, and discusses some limitations of the current approach along with recommendations for future improvements.

\section{THE SOLID SOLUTION PROBLEM}

One aspect of the geochemical modeling of water-rock interactions is the prediction of the precipitation of secondary phases during the reactions. Water-rock interactions involving solid phases of fixed stoichiometry are modeled by forcing mineral phases to precipitate when their saturation indicies are exceeded. The saturation index (SI) for the 
phase $i$ is defined as:

$$
\mathrm{SI}_{\mathrm{i}}=\log \left(\frac{\mathrm{Q}_{\mathrm{i}}}{\mathrm{K}_{\mathrm{i}}}\right)
$$

where $Q$ is the activity product for phase $i$ and $K$ is the solubility product for phase $i$. The phase is supersaturated with respect to a given solution composition when $\mathrm{Sl}_{i}$ is greater than zero.

For solid solution phases which have variable composition. the treatment is more complicated because the saturation index of the solid is a function of both the solution composition and the solid composition. The problem of treating solid solutions then becomes that of determining the least soluble solid solution composition for a given fluid composition, and then determining the saturation index for that phase.

The least soluble solid solution composition for a given fluid composition is calculated by finding the maximum of the saturation index of the solid solution. The saturation index for a solid solution (ss) is defined in an analogous way to equation (1) for a fixed composition phase (BOURCIER, 1985):

$$
\mathrm{SI}_{\mathrm{sB}}=\sum_{\mathrm{i}=1}^{\mathrm{n}} \mathrm{X}_{\mathrm{i}} \cdot \log \left(\frac{\mathrm{Q}_{\mathrm{i}}}{\mathrm{K}_{\mathrm{i}} \cdot \mathrm{a}_{\mathrm{i}}}\right)
$$

where $X_{i}$ is the mole fraction of component $i$ in the solid solution, $a_{i}$ is the activity of component $\mathrm{i}$ in the solid solution. and $\mathrm{n}$ is the number of components in the solid solution.

Ideal solid solutions for which $X_{i}=a_{i}$, a simple analytical solution for the maximum value of equation (2) is:

$$
\mathrm{X}_{\mathrm{i}}=\left(\frac{\mathrm{Q}_{\mathrm{i}} / \mathrm{K}_{\mathrm{i}}}{\sum_{\mathrm{n}} \mathrm{Q}_{\mathrm{n}} / \mathrm{K}_{\mathrm{n}}}\right)
$$

where the sum is over all the components of the solid solution. Equation 3 is used to calculate the mole fraction of each component in the solid solution from the saturation indices of each endmember component of the solid solution and the given solution composition. This equation is programmed into the subroutine HPSAT of the EQ3/6 package.

For non-ideal solid solutions. the relationship $X_{i}=a_{i}$ does not hold and a simple analytical solution for the maximum of equation (2) does not exist. In this case, a numerical method must be used to find the maximum of the affinity function. In EQ3/6 the Simplex method was chosen for this task. The Simplex method is a well known algorithm for solving linear programming problems (ANTON et al.. 1974). It is also used for ideal site-mixing solid solution models where again the relationship $X_{i}=a_{i}$ does not hold. 
to be modeled. If this interval is zero, the system behaves as a true open system. If DLZIDP is 0.1 . the product phases are continually back-reacted with the system for each one tenth of the reaction progress. at which point the product phases are isolated from the system. Varying the size of the DLZIDP parameter controls the extent of back-reaction of the system and is therefore useful for modeling zoning of solid solutions.

The solid solution option is invoked in the EQ3NR and EQ6 input files by setting the IOPT4 parameter equal to 1 . No other changes are needed. For EQ3NR runs where a fixed composition solid solution is assumed to be in equilibrium with a fluid phase (i.e. $J F L A G=20$ option), IOPT4 should be set equal to 2 .

\section{SOLID SOLUTION DATABASE}

Most solid solutions present in the EQ3/6 database are assumed to follow ideal molecular mixing relations (see Table 1). By definition, ideal molecular mixing models hold that the enthalpy of mixing is zero, and that the endmembers mix as complete molecular entities. This is in contrast to site mixing models where ions are allowed to mix randomly on sites, independent of the populations on other sites. For the case where only one site is populated by more than one ion (such as the calcite-structured carbonate solid solution). molecular mixing and site mixing are identical. For solid solutions that have multiple sites. molecular mixing models therefore neglect the small favorable entropy of independent mixing over several sites and enthalpy changes associated with non-ideal mixing.

Ideal mixing is assumed for most minerals because experimental data on non-ideal mixing is generally not available for the relatively low temperature range (less than $300^{\circ} \mathrm{C}$ ) of the EQ3/6 database. The equilibration rates of minerals are usually too slow at these temperatures, and metastability too common to allow useful thermodynamic data to be obtained from experiments. However, in nature. metastable low temperature phases are common, and it may be that for some systems, the assumption of ideal mixing is a better approximation for what precipitates in a real system than the thermodynamically most stabie composition predicted from a rigorous non-ideal solid solution model derived from high-temperature data.

Additional solid solutions can easily be added to the EQ3/6 database. First add the appropriate block to the solid solution section of the file DATA0. A sample block for the orthopyroxene solid solution is given in Figure 2 below.

The data block contains the following information: the name of the solid solution (which must be distinct from any other solid), the number of endmember components, the type of solid solution model, and the names and maximum mole fractions of endmembers. The types of solid solution models avallable are listed in subroutine LAMDA and include ideal. third-order binary. Maclaurin binary, cubic binary with P.T dependence. Guggenheim 
Table 1. Solid Solutions in the EQ3/6 Database

\begin{tabular}{|c|c|c|c|}
\hline NAME & ENDME: & MBERS & SOL" TION MODEL \\
\hline$(\mathrm{Na}, \mathrm{K})$-sanidine & sanidine high & albite high & ideal \\
\hline biotite & $\begin{array}{l}\text { phlogopite } \\
\text { pd-oxyannite }\end{array}$ & annite & idea! \\
\hline $\begin{array}{l}\text { saponite-tri } \\
\text { (trioctahedral) }\end{array}$ & $\begin{array}{l}\text { saponite-Ca } \\
\text { saponite-K } \\
\text { saponite-Na }\end{array}$ & $\begin{array}{l}\text { saponite-H } \\
\text { saponite-Mg }\end{array}$ & ideal \\
\hline $\begin{array}{l}\text { smectite-di } \\
\text { (dioctahedral) }\end{array}$ & $\begin{array}{l}\text { beidellit- } \mathrm{Ca} \\
\text { beidellit-Mg } \\
\text { nontronit- } \mathrm{Ca} \\
\text { nontronit-Mg } \\
\text { montmor- } \mathrm{Ca} \\
\text { montmor- } \mathrm{Mg}\end{array}$ & $\begin{array}{l}\text { veidellite- } \mathrm{K} \\
\text { beidellit- } \mathrm{Na} \\
\text { nontronit-K } \\
\text { nontronit- } \mathrm{Na} \\
\text { montmor- } \mathrm{K} \\
\text { montmor- } \mathrm{Na}\end{array}$ & ideal \\
\hline olivine & fayalite & forsterite & regular \\
\hline orthopyroxene & ferrosilite & enstatite & ideal \\
\hline plagioclase & albite high & anorthite & ideal \\
\hline carbonate-calcite & $\begin{array}{l}\text { calcite } \\
\text { rhodochrosite } \\
\text { smichsonite }\end{array}$ & $\begin{array}{l}\text { magnesite } \\
\text { siderite } \\
\mathrm{SrCO}_{3-\mathrm{cal}}\end{array}$ & ideal \\
\hline epidote-ss & epidote & clinozoisite & icleal \\
\hline mordenite-ss & $\begin{array}{l}\text { mordenite- } \mathrm{Na} \\
\text { mordenite- } \mathrm{Ca}\end{array}$ & mordenite- $K$ & ideal \\
\hline phillipsite-ss & $\begin{array}{l}\text { phillipsite-K } \\
\text { phillipsite-Na }\end{array}$ & phillipsite-Ca & ideal \\
\hline stilbite-ss & $\begin{array}{l}\text { stilbite- } \mathrm{Ca} \\
\text { stilbite- } \mathrm{Na}\end{array}$ & stilbite-K & ideal \\
\hline garnet-ss & andradite & grossular & ideal site-mixing \\
\hline chlorite-ss & clinochl-14a & daphnite-14is & ideal \\
\hline dachiardite-ss & $\begin{array}{l}\text { dachiardite- } \mathrm{K} \\
\text { dachiardite- } \mathrm{Na}\end{array}$ & dachiardite-Ca & ideal \\
\hline
\end{tabular}

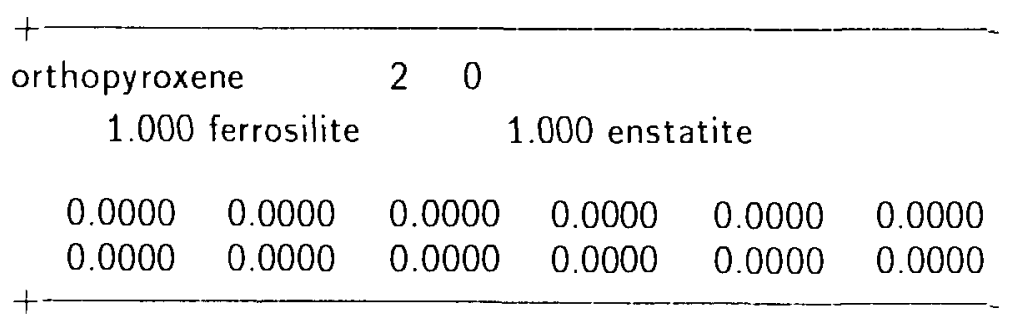

Figure 2. Solid solution data block for orthopyroxene.

binary. and regular ternary. The last twelve numbers in the pyroxene block (zeros in this 
binary. and regular ternary. The last twelve numbers in the pyroxene block (zeros in this case) are non-ideal mixing parameters used in subroutine LAMDA. The thermodynamic data blocks for the endmembers must be present ir. DATA0.

Thermodynamic data for solid solution endmembers, which are often hypothetical, are usually different than data for real phases having the same composition. In this case, an entry for the endmember should be placed into the DATAO file and given a different name than the real phase. For example. the calcite-structured carbonate solid solution has the component rhombohedral $\mathrm{SrCO}_{3}$, a solid phase that does not occur in nature. $\mathrm{SrCO}_{3}$ is distinct from strontianite which has the aragonite structure. Both solids have been placed into DATAO and given distinct names.

\section{EXAMPLE - MODELING DIAGENESIS USING THE SOLID SOLUTION OPTION OF EQ6}

This example of using the solid solution option of EQ3/6 simulates the reaction between minerals and pore fluids in a closed system during burial. The simulation yields the sequence and types of mineral dissolution and precipitation events that occur as the rock and fluid attempt to equilibrate with each other as temperature increases during burial (BRUTON, 1986). The initial pore fluid composition is that of a dilute river water of neutral $\mathrm{pH}$. The rock composition is that of an arkosic sandstone. The predicted sequence of mineral deposition and dissolution events is shown in Figure 3a for the case where no solid solution is considered, and with solid solutions of dioctahedral smectite. trioctahedral saponite, and calcite-structured carbonate in Figure $3 \mathrm{~b}$.

The diagenetic trends are similar in both cases. However, the stability fields of the clay and carbonate phases are expanded by treating them as solid solutions, and some minor phases such as hematite and paragonite are eliminated from the set of predicted secondary phases when solid solutions are considered.

Figure 4 shows the compositional variation of the 12-component dioctahedral smectite solid solution product phase during the diagenesis simulation described above. The solid solution model is an ideal mixing of molecular components with free energy values calculated using the method of TARDY and GARRELS (1974). The composition of the smectite phase changes abruptly at points coincident with the appearance or disappearance of other phases containing elements in common with the smectite. These changes do not correspond to significant changes in the fluid phase composition. An abrupt compositional change found in a natural smectite therefore may not necessarily be accompanied by a significant change in the fluid composition.

\section{FUTURE WORK}

Future work on solid solutions in the EQ3/6 code package will concentrate on puttirig in site mixing models for clays and zeolites. These models can be incorporated within 
a) Diagenetic sequence-without solid solution option

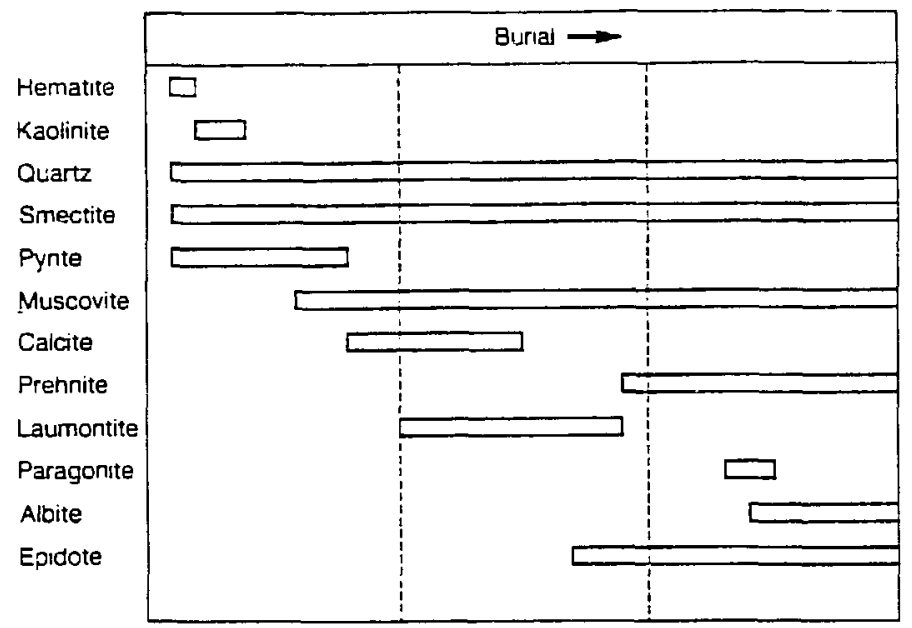

b) Diagenetic sequence-with solid sclution option

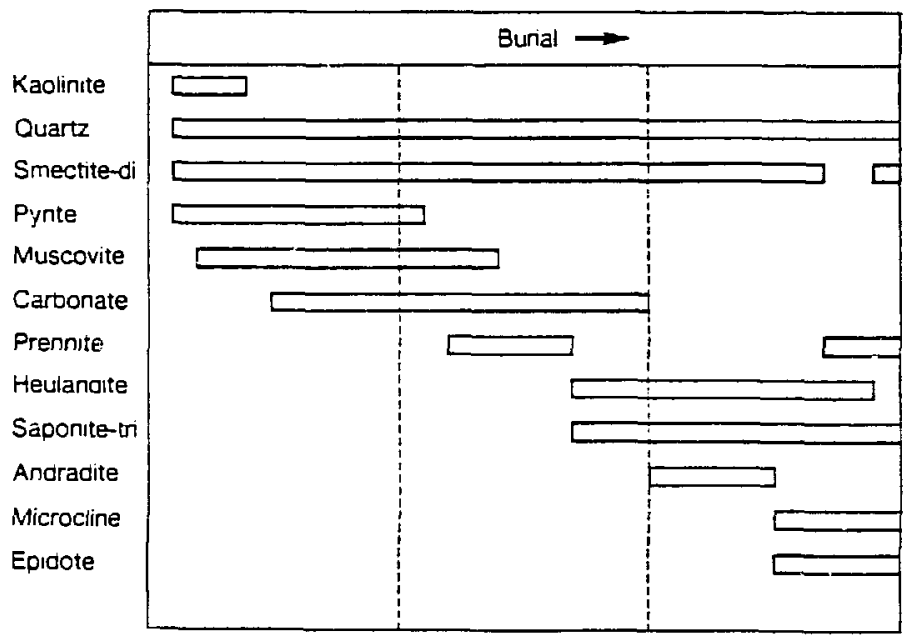

Figure 3. Predicted sequence of mineral precipitates for reaction of arkosic sandstone with river water. (a) no solid solution considered; (b) solid solutions of smectite. saponite. and calcite structured carbonate considered.

the existing Simplex algorithm by adding suitable site mixing models into the subroutirie LAMDA.

The incorporation of trace components into solid solution phases is not yet considered in EQ3/6. Some trace elements can be handled using the existing framework by adding the appropriate endmembers to the solid solution models already present. Additional coding will be necessary for incorporating data on the solubility of minor elements in mineral phases described by Henry's Law-type behavior. 


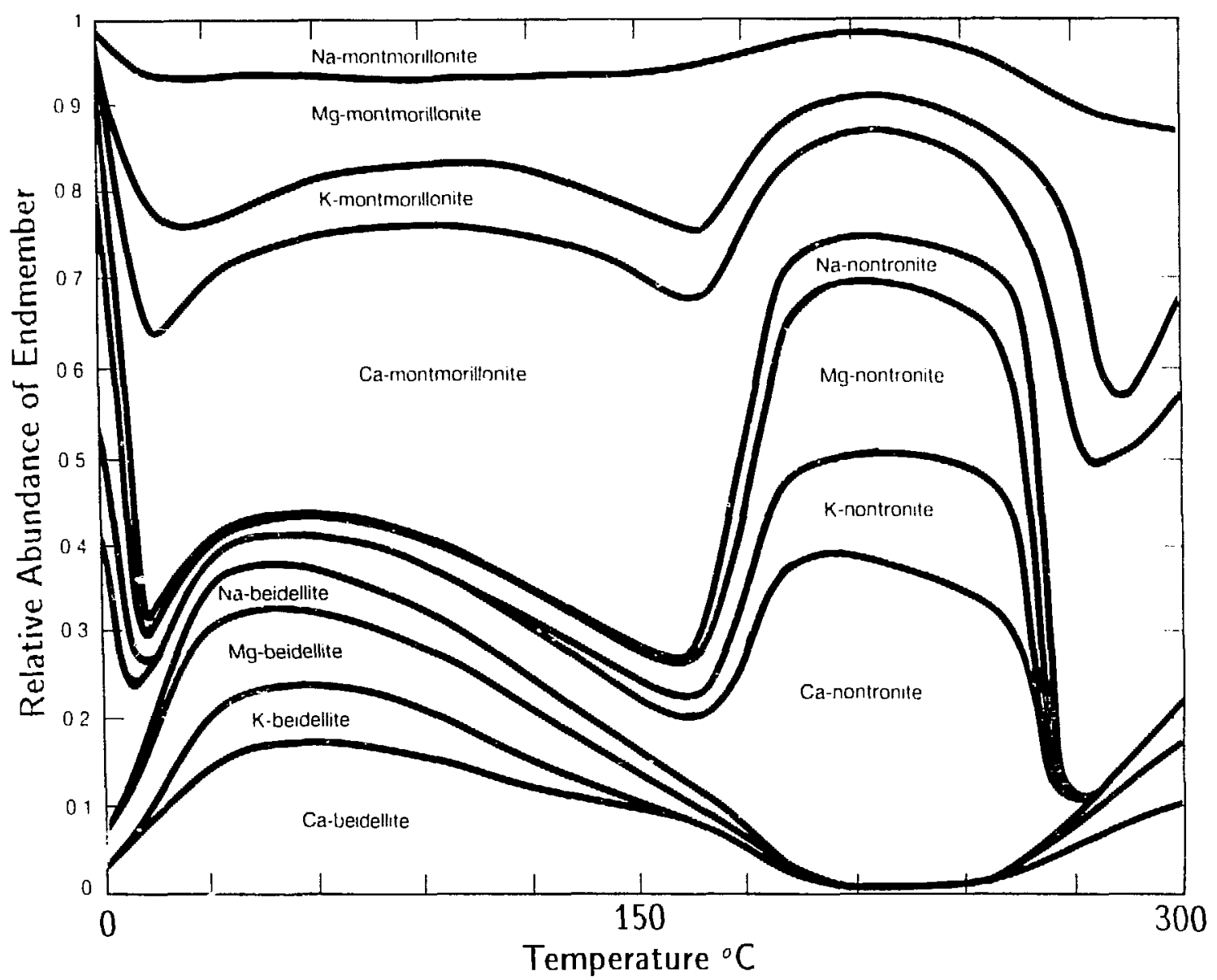

Figure 4. Compositional variation of smectite solid solution during diagenetic reaction of river water with arkusic sandstonec.

\section{REFERENCES}

ANTON. HOWARD, and BERNARD KOLMAN (1974) Applied Finite Nethematics, Academic Press, New York, 475 p.

BOURCIER. W. L. (1985) Improvements in the solid solution modeling capability of the EQ3/6 geochemical code. Lawrence Livermore National Laboratory, UCID 20587.

BRUTON. C. J. (1986) Predicting mineral dissolution and precipitation during burial: Synthetic diagenetic sequences. Procedings of the Workshop on Geochemical Modeling. Fallen Leaf Lake, California. September. 1986.

TARDY Y. and R. M. GARRELS (1974) A method of estimating the Gibbs energies of formation of the layer silicates. Geochimica et Cosmochimica Acta, 38:11.01-1116.

WOLERY. T. J. (1988) EQ3/6 - Status and future development. Procedings of the Workshop on Geochemical Modeling. Fallen Leaf Lake. California. September 1986. 
Hydrothermal and Geothermal Systems 
Preliminary Chemical Modeling of Epithermal Processes at Creede, Colorado: The Role of Fluid Mixing as an Ore Deposition Mechanism

\author{
Geoffrey. S. Plumlee ${ }^{1}$ and Daniel O. Hayba ${ }^{2}$ \\ U. S. Geological Survey

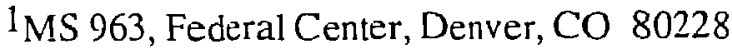 \\ 2959 National Center, Reston, VA 22092
}

\begin{abstract}
Continuing studies of epithermal ores from the Creede district, Colorado, have provided an extensive geological and geochemical basis for guiding quantitative chemical modeling of ore deposition processes in the Creede hydrothermal system. Preliminary modeling efforts to date suggest that the mixing of hot, metal-bearing brines with cooler, dilute, oxidizing groundwaters could have produced observed district-wide mineral zoning patterns. Initial boiling of the brines in the deeper parts of the Creede vein systems prior to mixing could also have contributed to the zoning patterns, however.
\end{abstract}

\title{
Introduction
}

During the past 30 years, extensive studies of Miocene epithermal Ag-Pb- $\mathrm{Zn}-\mathrm{Cu}$ ores from Creede, Colorado, have provided a detailed geological and geochemical understanding of the Creede mineralizing system. Numerical modeling can be used to evaluate the chemical validity of ore deposition mechanisms suggested by fluid inclusion, stable isotope and ore petrology studies. This report discusses the geological and geochemical evidence used to constrain chemical modeling of ore deposition processes at Creede, and presents preliminary calculations assessing the role of fluid mixing as an ore deposition mechanism.

\section{General Geologic and Hydrologic Setting}

The Creede mining district is located in the mid-Tertiary San Juan volcanic field of southwestern Colorado, in a complex of nested calderas. The $25 \mathrm{Ma}$ Creede ore deposits occur primarily as veins filling fractures of a graben extending to the north-northwest from the $26 \mathrm{Ma}$ Creede caldera (Figure 1). The bulk of the production has come from the Amethyst, $\mathrm{OH}, \mathrm{P}$ and Bulldog Mountain vein systems. The Creede ores are thought to have been deposited in response to boiling and fluid mixing at the top of a convectivelycirculating, saline hydrothermal system (Hayba et al., 1986).

Mineralogv and Mineral Zoning The same general sequence of mineralization stages can be correlated throughout the Creede district (Heald-Wetlaufer and Plumlee, 1984; Hayba et al., 1986). However, one of two main sulfide stages at Creede, the so-called " $B$ " stage, is strongly zoned mineralogically from north to south in the district. Sphalerite-galenachalcopyrite-chlorite-pyrite-hematite ores in the northern veins $(\mathrm{OH}, \mathrm{P}$, northern Amethyst and northern Bulldog Mountain systems) grade laterally into southern silver-rich, baritesulfide-native silver ores (southern Amethyst and southern Bulldog Mountain systems). Detailed mineralogical studies document that these northern and southeri mineral 
assemblages are correlateable facies reflecting the progressive north-to-south evolution of the ore-forming fluids as they traveled through the district vein systems (Barton, et al., 1977; Heald-Wetlaufer and Plumlee, 1984).

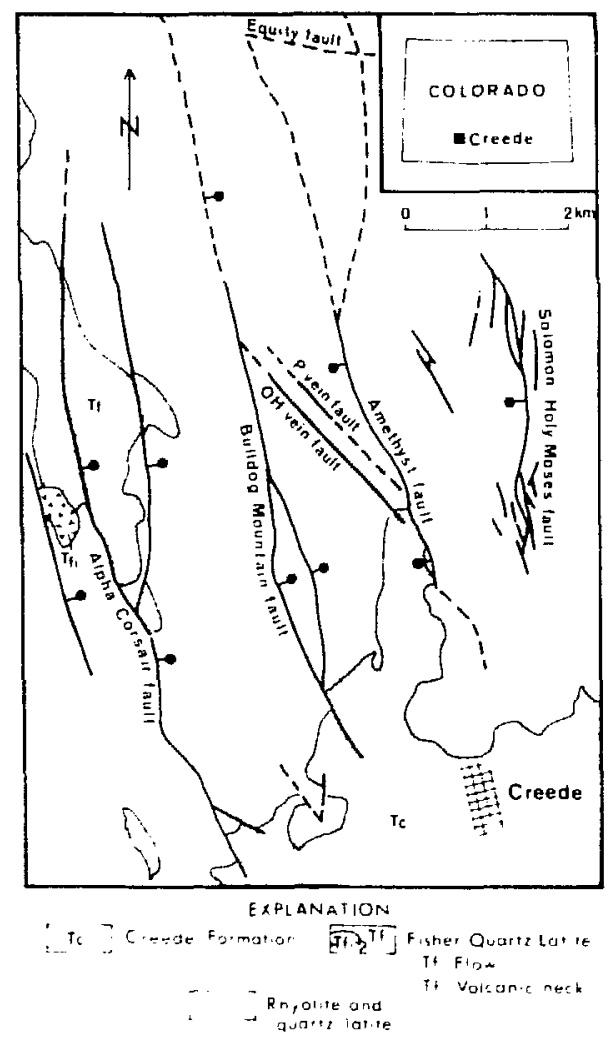

Figure 1. Geologic map of the Creede mining district showing locations of major vein systems.

The Role of Fluid Mixing as an Ore Deposition Mechanism

Extensive fluid inclusion and stable isotope studies indicate that the progressive north-tosouth mixing of hydrothermal brines with overlying cooler, dilute ground water was an important mechanism controlling ore deposition and mineral zoning patterns during the two main sulfide stages at Creede. In a detailed study of the D stage "orange-brown" sphalerite growth zone, Hayba (1984) documented a progressive decrease in fluid inclusion temperatures and salinities from deep northern localities in the $\mathrm{OH}$ vein to higher southern localities. When plotted on an enthalpy-salinity diagram, these data document a mixing trend between a hot brine $\left(\sim 285^{\circ} \mathrm{C}, 11.5 \mathrm{wt} \% \mathrm{NaCl}\right.$ eq. $)$ and a heated ground water $\left(\sim 160^{\circ} \mathrm{C}, \sim 0\right.$ wt\% salinity) analogous to steam-heated waters observed in the upper levels of active geothermal systems (Hayba, et al.,1986).

B Stage Fluid Mixing and Mineral Zoning Robinson and Norman (1984) also documented decreasing fluid inclusion temperatures and salinities with increasing elevation in B stage quartz from the southern Amethyst vein system. Robinson and Norman's fluid inclusion data from the southern Amethyst are plotted in Figure 2, along with B stage sphalerite data (Woods et al.,1982) from the $\mathrm{OH}$ vein to the north. These B stage data also reflect the progressive mixing between saline brines and a cooier, dilute overlying ground water. 
The strong north-south variations in B stage mineralogies discussed earlier correspond closely to the north-south trend of decreasing temperatures and salinities depicted in Figure 2. Deep vein ores deposited by the hottest, most saline fluids are sulfide-rich with hematite, chlorite, and pyrite gangue. With progressive mixing along the upper and southern $\mathrm{OH}$ and Amethyst veins, the fluids deposited increasingly barite- and silver-rich ores with rare chlorite, hematite, and pyrite. Similar north-to-south mineral zoning patterns and corresponding temperature-salinity trends are evident in the B-stage ores along the Bulldog Mountain vein system.

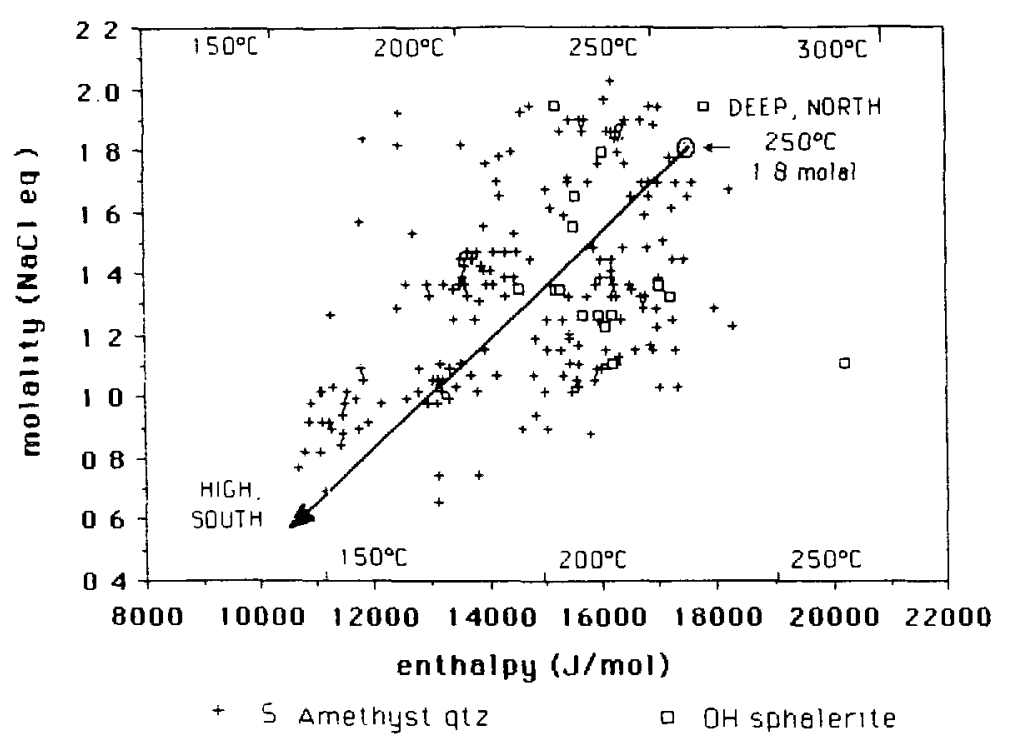

Figure 2. Enthalpy-salin ty plot of B stage fluid inclusion data from the $\mathrm{OH}$ vein (squares) and southern Amethyst vein systems (crosses). Temperature contours cut diagonally across graph, from lower right to upper left. Arrow marks the mixing trend used in the calculations.

\section{Chemical Constraints on Mineralization}

Through detailed fluid inclusion, stable isotope, and thermochemical analyses of the northern Creede ores (Barton, et al.,1977; Hayba et al., 1986; Rye et al., in prep), the chemical composition of the B stage hydrothermal brines as they first entered the ore zone can be estimated. The fluid composition so established is used as a starting composition in numerical modeling calculations of B stage ore deposition processes. The parameters used to estimate the initial brine composition for the modeling are listed in Table 1. Initial temperature and total salinity values used for the deep brine were $250^{\circ} \mathrm{C}$ and 1.8 molal $\mathrm{NaCl}$ eq. (Figure 2).

Mineralogical and thermochemical constraints Barton et al. (1977) proposed that the OI vein's chlorite-pyrite-hematite mineral assemblage likely served to buffer the redox state and sulfur content of the B stage ore-forming fluids. By assuming that the $\mathrm{pH}$ and aluminum content of the fluids entering the ore zone were fixed through equilibrium reactions with wallrock K-feldspar and K-mica, the chlorite-pyrite hematite buffer can be used to calculate the activities of several important species in solution through the following reaction (modified from Hayba, et al., 1986): 


$$
=5 \text { hematite }+5 \text { pyrite }+3 \mathrm{~K} \text {-mica }+9 \text { quartz }+9 \mathrm{H}_{2} \mathrm{O}+10 \mathrm{H}_{2}(\mathrm{ac})
$$

Duphnite ( $\left.\mathrm{Fe}_{5} \mathrm{Al}_{2} \mathrm{Si}_{3} \mathrm{O}_{10}(\mathrm{OH})_{8}\right)$, an idealized iron endmember, is used to approximate the Creede iron-rich chlorite. The stability field for daphnite relative to those for other ironbearing hydrothermal minerals is shown in Figure 3. If equilibrium did hold for reaction 1), then the activities and total amounts of $\mathrm{H}_{2}(\mathrm{aq}), \mathrm{H}^{+}, \mathrm{Al}^{+++}, \mathrm{H}_{2} \mathrm{~S}$, and $\mathrm{Fe}^{++}$in a solution of known temperature and salinity can be calculated (Table I). If saturation with sphalerite and galena is also assumed (sphalerite and galena were co-deposited with this assemblage in the $\mathrm{OH}$ vein $\mathrm{B}$ stage mineralization), then the total lead and zinc in solution can also be calculated. The absence of silver sulfides in the $\mathrm{OH}$ vein places a maximum limit on the total silver in solution. Similar mineral saturation arguments can be used to place bounds on other constituents in solution (ie, $\mathrm{Ba}^{++}, \mathrm{SO}_{4}=, \mathrm{F}^{-}$).

TABLE 1. Chemical parameters used to constrain initial brine composition.

\begin{tabular}{|c|c|c|}
\hline Parameier & Fixed at: & Fixed by: \\
\hline $\begin{array}{l}\text { 1. Temperature } \\
\text { 2. Total } \mathrm{Cl}\end{array}$ & $\begin{array}{l}250^{\circ} \mathrm{C} \\
\sim 18 \mathrm{molal}\end{array}$ & $\underset{\|}{\text { Fluid inclusion studies }}$ \\
\hline 3. $\mathrm{K} / \mathrm{Na}$ & $\begin{array}{l}\sim 1.8 \text { molal } \\
0.1\end{array}$ & $" \quad " \quad "$ \\
\hline $\mathrm{Ca} / \mathrm{Na}$ & $0.1-0.2$ & " $" \quad " \quad "$ \\
\hline 4. $\mathrm{pH}$ & $5.5 *$ & Kspar-mica equilibrium \\
\hline 5. $\mathrm{Al}^{+++}$ & $1.29 \times 10^{-16 *}$ & " \\
\hline 6. $\mathrm{Fe}^{++}$ & $1.41 \times 10^{-16 *}$ & Chlorite-pyrite-hematite buffer \\
\hline $\mathrm{H}_{2}(\mathrm{aq})$ & $1.59 \times 10^{-6 *}$ & \\
\hline $\mathrm{H}_{2} \mathrm{~S}(\mathrm{aq})$ & $7.94 \times 10^{-5} *$ & \\
\hline $\begin{array}{l}\text { 7. } \mathrm{Pb}^{++} \\
\mathrm{Zn}^{++}\end{array}$ & $\begin{array}{l}1.41 \times 10^{-9} * \\
3.12 \times 10^{-10} *\end{array}$ & Sphalerite, galena, saturation \\
\hline 8. $\mathrm{SO}_{4}=$ & $*$ & Maximum at anhydrite saturation. \\
\hline 9. $\mathrm{Ba}^{++}$ & * & Maximum at barite saturation. \\
\hline
\end{tabular}

Implications of sulfide-sulfate disequilibrium Detailed isotope studies of B stage sulfides and barites have demonstrated conclusively that equilibrium between reduced and oxidized sulfur species in solution was not attained (Bethke et al., 1973; Rye et al., in prep.). In modeling of the B stage ores, therefore, sulfate and sulfide in solution have been treated as independent variables, with no redox interaction between the two. Instead, redox equilibrium (other than 


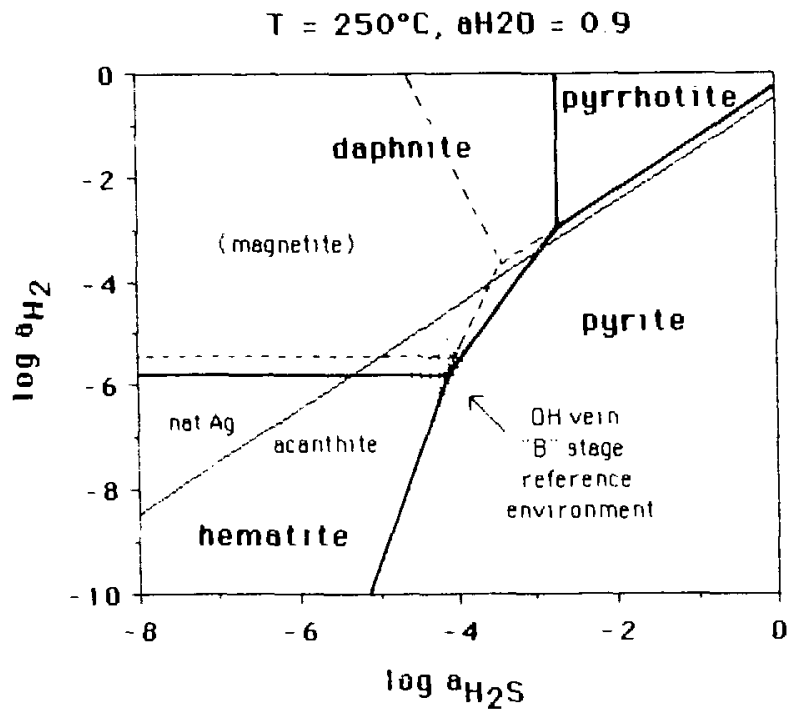

Figure 3. H2-H2S diagram showing stability fields of iron minerals and silver minerals. Daphnite field preempts magnetite field. Assumes saturation with $\mathrm{K}$-feldspar, Kmica, and quartz. Stippled area marks reference environment for $\mathrm{OH}$ vein $\mathrm{B}$ stage fluid chemistry.

sulfate-sulfide) is assumed to be controlled by dissolved hydrogen and its reactions with reduced sulfur species (Figure 3 ). Although the validity of this assumption is questionable at lower temperatures, evidence from active geothermal systems suggests that measured $\mathrm{H}_{2} / \mathrm{H}_{2} \mathrm{~S}$ ratios in solution reflect equilibrium with iron mineral assemblages at temperatures well below $200^{\circ} \mathrm{C}$ (Giggenbach, 1980).

Uncertainties in the thermochemical data Uncertainties in thermodynamic data can greatly affect both the starting fluid compositions calculated by the mineral equilibria discussed above, and the results of subsequent path calculations. For example, the calculated hydrogen, iron, and reduced sulfur contents in solution at the chlorite-pyrite-hematite triple point can vary by several orders of magnitude, depending on the free energy values used for daphnite in the calculations ${ }^{1}$. The calculated effects of cooling and dilution on the stability of iron minerals are also highly variable, depending upon the thermodynamic data used for ironchloride complexes.

Uncertainties in the chemistry of the overlying ground water The chemistry of the overlying ground water with which the hydrothermal brines mixed during the B stage mineralization is not well-constrained. The ground water was most likely dilute $(\sim 0 \mathrm{wt} \% \mathrm{NaCl}$ eq. $)$ and had temperatures of $\sim 100-130^{\circ} \mathrm{C}$ (Figure 2). By drawing analogies with steam-heated waters seen in active geothermal systems, the overlying waters at Creede most likely contained bicarbonate, some sulfate, and had slightly acid $\mathrm{pH}$ values. In the mixing calculations, a range of compositions and temperatures for the overlying ground water is evaluated, to see which could produce the observed mineral zoning patterns.

Published thermodynamic data for Fe-chlorites are highly variable. These calculations use free energy values for idealized Cireede "daphnite" empirically fixed by assuming equilibrium at $250^{\circ} \mathrm{C}$ with hematite, pyrite, and sphalerite of known iron content (Hayba et al., 1986). 
After caiculating starting chemical compositions using the constraints outlined above, the chemical effects accompanying the progressive cooling and dilution of B stage ore fluids can be modeled numerically. Preliminary chemical modeling is currently being conducted with an Apple Macintosh Plus personal computer, using a BASIC program patterned after the mair selme modeling program SOLVEQ (Reed, 1982). The program calculates concentrations of all component species and complexes present in solution, and the amounts of minerals precipitated in a given temperaiure, boiling or mixing increment. Mixing and boiling increments are calculated isoenthalpically.

Calcu'*.ed fluid mixing paths In order to fully assess the effects of all chemical and thermon'ymic uncertainties discussed above, many different mixing paths with different input parameters must be calculated. Results of calculations modeling the progressive mixing of a Creede "B stage" brine with a $100^{\circ} \mathrm{C}, 0$ wt\% salinity ground water (chosen as representing one extreme of possible ground water compositions) are shown in Figure 4. Even with the extreme (and probably unrealistic) ground water composition used, the calculated sequence of ore minerals deposited agrees relatively well with the district ore minerai zoning: a sphalerite-galena assemblage is produced with low degrees of mixing, and a native silver-acanthite-sphalerite-galena assemblage is produced at lower temperatures and extreme degrees of mixing 2 .

The only gangue mineral deposited in the calculations, however, is quartz, an uncommon mineral in the higher-temperature B stage ores. Hematite, pyrite and barite all become undersaturated with the first mixing increment, and remain undersaturated throughout the rest of the mixing calculation. In order to precipitate hematite, pyrite, and barite by mixing, the calculations show that the overlying ground water must have had a significant sulfate content, and also must have been able to oxidize the deep brine. Such an oxidizing chemistry would be similar to that of steam-heated waters seen in active geothermal systems, and so may be realistic for the Creede ground water. Boiling is also an oxidizing process, however, and could also have triggered deposition of the deeper, northern chlorite-pyrite-hematite-sulfide ores; after boiling, the same fluids could then have mixed to produce the barite- and silverrich southern ores. Further calculations are underway to assess the role of boiling as a deposition mechanism in the deep, northern veins.

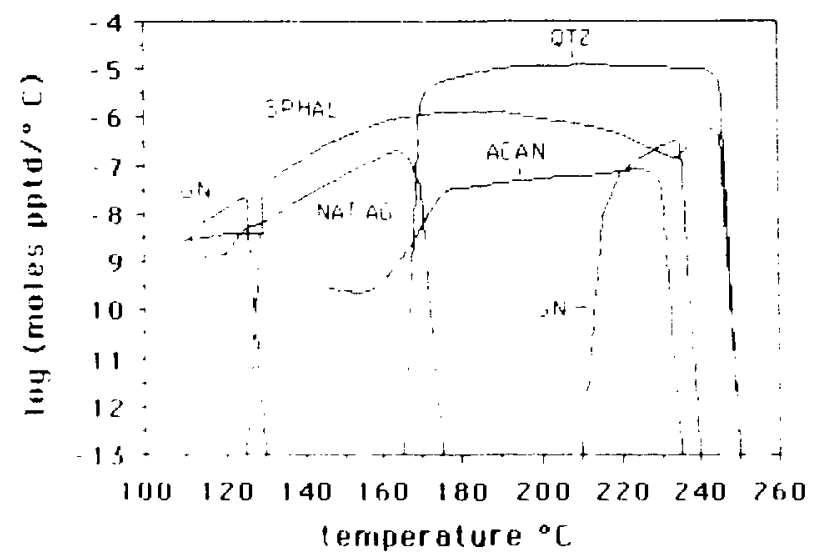

Figure 4. Calculated moles of minerals precipitated per degree temperature drop during the progressive mixing of a $250^{\circ} \mathrm{C}, 1.8$ molal $\mathrm{NaCl}$ eq. brine with dilute, $100^{\circ} \mathrm{C}$ ground water.

2The gap in galena deposition between $210-130^{\circ} \mathrm{C}$ is probably an artifact of the way the program evalates multiple mineral supersaturations, and therefore is not realistic. No equivalent gap in galena occurrence is observed in the Creede zoning patterns. 


\section{Conclusions}

Preliminary chemical modeling of ore deposition processes at Creede suggest that the progressive cooling and dilution of a $250^{\circ} \mathrm{C}, 1.8$ molal $\mathrm{NaCl}$ eq. brine by a cooler, dilute, oxidizing ground water is a valid mechanism to produce the mineral assemblages and mineral zoning patterns observed in the B sulfide stage; boiling in the deep, northern veins may also have occurred. Many more modeling runs are needed, however, to assess how the numerous geological, geochemical, and thermodynamic uncertainties will affect the calculations.

Future long-term U.S.G.S. modeling efforts at Creede will examine the chemistry and hydrology of the deeper and input parts of the hydrothermal system, as further geological and geochemical constraints become available.

\section{References}

BARTON P. B. JR., BETHKE P. M., and ROEDDER E. (1977) Environment of ore deposition in the Creede mining district, San Juan Mountains, Colorado: Part III: Progress toward interpretation of the chemistry of the ore-forming fluid for the $\mathrm{OH}$ vein. Econ. Geol., V $\underline{72}, 1-24$.

BETHKE P.M., BARTON P.B. JR., and RYE R.O. (1973) Hydrogen, oxygen and sulfur isotopic compositions of ore fluids in the Creede district, Mineral County, Colorado (abs.). Econ. Geol., V 68, 1205.

GIGGENBACH W.F. (1980) Geothermal gas equilibria. Geochim. Cosmochim, Acta, V 44, 2021-2032.

HAYBA D.O. (1984) Documentation of thermal and salinity gradients and interpretation of the hydrologic conditions in the $\mathrm{OH}$ vein, Creede, Colorado (abs.). Geol. Soc. Am., Abs. wi. Progs., V 16, no. 6, 534.

HAYBA D.O., BETHKE P.M., HEALD P. and FOLEY N.K. (1986) Geologic, mineralogic, and geochemical characteristics of volcanic-hosted epithermal precious metal deposits. in, Berger, B.R., and Bethke, P. M. , eds., Geolcgy and Geochemistry of Epithermal Systems: Society of Economic Geologists, Reviews in Economic Geology, $V$ 2, $129-167$.

HEALD-WETLAUFER P. and PLUMLEE G.S. (1984) Significance of mineral variations in time and space aiong the Bulldog Mountain vein system with respect to the district-wide hydrology, Creede district, Colorado (abs.): Geol. Soc. Am., Abs. wi. Progs., V 16, no. 6,535 .

REED M.H. (1982) Calculation of multicomponent chemical equilibria and reaction processes in systems involving minerals, gases, and an aqueous phase. Geochim. Cosmochim. Acta., V 46, 513-528.

ROBINSON R.W. and NORMAN D.I. (1984) Mineralogy and fluid inclusion study of the southern Amethyst vein system, Creede mining district, Colorado. Econ. Geol., V 79, 439-447.

WOODS T.L., BETHKE P.M., and ROEDDER E. (1982) Fluid inclusion data at Creede, Colorado in relation to mineral paragenesis. U. S. Geological Survey, Open-File Report 82-813, $61 \mathrm{p}$. 
BOILING OF GEOTHERMAL WATERS: PRECIPITATICN OF BASE AND

PRECIOUS METALS, SPECIATION OF ARSENIC AND ANTIMONY,

AND THE ROLE OF GAS PHASE METAL TRANSPORT.

Nicolas F. Spycher and Mark H. Reed Dept. of Geology, University of Oregon

Eugene, OR 97403

\section{Abstract}

Multicomponent heterogeneous equilibrium calculations are used to model the boiling of a Broadlands-type water, mixing of the boiled water with an acid sulfate water and condensation of the gas phase separated from the boiled water. Minerals, gases and aqueous species containing arsenic, antimony and mercury are included in the calculations. Upon boiling, silicate and sulfide minerals precipitate due to temperature drop and $\mathrm{pH}$ increase, respectively, and mercury partitions into the gas phase. Gas transport of arsenic and antimony is insignificant. Boiling of a sulfide-deficient water leads to native gold and silver deposition, at temperatures depending of the extent of sulfide deficiency of the solution. Mixing with acid sulfate water results in gold and enargite precipitation, together with stibnite and orpiment if the temperature is below $100 \mathrm{C}$. Condensation of the gas phase results in precipitation of cinnabar from reaction between $\mathrm{Hg}$ gas and $\mathrm{H}_{2} \mathrm{~S}$ gas.

Introduction

Computer program CHILLER of Reed (1982) computes multicomponent heterogeneous chemical equilibria and is designed to model cooling, fluid-fluid mixing, fluid-solid-gas reactions, boiling of aqueous solutions and condensation of gases. This program was used here to simulate ore deposition in an epithermal system. Results of such calculations have previously been presented by Reed and Spycher (1985). A similar approach is used here, except that provisions have been included to take into account nonideality of the gases (Spycher and Reed, in prep.) and to include an internal enthalpy constraint in the boiling calculations. In this study, special attention is given to the effect of aqueous sulfide concentration on gold precipitation, and to the the speciation of arsenic and antimony in the aqueous and gas phase. Mercury deposition from the gas phase is also investigated.

Boiling: Methods of Calculation

When simulating boiling, for any given bulk composition, temperature, and total enthalpy of a system, program CHILLER is used to solve for the amount and and composition of the aqueous, solid and gas phases at equilibrium, and for the pressure at which gas and liquid are in such proportion that the sum of their respective heat contents equals the total enthalpy of the 
initially homogeneous aqueous phase, plus an optional heat gain or loss for the system. This is accomplished by solving simultaneously a set of mass balance and mass action equations (Reed, 1982) and an enthalpy equation. The approach used here is different from that of Drummond and Ohmoto, (1985) in that true heterogeneous equilibrium is computed. The amount of each gas species in equilibrium with the aqueous phase is dictated by mass balance/mass action equations that are similar in form to the equations used for mineral solid solutions (Reed, 1982). Mass action equations for gases make use of true equilibrium constants, which are different from Henry's law constants, $\mathrm{K}_{h}$, in being independent of salinity and defined for a given specific chemical reaction. For example, for $\mathrm{CO}_{2}$, we can write the following reaction:

$$
\underset{(\mathrm{g})}{\mathrm{CO}_{2}}+\underset{\mathrm{H}}{\left.\mathrm{H}_{2} \mathrm{O}\right)}=\underset{(\mathrm{aq})}{\mathrm{HCO}_{3}^{-}}+\mathrm{H}_{(\mathrm{aq})}^{+}
$$

for which the mass action equation is:

$$
k=\frac{a_{\mathrm{HCO} 3}{ }^{-} \mathrm{a}_{\mathrm{H}}{ }^{+}}{\mathrm{a}_{\mathrm{H} 20 \mathrm{f}^{\mathrm{f}} \mathrm{CO} 2}^{\gamma}}=\frac{\gamma \mathrm{m}_{\mathrm{HCO} 3}-\gamma \mathrm{m}_{\mathrm{H}}{ }^{+}}{\gamma \mathrm{m}_{\mathrm{H} 2 \mathrm{O}} \phi \mathrm{P}\left(\mathrm{n}_{\mathrm{CO} 2} /\left(\mathrm{n}_{\mathrm{CO} 2}+\mathrm{n}_{\mathrm{H} 2 \mathrm{O}}+\mathrm{n}_{\mathrm{H} 2 \mathrm{~S}}+\ldots\right)\right)}
$$

The associated mass balance equation for carbonates is:

$$
\mathrm{Mt}_{\mathrm{HCO}} 3^{-}=\mathrm{nw}\left(\mathrm{m}_{\mathrm{HCO} 3} 3^{-}+\mathrm{m}_{\mathrm{H} 2 \mathrm{CO} 3}+\mathrm{m}_{\mathrm{CO} 3^{2}}-\ldots\right)+\mathrm{n}_{\mathrm{CO} 2}+\underset{+}{n_{\mathrm{Ca}}+\ldots}
$$

In these equations, a stands for activity, $f$ is fugacity, $m$ is molality, $n$ is number of moles, nw number of kilograms of solvent water in the aqueous phase, Mt is the total moles of a component species in the system, and $\gamma$ and $\phi$ are activity and fugacity coefficients, respectively. Similar equations are written for each gas species and each component species. From such equations, we can solve simultaneously for the amount of $\mathrm{CO}_{2}$, for example, in the gas phase $\left(\mathrm{n}_{\mathrm{CO}}\right)$ and in the aqueous phase $\left(\mathrm{m}_{\mathrm{HCO}}\right.$ $\left.+\mathrm{m}_{\mathrm{H} 2 \mathrm{CO} 3}+\ldots.\right)$. One of the advantages of this approach is that the amount and composition of both the aqueous and gas phases are simultaneously determined. Gases can be boiled off as well as recondensed, in the same way that minerals can be either precipitated or dissolved. Also, because we do not use Henry's law constants, speciation as a function of $\mathrm{pH}_{2}$ of a gas dissolved in the aqueous phase (e.g. $\mathrm{HCO}_{3}^{-}, \mathrm{H}_{2} \mathrm{CO}_{3}, \mathrm{CO}_{3}{ }^{-}$) can be taken into account. Henry's law constants are commonly determined for systems of gas- $\mathrm{H}_{2} \mathrm{O}-\mathrm{salt}$, where the $\mathrm{pH}$ is fixed by the concentration of dissolved gas and its pK. If pH is changed le.g., by adding $\mathrm{NaOH}$, the concentration of the aqueous gas species changes and the normal Henry's law treatment may not apply in the usual way. For example, in the $\mathrm{CO}_{2}-\mathrm{H}_{2} \mathrm{O}$ system with $\mathrm{CO}_{2}$ gas, the dominant aqueous carbonate species is $\mathrm{H}_{2} \mathrm{CO}_{3}$. If $\mathrm{pH}$ is increased so that $\mathrm{HCO}_{3}$ - dominates, the Henry's law constant must be used with the remaining $\mathrm{H}_{2} \mathrm{CO}_{3}$, not total aqueous carbonate. In our approach, the "salting out" of gases is directly taken into account because activity coefficients, which are function of salinity, are part 
of the mass action equations. Also, inclusion of fugacity coef ficients in the mass action equations for the gases is a simple way to account for non-ideality and non ideal mixing of gases.

\section{Boiling of Geothermal waters}

Many of the detailed effects of boiling on ore deposition have already been discussed by Reed and Spycher (1985) and Drummond and Ohmoto (1985). The calculations presented here apply to the Broadlands-like water composition used by Reed and Spycher (1985) with new metal concentrations of Brown (1986). As a hydrothermal solution rises from deptin to the surface, the hydrostatic pressure decreases until saturation pressure of the solution is reached. Further pressure drop leads to boiling. no heat is transferred to or from the host rock (isoenthalpic boiling), the temperature of the solution decreases because heat is used to vaporize the water. Calculated boiling results are shown in figures 1,2 and 3 for such isoenthalpic boiling from $280 \mathrm{C}, 80$ bars to $101 \mathrm{C}$, 1 bar (0 to 36 wt.percent degassing). Degassing of $\mathrm{CO}_{2}$ causes the $\mathrm{pH}$ to increase in accordance with the reaction: $\mathrm{H}^{+}+\mathrm{HCO}_{3}^{-}-\rightarrow \mathrm{CO}_{2}+\mathrm{H}_{2} \mathrm{O}$. In sharp contrast, the same solution cooled without boiling experiences a pH drop (figure lb) because the weak acids dissociate as temperature decreases. $\mathrm{H}_{2} \mathrm{~S}$ loss to the gas phase depletes aqueous sulfide, and boiling out of reduced gases such as $\mathrm{CH}_{4}$ and $\mathrm{H}_{2}$ partly oxidizes sulfide so that aqueous sulfate concentration increases. Upon boiling, silicates precipitate because of temperature drop, and deposition of sulfide ninerals ( $f$ igure 2) results from the increase of $\mathrm{pH}$ (Reed and Spycher, 1985). Quartz was not allowed to form below $200 \mathrm{C}$ because its precipitation is kinetically retarded at $\mathrm{T}<$ $200 \mathrm{C}$. All minerals were fractionated as they formed, precluding cheir back-reaction with the solution. Gases were not fractionated.

To examine the effects of boiling on gold precipitation, we can write the following reaction:

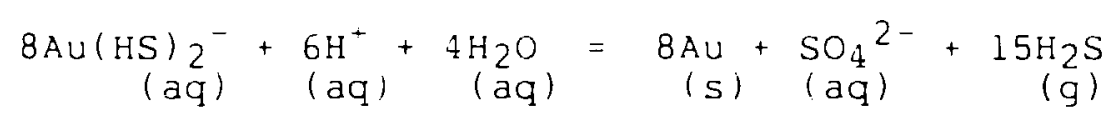

According to this reaction, the $\mathrm{pH}$ increase accompanying boiling would stabilize gold in solution. However, according to the same reaction, losing $\mathrm{H}_{2} \mathrm{~S}$ to the gas phase by boiling could lead to gold precipitation. The effect of such sulfide loss on gold precipitation is more pronounced in sulfide-deficient waters. The water used in our calculation contained 340 ppm total sulfide. Gold barely saturates in this water at $100 \mathrm{C}$, and it is absent at nigher temperatures. Numerical boiling of the same water, but with slightly smalier suifide concentrations of 255 and 204 ppm rauses gold to precipitate, as shown in figures $2 b$ and $2 \%$. it is thus evident that boizing causes golu to precipitate trom sulide-deficient waters but not from sulfide-exces waters :hat are atherwise the same. It is also apparent from figure 2 that the smalier the concentration of aqueous sulfide, the nigher remperature of precipitation of gold and base metai sulfides ard che 

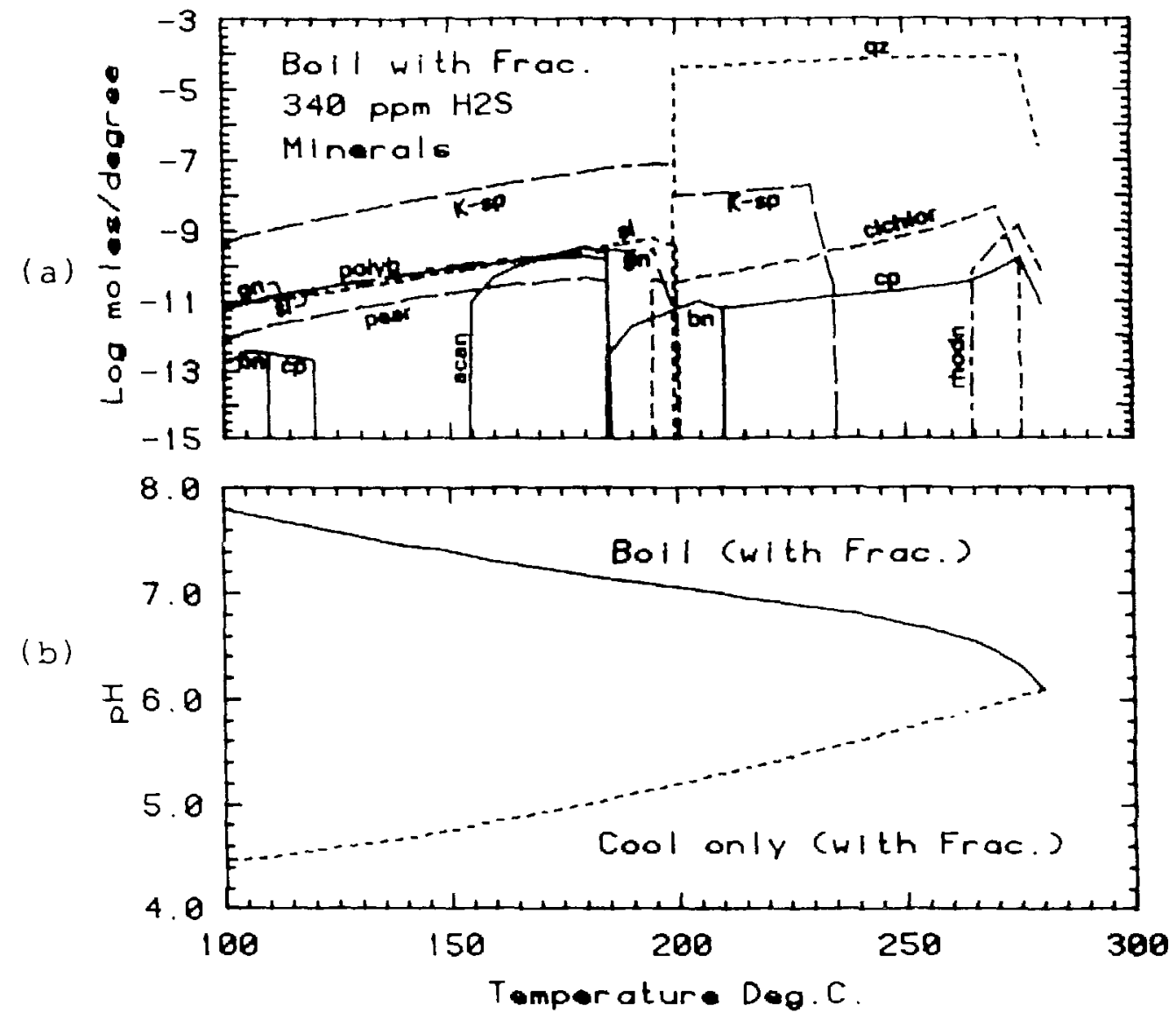

\section{Figure 1 (See text)}

more native silver forms in place of acanthite. Furthermore, it is likely that sulfide loss through precipitation of sulfide minerals from high chloride-low sulfide waters would lead to gold precipitation (see discussion by Reed and Spycher, 1985).

Arsenic and antimony aqueous species were included in the calculations. Data for arsenic oxyacids and antimony hydroxides were taken, and slightly modified, from Sergeyeva and Khodakovskiy (1969), and Popova et al. (1975). Data for thiosulfides were derived from least square fits and multicomponent equilibriun calculations witn published solubility data (Spycher and Reed, in prep.). At high temperatüe and $\mathrm{pH}, \mathrm{H}_{3} \mathrm{AsO}_{3}$ and $\mathrm{Sb}(\mathrm{gH})_{3}$ are quite stable relative to the chicsilfides $\mathrm{HAS}_{2} \mathrm{~S}_{4}-\mathrm{As}_{2} \mathrm{~S}_{4}{ }_{-}$and $\mathrm{HSb}_{2} \mathrm{~S}_{4}$, and dominate over the whole temperature range when boiling. (After a very recent revision of our study on arsenic thiosulfides, we conlcude that the arsenic species are $\mathrm{H}_{2} \mathrm{As}_{3} \mathrm{~S}_{6}{ }^{-}$ and $\mathrm{HAS}_{3} \mathrm{~S}_{6}{ }^{-}$instead. This does not affect the results presented herel. When the solution is cooled without boiling, thiosulfides become dominant below $150 \mathrm{C}$ because of the lower pH and larger sulfide concentration owing to the lack of $\mathrm{H}_{2} \mathrm{~S}$ degassing. The 
(a)

(b)
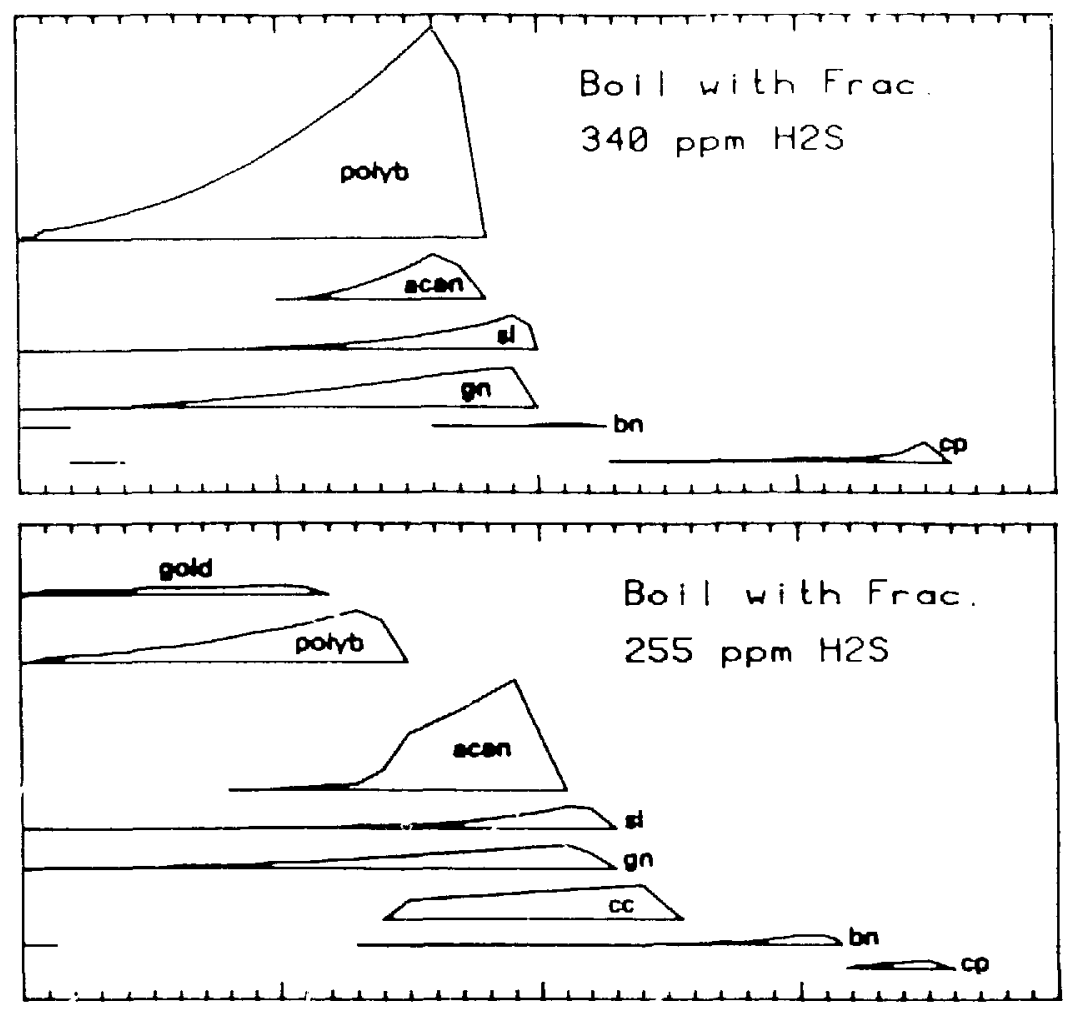

(c)

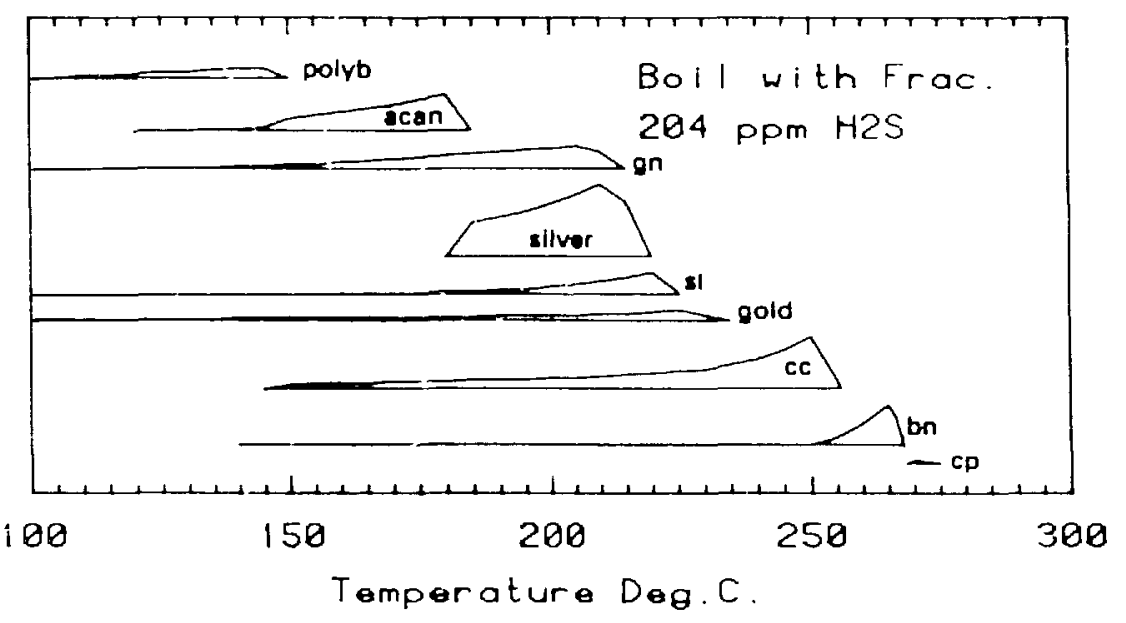

Figure 2 (See text)

equilibrium between As and Sb hydroxides (oxyacids) and thiosulfides as a function of $\mathrm{pH}$ can be described by the following equilibria:

$$
\begin{array}{ll}
\mathrm{HSb}_{2} \mathrm{~S}_{4}^{-}+6 \mathrm{H}_{2} \mathrm{O} & =2 \mathrm{Sb}(\mathrm{OH})_{3}+3 \mathrm{H}^{+}+4 \mathrm{HS}^{-} \quad\left(\text { for } \mathrm{pH}>\mathrm{pKH}_{2} \mathrm{~S}\right) \\
\mathrm{HSb}_{2} \mathrm{~S}_{4}+6 \mathrm{H}_{2} \mathrm{O}+\mathrm{H}^{+}=2 \mathrm{Sb}(\mathrm{OH})_{3}+4 \mathrm{H}_{2} \mathrm{~S} & \text { (for pH<pKH})
\end{array}
$$

Depending on whether the $\mathrm{pH}$ is smaller or larger than the $\mathrm{pK}$ for 


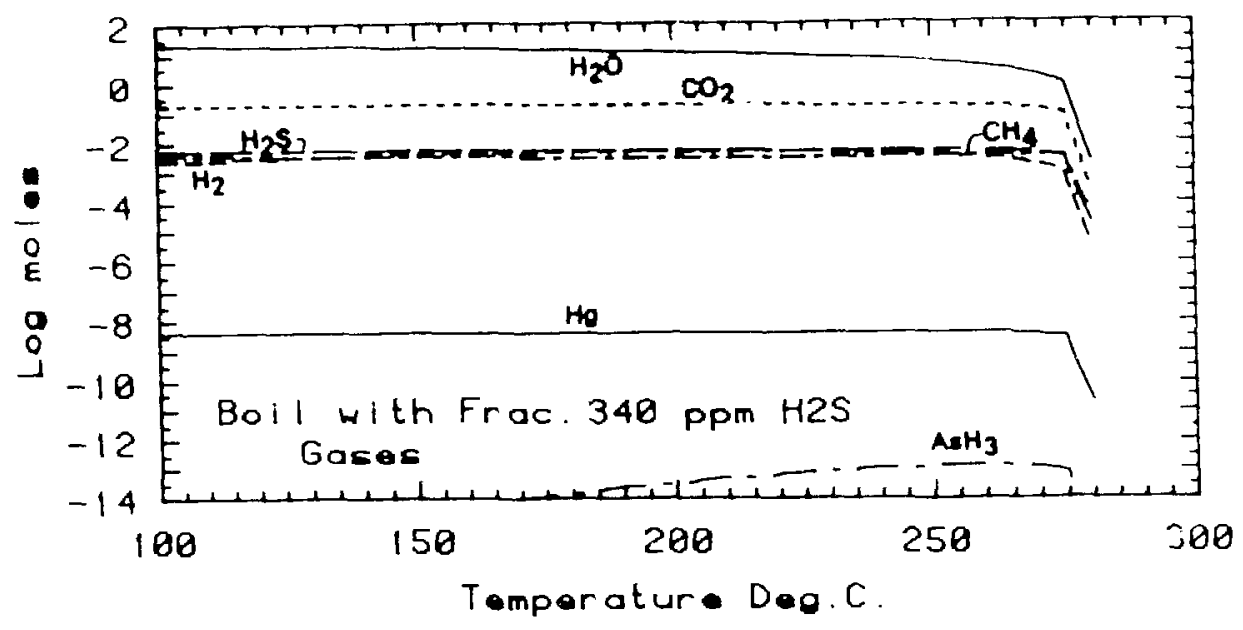

Figure 3 (See text)

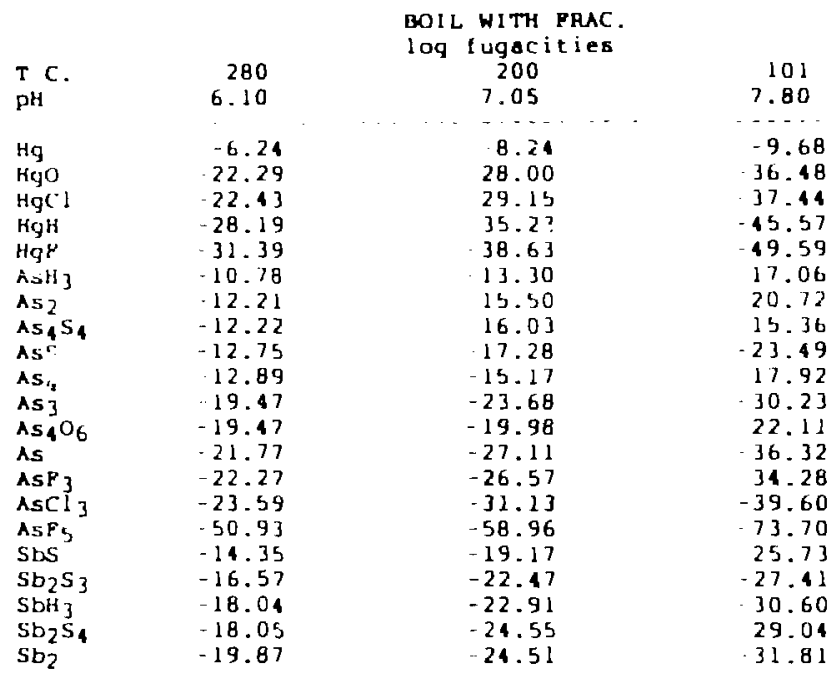

Table 1

the first dissoriation of $\mathrm{H}_{2} \mathrm{~S}$, acidification will either star $\mathrm{i}$ lize or destabilize hydroxides relative to thiosulfides. Because $\mathrm{pK}\left(\mathrm{H}_{2} \mathrm{~S}\right)$ is near $\mathrm{pH}$ neutral, in low-sulfide waters, thiosulfides are more abundant at $\mathrm{pH}^{\prime} \mathrm{s}$ around neutral.

We investigated the importance of gas phase transport of metals by incluaing thirty mercur $;$, arsenic and antimony gases in our calculations. Almost all the mercury partitioned into the gas phase as $\mathrm{Hg}$ gas over the entire boiling interval. The concentrations of arsenic and antimony in the gas phase were insignificant. The calculated gas :omposition, and calculated gas fugacities of $\mathrm{Hg}$, As and some $\mathrm{Sb}$ species are shown as functions of temperature in figure 3 and table 1 . Arsine $\left(\mathrm{AsH}_{3}\right)$ is the dominant arsenic gas species, but its fugacity is too low to be geologirally significant for As transport. Arseric has been 
reported in gas condensates from few geothermal areas and we wonder what other gas species, if any, could play an important role in transporting arsenic in the gas phase.

Fluid-Fluid + ing

In order to model mineral deposition in hot spring environments, we numerically mixed the boiled water at 1 bar with an acid sulfate water. The acid sulfate water was previously generated by numerically oxidizing the gas phase separated from the boiled water at $100 \mathrm{C}$, I bar, with atmospheric oxygen (Reed and Spycher, 1985). The mixing calculations were carried out at 100 $\mathrm{C}$ and $90 \mathrm{C}$. The sequences of mineral precipitation resulting from these calculations are shown in figures $4 \mathrm{a}$ and $4 \mathrm{~b}$ as a function of the mass of acid sulfate water added to the boiled

(a)

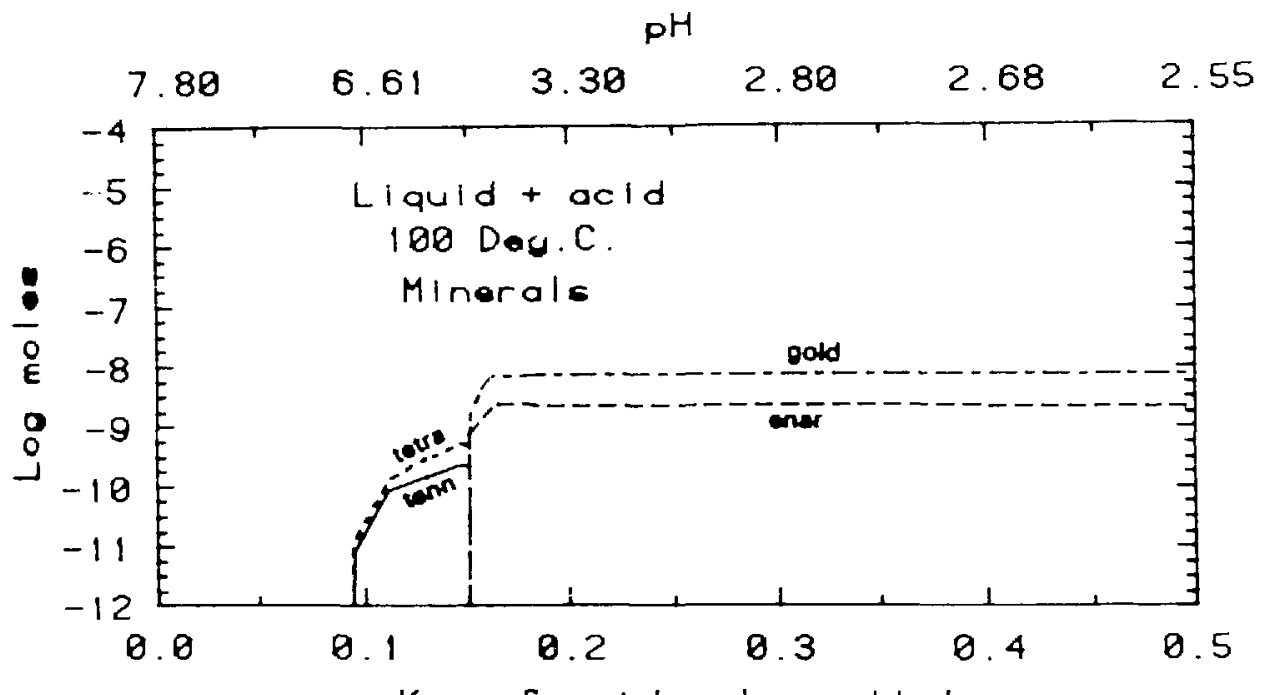

Ko. of acld woter added

$\mathbf{p H}$

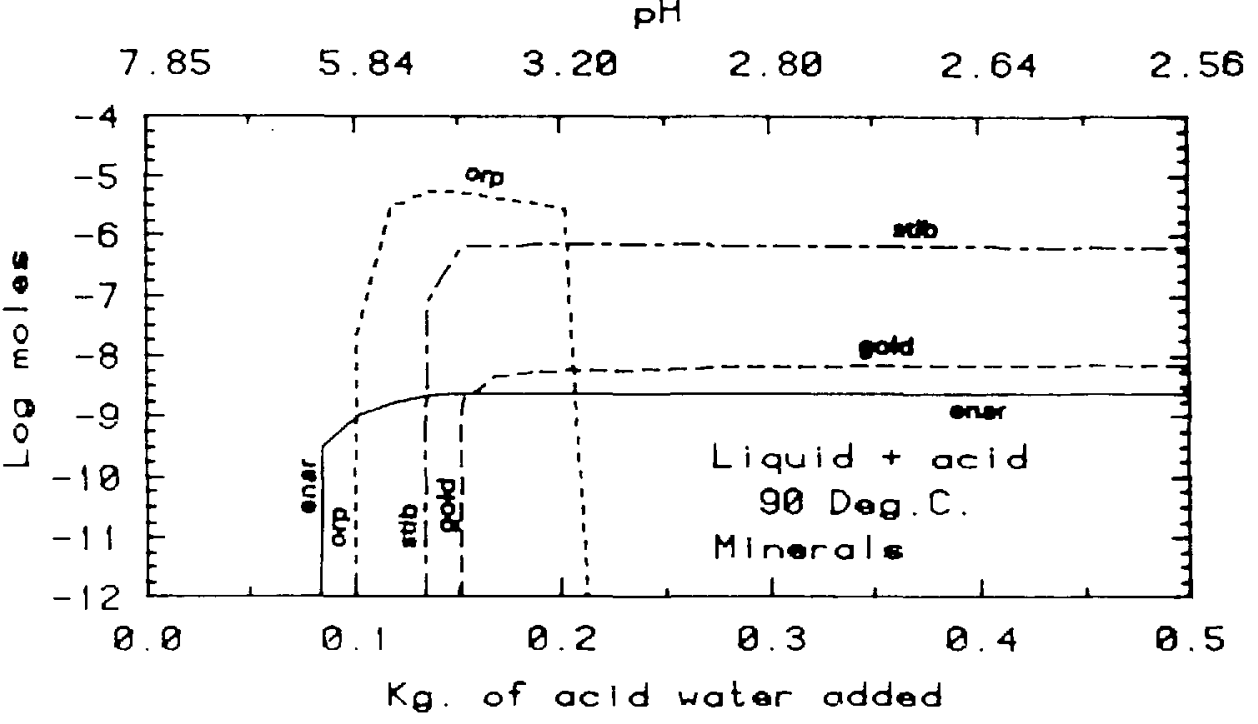

Figure 4 (See text) 
water. The $\mathrm{pH}$, originally fixed by bicarbonate, decreases following a titration-like curve after which it becomes fixed by sulfuric acid. At $100 \mathrm{C}$, such acidification results in precipitation of tennantite-tetrahedrite (solid solution), which is replaced by enargite and gold as pH further decreases (figure $t a$ ). At $100 \mathrm{C}$, after few mixing increments, gases exsolve because of the acidification effect on $\mathrm{CO}_{2}$ (Reed and Spycher, 1985). This degassing maintains the $\mathrm{pH}$ at higher values in the early stages of mixing. The same calculation carried out at $90 \mathrm{C}$ does not show this secondary degassing because gas partial pressures are too small at lower temperature. The result is that, at $30 \mathrm{C}$, stibnite and orpiment precipitate together with enargite and gold (figure 4b), precluding precipitation of sulfosalts. This suggests that cooling is required, together with acidification, in order to precipitate stibnite and orpiment. Our calculation showed that although orpiment precipitated, a lot of arsenic (10 times more) was still in solution, whereas almost all antimony was precipitated as stibnite.

\section{Gas Condensation}

In our boiling calculations, most of the mercury partitioned into the gas phase. We wondered whether cinnabar could be deposited by condensing the gas phase. We separated the gas from the boiled water at $101 \mathrm{C}$ and $l$ bar, and numerically cooled it to $25 \mathrm{C}$ at the constant pressure of 1 bar. Most of the mercury stays in the gas phase down to about $80 \mathrm{C}$. Below this temperature, cinnabar starts to precipitate as $\mathrm{Hg}$ gas reacts with $\mathrm{H}_{2} \mathrm{~S}$ gas. As expected, after condensation, the remaining gas is mainly $\mathrm{CO}_{2}$.

\section{References}

BROWN K.L. (1986) Gold deposition from geothermal discharges in New Zealand. Economic Geology, v.81, 979-983.

DRUMMOND S.E. and OHMOTO H. (1985) Chemical evolution and mineral deposition in boiling hydrothermal systems. Economic geology, v.80, 126-147.

POPOVA et al. (1975) Experimental determination of the thermodynamical properties of hydroxo- and hydroxofluoride complexes of antimony at temperatures up to 200 C (in Russian). Geokhimiia, no. $6,835-843$.

REED M.H. (1982) Calculation of multicomponent chemical equilibi ia and reaction processes in systems involving minerals, gases and aqueous phase. Geochemica et Cosmochemica Acta, v.46, $513-528$.

REED M.H. and SPYCHER N.F. (1985) Boiling, cooling and oxidation in epithermal systems: a numerical approach. In Geology and Geochemistry of Epithermal Systems: Society of Economic Geologists, Reviews in Economic Geology, v.2, ch.11, 249-272, Berger B.R. and Bethke P.M., editors.

SERGEYEVA E.I. and KHODAKOVSKIY I.L. (1969) Physicochemical conditions of formation of native arsenic in hydrothermal deposits. Geochemistry International, v.6, 681-694. 


\author{
Peter B. Larson \\ Department of Ceology \\ llashington State University \\ Pullman, WA g.960-2012 USA
}

\title{
Absiract
}

llater/rock interaction in hydrotherial systelis typically results in the levelopment of alteration product phases and miss transfer of oxygen isotopes arong minerals and aqueous solutions. The hydrotherial system that was cstablished in the Lake City caldera, San Juan Ilountains, Colorado, shortly afier collapse about 23 ila is we 11 -úocumented, and the quaritity of nineral alteration prociucts in the hydrothermal'y altered rocks correlates with the amount of oxyen isotone depletion measured in the roclis. Two units, the caldera-fill Sunshine Peal. Tuff and the Precaribrian Cranite of Cataract Culch ouiside the southwest nargin of the caldera ring fault, are both mineralogically uriforis. The proportion of sanidine phenocrysts in tuff samples that has been altered to product phases was estinated and the whole-rock oxygen isotope composition of each sample was measured. Trajectories that nimic oxyner isotope water/rock ratio trajectories, calculated using the water/rock equations of Taylor (1977), were gererated when the volume of sanidine alteration was plotted against the whole-rock oxycei isotope composition neasured for each sample. A similar correlation was found for the Precambrian aranite when the anount of primary biotite altered to chlorite and sericite was used. These results show that both the quaitity of mineral products and the amount of oxygen isotope depletion developed in a hydrothermal system are coupled functions of the progress of water/rock interaction. These relationships have been used to interpret the geometry of the Lake city liydrothermal system. The excellent documentation of mineral alteration arid isotope depletion in this syster provides a unique opportunity to test geochenical modeling codes in a natural hydrothermal system.

\section{Introduction}

liater/rock reactions in natural bycirothermal systems are recorded by several types of chenical changes in the altered rocks: (1) reactions between minerals and the fluid can produce new "alieration" minerals in the rocii, and $(z)$ some minerals cain exchange structurally-bourid oxygen wich the fluid such that their initial oxygen isotope compositions al so becorie. altersi. Geocherical mociels of water/rock interaction that utilize the reacion proaress variable have shown that the ariount of alteration minerals procinceci in a rock is a function of tie exicnt to which a reaction has proconcied (e.c. lielgeson et a]., 1070). However, water/rock reactions in nacural hycircthermal sysiens occur in a dyiamic anviroment where the fluid

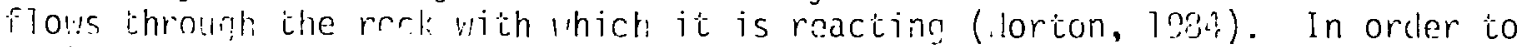
apply racitioi path locicls ts a naturally altered sample, it is therefore necessary to know: the anoun: of hydrothermal fluid that has reacted with the sample, and to know the axtent of water/roc!: reaction that the fluid has 
experienced prior to reaction with the sanple. One conveniont method of measuring these parameters is oxygen isotope analyses of the altered rocks.

ilumcrous studies have demonstrated that vater/rock interaction in ncteoric-hycirothernal systems typically produces oxygen isotope depletions in the altered rocks (e.g. Criss and Taylor, 1073). Taylor (197\%) has uscd mass balance to cievelop equations that calculate water/rock ratios using oxygen isotope analj'ses of whole-rock samples. These equations are used to calculate the volume of fluid that has reacted with a rock when the whole-rock. oxyger isotope composition has been ncasured. These technicues have recentif been applied to the hydrothernal systom associated with the Lake City calciera (.3 ila), Colorado (Larson and Taylor, 1936a,b). These stuclies show that the ainount of alteration minerals produced in two units, the calciera-fill Sunshine Peak Tuff and the Precambrian granite of Cataract Culch southwest of ihe caldera, correlate with the anount of measured oxygen isotope depletion. Thus, the oxygen isotope clepletion that accompanies mineral alteration provides an independent gauge of the amouit of fluid involved in tire reaction anci also a measure of the previous history of that fluici in the hycirothermal systent.

Ceology of the Lake City Caldera

Ihe Lake City caldera $(11$ by $74 \mathrm{~km})$ collapsed in response to eruption of the Sunshine Peak Tuff 23 ila (Lipman, 1076; Steven and Lipman, 1976). The iuff corprises three nembers with an overall thickness greater than $1.3 \mathrm{~km}$ (lion et al., 197.). Saridine, quartz, and biotite occur as phenocrysts in all three menbers, and plagioclase is found as phenocrysts in the upper member. The tuff ranges from an alkali rhyolite (Tower member 76 percent sion) to a quartz trachyte (upper member on percent sioz). Quariz latites were subsequently erupted as ring domes on the eastern caldera ring fracture. $\lambda$ flat-topped quartz syenite intrusion then accompanied resurgence in the north central part of the caldera. A hydrothermal systen developed in the caldera shortly after it collapsed, and nearly all the roclis in the caldera are now hydrothermaliy altercd. K-Ar ane cieterninations for biotite, sanidine, and alunite have shown that the tuff, ring domes, resurgent intrusion, and alteration in the caldera are all concordent at 23 ia (Hon et a 1., 1033; iehnert at al., 19:30). Differential erosion has now exposed the altereá rocks from near-surface solfataric alteration down through about 2 km into the resurgent intrusion, which served as a heat engine to convectivoly cirive the neteoric-hycirothermal fluici.

The caldera was emplaced in older intermediate Tertiary volcanic rocks of the San Juan volcaric province, and these rocks now forn most of the outer wall of the caldera rirg fault except along the west and south margins of the caldera. liere, the Precambrian granite of Cataraci Culch forms the wall. The volcanic rocks unconformably overlic che granite. The granite consisis of inearly equal proportions of quartz, orthoclase, and plagioclase, with 5 percent biotite and 1 percent muscovite. The west edne of the ring faul: al so iruncates the older Eureka graber which has extensively faulted the granite and the older volcanic rocks in that area. 
The Latic City hidrothermal susteril has altered nearly all the rocks in the caldo; a, and has also affectei all of the exposed aranice. quartz voins wora deposited by the hydrothermal fluids in fracturos and faults. The type and quantity of alteration products in the cuff chançe gradatioilally away from the quartz veins, and five facies (zones) have been identifies in the silallow part of the caldera. zone I, developed within about a meter of the voins, consists of total silicification of the tuff. Zone II, devoloped within teis of neters of zone I, consisis of total replacement of saiiline and biotite by quartz and kalinite/illite. zone II gracies outwarci fron zone II. It conprises partial replacenent of sanicine by kaolinite/illite and minor cuartz and total replacement of biotite by sericito. ione IV, the most extensively devclopeci of the facies, consists of partial replacemeit of sanidine by kalinite/illite and partial sericitization of biotite. Locally, chlorite accompanies the sericite. Iii zone $V$, sanidine exhibits only minor alteration, and more comonly oily shows turbidity. Biotite in zone $V$ is fresh. zones I through III are controlled by proximity to the quartz-filled fractures and these zones are collectively called the fracture regine. Shallow solfataric alteration in the ring domes is also part of this regime.

Alteration in arid adjacent to the resurgeni intrusions is listinct from the fracture regine alteration, and is called the intrusive regime. This regine contains two facies. (1) l'ornfelsed tuff, developed ithin sevaral huricired r.eters of the intrusive contact, is characterized by recrysicallization of the glassy groundnass to an evon-grained rixture of quartz and sanicine. Sanidine pherocrysts in the hornfelsed tuff are typically unirixed to perticite. Hycotherial alteration in this tuff is similar to zone IV alteracion. (2) nlteration in the resurgent intrusive rocls is similar to that in the tuff, except chlorite comonly accompanies the sericite as ati alceration product of biotite.

A tinird alteration regime, called the stratigraphic regine, inclucles the zone IV and $y$ facies and an adelitional chlorite/calcite facies. This facies is best exposed in dieeply eroded parts of the caldera away fron tho resurgent inirusion. It is typified by calcite and a green clay that partially replaces sanidine, and by biotite that is partially altered to chlorite without sericite. Juartz veins that cut this facius usually contain sulfide miiarals and have narrow sericitic selvages.

liydrothermal alteration in the Precambrian granite is less complex thai in tine tuff. Eiotite in the graitite has ben altarad to variable proportions of chiorite anci sericite. Excepi for turbicity in the orthoclase, other mineralogic alteration in the granite is not common. The granito can be subdivided into throe geographic groups basod on their proxinity to tie Fureka graben, which transects the granite's wosterii exposure. (1) rranite within the graben comprises the Eurelia graben group, in which bioitie is almost completely altered to product phasas. (a) $A 5.5$ to 9.7 kin group is axposed within those istances of the graben axis. Biotice in this group is altered to variable anounts of product phases, but is usually not completely altered. (3) Cranite in the $2.0 \mathrm{~km}$ oroup contains biotite that is only slinhtiy a teroci. 
Rolationships Gotween ilineral Alteration arid ije leplations

l'hole-rock oxygen isotope analyses of 37 Pr:cambrian grarite samplas dich 15? caldera-fill samples were conducted (Larsor anil Taylor, 1njoa,b). Patrograptic exdination of thiir sections wh used to estimate the volum of granite biotite that has been altered to produci phases. niso estimaicen was the voline of saididine that has been altered to proiuct phases iii the tuff ani resurgant inirusive samples. Ixygei isotope analyses of outflow facies tuff shou this unit hav an initial oxygen isotope value of +7.2 per mil. The initial isctope value for the granite was +n.2. Slearly all of the analyzed samples have isotope values lower thai the initial values, indicatinn that the." have exchanged oxyoan with a meteoric-hydrothermal fluid. iiil-Tertiary westirin San Juan meteoric water had an oxygen isntope value of about -15 p.r mil. These initial values were used to coilstruct nodel water/rock ratio plois for the Precambrian granite, the tuff, and resurgent intrusions using ine lacer/rocl: ecuations of Taylor (1077). Figure 1 shows these ?lots for ihe frecaribriain granite. Both opeil and closed systen plots for iemperatures 0. On and ino c are shown for iritial water isotope valuas of -15 and -5 per mil. A value of -5 is typical of an 130-shifted meteoric-hydrothermal filuid. A sinilar plot has bean generateri for the Sunshine Peali Tuff (Larson and Taylor. 10306).

Figure 2 shows measureri whole-rock oxygen isotope values for the Precaubriain nraitito plotted agaiist the volume percent of the biotite that has bos alierad. The three groups of granite samples are delineated on Figure?, an: the j.j to $0.0 \mathrm{~kg}$ group of the granite has been subdivided into highalevation and low-elevation subgroups. Comparisons between figures 1 and ? sugg?si the following relationships between water/rock ratios, ienperaiure, anci olevaion in the granite. (1) The $0.0 \mathrm{~km}$ group experianceci the lowest ismperatur: alteration and, locally, the smallest water/rock ratios. (a) The rrabch group experiencel high temperature and high water/rock ratio alteration. (3) "ertical variations of isotope values exist in both the $j . j$ to

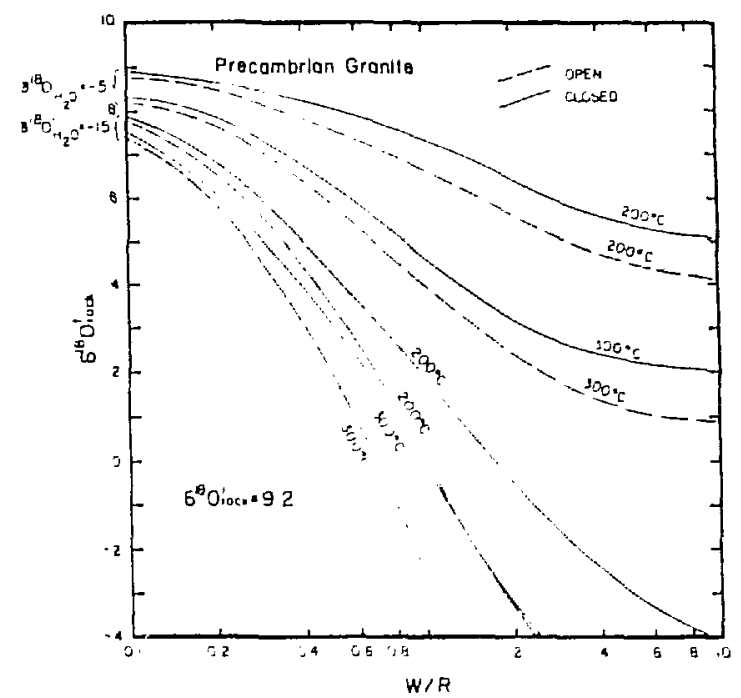

Finure 1. locel Water/rocl ratio trajectories for the Precambrian granite.

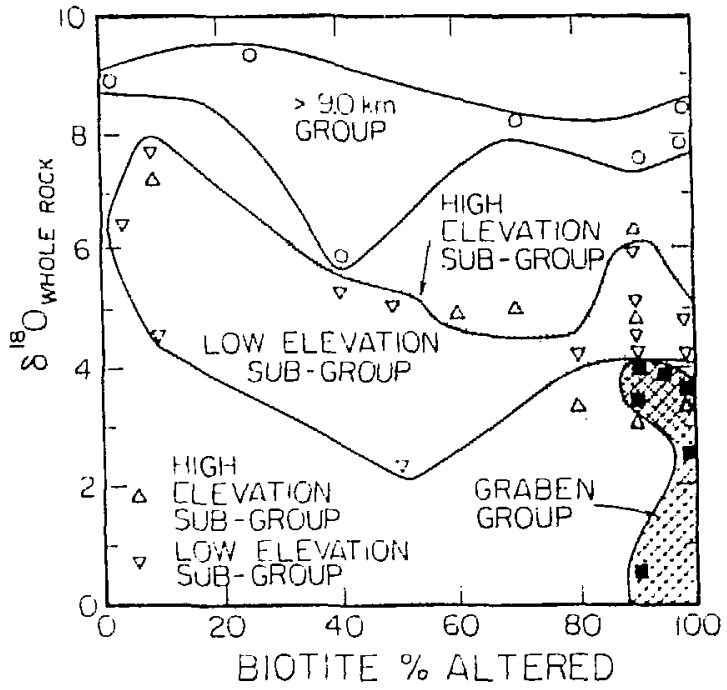

rigure 2. ieasured oxygen isotope values vs. volune percent altered biotite for the granite. 
?.? kin group arid the $9.0 \mathrm{~km}$ ģroup, with lower values at lower elevatioirs. This sugnests that a vertical themal grasient existed throughoui the granite awa from the araben. However, in the nicisle aroun ihe lowest (drepnsi) sarples exhibit the sriallest ariount of biotite alteration arie are al so the ast 130 ciepleted samples in the group. (2) A lateral gradient also nrobably existed with cooler temperatures away froli the crabei.

Figures 3 and 4 show oxygen isotone values for the tuff and resurgent incrusion samples plotted açainst the volume percent of sanidine that has beei altered. ioulel waterírock ratio plots for these rocks are rearly identical to those for the oranite (Fiq. 1). Comparisons anong Figuras 1 , $i$, and 4 suggest that each of the three regines of alteration was prociuceci it listinct, but oradational, environmeits. (1) The fraciure regine was altered wiser hiçh water/rock ratios but relatively noderate temperature conditions. This alteration was proriuce: adjacent to fractures that served as major flow chainels for ine hydrothermal fluids. (?) The inirusive reginia was a higheriemperature regine, but one with very strong lateral and vertical aradients. $\therefore 7$ though these rocks have lower isotope values thai the fracture regine tuff, ihey are nuch less mineralogically altered. (3) The chilorite/calcite alierei samples nlot at intemediate positions between the other two regimes. Tilis alieraition occurs ieep in the stratigraphic secucice, beneath cine argillized Luff, and peripheral to the intrusiva reaime. The low-crade alteration tyres (zones IV ani $V$ ) that occupy most of the area of the callera must be considereci to include low-ạrade, low water/rock ratio end nombers of all tinee alteration rogines.

The volume of nineral alteration products in altered samples correlates with the amouit of oxygen isotope exchange between the rocks anci the hyitro-

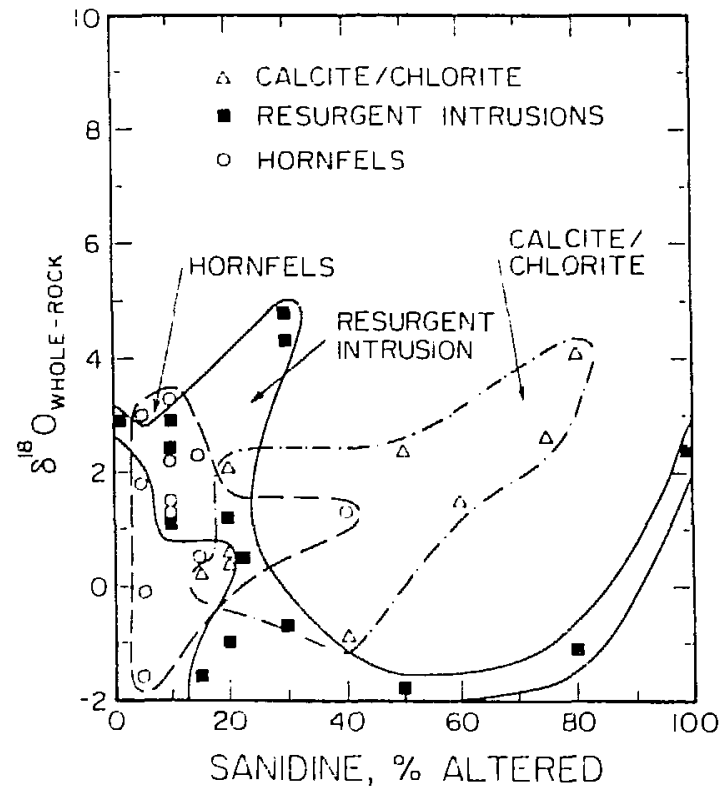

Figure 3. lleasured oxygen isotope values vs. volume percent altered saniline in the non-fracture regime turis.

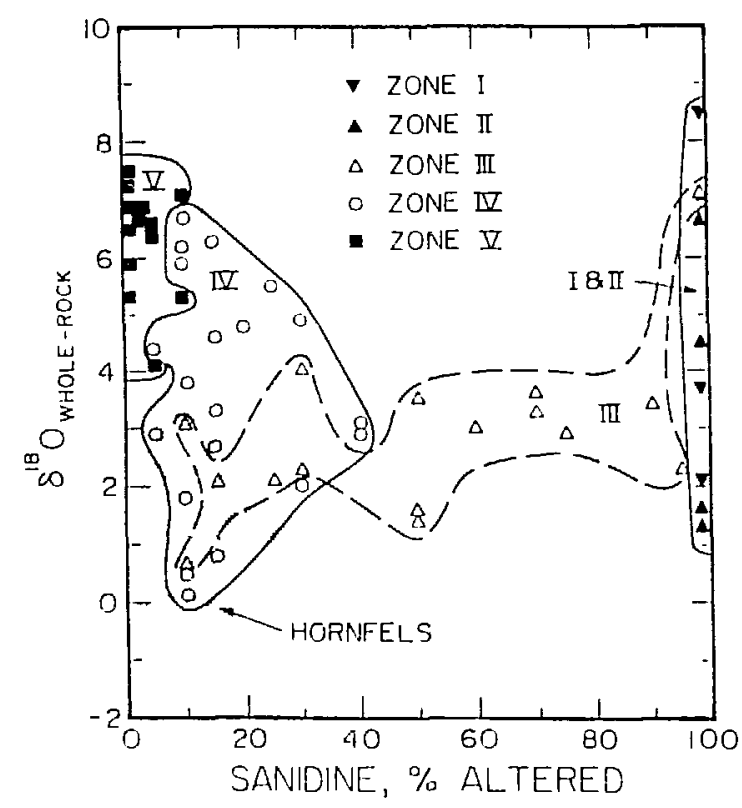

Fiqure $\lambda_{i}$ icasured oxygen isotope values vs. volume percent altered sanidine in the fracture rorine tuff. 
therral fluic.. liowever, the degree of ritneralogic alieration in the salples

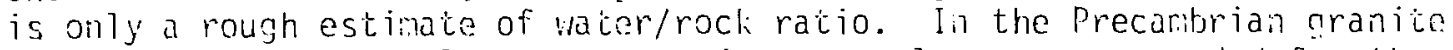
J.j to ?. n group, the lowest oxygen isotone values were recorded for the sa.iples that cisplayeci the least amouit of biotite alioration. Niso, in the caldera the rost isotopically depletes: samples, those from the intrusive regine, do noi cxhibit as great a decrese of miner logical alteration as th? sracture regiole samples. The production of alieration products is strongly dependent oil fluid cheristry, as well as on tenperatur? and water/rock ratio. But oxycen exchange between the thuid and rock is not kinowit to be a function of fluid chemistry.

\section{Summary}

iineralogic alteration and oxygen isotope exchange batween notsorichyctrothemal fluids and rocks have occurred in the n? la Lake City hydrotherial systen. In the Suinshine Peal fuff and the Precambrian granite of Cataract ?ulch the volume of ineral alteration products in the samples correlaies witi: the amount of oxygen isotope depletion. These rasults show tiat fraciured anci falliced rocks adjaceit to aind above the resurgent incrusion experienced the hinhest ratios of water/rock interaction in the caldera. The ionperaturs of alteration was higher, but water/rock ratios were lower, in and around the resurgent intrusion. In the granite, the highly-faulted Eurcka grabei experienced high water/rock ratios. The graben structures probably were a major recharge channel for the caldera hydrothermal systom. !:ater/rock ratios and the temperature of alteration in the granite drecrease sradationally away from the graben.

\section{References}

CRISS R.E. and TAYLOR KI.P. (1033) An 130/100 and D/li study of Tertiary hydroinerial systems in the southern half of the Idaho batholith. Geol. Soc. Aner. Bu17. 0.\%, 6.:0-66.3.

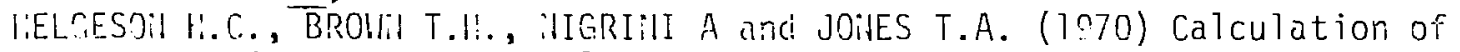
rass traisfer in geochenical processes involving agurous solutions. eochin. Cosmochir. Acta 34, 500-502.

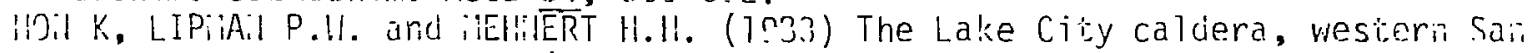
Juai itountains, colorado (abs.). Geo1. Soc. Aner. . Abs. with Prog. 15, 330.

LARSO!I P.B. and TAYLOR H.P. J?. (1936a) An oxygen-isotope study of water/rock interaction in the granite of Cataract rulch, western San Juan inntains, Colorado. Seol. Soc. Amer. Bul1. 97, 505-515.

LARSOII P.B. and TAYLOR H.P. JR. (10,06) 130/160 relationships in hy.jothermally alterea rocks from the Lake City caldera, San Juan íountains, Coloracio. Jour. Volcan. Cootherm. ?2s, in press.

LIPliAil P.ll (1976) Eeolonic map of the Lat: C City caldera area, western San Juan iounta ins, southwesterii Colorado. ".s. reol. Surv. ilap I-no.?.

:IEH:IERT I.J!., SLACK J.F. and CEBULA G.T. (1930) i-Ar age of alunite altoration at red ilountaib, Lake rity arna, western San Juan ilountains, Colorars. Isochrnit/!est $20.0-11$.

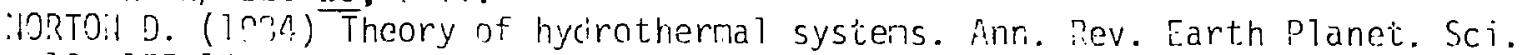
$12,150-177$.

STE!Eil T.A. and LIPliAil P.!!. (107G) Calcieras of the San Juan volcanic field, southwestern Colorado: 1.5 . Ceol. Surv. Prof. Paper nge, is p.

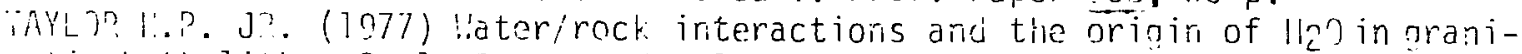
ic batholittis. Seol. Snc. Londori 13?. 500-55?. 


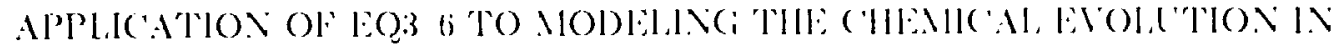

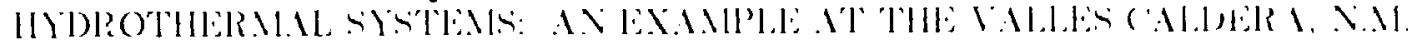

\author{
All l' White and Naney J. ('huma

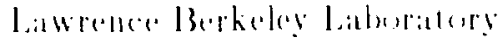 \\ Cniversity of ('alifornia \\ Berteley. ('allifornia $917: 0$
}

\title{
Abstract
}

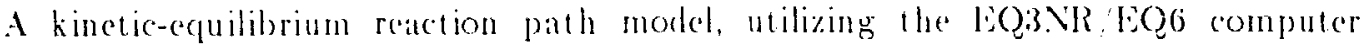
code, is produced for the central 300 " "hydrothermal reservoir and the associated hot spring system in the Valles C'aldera, New Mlexico. L.t. A. A average rock-water ratio of $0.7 \mathrm{kg.k \textrm {g } ^ { - 1 }}$, a total reaction time of $2.9 \times 10^{55} \mathrm{years}$, and a 11 uid residence lime of $1.9 \times$ $10^{3}$ years are calculated for the system based on ${ }^{18} \mathrm{O}$ and $\mathrm{L}$ i mass bilances atid fluxes. $A$ low reactive surface area of $6.15 \times 10^{2} \mathrm{~cm}^{2} \cdot \mathrm{kg}^{2}$, derived with a hydrothermal kinetic rate expression, implies a fracture dominated system controlled in part by diffusion. "The reservoir fluid chemistry and secondary mincral assemblage are surcessfully reproduced by the model using only one fitting parameter, the mass of cabon derived from underlying Paleozoic rocks. The fluid-mineral chemistry is fixed hased on phase rule constraints and is controlled by chloride sources in the primary glass phase and by temperature.

\section{Introrluction}

The number and complexity of geochemical mass action computer codes have increased markedly in recent years. In addition to mathematical and computational sophistication, such simulators have come to rely on recent developments in estimating thermodynamic properties at high temperatures, pressures, and salinitics, in describing kinetic reaction rates using transition state theory, and on analytical and numerical methods of coupling geothermal reactions with fluid and heat flow. As pointed out by Giggenbach (1981), the complexity and intractability of such codes will soon rival those of the natural geochenical systems which they are designed to describe. Few studies have successfully validated such simulations against well-defined natural georhemical systems.

The Valles hydrothermal system, located in the Jemez Mountains, northern New Mexico, is in many ways ideal for applying such a geochemical mass action model as EQ3NR/EQ6 (Wolery, 1979; Wolery, 198.1) because the Valles area (Figure 1) contains a relatively simple lithology, has geographically defined recharge and discharge systems and contains adequately characterized fluids and sccondary mincralogy.

The topographic and structural features of the Valles Caldera were formed during and after the erruption of the 1.1 MYP' rhyolitic Bandelice 'T'uff. A central high temperature geothermal rescroir termed the Baca lickl. contained principally in the Bandelier Tuff, is located on the western flank of Redondo P'ak. a resurgent dome structure within the caldera. The area has been extensively cxplored for potential geothermal development with chemiral dat in from the wells being the mest complete for any caldera system in North Americia. Published datia on the Baca fluid chemistry include work by White (1980) and Truesdell and Jinik (1986). 


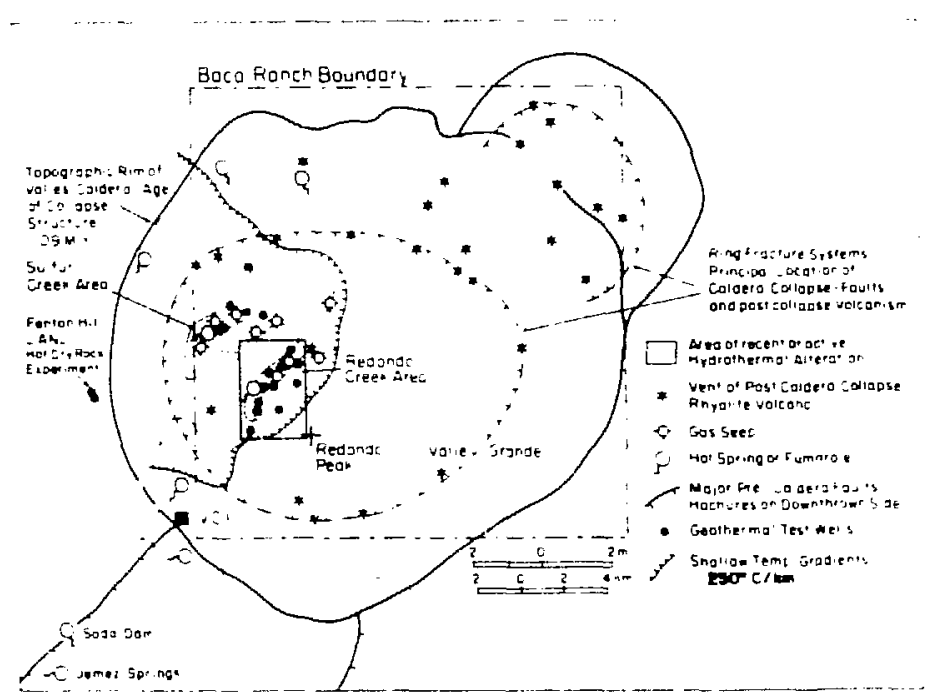

Figure 1. Map of the Valles (aldera area including location of latea well ficld at Redondo ('reeti and majer fluid discharge points at foda Dam and Jene\% siprings.

A phylitic mineral alteration sequence in the tuff is closely associated with documented major thermal fluid entries in the Baca wells (IIulen and Nielson, 1986). Phylitic alteration is characterized by partial to complete destruction of all original rock-forming minerals except quartz and the formation of micaceous illite with variable amounts of secondary quartz, pyrite, calcite, chlorite, epidcte, and $K$ leldspar. The thermodynamic relationships between the Baca reservoir fluids and secondary mineral assemblages were calculated using the EQ3NR program by White (1986). Cation activity ratios involving $\mathrm{Na}, \mathrm{K}$, Ca, Mg. and $\mathrm{II}$ indicated that the reservoir lluids were in general equilibrium with respect to albite. K-mica, epidote, and chlorite. Solubility calculations involving non-aluminum phases indicated that the fluids were saturated with quartz, calcite, anhydrite, dolomit 2 , and siderite.

The EQ3NR EQ6 software packige was used to perform the numerical simulations of the hydrothermal reservoir system. In explicit pll. an input requirement for EQ3NR, is not available directly from flashed wellhead water and gas analyses. This problem was overcome by coupling the EQ3.NR code with the PII code (Ilenley et. al, 1981) which interactively calculates reservoir pll based on concentrations of proton-ionizable aqueous species and total gas content including $\mathrm{CO}_{2}, I_{2}, \mathrm{~S}$ and $\mathrm{NII}_{3}$. Oxygen fugacities were calculated in the EQ3NR code based on the H., $\mathrm{H}_{2} \mathrm{O}$ couple. A fixed fugacity subroutine (Delany and Wolery. 198.1) is cmployed in modeling CO.2 degassing. The EQ6 program was originaly decigned to compute reaction paths under either closed or flow-through conditions. The difference in the options relate to whether or not the mineral phases remain in contart with solutions as temperatures and compositions change. In the available computer package only the clesed system option was operational. The EQ6 program was modified in the present study to include the kinctic rate expression of Wood and Walther (1983). The mass balance parameters in the program were determined by numerically intergrating the rate expression using Simpsons liormula (Ake and Anderson, 197.1). A number of arlditions and morlifications to the thermodynamie data base were made to more chosely approximate lhe mincosl assemblages observed in the Valles systcm. 
A quantitative estimate of the mass of rock reacted, a requirement in the model catculations. is based in part on the partitioning of the ${ }^{18} \mathrm{O}$ isotope hetween hydrothermat fluids and rocks. For a completely closed system, the ratio of mole atoms of oxygen in the fluid (N) to oxygen in the rock iR) can be (aklulated by the retationship) (Taylor. 1977 .

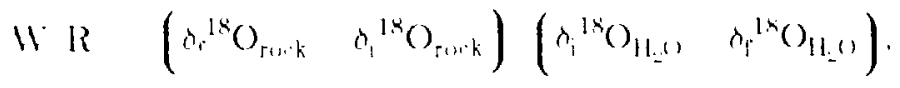

where ${ }^{18} \mathrm{O}$ is calculated in parts per mil., and $\mathrm{i}$ is the initial value and $\mathrm{f}$ is the final value alter exchange. For a completely open system in which each increment of water inakes only a single pass through the hydrothermal system, the extent of reaction can be calculated by the relationship:

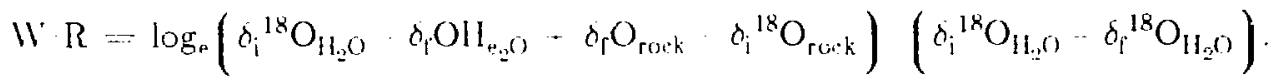

Extensive $\delta^{18} \mathrm{O}$ data (Figure 2) exist for regional meteoric water as well as hydrothermal fluids within the caldera (Vuataz and Coff, 1986; and White, 1986), and indicate an approximate $2.1 \% 0$ enrichment in the latter case. Much more limited dara for the Bandelier Tuff (Lambert and Epstein. 1980) indicate that the reservoir rocks are depleted in ${ }^{18} \mathrm{O}$ by approximately $6.9^{\mathrm{C}} \mathrm{co}$.

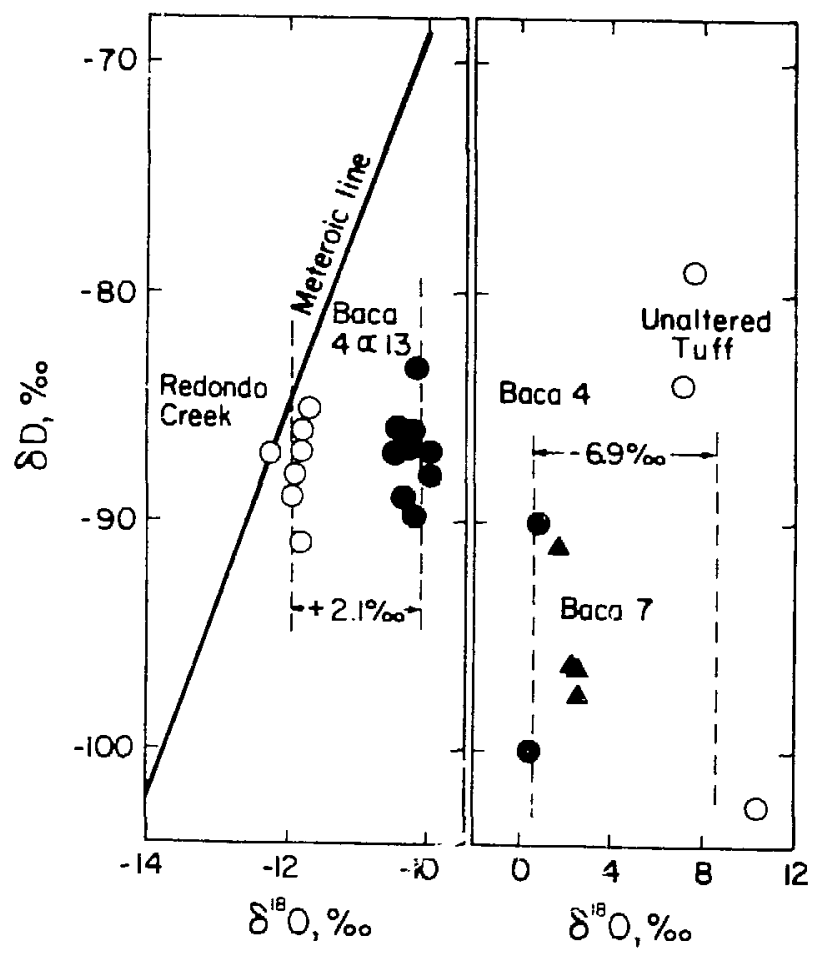

Figure 2. Extent of oxygen-18 increase in fluids and dererease in Bandedier Tuff as a function of hydrotherma! alteration. Op.n and closed circles are respective denterium-oxygen-1s date for surfare neseroje water and Baca wells. Open and reserd traingles are respertwe data for whaltered Bandelier Tuff and altered tulf 

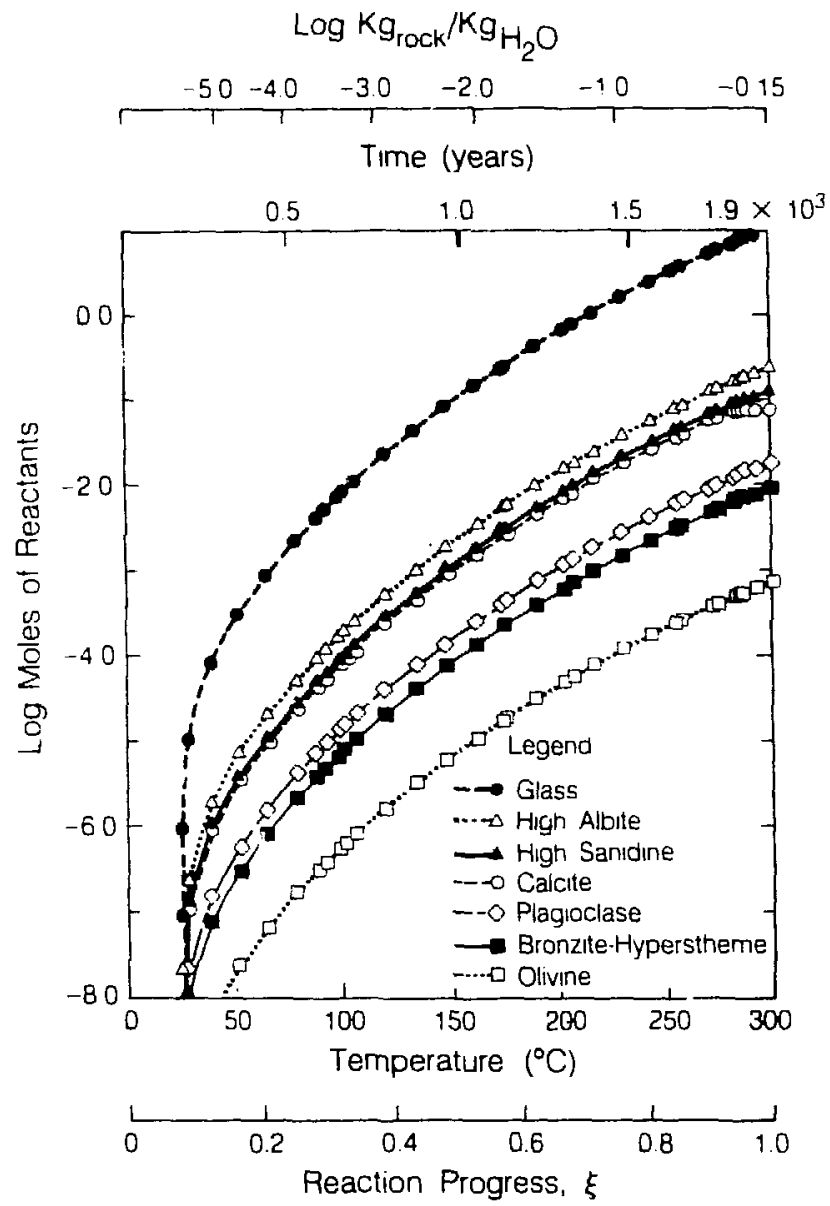

Figure 3. Moles of primary glass and minerals reacted as a function of the kinctic rate expression and plotted as functions of the reaction increment $(\xi)$, time, temperature, and total rock mass.

Equation 1 thereby results in a calculated rock mass of $0.4 \mathrm{~kg}$ per $\mathrm{kg}$ of waier for the closed system condition. Equaticn 2 producus a reacted rock mass of $0.9 \mathrm{~kg}$ of fuid assuming a flow-through scenerio. An average $\cdots$ lue of $0.7 \mathrm{~kg} \cdot \mathrm{kg}^{-1}$ employed in the model is comparable to ratios calculated for the Saltun Sea and Warakei geothermal systems.

The EQNR3/EQ6 model considers reaction rates of the individual primarily mineral phases (Figure 3 ). Composition data and relative amounts of minerals are from estimates provided by Roy Bailey, U.S. Geological Survey and Jamie Gardner, Los Alamos National Laboratory. Ample hydrothermal sources of all elenents, except chloride and carbon, occur in the primary mineral assemblage. Chloride is the principal anion in the Valles hydrothermal fluids and controls the overall chemistry by electrical charge balance and by the fact that it is not const:ained by fluid-rock equilibria. An average of $2100 \mathrm{mg} \cdot \mathrm{kg}^{-1} \mathrm{Cl}$ has been reported for pumeceous layers in the Bandelier Tuff (Gardner t. al., 1986). Based on this analysis, a reacted rock-water ratio of $0.7 \mathrm{~kg}^{-\mathrm{kg}^{-1}}$ would release $1,470 \mathrm{mg} \cdot \mathrm{kg}^{-1} \mathrm{Cl}$ to the $\mathrm{flu}$ id compared to a average measured composition of $1960 \mathrm{mg} \cdot \mathrm{kg}^{-1} \mathrm{Cl}$, indicating that host rocks are the principal Cl source. This conclusion is in agreement with observed secular ${ }^{36} \mathrm{Cl}$ equilibrium between water and rock in the Valles system (Phillips et. al., 1984). 
The high concentrations of ( $\mathrm{O}_{2}$, in the hydrothermal Huids $17 \times 10^{\circ} 10.3 .4 \times 10^{4}$ mg.kg-1; White, 1986) require an adclitional source of carbon not contained in the meteoric recharge water nor in the primary rokanic rocks. Similarities in the ranges in $\delta^{13} \mathrm{C}$ of the Valles hydrothermal fluids $(-3.810-1.8 \%$ oo) and of the underlying Maderi limestone $\left(-3.1-5.6^{\circ} \circ 0\right)$ suggests that the carbon originated from themat metamorphism of limestone (Truesdell and Janik, 1986). Thermal metamorphism is supported by the presence of minor amounts of calciums silicates including diopside and actinolite in the underlying Madera formation (Hulen and Niekon, 1986). Calcite is assumed to be the principal carbon source although it occurs as a prinary mineral only in the spatially separated Madera Formation. Likewise. Ca-Mg silicates are allowed to preciphitate in the secondary mineral assemblage, even though they are observed within the limestone and not in the overlying volcanic sequence.

The lithium fluxes in hot spring discharge from the reservoir can be linked with the mass ratio to estimate reaction limes in the reservoir. The calculations are bated on evidence from the $\mathrm{Na}-\mathrm{Li}$ geothermometer (White et. al., 1981) that li does reequilibrate in the hydrothermal system. The reaction time (1, sec) is cxpressed as the ratio between the total $\mathrm{Li}$ loss in the reservoir and the rate of Li loss in the discharging water.

$$
t=\frac{V \rho\left(\mathrm{C}_{i}-\mathrm{C}_{\mathrm{i}}\right)}{F}
$$

where $V$ and $\rho$ are the respective volume $\left(\mathrm{m}^{3}\right)$ and rock densily, $\left(\operatorname{gmecm}^{-3}\right) . \mathrm{C}_{\mathrm{i}}$ and $\mathrm{C}_{\mathrm{f}}$ are the initial and final lithium concentrations in the rock $\left(\mathrm{g}^{\mathrm{kg}} \mathrm{kg}^{-1}\right)$ and $F$ is the flux of lithium from the system $\left(\mathrm{g} . \mathrm{s}^{-1}\right)$. A total reaction tine of $2.9 \times 10^{5}$ years and a fluid residence time of $1.9 \times 10^{3}$ years can be calculated based on published estimates of the reservoir dimensions and porosity. Approximately 150 fluid reservoir volumes have passed through the system. Clearly from this calculation, the isotopic as well as the ideal geochemical model must be considered an open rather than closed system.

A hydrothermal rate expression. applicable to all silicate minerals (Wood and Walther, 1983) can be rewritten in a Arrhenius expression,

$$
k=\frac{1}{N} 10\left(\frac{-2900}{T}-6.85\right),
$$

where $N$ is the moles of oxygen atoms in the reacting mineral phase and $T$ is temperature $\left(\mathrm{K}^{\circ}\right)$.

The assumption is made in the rate calculations that fluid movement in the reservoir is constant over the $1.9 \times 10^{3}$ years and that it occurs along a lincar temperature gradient. The single pass model permits both temperature and time to be described as linear functions of $\xi$, the reaction variable in the reaction path calculation. Mathematically the mass of a reacted mineral, $M$, can be written based on the above conditions as,

$$
M \ldots R_{k} \int_{\xi=0}^{\varepsilon=1} 10\left|\frac{200}{208+15+300 \xi}\right| \delta \xi
$$

where the effective rate constant is dferta al as

$$
l_{k} \frac{10^{4.15}}{x} i
$$


A summation of the amount of each mineral phase reacted in Figure 3 at $\xi=1$ equals 18.91 moles of oxygen. The total mineral assemblage has an oxygen content of 1.82 moles of $\mathrm{O}_{2}$ per mole of rock. The resulting value of reactive surface area, $A$, integrated over the entire temperature based on Equations 5 and 6 is therefore $6.15 \times$ $10^{2} \mathrm{~cm}^{2}$ per $\mathrm{kg}$. of rock.

\section{Results}

The E23NR/EQ6 simulation of the high temperature reservoir successfully reporduces the fluid chemistry and secondary mineral assemblage using only one undefined fitting parameter, the mass of calcium carbonate supplied to the system. Calcite dissolution contributes carbon to the system which increases the $\mathrm{P}_{\mathrm{CO}_{2}}$ and ralcium which promotes epidote saturation and fixes the $\mathrm{P}_{\mathrm{O}_{2}}$. Plots of $\mathrm{P}_{\mathrm{CO}_{2}}$ and " ${ }^{\circ}$. against temperature for variable amounts of reacted calcite are presented in Firure 4 . Parameters of $\mathrm{pH}$, $\mathrm{PCO}_{2}$ and $\mathrm{P}_{\mathrm{O}_{2}}$ in addition to other aqueous species, are controlled by complex interactions involving dissolution of primary minerals alud precipitation of secondary minerals.
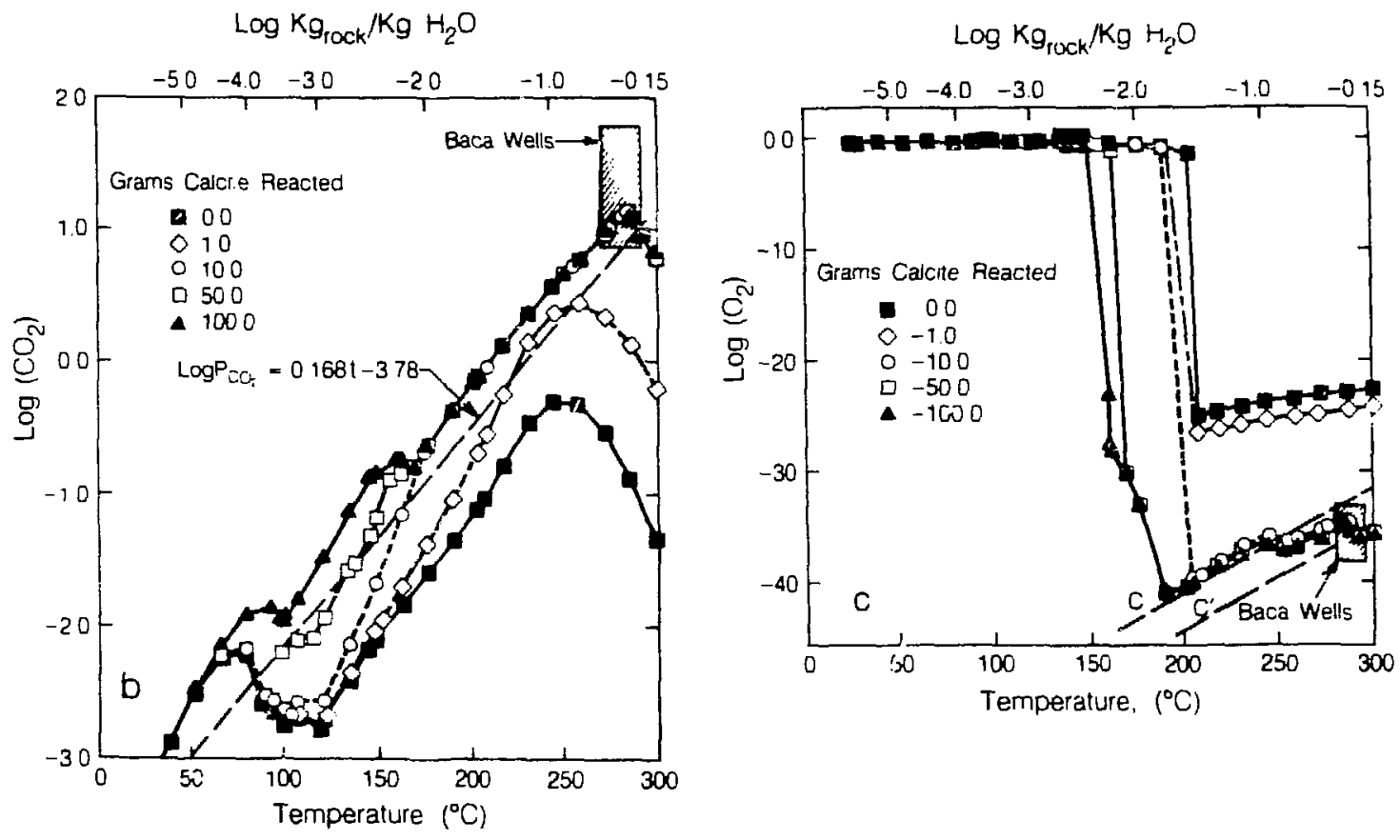

Figure 1. Reaction path $P_{C n_{2}}$ and $P_{O_{2}}$ versus temperature for differing masses of reacted calcite. Shaded areas are ranges in Baca Reservoir chemistry. Iine $B$ indicates Peo, conirol from Ca silicateralcite equilibria (Equation 7) and; line $C$ and $\left(", l_{2}\right.$ control from silicate-pyrite buffers (D'Amore and Gianclli. 1981). 
The simulated $\mathrm{P}_{\mathrm{CO}}$ (Figure 4) is strongly related to the extent of (as lae reatetion with the maximum partial pressures becoming univarient with lomperature again al at reacted carcite mass of $1 \times 10^{-2} \mathrm{~kg}$ or athore. This P'co-tempenature relationship generally follows the approximate lit to k leldspar-illite conexistence represented by the expression (Ciggenbach, 1981)

$$
\log P_{C(1.2}-0168 T-38
$$

which may be represented by the thermodynamically sperilie and momber components.

$$
0.5 \text { clinozosite }-0.75 \text { microcline }+\mathrm{CO}_{2}:-2 \text { calcite }+0.75 \mathrm{~K}-\mathrm{mica}+1.5 \mathrm{5iO} 2
$$

Variations in the fit between the reaction path simulation and Equation o are related to differing solid solution composition involving clinozosite-cpidole and limica-illite.

The simulated $\mathrm{P}_{2}$ of the system (Figure 4 ) decreases markedly in the temperature range $150^{\circ}-210^{\circ} \mathrm{C}$ corresponding to the onset of pyrite precipitation. The $\mathrm{P}_{\mathrm{O}_{2}}$ also decreases with increasing calcite reaction below a total reacted calcite mass of $1 \times 10^{-2} \mathrm{~kg}$ and becomes invarient above $200^{\circ} \mathrm{C}$ for a calcite mass of $1 \times 10^{-2} \mathrm{~kg}$ or greater. The fixed $\mathrm{O}_{2}$ simulation reproduces reservoir $\mathrm{P}_{\mathrm{O}_{2}}$ at comparable temperatures, as calculated from the $\mathrm{H}_{2} / \mathrm{H}_{2} \mathrm{O}$ couple, and also falls within the range of a $\mathrm{P}_{2}$ mineral buffer involving in part py rite- epidote-chlorite proposed by D'Amore and Gianclli (198-1). The lines C and $\mathrm{C}^{\prime}$ in Figure 4 correspond to their buffers assuming respective epidote compositions, pistalit $2=0.275$ and 0.125 , and with a fixed $\mathrm{Fe} / \mathrm{Mg}$ chlorite ratio of 0.5 .

When the mass of $\mathrm{CaCO}_{3}$ equals or exceeds $1 \times 10^{-2} \mathrm{~kg}$, the chemical components of the hydrothermal system become equilibrated with a full assemblage of secondary minerals. Under such conditions there are 12 chemical components (C) in the system, $\mathrm{Na}, \mathrm{K}, \mathrm{Ca}, \mathrm{Mg}, \mathrm{A} ., \mathrm{Fe}, \mathrm{S}, \mathrm{O}, \mathrm{C}, \mathrm{Si}, \mathrm{H}$, and $\mathrm{Cl}$ and 11 stable mineral phases (P), quartz, calcite, pyrite, magnetite, dolomite, diopside, epidote, chlorite, albite, K-leléspar and illite (K-mica). Tlierefore three independent variables ( $F$ ) must exist in the system ba.ed on the Gibbs phase rule, $\mathrm{P}+\mathrm{F}=\mathrm{C}+2$. From the data of Hclgeson et al. (1978), the change in the free energy of formation of minerals as a function of pressure up to a hundred bars will not significantly influence overall stability. This reduces the number of variables in the equilibrated system to two, temperature and the mobile Cl component, a condition representive of many hydrothermal systems (Arnorsson et. at., 1982).

Chemical and gas parameters generated by the code such as $\mathrm{P}_{\mathrm{CO}_{2}}$ and $\mathrm{P}_{\mathrm{O}_{2}}$ closely adhere to analytical solutions to phase equilibria developed by previous workers. In rock-dominated, highly equilibrated systems such as the Baca reservoir, a mass action code such as EQ3NR/EQ6 may be expected to repioduce results generated by analytical considerations of equilibria as shown by Giggenbach (1984). The agreement between the two approaches for the Baca reservoir is therefore a validation of the computational methods employed in the code.

\section{References}

Ake, G.D. and Anderson, N. (1974) Numerical Methods. Prentice-llall lne. Englewood, N.J., $572 p$.

Arnorsson, S., Gunnlaugsson, E. and Sevavorsson, 11. (1982l) The chernistry of geothermal waters in Iccland. Il. mineral equilibra and independent variables controlling water compositions. Gcochim. et Cosmochim. Act. 17, 5.17-566. 
D'Amore. F. and Gianelli, G. (1081) Mineral assemblages and oxygen and sulphur fugarties in natural water-rock interaction processes. Cicochim. Cosmochim. Actal 18 . $817-857$.

Gardner, J.N., Goff, F., Garcia, S., and Ilagan, R. (1986) Stratigraplic relationships and lithologic variations in the Jemez volcanic tield, New Mexico. J. Cicophys. Res, 91, $1763-1978$.

Giggenbach, W.F. (1981) Mass transfer in hydrothermal alteration systems - A conceptual approach. Geochimica Cosmochimica Acta 18. 2693-2711.

Helgeson, H.C Delany, J.M., Nesbitt, H.W., and Bird, D.K. (1978) Summary and crituque of the thermodynamic properties of rock-forming minerals. Amer. J. Science $278-1,1-228$.

Henley, R.W., Truesdell, A.H. and Barton, P.B., Jr. (1984) Fluid-mineral equilibria in hydrothermal systems. Reviews in Economic Cicologg, 1, $268 \mathrm{pp}$.

Phillips, F. M., Goff, F., Vuataz, F. Bentley, II. W. Elmore, D. and Gove, H. E. (1981) Chlorine $-3 b^{\circ}$ as a tracer in genthermal systems: Example from the Valles Caldera. New Mexico. Geophys. Res. Lett. 11, 1227-1230.

Taylor, H.P. (1977) Water-rock interactions and the origin of $\mathrm{H}_{2} \mathrm{O}$ in granitic batholiths. J. Gieol. Soc. (London) 133, 509-5.58.

Truesdell, A.F. and Janik, C. (1980) Reservoir processes and fluid origins in the Baca geothermal system, Valles Caldera, New Mexico. J. Geophys. Res. 91, 1817-183.1.

Vuataz, F.D. and Goff, F. (1986) Isotope geochemistry of thermal and nonthermal waters in the Valles Caldera, Jemez Mountains, northern New Mexico. J. Geophys. Res. $91,1835-1854$.

White, A.F. (1986) Chemical and isotopic characteristics of fluids within the Baca Geotlermal Reservoir, Valles Caldera, New Mexico, J. Geophys. Res. 91, 185.5-1866.

Wolery, T.J. (1979) Calculation of chemical equilibrium between aqueous solution and minerals: The EQ 3:6 software package. Lawrence Livermore Laboratory Dept UCRL-5.2658, 38pp.

Wolery. T.J. (1984) EQ3.NR. A computer program for geochemical aqueous speciation solubility calculations: users guide and documentation. Lawrence livernoro National Labora:ory LCCRL-53111. 85p.

Wood, B.J. and Walther, J.V. (1983) Rates of hydrothermal reactions. Sicience 202. 113115 . 


\author{
D. R. Janecky \\ Los Alamos National Laboratory \\ Los Alamos. NM 87545 USA
}

\begin{abstract}
Experimental seawater-peridotite reaction pathways to form serpentinites at $300^{\circ} \mathrm{C} .500$ bars. can be accurately modeled using the EQ3/6 codes in conjunction with thermodynamic and kinetic data from the literature and unpublished compilations. These models provide both confirmation of experimental interpretations and more detailed insight into hydrothermal reaction processes withir th: oceanic crust. The accuracy of these models depends on careful evaluation of the aqueous speciation model. use of mineral compositions that closely reproduce compositions in the experiments, and definition of realistic reactive components in terms of composition. thermodynamic data, and reaction rates.
\end{abstract}

\title{
Introduction
}

For several reasons. oceanic serpentinization processes offer an ideal case for testing and examining hydrothermal water-rock reaction models. First. serpentinites and their precursor peridotites are composed of relatively restricted assemblages of minerals. Second. the processes. precursors. and products of serpentinization have been extensively characterized by field and laboratory studies of mineral assemblages. mineral stability. chemical compositions. reaction pathways, and mineral dissclution kinetics (Janecky and Seyfried. 1986: Murphy. 1985: and references therein). This paper will discuss how examination of hydrothermal seawater-peridotite serpentinization reaction pathways illustrates the constraints and limitations of reaction pathway modeling and the necessity of integrating database evaluation. geology. and experimental results into the modeling process.

Serpentinized peridotites are relatively common rocks found both in oceanic and continental crust. Oceanic ultramafic rocks undergoing serpentinization are composed primarily of olivine. enstatite. and diopside in the variable proportions that form dunites. harzburgites. Iherzolites. and aluminous peridotites, and are primarily derived from the mantle (Bonatti and Hamlyn. 1981: Nicolas and Poirier. 1976: and references therein). Serpentine is the dominant alteration phase (primarily lizardite as defined by XRD). but magnetite. talc. hematite. chlorite. tremolite-actinolite. scapolite. truscottite. sepiolite, magnesite. and aragonite are also found in varying amounts (Aumento and Loubat. 1971: Aumento. 1970: Prichard. 1979: Engel and Fisher. 1975: Bonatti et al.. 1980: Bonatti and Hamlyn. 1981). Brucite appears to be much less common in oceanic than in continental serpentinites. whereas Ca-bearing silicates (e.g.. tremolite-actinolite) appear to be more common, even in alteration products of low-Ca peridotites. Serpentine minerals are Fe-bearing in both oceanic and continental occurrences (Dick. pers. comm.: Dungan. 1979: Wicks and Plant. 1979) and less than 5\% magnetite is present (Smith et al. 1982)

Experimentai interaction of equigranular peridotites with seawater or "evolved"-seawater solutions at elevated temperatures and pressures has produced mineral assemblą̧es and compositions that are generaliy similar to those described from oceanic samples above (Janecky and Seyfried. 1986, and references therein). In addition. these experiments have defined solution reaction pathways and relative reaction rates between olivine. enstatite, and diopside. 
Seawater initially loses $\mathrm{Mg} . \mathrm{Ca}$. and $\mathrm{SO}_{4}$. and $\mathrm{pH}$ decreases, but $\mathrm{SiO}_{2}$ and $\mathrm{Fe}$ increase. After approximately 1000 hours of experimental reaction. $\mathrm{pH}$ increases and $\mathrm{Mg}$. $\mathrm{Ca}, \mathrm{SiO}_{2} . \mathrm{Fe}, \mathrm{Cl}$. and $\mathrm{CO}_{2}$ decrease. This division into two stages of reaction is also found in the mineralogical evolution of the system: the first stage involves olivine plus pyroxenes reacting to form ser pentine: in the second stage olivine reacts to serpentine anud Lrucite after the pyroxenes have been consumed. Relative reaction rates between olivine. enstatite. and diopside. determined from these experıments with equigranular starting materials. are approximately $1.0 / 1.0 / 0.1$ in moles per unit time, or (corrected for relative surface areas) 1.0/3.3/0.7 in moles per unit time per unit surface area.

\section{Methods and Materials}

The reaction path models discussed below were calculated using the EQ3/6 code package (Wolery. 1978. 1979. 1983). Parameters for the aqueous solvent and extended Debye-Huckel activity coefficients were calculated by the methodology and thermodynamic data of Helgeson (1969). Helgeson and Kirkham (1974a and b. 1976). Lietzke and Stoughton (1975). and Helgeson et al. (1981). Dissociation constants for pertinent aqueous species from $25^{\circ} \mathrm{C}$ to $350^{\circ} \mathrm{C}$ were compiled from the literature or taken from other unpublished compilations (Janecky. 1982: Janecky and Seyfried. 1983: Seyfried and Dibble, 1980: Karaka and Barnes. 1973). Mineral hydrolysis constants were calculated using the SUPCRT computer code and thermouynamic data for minerals. aqueous ions. gases. and water (Helgeson et al.. 1978: Helgeson and Kirkham. 1974a and b. 1976: Helgeson et al.. 1981). Thermodynamic data for sheet silicates not included in Helgeson et al. (1978) were taken from the data set estimated by Wolery (1978): data for Mg-hydroxy-sulfate-hydrate (MHSH) was taken from Janecky and Seyfried (1983).

Although a universal, verified database for hydrothermal systems would be of tremendous advantage to geochemical modelers. it is necessary to critically examine any such database because of known uncertainties in aqueous activity coefficient models and incomf.ete and/or ill. defined aqueous dissociation reaction constant data for solution composition, temperature. and pressure. In the case of the database for solution and minerals specified above. its applicability has been examined and partially verified by comparing calculation results with a variety of experimentai data. including seawater heating experiments (Janecky and Seyfried. 1983: Bischoff and Seyfried. 1978). serpentinization experiments (Seyfried and Dibble. 1980: Janecky and Seyfried, 1986; Janecky. 1982). and magnetite hematite experiments (Janecky et al.. 1986). Though data for lizardite does not exist in the database. these calculations indicated that chrysotile thermodynamic data could be used in examining the experiments in which lizardite was the primary serpentine formed (Seyfried and Dibble, 1980: Janecky. 1982: Janecky and Seyfried. 1986).

Initial reactants used in the calculations were 546 millimolal $\mathrm{Cl}^{-}$seawater (Millero, 1974) and harzburgite composed of 75 and 25 wt.\% olivine and enstatite. respectively. Olivine and enstatite compositions were those of the minerals used experimentally by Janecky and Seyfried (1986). Individual minerals, rather than bulk harzburgite, were used as reactants because the reaction rates observed experimentally were a function of the dissolution rates specific to each mineral and the amount of mineral present.

Results

Harzburgite rear:ion with seawater at $300^{\circ} \mathrm{C} .500$ bars. calculated for experimentally defined relative reaction rates. generally matches the results of experimental reaction pathway investigations discussed above (Figure 1). However, the calculations indicate formation of significant amounts of talc not found in experimental products and magnetite in excess of that produced in the experiments. As a consequence. dissolved $\mathrm{Fe}$ and $\mathrm{f}_{\mathrm{O}_{2}}$ are significantly 
lower in the calculated model than in the experiments A major factor in these discrepuncies is the formation of pure $\mathrm{Mg}$-serpentine. In contrast to the formation of 10 mole $\% \mathrm{Fe}$ serpentine in the experiments. as lllustrated by the reaction

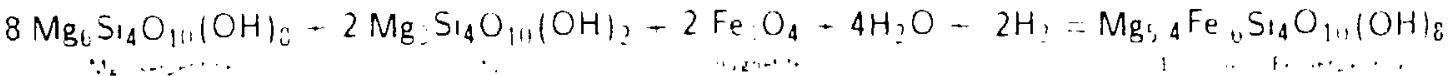

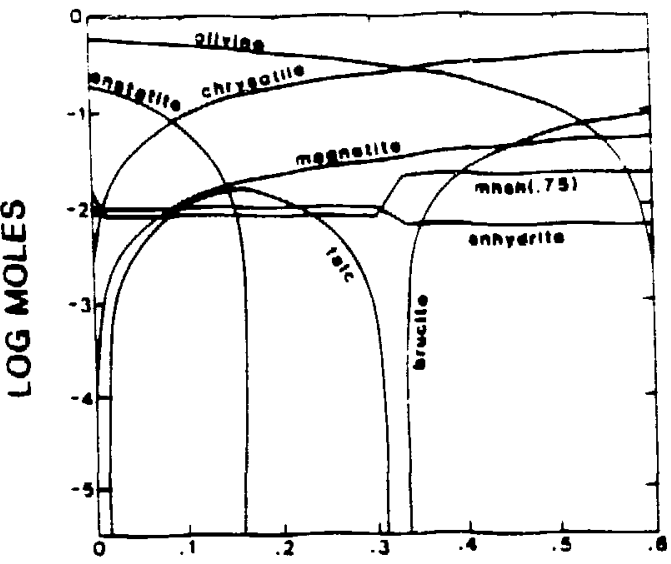

REACTION PROGRESS

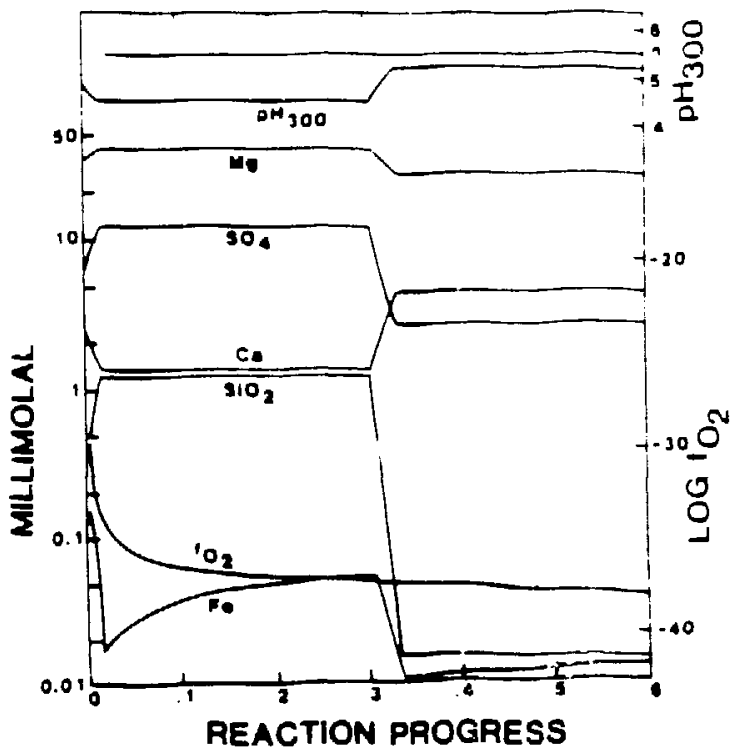

REACTION PROGRESS

Figure 1. Calculated harzburgite reaction pathway with seawater at $300^{\circ} \mathrm{C} .500$ bars. for a total water-rock mass ratio of 10 . Relative reaction rates were set to those determined in experimental studies (Janecky. 1982; Janecky and Seyfried. 1986) and sulfate-sulfide equilibrium was suppressed.

Dissolution constants for an Fe-bearing serpentine. equivalent to that experimentally formed. were calculated using data for chrysotile ard greenalite from the database, assuming an ideal solid solution. Calculated reaction pathways using this estimate for a fixed solid solution serpentine are much more consistent with the experimental resuits (Figure 2) In rarticular. magnetite amounts and the $\mathrm{f}_{2}$ pathway in this inodel closely reproduce those observed experimentally. Fe in solution. during the first stage of reaction. increases by approximately one order of magnitude in this calculation relative to the first. which is closer to experimental results but still approximately one half of the concentrations observed experimentally. One possible explanation for this difference is lack of equilibration between magnetite and solution in the experiments: this explana:ion is consistent with kinetics of equilibration observed in magnetite-hematite experiments (Janecky et al.. 1986).

The second model (Figure 2) also includes calculation of $\mathrm{pH}$-dependent dissolution rates by using transition state theory models (Murphy. 1985, and references therein). Input data to these kinetic models were extrapolated to $300^{\circ} \mathrm{C}$. from data extracted from low-temperature 

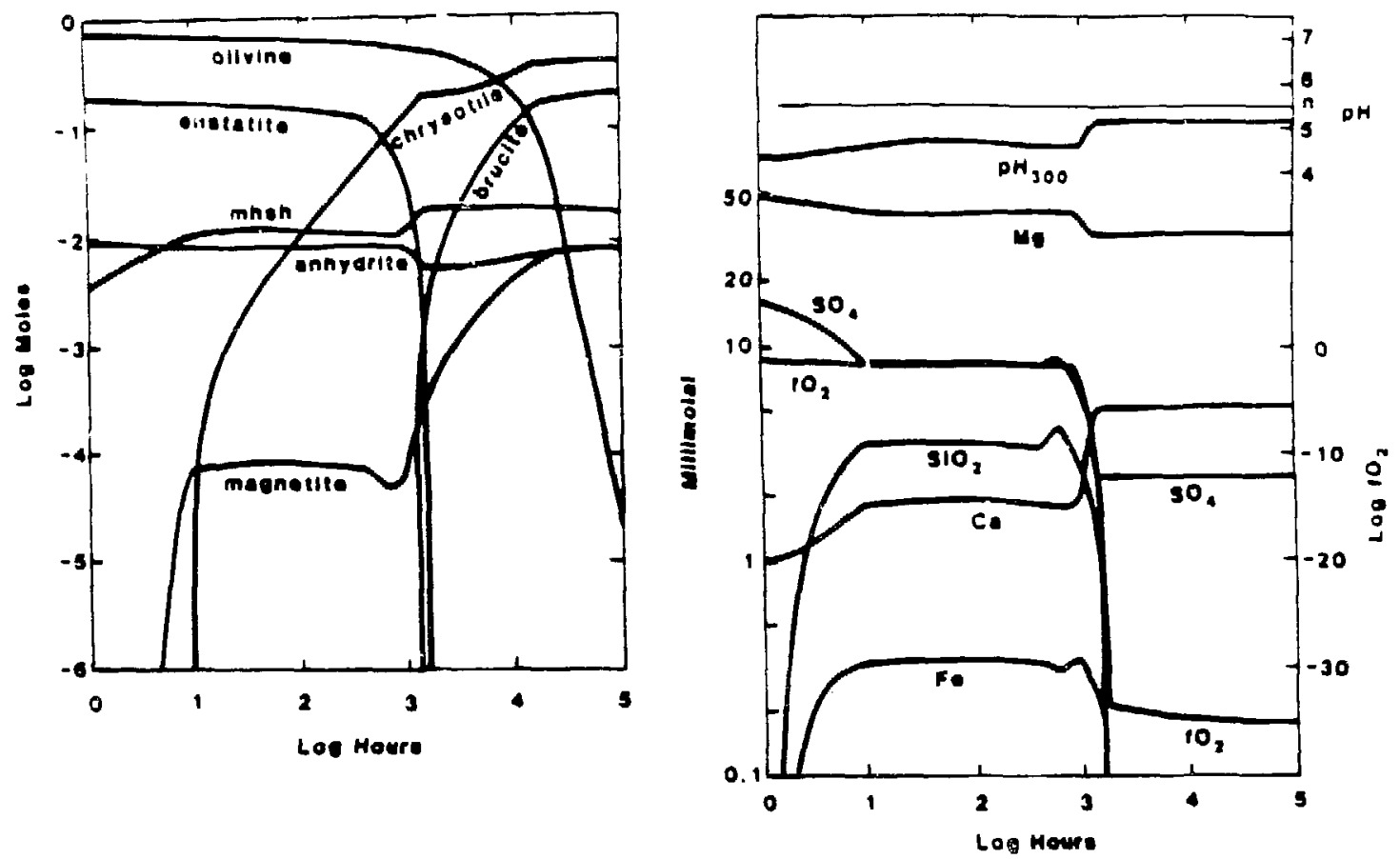

Figure 2. Calculated harzburgite reaction pathway with seawater at $300^{\circ} \mathrm{C}$. 500 bars. for a total water-rock mass ratio of 10 ; the serpentine composition was constraired to be 10 mole $\% \mathrm{Fe}$ end-member. Reaction rates were calculated using transition state theory models and data from Murphy (1985) that were extrapolated to conditions of interest.

dissolution experiments (Grandstaff. 1977. 1978. 1980) by Murphy (1985). These data confirm the relative rates for equigranular olivine and enstatite determined from the experimental studies. and they accurately model the timing of enstatite disappearance and consequent chemical and minera! assemblage changes in the experiments. Differences between experimental results and the moaels in the second stage of reaction (particularly in $\mathrm{pH}$ ) are probably due to precipitation of $\mathrm{CI}^{-}$and incorporation of $\mathrm{Fe}$ into brucite during the experiments. both of which are not accounted for in the models.

\section{Conclusions}

This modeling effort indicates that accurate results can be obtained when the investigator is cognizant of three major aspects of the modeling process: (1) Does the database provide consistent results for carefully constrained parts or examples of the system of interest? (2) Are reaction components and rates consistent with the system to be modeled? (e.g. Is reaction of a bulk rock composition reasonable. or must the rock be subdivided into mineral components?) and (3) Are the mineral compositions calculated by the rnodels consistent with natural and/or experimental systems for at least major elements (and minor elements if they are also included)? The success of the efforts described above in modeling the experimental serpentinization reaction pathway prepares the way for more extensive investigation of serpentinization reactions by allowing a wide variety of variables to be investigated, including variations in grain size between olivine and enstatite and reactions with other possible solutions such as those from adjacent basaltic crust (Janecky. 1982: Janecky. 1986: Janecky and Seyfried. in prep.). 
This work has benefited from discussion and collaboration with $W$. Seyfried. H. Dick. T. J. Wolery. W. Murphy. and K. Kimball. Comments and suggestions by C. J. Duffy and J. Heiken substancially improved this manuscript. The research was supported by NSF Grants OCE-7908569 and OCE-820056. Preparation of this paper and continued refinement of these approaches to examining the consequences of water rock interaction is supported by funding from US DOE Office of Basic Energy Science to Los Alamos National Laboratory.

\section{References}

Aumento. F. (1970) Serpentine mineralogy of ultrabasic intrusions in Canada and on the Mid-Atlantic Ridge. Geol. Surver Canada Paper 69-53

Aumento. F. and Loubat. H. (1971) The Mid-Atlantic Ridge near 45N. XVI. Serpentinized ultramafic intrusions Can. Jour. Earth Sci. 8 631-663.

Bischoff. J. L. and Seyfried. W. E.. Jr. (1978) Hydrothermal chemistry of seawater from $25^{\circ} \mathrm{C}$ to $350^{\circ} \mathrm{C}$. Am. Jour. Sici. 278 838-860.

Bonatti. E. and Hamlyn. P. R. (1981) Oceanic ultramafic rocks. in The rea 7. 241-283 (C. Emiliani, ed.) J. Wiley and Sons. New York.

Bonatti. E.. Lawerence. J. R.. Hamlyn. P. R., and Breger. D. (1980) Aragonite from deep sea ultramafic rocks. Geochim. Cosmochim. Acta 44 1207-1215.

Dungan. M. A. (1979) A microprobe study of antigorite and some serpentine psuedomorphs C'an. Mineral. 17 771-784.

Engel. C. C. and Fisher. R. L. (1975) Granitic to ultramafic rock complexes of the Indian Ocean ridge system, western Indian Ocean. Geol. sioc. Am. Bull. 86 1553-1578.

Grandstaff. D. E. (1977) Some kinetics of bronzite orthopyroxene dissolution. Geochim. Cosmochim. Acta 41 1097-1103

Grandstaff. D. E. (1978) Changes in surface area and morphoiogy and the mechanism of forsterite dissolution. Geochim. Cosmochim. Acra 42 1899-1901.

Grandstaff. D. E. (1980) The dissolution rate of forsteritic olivine from Hawaiian beach sand. in Proceedings of the $3^{\text {rd }}$ International Symposium on Mater-Rock Interaction (Edmonton. Canada).

Helgeson. H. C. (1969) Thermodynamics of hydrothermal systems at elevated temperatures and pressures. Am. Jour. Sci. 267 729-804.

Helgeson. H. C. and Kirkham. [. H. (1974a) Thesretical prediction of the thermodynamic behavior of aqueous electrolytes at high pressures and temperatures. 1. Summary of the thermodynamic/electrostatic properties of the solvent. Am. Jour. Sici. 274 1089-1198.

Helgeson. H. C. and Kirkham. D. H. (1974b) Theoretical prediction of the thermodynamic behavior of aqueous electrolytes at high pressures and temperatures. II. Debye-Huckel parameters for activity coefficients and relative partial molal properties. All: Jour. Sici. 274 1199-1261

Helgeson. H. C. and Kirkham. D. H. (1976) Theoretical prediction of the thermodynamic behavior of aqueous electrolytes at high pressures and temperatures. III. Equation of state for aqueous species at infinite dilution. Am. Jour. Sici. 276 97-240.

Helgeson. H. C.. Kirkham. D. H. and Flowers, G. C. (1981) Theoretical prediction of the thermodynamic behavior of aqueous electrolytes at high pressures and temperatures. IV Calculation of activity coefficients. osmotic coefficients, and apparent molal and standard and relative partial molal properties to $600^{\circ} \mathrm{C}$ and $5 \mathrm{~kb} . \mathrm{Am}$. Jour. sici. 281 1249-1517.

Helgeson. H. C.. Delany. J. M.. Nesbitt. H. W. and Bird. D. K (1978) Summary and critique of the thermodynamic properties of rock-forming minerals. Am. Jour. Sici. 278a 1-229.

Janecky. D. R. (1982) Serpentinization of peridotite within the oceanic crust: Experimental and theoretical investigations of seawater-peridotite interaction at $200^{\circ} \mathrm{C}$ and $300^{\circ} \mathrm{C} .500$ bars. PhD. thesis. University of Minnesota. 244p.

Janecky. D. R. (1986) Peridotite-solution interaction within the oceanic crust: Theoretical investigations. EOS. Am. Geophys. Union 67392 
Janecky. D.R and Seyfried. W. E.. Jr. 11983) The solubility of magnesium hydroxide sulfate hydrate in seawater at elevated temperatures and pressures. Am. J. Sri. 283831860

Janecky, D R and Seyfried. W. E.. Jr. (1986) Hydrothermal serpentinization of peridotite within the oceanic crust Experimental investigations of mineralogy and major element chenustry Cinchim. (imomim. Arta $501357-1378$

Janecky. D R. Seyfried. W. E.. Jr and Berndt. M. E. (1986) Fe-O.S redox reactions and

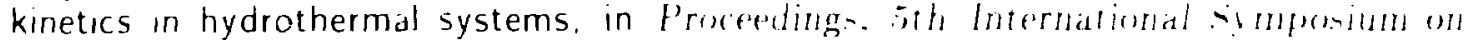
Ilater-kuck hitraction

Karaka. Y K and Barnes. I. B. (1973) SOLMNEQ: Solution-mineral equilibrium computa tions. NTIS. IS. Dept. of Commerce Pl, $215899.92 p$

Lietzke. M. W and Stroughton. R. W. (1975) The prediction of osmotic and activity coefficients for electrolyte mixtures at elevated temperatures. Oak Ridge Valional Labrator! R+p. $499916 p$

Millero. F. J. (1974) Seawater as a multicomponent electrolyte solution, in The sea 5. 3-80 (E.D. Goldberg. ed.) Wiley-Interscience. New York.

Murphy. W. M. (1985) Thermodynamic and kinetic constraints on reaction rates among minerals and aqueous solutions. PhD. thesis. University of California. Berkeley. 160p.

Nicolas. A and Poirier. J. P. (1976) Cristalline plasticity and solid state flow in mel anorphic rock. J. Wiley and Sons. 444p.

Prichard. H. M. (1979) A petrographic study of the process of serpentinization in ophiolites and the ocean crust. Contrib. Mineral. Percol. 68 231-241.

Seyfried. W. E.. Jr. and Dibble. W. E. Jr. (1980) Seawater-peridotite interaction. an Experimental study at $300^{\circ} \mathrm{C}$. 500 bars: Implications for the origin of oceanic serpentinites. Georhim. Comorhin. No 44 309-321.

Smith. G. M. Janecky. D R. Banerjee. S. K. and Seyfried. W. E.. Jr. (1982) Magnetic characteristics of experinental and natural serpentinites. EO.t. Trans. Am. Cieophis. Inini 63918

Wicks F J and Plant. A G. (1979) Electron-microprobe and x-ray-microbeam studies of serpentme textures. ('in. Minfial. $17785-830$.

Wolery, $T$ J (1978) Sone chemical aspects of hydrothermal processes at mid-oceanic ridges ... a theoretical study 1 - Basalt-seawater reaction and chemical cycling between the ocearuc crust and the oceans 11 . - Calculation of chemical equilibrium between aqueous solutions and minerals. Unpublished PhD. thesis. Northwestern University.

Wolery. T J (1979) Calculation of chemical equilibrium between aqueous solution and minerals the EQ3/6 software package. Lawrence Livermore National Laboratory UCRL52658

Wolery. T. J. (1983) EQ3NR: A computer program for: ichemical aqueous speciationsolubility calculations: User's guide and documentation. Lawrence Livermore National Laboratory UCRL-53414. 


\author{
R.C. Arthur \\ Rockwell Hanford Operations \\ Richland, WA 99352 USA
}

\title{
Abstracl
}

Theoretical simulations of hydrothermal reactions of Columbia River Basalts and groundwater, using EQ3/6, show significant differences in the predicted concentrations of aqueous components and in predicted alteration mineralogy depending on small compositional differences in the solid reactants used in the models. This sensitivity is not a simple function of the differences in composition of the reactants. Mass balance considerations show that the variations are due to both the differences in the reactant compositions and the similarity of the predicted amounts of the components precipitated in alteration minerals. When applied to reaction-path models, sensitivity analyses must be bounded by the uncertainties in measured parameters as well as by the uncertainties in the conceptual models of the system.

\section{Introduction}

The Basalt Waste Isolation Project (BWIP) is investigating the feasibility of constructing a high-level nuclear waste repository in the Columbia River Basalts of southeastern Washington. Characterizing the expected near-field geochemical environment in the repository is necessary in order to assess the performance of natural and engineered barriers in limiting the release of radionuclides to the accessible environment for periods up to 10,000 years. The BWIP is developing a conceptual model of the expected repository environment by integrating the results from hydrothermal experiments and studies of selected characteristics of natural analogs (e.g., geothermal systems in lcelandic basalts (Ulmer and Grandstaft, 1984)), and through theoretical simulations of basaltwater interactions. Preliminary modeling studies have been conducted to simulate reactions involving basalts from either the Cohassett or Umtanum flows of the Grande Ronde formation and synthetic groundwater at $300^{\circ} \mathrm{C}$.

When dealing with the dissolution of Cohassett or Umtanum basalts there are three reasons to consider the dependence of predicted reaction paths on the composition of the dissolving phase. First, the phases in Umtanum and Cohassett basalts apparently react at different rates. The dominant reactive phase in autoclave experiments appears to be the glassy intersertal mesostasis of the basalts (Allen et al., 1986; Moore et al., 1985). The mesostasis developed from late stage residual fluids evolved from a parent basaltic magma (Long et al., 1984). Consequently, while bulk rock compositions are typical of continental flood basalts, the composition of the mesostasis is more dacitic to rhyolitic (Allen and Strope, 1983). Reaction path models should therefore use the composition of the evolved mesostasis and not a composition based on bulk rock analyses to represent the dominant solid reactant.

The preferential reactivity of the mesostasis leads to a second concern in selecting an accurate composition ior the reactive phase in the simulations. That concern is due to the highly variable composition of the mesostasis in Cohassett and Umtanum rocks (Allen and Strope, 1983; Allen et al., 1985). The mesostasis consists of nearly equal amounts of glass and microcrystallites predominantly of plagioclase, pyroxene and titaniferous magnetite (Allen and Stiope, 1983). Microprobe analyses of the mesostasis may therefore represent a composite of the giass and microcrystalline phase compositions. While this may account for some of the variability in composiions, Allen and Strope (1983) have shown

- Present address: Battelle, Pacific Northwest Laboratories, PO Box 999, Richland WA., 99352 
that the glass composition itself is also variable on a very small scale (microns), and that there may be more than a single type of glass present.

Finally, differences in mesostasis compositions will to some extent lead to differences in predicted reaction paths. Because the thermodynamic stabilities of mairy of the alteration minerals produced by basalt/water reactions are similar (Arnorsson et al., 1983), the predicted occurrence of one mineral rather than anoth,, may depend on small variations in the relative abundances of cationic constituents released to sclution as the mesostasis dissolves.

The question addressed in the present study therefore is whether or not the observed variability in the composition of the mesostasis in Cohassett and Umtanum basalts can lead to significant differences in predicted reaction paths.

\section{Model Parameters}

The sensitivity of predicted reaction paths on the variability in mesostasis compositions was determined by conducting a set of simulations of rock/water hydrothermal reactions which differed only by the composition chosen for the mesostasis. The five analyses of the mesostasis from Cohassett and Umtanum basalts considered are shown in Table 1 . The data in the table are normalized arbitrarily to 20 moles oxygen/mo!s mesostasis. Samples are from the entablature unit of the Umtanum flow (RLE-1 and RUE-2), the entablature unit of the Cohassett flow (RCE-1), and the colonnade units of the Umtanum and Cohassett flows (RUC-1 and RCC-1, respectively).

Table 1. Mesostasis compositions (moles/mole mesostasis).

\begin{tabular}{|c|c|c|c|c|c|}
\hline & RUE-1 ${ }^{1}$ & RUE-2 2 & $R C E-1^{3}$ & RUC $-1^{3}$ & $\mathrm{ACC}-1^{3}$ \\
\hline $\mathrm{Si}$ & 7.34 & 7.17 & 7.53 & 8.14 & 8.26 \\
\hline $\mathrm{Ti}$ & 0.14 & 0.13 & 0.09 & 0.06 & 0.06 \\
\hline $\mathrm{Al}$ & 1.89 & 1.72 & 1.91 & 1.66 & 1.64 \\
\hline $\mathrm{Fe}$ & 0.76 & 1.03 & 0.52 & 0.14 & 0.18 \\
\hline $\mathrm{Mg}$ & 0.09 & 0.10 & 0.09 & - & \\
\hline $\mathrm{Ca}$ & 0.46 & 0.49 & 0.38 & 0.06 & 0.08 \\
\hline $\mathrm{Na}$ & 1.05 & 1.62 & 0.94 & 0.88 & 0.60 \\
\hline$K$ & 0.39 & 0.40 & 0.50 & 0.94 & 0.84 \\
\hline$P$ & 0.07 & 0.06 & 0.06 & 0.02 & - \\
\hline$M n$ & --- & 0.02 & 0.04 & - & - \\
\hline
\end{tabular}

1 -- Based on analysis reported in Allen and Strope (1983)

2 -- Based on analysis reported in Noonan et al. (1981)

3 -- Based on analysis reported in Allen et ai. (1985)

Other than the differences in mesostasis compositions, all run r,arameters were the same in the simulations. Each run modeled the irreversible, incongruent dissolution of 100 grams of mesostasis in 1 $\mathrm{kg}$ of solution at $300^{\circ} \mathrm{C}$. The only restriction placed on reaction products wa: hat all silica polymorphs other than cristobalite were not allowed to precipitate. This restriction place; - r: in maximum aqueous silica concentrations in the simulations.

The initial solution composition used in all of the simulations was taken as the starting solution composition in one experiment in which Umtanum entablature was reacted at $300^{\circ} \mathrm{C}$ and $30 \mathrm{MPa}$ (run BR-8 in Moore et al., 1985). The initial radox state of the solution was set in the simulations by assigning an oxygen fugacity of 0.21 bars (air saturation). 
The simulations were carried out using the 3230 version of EQ3/6 (Wolery 1983:1984). In each case the initial solution was charge balanced at $25^{\circ} \mathrm{C}$ (by adjusting the concentration of $\mathrm{Na}^{+}$) using EQ3. Then the solution was charge balanced at $300^{\circ} \mathrm{C}$ by adjusting $\mathrm{H}^{+}$concentrations in order to fix the high-temperature $\mathrm{pH}$. This solution was used as the initial solution in the reaction-path runs. Before the first increment of mesostasis dissolution, EQ6 equilibrated the aqueous phase by precipitating small amounts of minerals with which the initial solution was supersaturated at $300^{\circ} \mathrm{C}$. This procedure ensured that the mesostasis reacted with an identical high-temperature aqueous phase in each simulation. The following assumptions were employed in all of the simulations: 1) equilibrium among the aqueous solution and alteration minerals is maintained in the closed system during the irreversible dissolution of the mesostasis, 2) no solid-solution minerals precipitate, and 3) release of components from the mesostasis takes place stcichiometrically.

\section{Besults of the Simulations}

The simulated solution compositions are shown in Figure 1, where it can be seen that significant variations occur in the concentrations of $\mathrm{Na}, \mathrm{K}, \mathrm{Ca}$, and $\mathrm{Al}$, and in $\mathrm{pH}$ and redox conditions $\left(\log \mathrm{fO}_{2}\right)$. Very little variation in $\mathrm{Si}$ concentrations exists, largely because its concentration becomes fixed in all of the simulations by cristobalite solubility.

Tne trends exhibited in Figure 1 for $\mathrm{Na}, \mathrm{K}, \mathrm{Al}, \mathrm{Ca}$ and $\mathrm{pH}$ fall into two distinct groups. One group (RUE-2 and RUC-1) is characterized by increasing $\mathrm{pH}, \mathrm{Na}$ and $\mathrm{K}$, and decreasing $\mathrm{Al}$ and $\mathrm{Ca}$. The second group (RUE-1, RCE-1 and RCC-1) shows generally opposite trends: $\mathrm{pH}$ and $\mathrm{Na}$ decrease continuously, $\mathrm{K}$ decreases after an initial rise (coincident with group 1 samples), and $\mathrm{Ca}$ and $\mathrm{Al}$ generally increase following initial declines (common to all of the samples).

The differences in the trends between these groups are not simply related to differences in the composition of the mesostasis. For example, although sample RUE-2 is the most Na rich mesostasis in the simulations, the other group 1 sample, RUC-1, is one of the most Na deficient. Similarly, RUC-1 is the rinost $K$ rich member of the set but RUE-2 is nearly the most $K$ deficient. It appears therefore that the groups cannot generally be interpreted a priori based on the relative enrichment of the components in the mesostasis. An important exception, however, is that the steep drop in $\mathrm{Log} \mathrm{IO}_{2}$ can be correlated reasonably well with the concentrations of ferrous iron in the mesostasis.

The two general trends in the aqueous component concentrations also cannot be simply related to differences in alteration mineralogy. For example, Figure 2 shows the abundance of alteration minerais for a range of reacticn progress coincident with the onset of differences in aqueous concentrations for RUE-1 (group 1) and RUE-2 (group 2). The alteration minerals and their abundances are very similar in the two simulations. Important differences are present, however, including the disappearance of epidote in HUE-2 and its persistence in RUE-1, and the substitution of Ca-saponite for $\mathrm{Na}$-saponite in RUE-1. Although these differences may affect the aqueous concentrations of $\mathrm{Ca}$, similar controls on other components are not t'vident. For example, $\mathrm{Na}$ control by alteration mineralogy is not obvious because for both runs nearly the same amounts of identical Na-bearing minerals precipitate. The behavior of the only K-bearing mineral in Figure 2, phlogopite, is also very similar in both runs.

Tilese results indicate that: 1) predicted reaction paths can be very sensitive to the measured, relatively narrow, range of mesostasis compositions used in the models, and 2) the sensitivity cannot be interpreted simply on the basis of the differences in the compositions of the mesostases. To account for these results an evaluation of the causes of sensitivity in reaction path models is necessary and this is considered in the next section. 


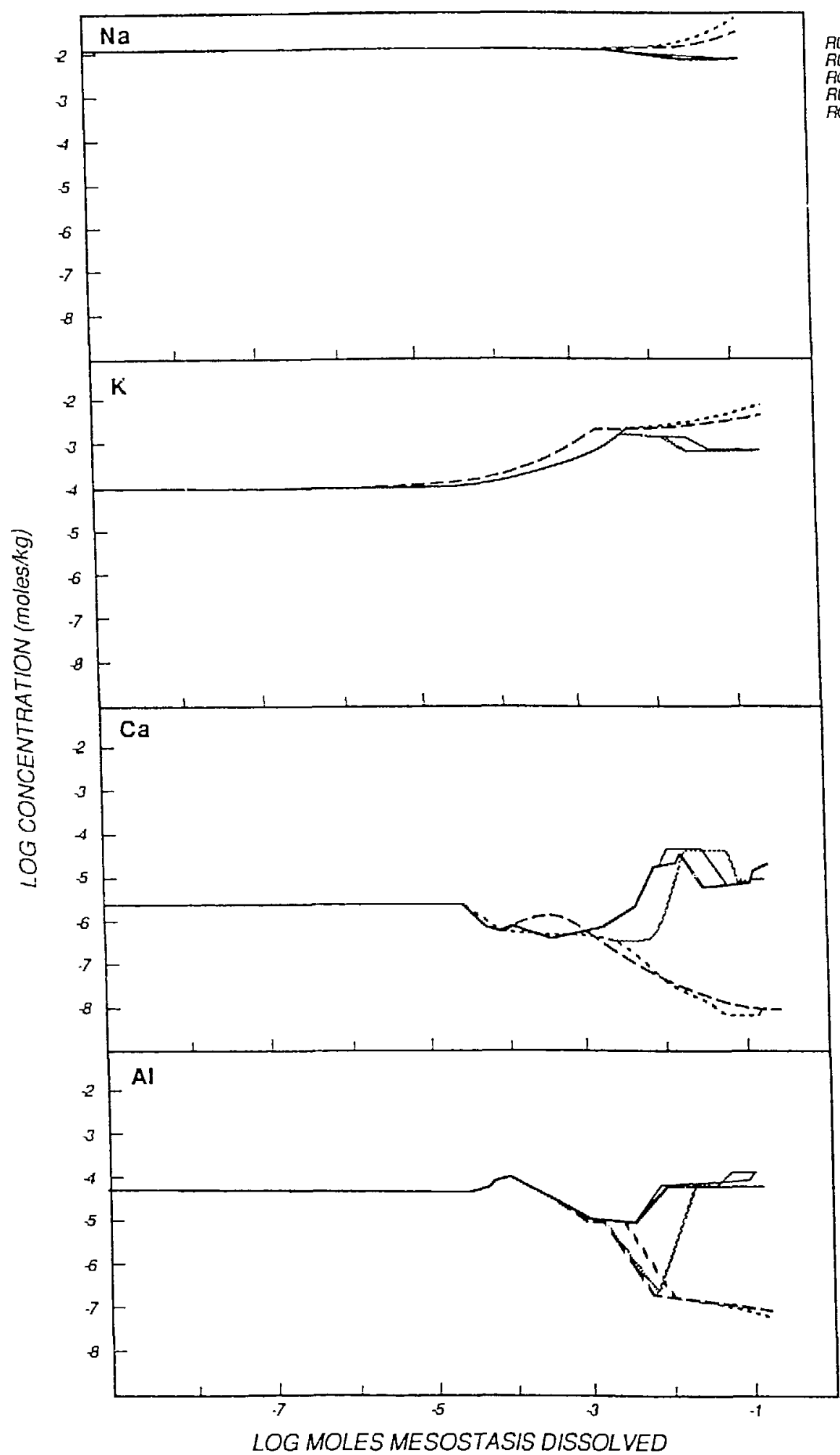

RUE 1 RUE 2 ........

PCE 1

RUC 1 :- -

RCC. 1 


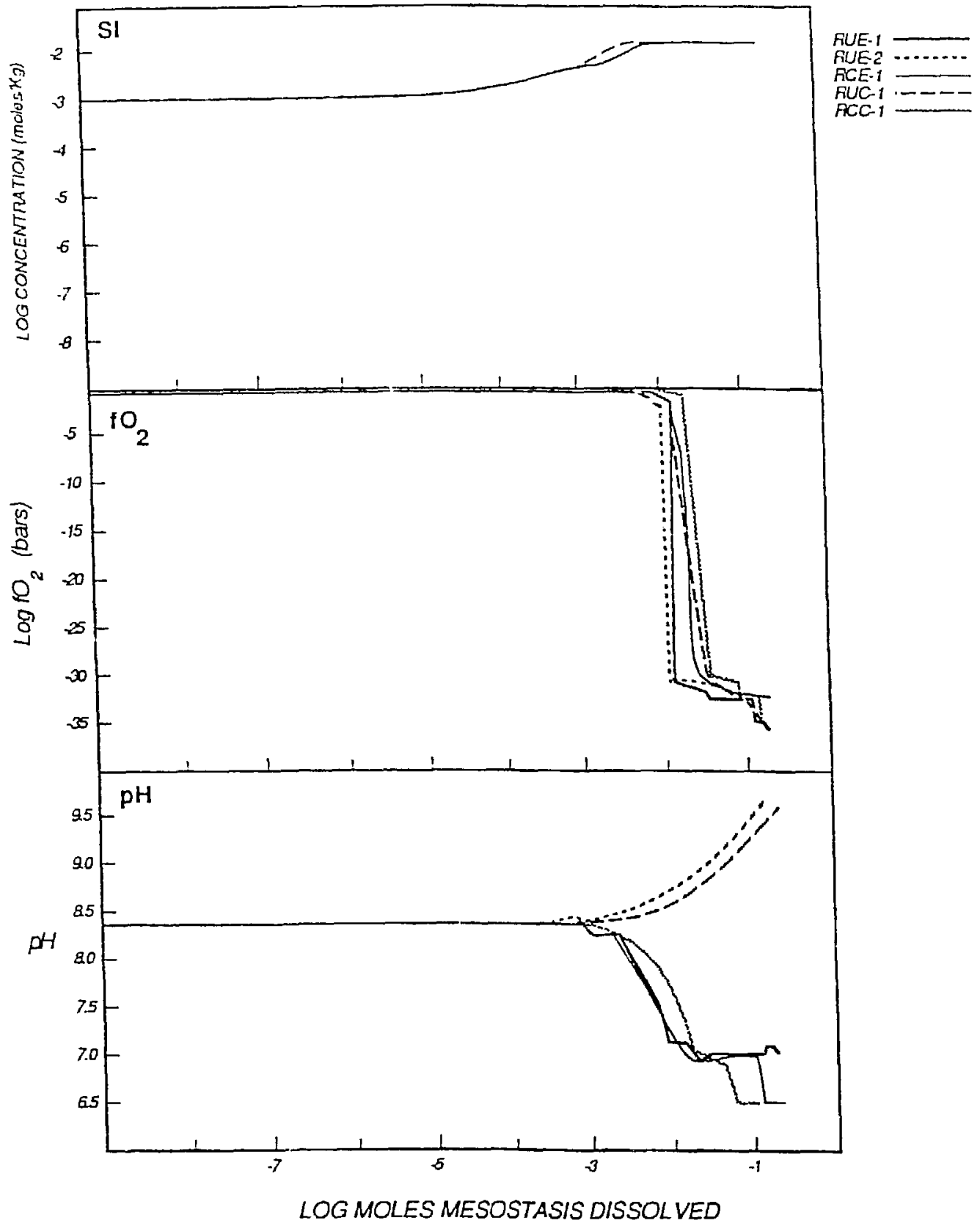

Figure 1. Aqueous Component Reaction Paths (Continued)

\section{Sensitivity in Reaction Path Models}

Reaction paths in closed systems are constrained in part by a mass balance for each component, $i$, of the system (Heigeson, 1968), where, in the current model, i may exist in the mesostasis, alteration minerals and aqueous solution. Thereiore, at any stage of reaction progress:

$$
v_{i, \text { meso }} m_{\text {meso }}+\Sigma v_{i, j} m_{j}+\Sigma v_{i, k} m_{k}=m_{i, t o t}
$$



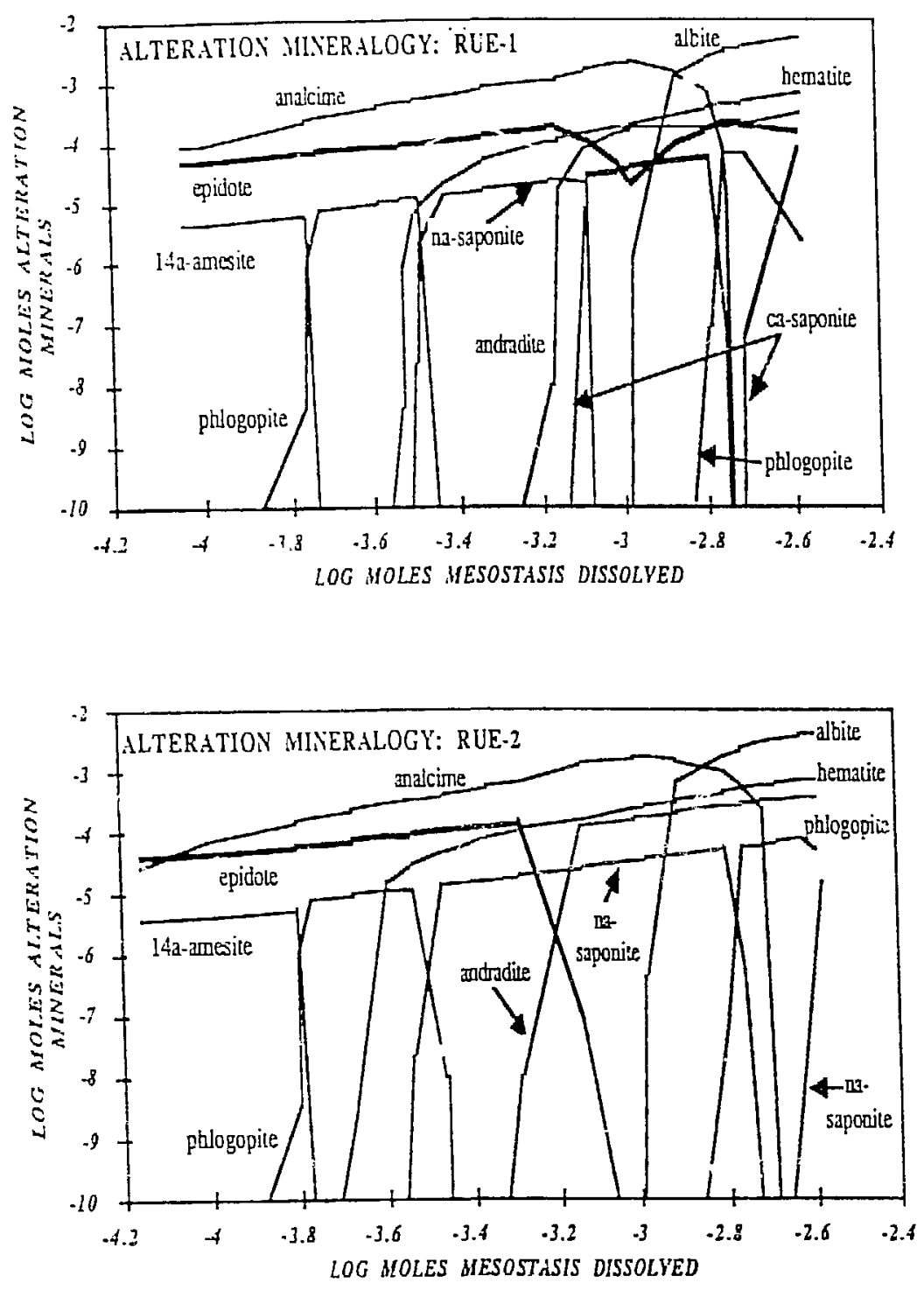

Figure 2. Comparison of predicted alteration mineralogy between runs RUE-1 and RUE-2.

where $v_{i, m e s o}, v_{i, j}$, and $v_{i, k}$ are the number of moles of the monatomic component, $i$, in one mole of mesostasis (meso), the jth alteration mineral and the kth aqueous species. The parameter $m$ is the number of moles of the subscripted solid or aqueous entity (in the system with $1 \mathrm{~kg}$ of water), and the sums in equation (1) are for all $j$ minerals or $k$ aqueous species. The total number of moles of $i$ in the system, $m_{i, t o t}$, is independent of reaction progress.

For an increment of mesostasis dissolution, $d m_{\text {meso }}$, equation (1) becomes

$$
-v_{i, \text { meso }}+\Sigma v_{i, j} d m_{j} j d m_{\text {meso }}+\Sigma v_{i, k} d m_{k} / d m_{\text {meso }}=0
$$

where the derivatives are negative for dissolution of a solid, or for decreasing aqueous species 
concentrations. The terms in equation (2) can be related to the results of the simulations discussed earlier. The coefficients in Table 1 are equal to $v_{i}$, meso for each of the components in the table. The term, $\Sigma v_{i, k} d m_{k} / d_{m e s o}$ is reflected in Figure 1 for the componenis $\mathrm{Na}, \mathrm{K}, \mathrm{Ca}, \mathrm{Al}$ and $\mathrm{O}_{2}$. The term, $\Sigma_{v_{i, j}} \mathrm{dm}_{\mathrm{j}^{\prime}} \mathrm{dm} \mathrm{m}_{\text {meso }}$ for $\mathrm{i}$-bearing minerals can be obtained from data such as shown in Figure 2

The sensitivity of the predicted reaction paths on mesostasis compositions can be interpreted in terms of the component mass balance equation. Equation (2) indicates that the divergence of slopes for any two reaction paths in Figure 1 (as determined from the third term in the equation) can result only if the net rate of i precipitated in alteration minerals in two reaciion paths (the second term in equation (2)) is similar and is bracketed by the values of $v_{i}$ meso used in the runs. This means that divergence sensitivity depends not only on the differences in composition of the mesostasis chosen for the runs but also on the similarity of the predicted reaction paths, insofar as the paths predict similar amounts of the component precipitated in alteration minerals. Divergence will not result, despite a significant difference in reactant compositions, if the resulting reaction paths are also sufficiently dissimilar.

To illustrate these relationships, consider the Na data for runs RUE-1, RUE-2 and RUC-1. The Na content of RUE-2 mesostasis is greater than in RUE-1 and this leads to the divergence in $\mathrm{Na}$ concentrations shown in Figure 1, because the amount of Na precipitated in secondary minerals is very similar (see Figure 2). On the other hand the $\mathrm{Na}$ content of RUC-1 is even less than RUE-1, yet its $\mathrm{Na}$ path virtually parallels that of RUE-2. This is because the reaction path for RUC-1 involves the precipitation of more phlogopite and (later) K-feldspar because of the high K content of RUC-1 mesostasis. Frecipitation of K-bearing minerals decreases the amount of other components, like $\mathrm{Al}$, available for the precipitation of Na-bearing phases such as albite. As a result, the amount of $\mathrm{Na}$ precipitated in alteration minerals is less than the amo'.nt of $\mathrm{Na}$ dissolved from the mesostasis which leads to an increasing aqueous $\mathrm{Na}$ concentration in the fluid. This key dissimilarity in the predicted reaction paths compensates for the differences in reactant compositions between samples RLE-2 and RUC-1 so that the trends in aquenus Na concentrations evolve very similarly.

The sensitivity of the aqueous component data in Figure 1 can thus be interpreted relative to the first two terms in the mass balance equation. These iwo terms differ in one very important respect. The first term in equation (2) is independent of any assumptions used to define the conceptual model of the system (i.e., it is derived from measurement). The derivative in the second term of the equation, however, can be very dependent on the assumed conditions in the model. This is because the precipitation of alteration minerals is governed fundamentally by mass-action relationships, and assumptions (e.g., equilibrium, solid-solution formation, quality of the thermodynamic data) must usually be made before these relationships can be employed in mass-transfer models. In the present study, these assumptions have been specified in the section describing model parameters. Because of the implicit dependence of the second term in the mass balance equation on model assumptions, the sensitivity analysis in this study is only directly applicable to the adopted conceptual model.

\section{Conclusions}

Sensitivity analyses can be applied to reaction-path models of water/rock reactions, and component mass balance equations provide a useful basis for interpreting the causes of the sensitivity. The present study has shown that significant differences in reaction paths can arise from small differences in the composition of the starting solid reactants. A complete analysis of sensitivity, however, must be bounded by both the uncertainty in reactant compositions as well as by the assumptions (i.e., the uncertainties) in the conceptual models of the system. 
S.A. Rawson provided the entablature data in Table 1 and provided many useful discussions of mesostasis compositions, mineralogy and textures.

\section{Relerences}

Allen, C.C. and Strope, M.B. (1983) Microcharacterization of basalt-- Considerations for a nuclear waste repository. Microbeam Analysis - 1983, 51-54, San Francisco Press, San Francisco.

Allen, C.C., Kasper, R.B., Lane, D.L., Johnston, R.G., and Rawson, S.A. (1986) Experimental approaches to determining the extent of equilibrium in a basaltic hydrothermal system. in Burkholder, H.C. (ed.), High-Level Nuclear Waste Dispesal. 371-380, Battelle Press, Richland. WA.

Allen, C.C., Johnston, R.G., and Strope, M.B. (1985) Characterization of reference umtanum and cohassett basalt. SD-BWI-DP-053, Rockwell Hantord Operations, Richland, WA, 47p.

Arnorsson, S., Gunnlaugsson, E., and Svavarsson, H. (1983) The chemistry of geothermal waters in Iceland. II. Mineral equilibria and independent variables controlling water compositions. Geochim. et Cosmochim. Acta. 47, 547-566.

Helgeson, H.C. (1968) Evaluation of ireversible reactions in geochemical processes involving minerals and aqueous solutions -1 . Thermodynamic relations. Geochim. et Cosmochim. Acta. 32 , 853-877.

Long, P.E., Landon, R.D., Cross, R.W., Fairchild, K.R., and Chamness, M.A. (1984) Geology of candidate repository horizons. in Long, P.E., (ed.), Repository Horizon Identification Report, SD-BWI-TY-001 DRAFT, vol. 1, Rockwell Hanford Operations, Richland, WA.

Moore, E.L., Ulmer, G.C., and Grandstaff, D.E. (1985) Hydrothermal interactions of Columbia Plateau basalt from the umtanum flow (Washington, U.S.A.) with its coexisting groundwater. Chem. Geol. $49,53-71$.

Noonan, A.F., Fredriksson, K. and Nelen, K. (1981) Phase chemistry of the umtanum basalt, a reference repository host in the columbia plateau. in Moore, J.G., (ed.), Scientific Basis to Nuclear Waste Management, 3, 51-58, Plenum Press, N.Y.

Ulimer, G.C. and Grandstaff, D.E. (1984) lce!andic basaltic geothermal field: A natural analog for nuclear waste isolation in basalt. SD-BWI-TI-257. Rockwell Hanford Operations, Richland, Wa, 41p.

Wolery, T.J. (1983) EQ3NR, a computer program for geochemical aqueous speciation-solubility calculations, user's guide and documentation. Lawrence Livermore Laboratory (UCRL-53414). $191 \mathrm{p}$.

Wolery, T.J. (1984). EQ6, a computer program for reaction-path modelling of aqueous geochemical systems, user's guide and documentation. Lawrence Livermore Laboratory (in press). 
Sedimentary and Low Temperature Environments 


\author{
John H. Weare. Nancy Moller. \\ Jerry Greenberg, and Andrew Felmy \\ Department of Chemistry B-014 UCSD \\ La Jolla, CA 92093 USA
}

Recently there has been considerable interest in predicting the long-range geochemical behavior of nuclear waste repository sites via thermodynamic modeling. The success of such an approach relies on the availability of highly accurate and general chemical models. While aqueous solution models of the required generality are available, their accuracy for the most part has not been tested against laboratory data. The limited testing that has been done (e.g.. Kerrisk (1981): Harvie and Weare (HW) (1980)) has shown that chemical model calculations may differ significaritly from experimental values, particularly above dilute concentration $(1>.1 \mathrm{~m})$. This testing underscored the necessity of carefully validating geochemical models for application to complex natural settings.

The recent work of Harvie, Moller, and Weare (HMW) (1984) has shown that it is pussible to develop geochemical models which are highly reliable from dilute to high concentration if sufficient attention is paid to phenomenology, parameterization and model validation. The HMW solubility modeling approach is based on the aqueous electrolyte equations of Pitzer (1973). HMW showed that models of highly complex systems $\left(\mathrm{Na}-\mathrm{K}-\mathrm{H}-\mathrm{Mg}-\mathrm{Ca}-\mathrm{Cl}-\mathrm{OH}-\mathrm{HSO}_{4}-\mathrm{SO}_{4}-\mathrm{HCO}_{3}-\mathrm{CO}_{3}-\mathrm{H}_{2} \mathrm{O}-\mathrm{CO}_{2}(\mathrm{~g})\right.$ ) can be parameterized entirely from data in relatively simple binary and ternary systems. In the HMW approach, the accuracy of the final model parameterization is routinely tested by extensive comparison to laboratory solubility data in these and more complicated systems. The agreement with the latter represents the reliability of model predictions since these data were not used in the model parameterization. Validation of model predictive capabilities also includes comparison to field data. These $25^{\circ} \mathrm{C}$ solubility models have been successfully applied to a variety of natural settings (e.g., Harvie, Weare, Hardie and Eugster (1980), Brantley, Crerar, Mọler, and Weare (1984)).

The applicability of the solubility models of Weare and coworkers will be significantly broadened by including variable temperature. Recently, Moller (in preparation) has constructed a variable temperature model which accurately calculates solubilities in the $\mathrm{Na}-\mathrm{Ca}-\mathrm{Cl}-\mathrm{SO}_{4}-\mathrm{H}_{2} \mathrm{O}$ system from $25^{\circ} \mathrm{C}$ to $250 \mathrm{C}$ and from zero to high concentration $(1-18 . \mathrm{m})$. Fig. (1) compares this model's calculated (solid line) anhydrite solubilities in aqueous $\mathrm{NaCl}$ solutions with the experimental data at $200 \mathrm{C}$. Also included in this figure are the solubilities predicted by EQ3/6. Results for other solutions (e.g., $\mathrm{CaSO}_{4}-\mathrm{Na}_{2} \mathrm{SO}_{4}-\mathrm{H}_{2} \mathrm{O}$ ) and for other temperatures are 
similar. The EQ3 6 results (shown by the dashed ine on the figure) were calculated using the B-dot equation of Helgeson (1969) and the EQ3NR code of Wolery (1983). New versions of EQ3 6 will include an option to use the $25 \mathrm{C}$ HMW model (Wolery. personal communication!. While the number of parameters in the HMW and variable temperature models is large, it is roughly the same number as used in the less accurate chemical models based on in parning (HW (1980)! The solubility modeis of Weare and coworkers include ion pair species explicitly in the specific interaction formalism of Pitzer only when there is clear evidence of association (e.g. $\mathrm{H}+\mathrm{SO}_{4}=\mathrm{HSO}_{4}$ ). When ion pairs are included, it is generally necessary to accurately account for changes in the activity of the associated species in order to obtain reliabie predictions at high concentration.

The $25 \mathrm{C} \mathrm{HMW}$ model and the variable temperature model include species for which sufficient data are avalable for detailed parameterization. When little data exist for a system, parameterization of any geochemical model must rely on approximations based on chemically similar systems. Extensively validated models of wellcharacterized systems for which an adequate database is available are important for such approximations. The success of such an approach using the Pitzer formalism is illustrated by the models of the $\mathrm{BaSO}_{4}-\mathrm{NaCl}-\mathrm{H}_{2} \mathrm{O}$ system at $25 \cdot \mathrm{C}$ (Rogers (1981)) and at $100 \mathrm{C}$ to $250 \mathrm{C}$ (Moller, in preparation) using parameters based on the $\mathrm{CaSO}_{4}$ system.

The HMW model has now been extended to treat the chemically very complicated borate system (Felmy and Weare (FW), to be published Geochim. Cosmochim. Acta.). This system involves complex borate polymerization reactions as well as acid-base reactions. Solubility predictions of this model (solid lines) are compared to laboratory solubility data in Fig. (2).

The borate model was developed to study borate deposition in natural environments. Borate minerals are very soluble and therefore are products of highly evaporated waters. An important example of borate ceposits occurs in Searles Lake (southeastern California). The economic importance of the formation waters from this system has led to their being frequently sampled. A field validation of the FW model is shown in Table (1) which gives the normalized saturation indices for the minerals known to be in the formation. The normalized S.I. in FW is equal to the logarithm of the saturation ratios $(\mathrm{SR}=\Pi$ activity (ion) $/ \mathrm{Ksp}$ (mineral)) divided by the number of ions in each solid. In every case, the calculated S.I. values are within .03 pK units of the equilibrium value of 0 . A more extensive discussion of these results is given in FW. This comparison to a complex natural setting serves as a stringent test of the accuracy of the model. It also shows that, within the accuracy of the model, the formation water is in equilibrium with the mineral formation.

The borate model was also used to simulate the formation of the Searles Lake mineral deposit. In this simulation, the initial composition of the water was taken to be that of Owens River, which is the principal source of the Searles Lake water. Owens River water was evaporated to dryness at $25 \mathrm{C}$ using the equilibrium algorithm of Harvie. Greenberg and Weare (to be published, Geochim. Cosmochim. Acta.). The results of this simulation are discussed in detail in FW. In order to correctly predict 
Table 1: Normalized mineral saturation indices for interstital brines th the Searies Lake upper salt " calculated by the model of Felmy and Weare.

\begin{tabular}{c|c} 
M.neral & S.1. \\
Aphthitalite & $-.0210^{\circ}$ \\
Borax & .0145 \\
Burkeite & .0104 \\
Halite & .0115 \\
Thenardite & .0015 \\
Trona & .0077
\end{tabular}

the observed mineral formation, two important restrictions had to be placed on the evaporation pathway. First, in order to allow the formation of trona, a mineral which comprised $37^{\circ}$, of the volume of the formation, backreactions forming pirssonite Detween the upper salt and the calcium carbonate-rich parting mud had to be prevented. Second, in order to keep the magnesium in the brine high enough to eventually precipitate northupite, a mineral which is present in the upper salt, dolomite precipitation had to he prevented in the early stages of evaporation.

Our applications of well-defined chemical models to field settings have several important implications for applying models to natural systems in general. First, we have shown that detailed models of systems with very complex chemistry can be developed which are accurate to high concentration. Second, the Searles Lake application showed that the model not only could correctly predict the geochemistry of a complex natural system but also that the mineral formation is in equilibrium with the formation water. Third, (and perhaps the most important for assessing the feasibility of using models to reliably predict geochemical processes on a long-time scale) certain geochemical controls (e.g. late dolomitization and limited communication between units in the formation) were necessary to bring the model into good agreement with the chemistry of the real setting These controls affected only the interpretation of field processes and in no way affected the parameterization or validation of the model. in the application to the Searles Lake borate deposit, these controls led to important information about possible geochemical processes involved in the formation of evapcrative mineral deposits in lake beds. Prior to modeling the system, there was no a priori way to make these assumptions. This result has important implications when the application of less well-defined models to poorly defined settings is considered. In such situations, it may not be possible to separate effects due to model inaccuracies from the various unknown geochemical controls operating in the natural setting.

a. Data taken from Smith: 1970 ;

b. Uses Gale's water rteasurements 'See Felmy-Weare) Using Smith's water measure-

ments a higher SI. is obtaned. 
Figure 1

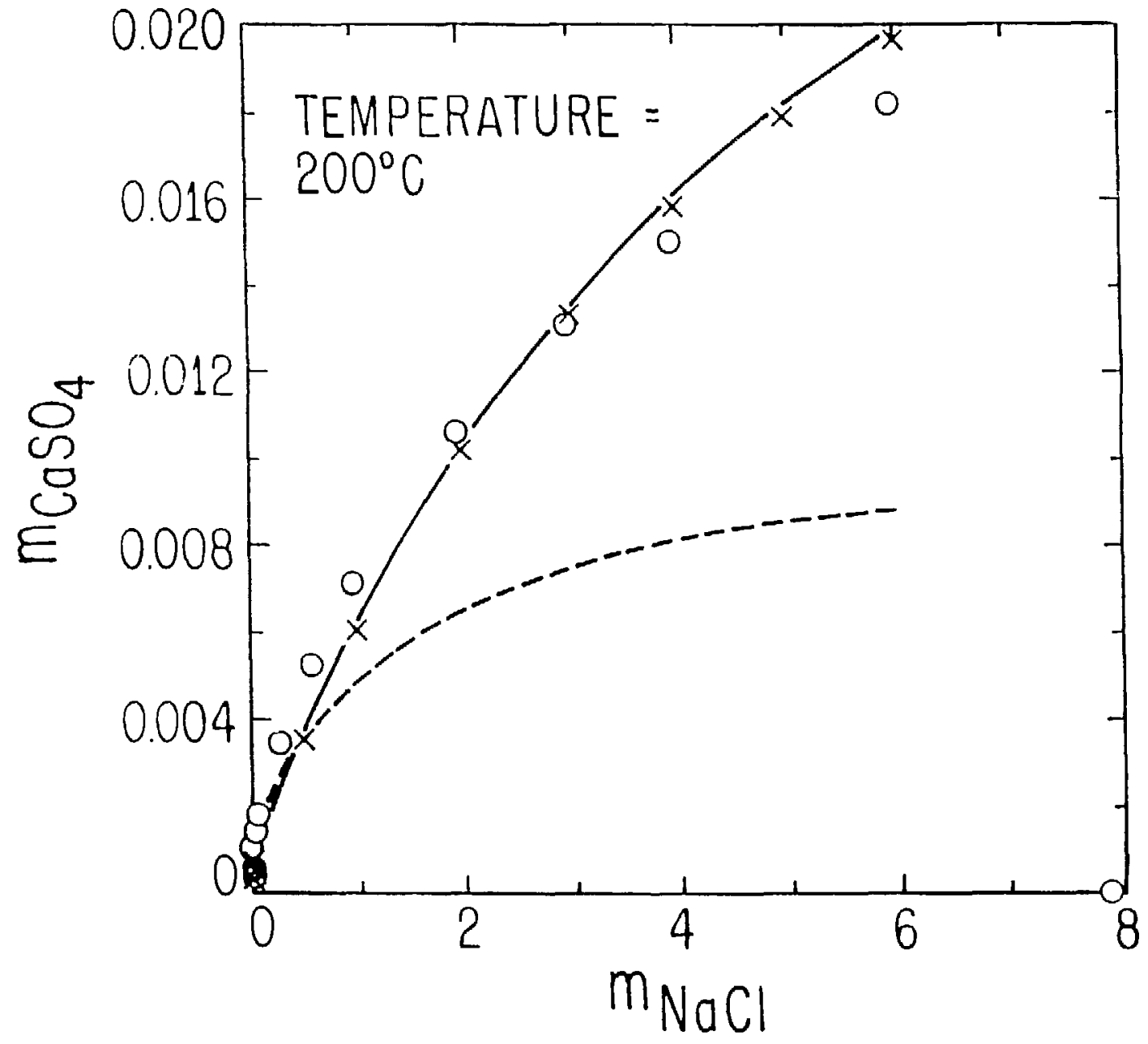

A comparison of anhydrite solubility in aqueous $\mathrm{NaCl}$ solutions at $200^{\circ} \mathrm{C}$ calculated by the variable temperature $\mathrm{Na}-\mathrm{Ca}-\mathrm{Cl}-\mathrm{SO}_{4}-\mathrm{H}_{2} \mathrm{O}$ model (solid line) of Moller (in preparation) with the experimental data of Blount and Dickson (1969) and Marshall, Slusher, and Jones (1964). Solubilities predicted by EQ3/6 (see text) are given by the dashed line. 
Figure 2

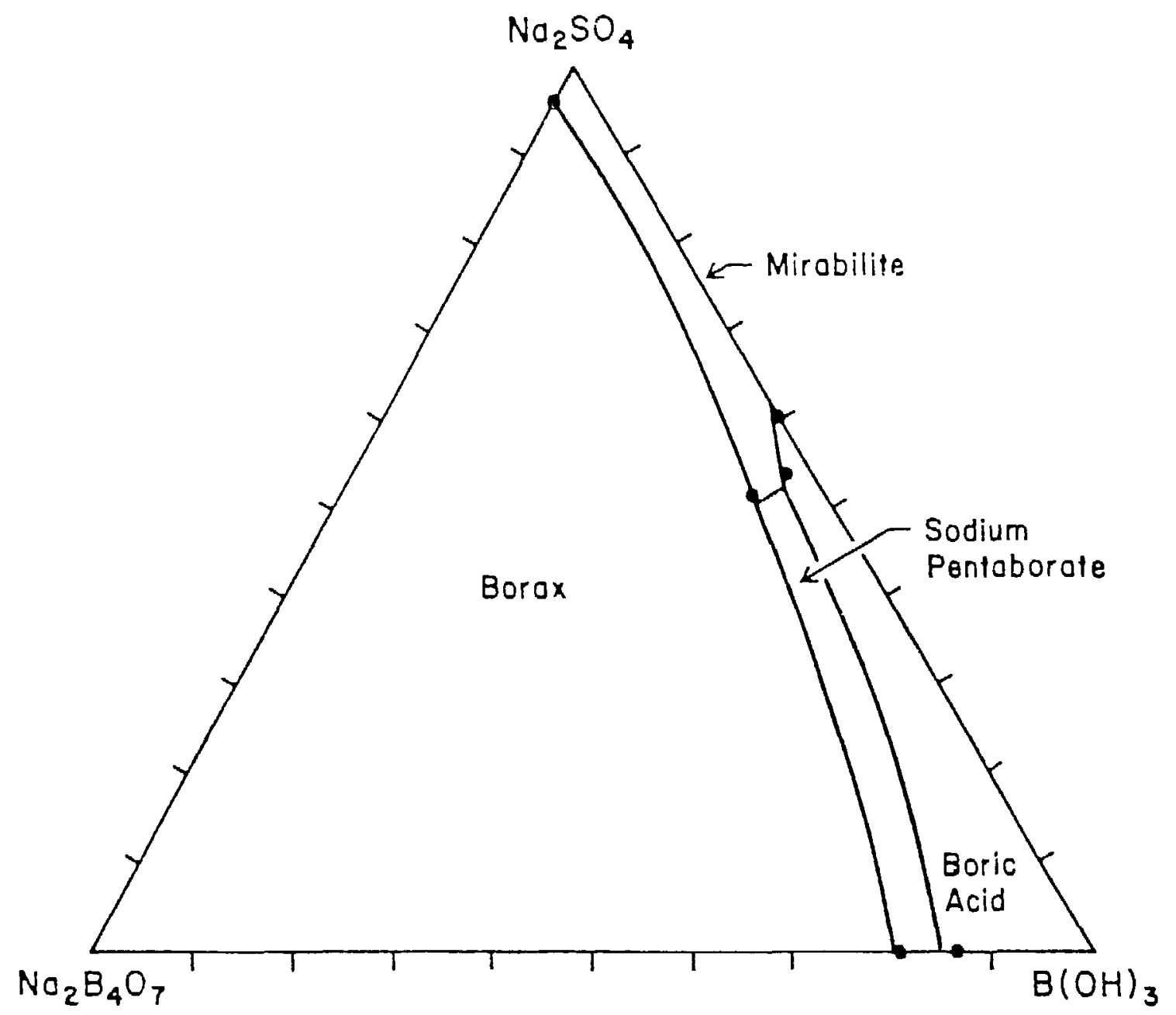

Janecke projection for the system $\mathrm{Na}_{2} \mathrm{~B}_{4} \mathrm{O}_{7}-\mathrm{B}(\mathrm{OH})_{3}-\mathrm{Na}_{2} \mathrm{SO}_{4}$ at $23.5^{\circ} \mathrm{C}$ calculated (solid lines) by the model of Felmy and Weare (to be published, Geochim. Cosmochim. Acta.). The closed circles represent the experimental data of Teeple (1929). 
ACKNOWLEDGEMENTS:

This work has been supported by funds from the Department of Energy: DOE DEAC-85SF-15522 and the National Science Foundation: NSF OCE 85-07902.

\section{REFERENCES}

BLOUNT C.W. and DICKSON F.W. (1969) The solubility of anhydrite $\left(\mathrm{CaSO}_{4}\right)$ in $\mathrm{NaCl}-\mathrm{H}_{2} \mathrm{O}$ from 100 to $450 \mathrm{C}$ and 1 to 1000 bars. Geochim. Cosmochim. Acta 33. 227-245.

BRANTLEY S.L., CRERAR D.A., MФLLER N.E. and WEARE J.H. (1984) Geochemistry of a modern marine evaporite: Bocana de Virrila, Peru. Jour. Sed. Petrol. 54. $447-462$.

HARVIE C.E., MDLLER N. and WEARE J.H. (1984) The prediction of mineral solubilities in natural waters: The $\mathrm{Na}-\mathrm{K}-\mathrm{Mg}-\mathrm{Ca}-\mathrm{H}-\mathrm{Cl}-\mathrm{SO}_{4}-\mathrm{OH}-\mathrm{HCO}_{3}-\mathrm{CO}_{3}-\mathrm{CO}_{2}-\mathrm{H}_{2} \mathrm{O}$ system to high ionic strengtins at $25^{\circ} \mathrm{C}$. Geochim. Cosmochim. Acta 48, 723-751.

HARVIE C.E. and WEARE J.H. (1980) The prediction of mineral solubilities in natural waters: The $\mathrm{Na}-\mathrm{K}-\mathrm{Mg}-\mathrm{Ca}-\mathrm{Cl}-\mathrm{SO}_{4}-\mathrm{H}_{2} \mathrm{O}$ system from zero to high concentration at $25 \mathrm{C}$. Geochim. Cosmochim. Acta 44, 981-997.

HARVIE C.E., WEARE J.H., HARDIE L.A. and EUGSTER H.P. (1980) Evaporation of seawater: calculated mineral sequences. Science 208, 498-500.

HELGESON H.C. (1969) Thermodynamics of hydrothermal systems at elevated temperatures and pressures. Am. J. Sci. 267, 729-804.

KERRISK J.F. (1981) Chemical equilibrium calculations for aqueous geothermal brines. Los Alamos, N.M. Science Lab. Report LA-8851-MS.

MARSHALL W.L., SLUSHER R. and JONES E.V. (1964) Solubility and thermodynamic relationships for $\mathrm{CaSO}_{4}$ in $\mathrm{NaCl}-\mathrm{H}_{2} \mathrm{O}$ solutions from $40^{\circ} \mathrm{C}$ to $200^{\circ} \mathrm{C}, 0$ to 4 molal $\mathrm{NaCl}$. J. Chem. Eng. Data 9, 187-191.

PITZER K.S. (1973) Thermodynamics of electrolytes. I: Theoretical basis and general equations. J. Phys. Chem. 77, 268-277.

ROGERS P.S.Z. (1981) Thermodynamics of geothermal fluids. Ph.D. Dissertation, U.C. Berkeley, Berkeley, Ca.

SMITH, G.I. (1976) Origin of lithium and other components in the Searles Lake evaporites California, In: Lithium Resources and. Requirements by the Year 2000. J.D. Vine, ed: U.S. Geological Survey Prof. Paper 1005, p.92-103

TEEPLE, J.E. (1929) The industrial development of Searles Lake brines with equilibrium data. In American Chemical Society Monograph Series, The Chemical Catalog Company, Inc.

WOLERY T.J. (1983) EQ3NR A computer program for geochemical aqueous speciation-solubility calculations: user's guide and documentation. Lawrence Livermore Lab. Report UCRL-53414. 
MODELLING MASS TRANSFER REACTIQN FATES: CALCITE PRECIPITATION AND CO, OUTGASSING IN A KARST STREAM

Janet $S$. Herman and Michelle M. Lorah

Department of Environmental Sciences

University of Virginia

Charlottesville. VA 22903

\section{Abstract.}

While theoretical and experimental studies are widely reported in the geochemical kinetics literature, field studies are relatively few in number. In this study, the evolution of water chemistry along a well-defined flow-path was quantified by modelling the mixing of two discrete waters and mass transfer reactions between sampling points using WATEQF and PHREEQE and observed chemical compositions. The reaction time between sampling locations was estimated from measurements of stream discharge and geometry. The major reactions considered were $\mathrm{CO}_{2}$ outgassing and calcite precipitation from ground and surface waters in a limestone terrane. The kinetics of calcite dissolution and precipitation have been especially well-studied. and the reaction rates obtained from the combination of the mass transfer modelling and hydrologic measurements of this study could be compared with the rates predicted from a laboratoryderived rate law. The agreement in rates was generally within an order of magnitude and routinely within a factor of 2 or 3 . Least agreement between measured and predicted rates was obtained for sections of flow-path where relatively little change in bulk chemical composition occurred, which were the sections with the greatest mass transfer modeli ing error. For the travertine-depositing stream of Warm River Cave and Falling Spring Creek, VA. the coupling of equilibrium speciation and mass transfer geochemical models with simple field measurements in a hydrolagically well-defined system allowed successful field-based quantification of reaction rates.

\section{Introduction}

The processes of $\mathrm{CO}_{2}$ exchange and mixing of different carbonate waters exert a major control on the thermodynamic stability of calcite in solution. The co, content in carbonate groundwaters can reach values much above nốrmal atmospheric cọ , and when this groundwater emerges at or near the earth ${ }^{2}$ s surface, Co, outgasses. This exchange of CO, between solution and atmosphere is the dominant process causing supersaturation with respect to calcite in many carbonate waters. Several field studies have shown that the combination of a high supply rate of dissolved Co, to spring-fed streams and agitation of the water at cascades allows a great amount of co, outgassing to occur (Dandurand et al.. 1982), but no previoús study has quantified 


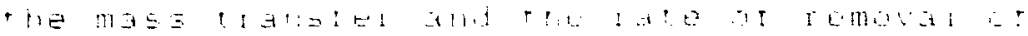

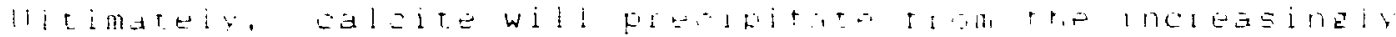

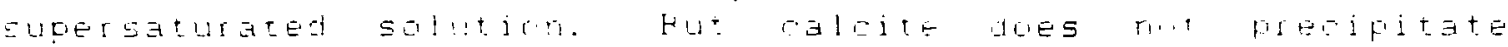
ammediztel; a

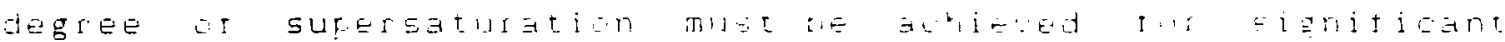

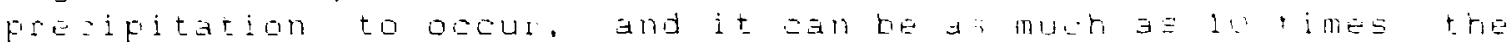
equilibrium oalcite solubility value. High degres Gi supessaturation witr respect to calaite have beer maintairid in salutions in both tield and laboratiry studies without noticeable caleite precipitation taking plä.

Mixing aí one water with another soiution that difters in Shamial armpostian will also cause a shirt in the saturation stale at the water witr respect to calcite. Because calcite solubility is a nan-linear tunatian af variaties suar as ion activity. pio, ianic strength, and temperature. mixing af two ajrtonate waters produces complex non-linear ettects. Mixing is believed to be a common process in subsurtace waters. however. geochemical field evidence of the lesults ar mixing is diticult $\because$ obtain.

Thermodynamic, or equilibrium. models can be used to deterinine whether or not a solution will tend to evolve cu- or ro precipitate alcite. kinetic intormation is requíred. however. to determine the rates at which these reactions occur. Many laboratory studies of calcite dissolution and precipitation binetics rave been conducted. Several different rate laws have been published. but the plummer et al. (1978) empirical model is the oniv one that attempts to describe both dissolution and precipitation rates at all solution pH and Fín values. Altrough the Plummer et al. rate law has been tested and generally supported by laboratory kirietic studies. the rate equation has not been tested in a field situation.

Very few resear:hers have quantified calcite dissolution or precifitation rates in field studies. The purpase of the present research is to conduct a tield investigation of co., butgassing. caicite precipitation or dissolution, and mixing a two carbonate waters. The effect of these processes on the chemical evolution of a travertine-depositirig stream is assessed Herman and Lorah. 1986). Rates of Co outgassing and calcite precipitation are quantified by mass tránster calculations and are compared to rates predicted with a laboratory-derived rate $1 \Xi W$.

\section{Metrigas}

The study area is located inside warm River Cave and along Falling Spring Ereek, Virginia (Herman and Loarh, 1986). The spring issuing in warm River Cave, like other thermal springs in the regicn, is ted by deeply circulated meteoric water that was rieated under a normal geothermal gradient. The thermal water circulates through a thick sequence of cambrian and ordouician 
I imestones and dolomites. The warm spring inside warm Riser Save exaeeds $3 g^{0}$. This spring water t lows through the cave as a warm stream and converges with a cold stream derived trom shal bw groundwater. The mixed stream ultimately resurges an the surtace as Falling Spring, issuing from the breakdown pile that Lises at warm fiver iave and formirg falling spring Creek. Approkimately $0.8 \mathrm{~km}$ downstream from Failing Spring, the stream breaches a small sandstone ridge and tlows over a $20-m$ vertical watertall. The clifi is covered in travertine and more travertine deposits are evident in the streambed immediately above and below the watertall.

Ten tield trips to collect water samples were completed between April. 1984, and June, 1985. Cave water samples wera collected on three of those trips. intve s established along a $5.2-k m$ stretch of Falling Spring Creek. Eeven collection sites inside warm River Cave were located along the accessible parts of the warm, cold, and mixed streams. Temperature, pH, conductivity, and discharge were determined in the tield. Complete major cation and anion analyses were pertormed on tiltered samples in the laboratory.

The data analysis included (1) defining the saturation state of the waters with respect to calcite aid c.0., (2) determining mass transfers of calcite and Cu, along thé flow path, and (3) calculating the rates of calcite precipitation and Co, qutgassing. Aqueous speciation, theoretical pco., and the saturation state of each solution sample was aetermined using WATEQF (Plummer et al., 1976) and the chemical concentration data and field $p H$ and temperature. Data were input to wATEQF with the program WATIN (Moses and Herman, 1986).

PHREEQE (Parkhurst et al., 1980) was used to determine mass transiers. Given an observed initial water composition and thermodynamic constraints for a set of plausible reactants and products, the model calculates the amounts of minerals or gases that would have to be added or lost from the solution to meet the thermodynamic constraints. Calcite and Co, are the most. plausible reactants or products controlling the water chemistry in this system. The $S I_{C}$ and $P_{2}$, values obtained from WATEQF were used as the thermodynamic constraints in PHREEQE. To calculate the mass transfer (mol $\mathrm{kg}^{-1} \mathrm{H}_{2} \mathrm{O}$ ) between two successive points along the flow-path, the S̆bserved chemical composition of the upstream site is input to PHREEQE and required to equilibrate with the Slc and PCD, of the dowristream site. The net amount of calcite that hac tobe precipitated or dissolved and the net amount of Co, that had to be added or lost from the water between the two sampling sites to produce the composition of the final water is calculated.

The mixing of warm and cold streams inside warm River Cave can also be simulated with PHREEQE. Mass balance was applied to the conservative constituent fluoride to define the fraction of each end-member water in the resulting mixture. That mixing 
fraction was applied to all other aonstituents in the warm and cold stream to estimate what their total concentrations would be. By comparing the predicted conservative mikture with the observed chemical composition of the mixed stream. mass transiers that occur during the mixing process are determined.

Rates las $\mathrm{kg}^{-1} \mathrm{H}, \mathrm{D} \mathrm{s}^{-1}$; of a leite precipitation or dissolution and Co, outgäsing were calculated using the mass transfers between two sites divided by estimates oi reaction time. The stream velocity was a alculated from discharge and cross-sectional area measurements. Reaction time was computed from distance between sampling sites divided by velocitv.

A laboratorv-derived equation for calcite dissolution and

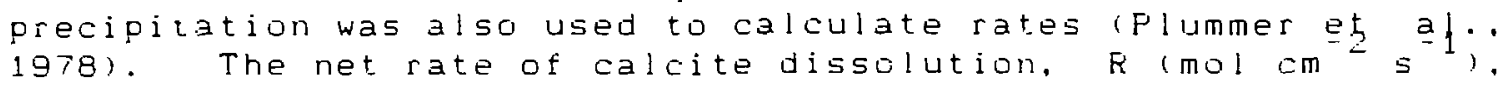
is the sim of three forward reaction rates and a backward reaction rate

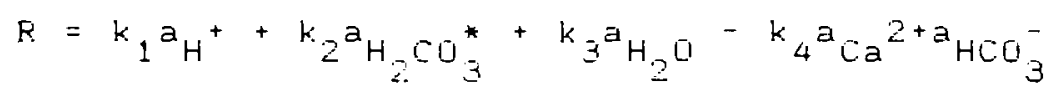

The activities of dissolved species are obtained from the WATEQ output. An estimated suriace area tor the streambed and the volume of water flowing between two sampling locations were used to convert the calculated calcite precipitation rates to the same units as the mass transfer rates.

\section{Results}

$\mathrm{Ca}^{2+}$ and $\mathrm{HCO}_{3}^{-}$dominate the chemical character ot the water at every point in ${ }^{3}$ this system. In the cave, the warm relatively concentrated water mixed with the dilute cold water to define the composition of the mixed stream. Cact and $\mathrm{HLG}^{2}$ concentrations decrease along the tlow-path. The largesf decreases occur in the cave at the junction of the warm and cold streams and on the surface at the falls and just downstream of the falis.

The cave and surface waters are almost always supersaturated with respect to CO, and calcite. Calculated Pco, values decreased downstream, eš́pecially just above and at thé waterfalls. but they remained above normal atmospheric values for the entire 6-km flow-path. Associated with the loss of Co. is an increase in pH. SI increased along the warm stream anu then dropped at the mixed Stream. During low-tlow conditions of summer and fall, the entire length of the surface stream was supersaturated. In the high-flow conditions of spring and winter, the springs were undersaturated, but the water was supersaturated by the time it reached the crest of the talls.

The mass transfer callulations show that calcite frecipitation ard co, outgassing craractfrized the chemical changes in the cave añd surface wäters. [ur ing the high-tiow 
conditions of winter. some calcite dissolution was calculated for early segments of the flow rath. Net calcite precipitation occurred throughout the year. but the total amount precipitated during the summer and fall was roughly twice that formed in the winter and spring months.

The rate results obtained by the two different methods agreed within an order of magnitude. Both methods gave the same trends, with low rates above the falls and higher rates at and downstream from the falls. At the falls, however, the mass transfer results showed a one or two order of magnitude increase while the rate equation predicted a much smaller increase in rate. During the few instances of calcite dissolution being predicted by the mass transfer calculations near the springs. the rate law predicted precipitation.

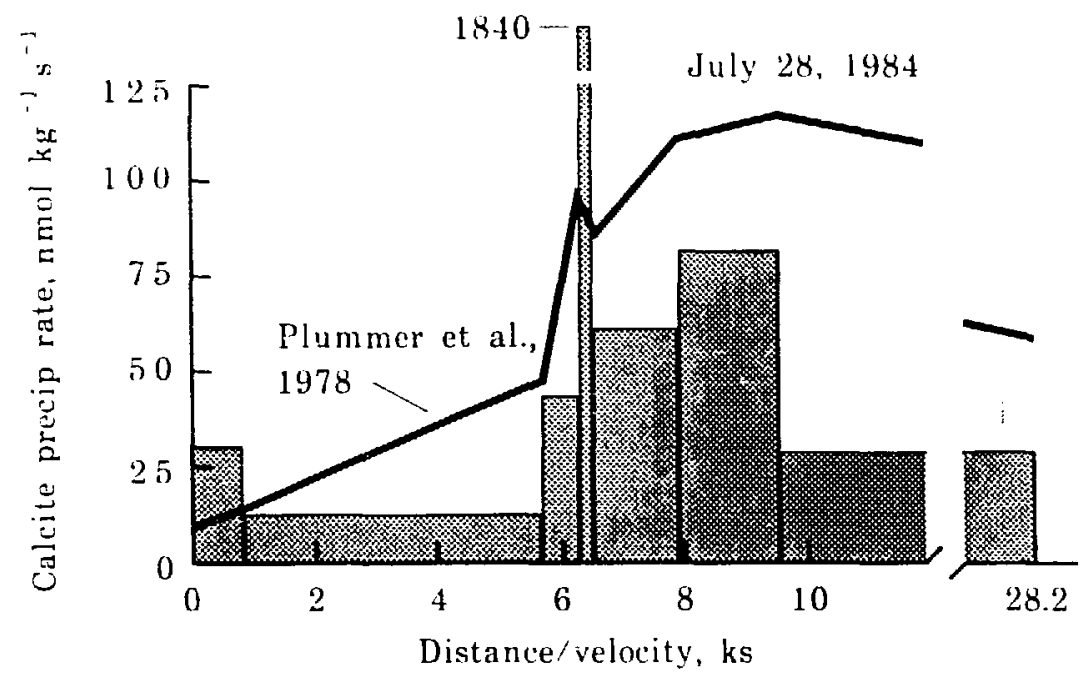

\section{Discussion}

The thermal spring water has an extremely high CO content. outgassing causes the $P C O$ of the water to drop significantly. The greatest decrease in hCo $_{3}^{-}$concentration in the cave occurs at the junction of the streams. The cold shallow groundwater dilutes the warm water, but calculations show that $\mathrm{CO}_{2}$ continues to outgas during the mixing of the two waters.

An important source of error in the mass transfer and rate calculations for the cave stream is the poorly-defined influx of cold groundwater to the warm stream. The estimates of $\mathrm{CO}_{2}$ outgassing and calcite precipitation from mass transfếr calculations reflect the inability to detine discrete inputs of grourdwater to the stream that caused dilution. The greatest variability in predicted reactions occurred in December when the dilution by shallow groundwater was greatest. 
Cin the surtace, the water continues to outgas, and tho pH increases. After a smocth. straight segment of stream where outgassing rates are low, the rates increase at the ritfles near the top of the ralls. At the talls, outgassing proceeds at a rare 10 to 30 times greater thar upstrealn. Rates decrease again downstream of the talls where the concentration gradient from solution to atmosphere is lower, the temperature is lower. and the stream is once again tollowing a relatively smooth path.

The thermal spring water is initiaily near equilibrium with respect to calcite. solution loses co. Rimstone dams are observed in the warm
stream. and they aŕe a sink tur calcium and bicarbonate. The Along its flow-path, $\quad$ l l c increases as the cold groundwater has much lower concentrations, and it was undersaturated with respect to calcite during high flow conditions. Diffuse input of such water would lead to calculation of calcite precipitation with PHREEQE, an error due to the poor definition of the flow system. At the obvious junction of the saturated warm stream and the undersaturated cold stream, an even more undersaturated mixture is formed.

The surface stream loses $\mathrm{CO}$, $\mathrm{pH}$ increases, and calcite precipitates. All these reactións are more dramatic than for the cave stream uecause the lower PCo, oi the open atmosphere and the greater turbulence in the steream cause more cu. to outgas. Although the stream water may be supersaturated. calcite precipitation is inhibited until the crest of the falls. Mass transfer calculations for the segments of stream between the springs and the falls show almost no calcite precipitation while the Sl. increases. Near the crest of the falls, a rapid increase in the SI, occurs in response to the higher outgassing rate. Just abové the falls the water reaches approximately 10 times supersaturation with respect to calcite and $5 i g n i f i c a n t$ precipitation begins. A large decrease in $\mathrm{Ca}^{2+}$ and $\mathrm{HCO}_{3}$ concentrations where there is no source of dilution indicates that signiticant calcite precipitation begins at the falls, with rates increasing two orders of magnitude over the rates immediately upstream. It is at the base of the falls that calcite is seen to form Iresh white crusts on everything. Calcite precipitation continues along the rest of the 4-km flowpath below the falls, but the rates are lower. By the last sampling site, Sl, finally decreases, but the solution is still supersaturated with respect to calcite. Seasonally. the amount of calcite precipitated in tre surface stream is tied to the mixing of the two waters inside the cave. During low-flow conditions the concentrated thermal water is not as diluted with shallow groundwater, and higher sl, values are reached, greater rates of precipitation are objerved, and larger mass of calcite is deposited.

Calcite precipitation rates were determined from the mass transters of calcite simulated with PHREEQE and from calculations with Plummer et al."s rate law. The rates obtained with PHREEQE are affected by errors in the simulated mass 
transters and in the hydrologic data used to obtain the reaction times. Both the chemical composition ot the initial water and the 51 of the final water aie needed to model mass transfer of calcite temperature measurements could cause error in predicted rates. one indication that the calculations were successful is that the final water composition predicted by PHREEQE to match the thermodynamic constraints of $\mathrm{Si}_{\mathrm{C}}$ and $\mathrm{PCO}_{2}$ matches the analyzed tinal water chemistry nearly exactly. Some PHREEQE results are clearly suspect. though. because they indicate calcite dissolution into a supersaturated water. These contradictory reults were only seen over stretches of stream where the ca concentration remained the same or changed very little. Because only very small changes in $\mathrm{Ca}^{2+}$ concentrations were being simulated by PHREEQE, relatively small errors in the chemical analyses or convergence errois in the model iterations would have been noticeable. Errors in reaction time could clearly lead to errors in rate estimates. Errars could arise from poor discharge measurements or from the incorrect assumption of uniform velocity along the entire stream on each sampling date. since the same estimates of reaction time were applied to both rate calculations, that error is not a factor in the comparison.

While laboratory precipitation studies have given support to the rate expression of Plummer et al. over a wide range of solution conditions, no field studies have previously reported the use of this rate law. The range of solution conditions and rates of calcite precipitation calculated for Falling Spring Creek agree with experimental values (Reddy et al., 1981). For the present studv. the mass transfer rate results are compared to ine rate equation predictions. These two methods of determining rates differ greatly. One approach derives from an experimental study of the kinetics of dissolution and precipitaiion reactions: the other approach applies mass balance calculations to observed chemical data for a natural water system (Plummer and Eack, 1980). Yet the results agree remarkably well. The largest difference is seen at the waterfall where the rate law always gave much lower rates. The agreement in rates at the falls is within a factor of 10 to 50 . The rate law results gave the maximum rate just below the falls. For all other segments of the stream than the falls, rates agreet within a factor of 1 to 10 .

Froblems in estimating the surface area of the stream could explain some of the disagreement between the rates. The Plummer et a!. expression gives reaction rates in terms of surface area. while PHREEQE results are in terms of volume of water. The results from Flummer et al.'s expression were multiplied by the surface area over which the chemical reactions could be occurring in Falling Spring Creek. The reactive surface area of a streambed is impossible to characterize accurately. A uniform rectangular shape was assumed. Although this description of tre streambed is clearly wrong, all other simple geometric shapes led to an estimate of area on the same order ot 
magnitude. At the waterifalis the streambed deviates more trom the geometic simplitication than at any other site. Because the large irregularly shaped deposits of travertine would provide numerous nucleation sites tor tresh calcite. the surface area might have been underestimated, leading to an underestimate of the rate law results.

\section{Conclusions}

Using a laboratory-derived rate law (Plummer et al.. 1978), calcite precipitation rates could be predicted within ar order of magnitude of the massi trensfer rates along falling spring Creek. Errors in surface area estimation at the talls led to a poor comparison ot the two types ot rates there. lmprecise definition of diffuse input of groundwater to the cave stream caused those mass transfer rates to be unreliable. uverall. however. the agreement between field-determined rates and the predictions of the rate law agreed very well - within an order of magnitude. The comparisons between the PHREEQE results and the rate law calculations d, not prove the validity of the rate expression, but considerirg the vastly different theoretical bases of the two methods. the agreement between the reaction rates is good enough to give encouragement that the rate law may be used outside of the laboratory.

\section{$\underline{\text { References }}$}

DANDURAND J.L., GUUT R., HOEFS J.. MENSCHEL G., SCHOTT J., and USDOWSK. E. (1982) Kinetically controlled variations of major components and carton isotopes in a calciteprecipitating spring. Chem. Geol. 36. 299-315.

HERMAN J.H. and LORAH M.M. (1986) CO, Outgassing and Calcite Precipitation in Falling Spring Creek, Virginia. Chem. Geol. In press.

MOSES C.O. and HERMAN J.S. (-986) WAT.N - A computer program for generating input files for WATEQF. Ground Water 24, 83-89.

PARKHURST D.L.. THORSTENSUN D.C., and PLUMMER L.N. (1980) PHREEQE - A computer program for geochemical calculations. U.S. Geol. Surv., Water-Resour. Invest. 80-96.

PLUMMER L.N., JONES B.F., and TRUESLELL A.H. (1976) WATEQF - A FORTRAN IV version of WATEQ, a computer program for calculating chemical equilibria of natural waters. U.S. Geol. Surv., Water-Resour. Invest. 76-13.

PLUMMER L.N., WIGLEY T.M.L., and PARKHURST D.L. (1978) The kinetics of calcite dissolution in CO -water systems at $5^{\circ}$ to $60^{\circ} \mathrm{C}$ and 0.0 to 1.0 atm Co. Amer. Jour. Sci. 278. 179-216.

PLUMMER L.N. and BACK. W. $2(1980)$ The mass balance approach: application to interpreting the chemical evolution of hydrologic systems. Amer. Jour. Sci. 280. 130-142.

REDDY M.M., PLUMMER L.N., and BUSENBERG E. (1981) crystal growth of calcite from calcium carbonate solutions at constant $\mathrm{PCO}_{2}$ and $25^{\circ} \mathrm{C}$ : A test of a calcite dissolution model. Geochim. Cosmochim. Acta 45. 1281-1289. 
PREDICTING MINERAL DISSOLUTION AND PRECIPITATION DURING BURIAL: SYNTHETIC DIAGENETIC SEQUENCES

\author{
Carol J. Bruton \\ Lawrence Livermore National Laboratory \\ P.0. Box 808 \\ Livermore, CA 94550 USA
}

\title{
Aostract
}

Diagenetic changes with depth, reflecting the influence of source terrane, depositional environment and burial history, can be simulated using the EQ3/6 geochemical model of fluid-rock interaction. Synthetic diagenetic sequences are constructed by simulating reaction between rocks and pore fluids during burial and tracking mineral precipitation and dissolution events that occur as the rock and fluid attempt to come to equilibrium with each other.

Four representative rock compositions, including a quartzose sandstone, two quartzofoldspathic sandstones and a volcanic sandstone, were chosen to simulate the control of source torrane on diagenesis. Using EQ3/6, the rocks were reacted with representative river and sea water to study the influence of fresh water and marine depositional environments, respectively, on diagenesis. The rock-fluid system was assumed to be closed. A burial rate of 0.07 $\mathrm{mm} / \mathrm{yr}$ along a geothermal profile with a gradient of $30^{\circ} \mathrm{C} / \mathrm{km}$, which was chosen to simulate present-day conditions in the Texas Gulf Coast, was modeled.

Rates of mineral dissolution were calculated in three different manners for comparison: 1) linear arbitrary kinetics; 2) zeroth order kinetics; and 3) transition state theory assuming $\mathrm{pH}$-independent rates. Subsequent fluid-rock reactions, including mineral precipitation, were assumed to be reversible and to occur instantaneously.

Simulation results indicate that the sequence of diagenetic events for reaction between a given rock and fluid is largely independent of the rate law used to describe mineral dissolution. Synthetic diagenetic sequences also agree reasonably well with observed diagenetic reactions in natural systems. Calculation of the absolute timing of diagenetic events, however, appears to depend on reactive surface area, precipitation kinetics, and other rate-limiting phenomena. Precipitation kinetics and potential rate-limiting phenomena must be provided for prior to effective application of kinetic models to the study of diagenetic processes.

\section{Introduction}

Diagenetic changes with depth, reflecting the influence of source terrane, depositional environment and burial history, can be simulated using geochemical models of fluid-rock interaction. The synthetic diagenetic sequences that are consiructed in this manner are analogous to paragenetic sequences determined through petrologic study. They are calculated as a function of 
rock type, fluid composition, temperature, and relative rates of fluid flow and mineral dissolution to simulate burial diagenesis in a wide variety of geologic settings. The timing of diagenetic events can be determined if rates of mineral dissolution are coupled to burial history.

Synthetic diagenetic sequences can be used to predict diagenetic changes with depth, determine controls of mineral dissolution and precipitation, and evaluate the consequences and relative importance of changes in source terrane, depositional environment and burial history on diagenesis. The purpose of this paper is to show that: 1) synthetic diagenetic sequences agree reasonably well with diageretic sequences determined by petrographic observation; and 2) that the absolute timing of diagenetic events appears to depend not only on the magnitude of mineral surface area, but also on precipitation kinetics and rate-controlling phenomena which have not yet been identified clearly.

\section{Synthetic Diagenetic Sequences}

Synthetic diagenetic sequences are constructed by simulating reaction between rocks and pore fluids during burial with the EQ3/6 computer software package of Wolery (1978). Four representative rock compositions, including a quartzose sandstone, two quartzofeldspathic sandstones with varying amounts of K-feldspar and plagioclase, and a volcanic sandstone, were chosen to simulate the control of source terrane on diagenesis. The rocks were reacted in separate simulations with dilute river water and sea water to study the influence of fresh water and marine depositional environments, respectively, on diagenesis. Reaction of quartzose sandstone with river water will be described in this paper.

Simulations yield the sequence and types of mineral precipitation and dissolution events that occur when the rock and fluid attempt to come to equilibrium with each other during the increases in temperature associated with burial. The rock-fluid system was assumed to be closed.

\section{Simulation Input}

The mineralogic composition of the quartzose sandstone used as an example in this study is listed in Table 1. The composition of the sandstone, an ortho-quartzite from Pettijohn (1975), is dominated by quartz, with minor amounts of kaolinite, microcline, albite, anorthite, calcite, magnetite and a $\mathrm{Mg}-\mathrm{chlorite}$ represented by $14 \AA_{-c i}$ inochlore. Equal amounts of albite and anorthite proxy for the end member components of an ideal plagioclase solid solution with the composition $\mathrm{An}_{50}$. Note that the presence of kaolinite and calcite suggests that the quartzose sandstone has been subjected to surface weathering. The composition of the dilute river water used in the simulations and listed in Table 2 was taken from Livingstone (1963). An Al concentration of $1 \mathrm{ppb}$ and a $\mathrm{pH}$ of 7 were assumed. A burial history consisting of uniform subsidence at a rate of $0.07 \mathrm{~mm} /$ year along a geothermal profile with a gradient of $30^{\circ} \mathrm{C} / \mathrm{km}\left(1.65^{\circ} \mathrm{F} / 100 \mathrm{ft}\right)$, which corresponds to a constant heating rate of $1.8^{\circ} \mathrm{C} / \mathrm{milli}$ ion years, was modeled. These conditions were chosen to approximate present day conditions in the Lower Tertiary 
Table 1. Mineralogic compositicn of type quartzose sandstone (from

Pettijohn, 1975).

$\begin{array}{lr}\text { Mineral } & \text { Vol } \\ \text { Quartz } & 93.3 \\ \text { Kaolinite } & 0.8 \\ \text { Microcline } & 1.3 \\ \text { Albite } & 0.9 \\ \text { Anorthite } & 0.9 \\ \text { Cal cite } & 2.4 \\ \text { l4 A-clinochlore } & 0.1 \\ \text { Magnetite } & 0.3\end{array}$

Table 2. Composition of type river water (from Livingstorie, 1963).

$\begin{array}{lc}\text { Species } & \text { mg/l } \\ \mathrm{Na} & 6.3 \\ \mathrm{~K} & 2.3 \\ \mathrm{Ca} & 15.0 \\ \mathrm{Mg} & 4.1 \\ \mathrm{Al} & 0.001 \\ \mathrm{SiO}_{2} & 13.1 \\ \mathrm{Cl}^{2} & 7.8 \\ \mathrm{SO}_{4} & 11.2 \\ \mathrm{HCO}_{3} & 58.4 \\ \mathrm{pH} & 7.0 \\ \mathrm{~T} . D .5 . & 118\end{array}$

Wilcox Group and Frio and Vicksburg Formations along the Texas Gulf Coast.

Rates of mineral dissolution were described using three methods for comparison: 1) linear rates of mineral dissolution that are not explicit with respect to time ( $i . e$ arbitrary kinetics) but are proportional to the volume fraction of the mineral in the rock; 2) zeroth order kinetics; and 3) transition state theory assuming $\mathrm{pH}$-independent rates of dissolution. Method 1 was used to illustrate a possible modeling approach when no estimates of rates of mineral dissolution are available. Rate constants from Walther and Wood (1986), which are applicable to high temperature reactions, were assumed to suffice at low temperatures in method 2. Rates of mineral dissolution are then calculated assuming that rates do not slow as equilibrium is approached. Method 3, in contrast to method 2, takes explicit account of the control of solution composition and the decrease of rates of dissolution close to equilibrium. Method 3 is, therefore, the most realistic of the three approaches, despite the fact that pH-independent rates were assumed. Intra-aqueous reactions and secondary mineral precipitation and dissolution were assumed to occur reversibly and instantaneously.

Rate constants used in transition state rate laws were taken variously from Knauss and Wolegy (1986; albite), correlation plots of Walther and Woou (1986; kaolinite, 14A-clinochlore, magnetite), Rimstidt and Barnes (1980; quartz) and Delany, Puigdomenech and Wolery (1985; calcite). Rate constants for microcline and anorthite were assumed to equal those of albite. Temperature dependencies of the rate constant were estimated from correlation plots of Walther and Wood (1986) if not given in the above references.

Rates of mineral dissolution were used to calculate synthetic diagenetic sequences as a function of time, temperature and surface area. Time and temperature were linked by assuming a constant heating rate of $1.8^{\circ} \mathrm{C} / \mathrm{million}$ years. Rates of dissolution vary, however, as a function of the surface area available for reaction. The surface area of each mineral was assumed to equal the total surface area of the rock multiplied by the volume percentage of the mineral in the rock. Total surface area was assumed to remain constant during burial. 
Simulation results indicate that the sequence of diagenetic events for reaction between a given rock and fluid is largely indeperident of the rate law used to describe mineral dissolution. The generalized diagenetic sequence for reaction of quartzose sandstone with river water is, therefore, first described independently of time. The synthetic sequence is then compared with petrologic descriptions of natural diagenetic sequences.

Diagenetic events predicted to occur during burial of quartzose sandstone and river water are showr. in figure 1. The depth of burial, and thus temperature, increase from left to right along the abscissa. The bars represent the stability range of each mineral. The beginning of the bar signifies the start of mineral precipitation, and the addition of the mineral to the stable diagenetic assemblage. The end of the bar indicates complete dissolution of the mineral, and its deletion from the stable phase assemblage.

Hematite, pyrite, smectite and quartz are the first phases to precipitate during burial. Hematice and pyrite represent early sinks for Fe. Smectite pracipitates throughout burial, and continually changes in composition from a Ca-nontronite to Ca-saponite and firally to Ca-beidellite. Tardy-Garrels estimation techniques are used to derive thermodynamic data for smectites in the EQ3/6 data base (Wolery, 1978). Quartz overgrowth formation is favored throughout burial. The carbonates dolomite and calcite precipitate next. Note that two generations of dolomite cement are formed, even though the simulation was made in a closed system. The formation of multiple generations of minerals or zoning does not, therefore, necessarily imply fluid flushing in an open system. Carbonates are followed by the clays muscovite and kaolinite. Muscovite, in these computations, can be considered as a proxy for an illite with a layer charge of -1 .

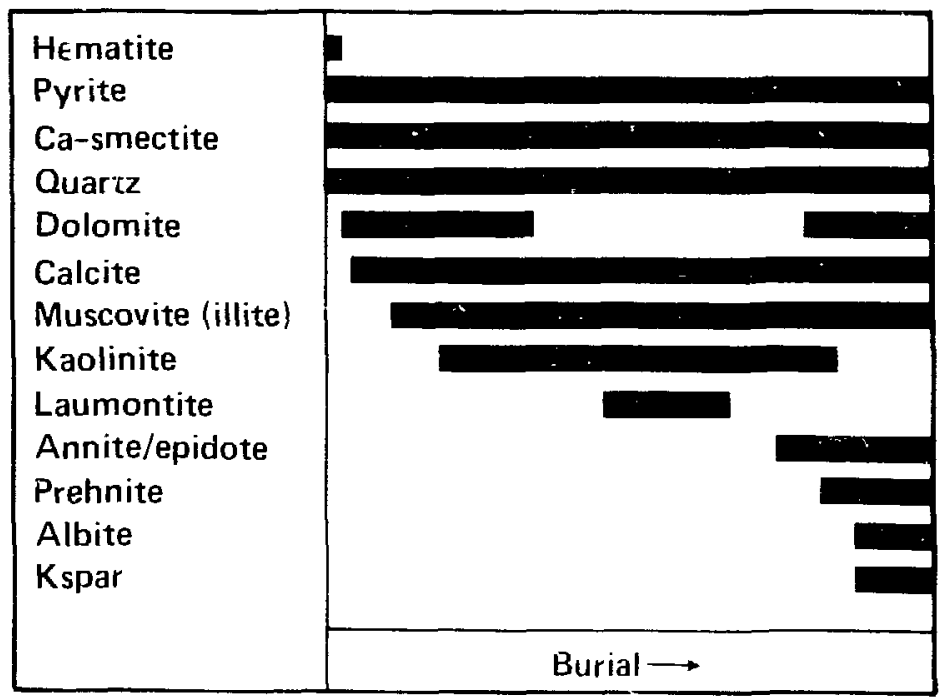

Figure 1. Generalized synthetic diagenetic sequence for reaction between quartzose sandstone and river water. 
The precipitation of laumontite signals entry into the zeolite metamorphic facies. Annite or epidote forms as a late sink for $\mathrm{Fe}$, depending on temperature. Prehnite precipitation is followed by albitization and the formation of K-feldspar overgrowths.

A chronological sequence of diagenetic events in sandstones deposited in fresh to brackish environments as determined through petroyraphic observation and compiled by McBride (1983) is shown in Table 3 . Hematite forms an early Fe-siluk, and is followed by a variety of clays, including chlor: smectite and kaolinite, which are analogous to smectite in tise simulation. Early K-feldspar and albite overgrowths were not formed in the simulations. Precipitation of quartz is followed by carbonates in both the simulated and observed sequences. A dissolution event s:-iibed to hydrocarbon migration was not reproduced in the simulaticns. The simulations were carried out assuming a closed system in which no fluid flow occurs. Dolomite dissolution occurred in the closed system model, nonetheless. Kaolinite is observed to precede illite and Fe-carbonate in nature. Kaolinite coexists with illite and carh. ade in the burial simulation. The zeolite in McBride's sequence : epresented by laumontite in the simulation.

Preliminary results suggest that synthetic diagenetic sequences predict general diagenetic trends reasonably well, even though the simulations were carried out in a closed system. Natural systems are considered to be open, and formation fluids evolve to saline brines at depth. The simulations, in contrast, are carried out in a closed system in which the fluid is constrained to remain relatively dilute. Nonetheless, the synthetic diagenetic sequences correspond wel? with observed diagenetic sequences.

\section{Iiming of Diagenetic Events}

Absolute timing of diagenetic events was calculated using zeroth order kinetics and transition state theory for comparison and contrast. The total surface area of the rock was calculated by assuming spherical grains and $30 \%$ porosity. A rock composed of spherical grains of $1 \mathrm{~mm}$ diameter and with $30 \%$ porosity has a total surface area of $10^{5.15} \mathrm{~cm}^{2} / \mathrm{kg}$ fluid. The

Table 3. Chronologic sequence of diagenetic events in sandstones deposited in non-marine environments deduced through petrographic study (after McBride, 1983).

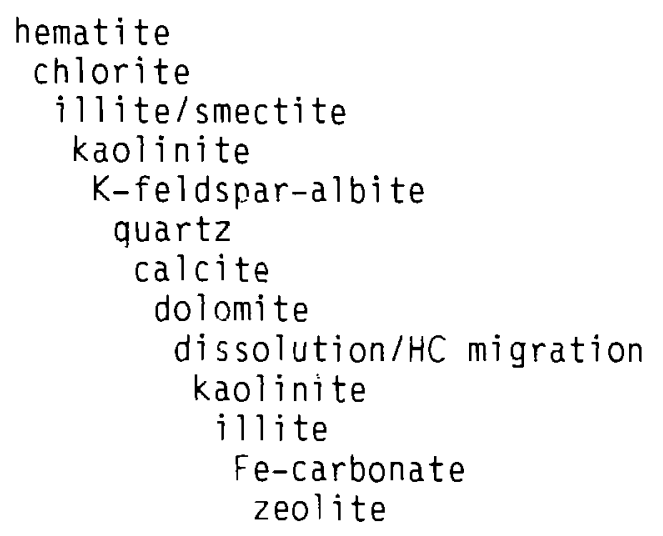


surface area of each mineral was calculated by multiplying the total surface area of the rock by the volume fraction of the mineral in the rock.

The synthetic diagenetic sequence as a function of time and temperature for reaction between quartzose sandstone and river water assuming a reactive surface area of $10^{5.15} \mathrm{~cm}^{2} / \mathrm{kg}$ fluid and zeroth order kinetics is shown in Figure 2. A diagenetic sequence similar to the one shown in Figure 1 is present in Figure 2, but is formed in a very short period of time. The entire diagenetic sequence up to prehnite precipitation forms within I million years as the temperature increases from 10 to $12^{\circ} \mathrm{C}$, and the rock is buried to a depth of $70 \mathrm{~m}$. Isotopic measurements, in contrast, suggest that kaolinite, for example, often precipitates between 50 and $100^{\circ} \mathrm{C}$, and albite may not precipitate until temperatures reach 100 to $150^{\circ} \mathrm{C}$.

Helgeson. Murphy and Aagaard (1984) suggest that reactive or effective surface area, which is in part controlled by the outcrop of surface active sites such as dislocations, is two orders of magnitude less than total surface area. Reduction of the surface area by five orders of magnitude, to $10^{0.15} \mathrm{~cm}^{2} / \mathrm{kg}$ fluid, was required to yield a more reasonable match to the natural data as shown in Figure 3 . Kaolinite starts to precipitate at $40^{\circ} \mathrm{C}$, and laumontite begins to precipitate after 35 my at $80^{\circ} \mathrm{C}$. However, albitization does not occur in the simulation even after 100 my, in contrast to its presence in Texas Gulf Coast reservoirs less than 50 my old.

The temperature dependence of mineral equilibration, in ${ }^{\circ} \mathrm{C}$, is shown in Figure 4 as a function of the logarithm of the surface area of the rock, expressed in $\mathrm{cm}^{2} / \mathrm{kg}$ fluid, given a porosity of $30 \%$. The time of equilibration, in millions of years, is given for reference along the top of the $x$ axis.

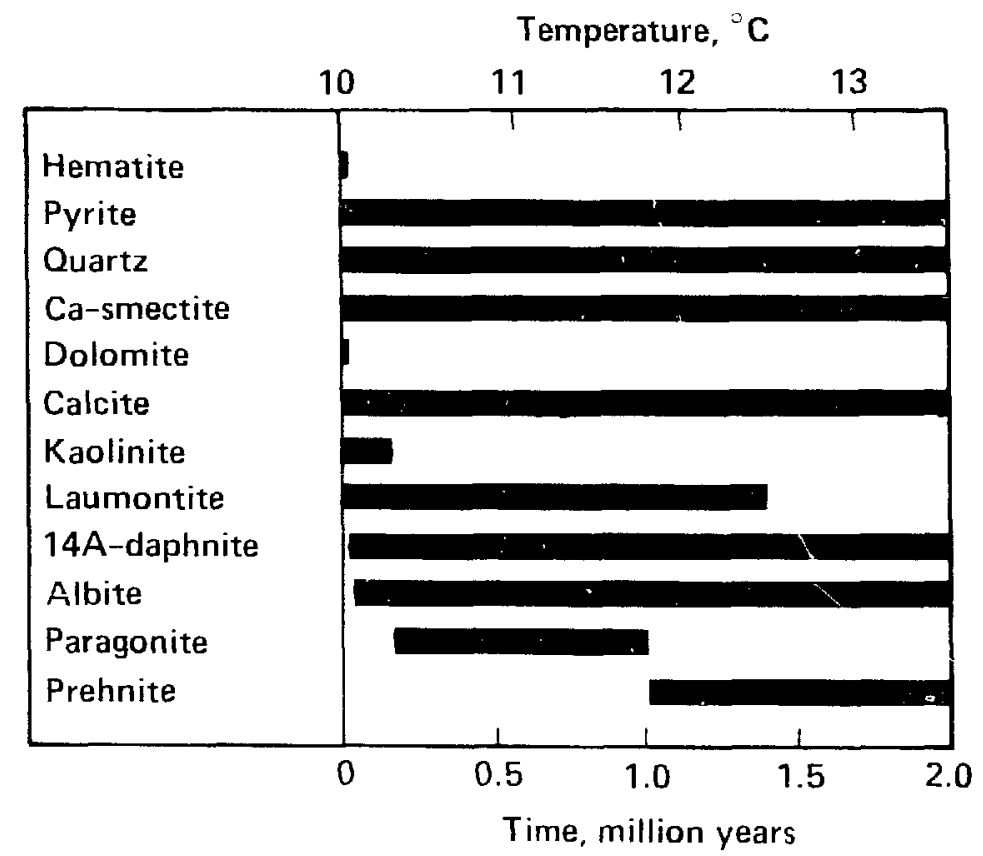

Figure 2. Synthetic diagenetic sequence for reaction between quartzose sandstone and river wator assuming zeroth order kinetics and a surface area of $10^{5} .15 \mathrm{~cm}^{2} / \mathrm{kg}$ fluid. 
Temperature, ' $\mathrm{C}$

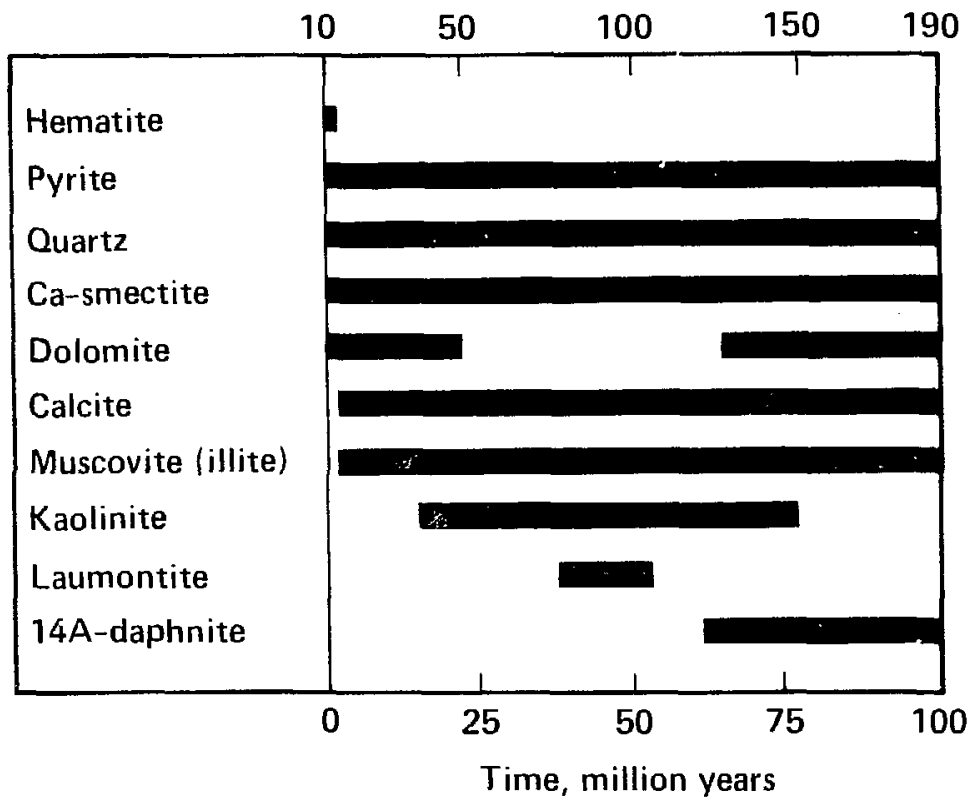

Figure 3. Synthetic diagenetic sequence for reaction between quartzose sandstone and river water assuming zeroth order kinetics and a

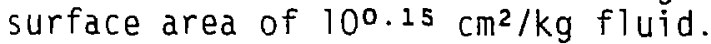

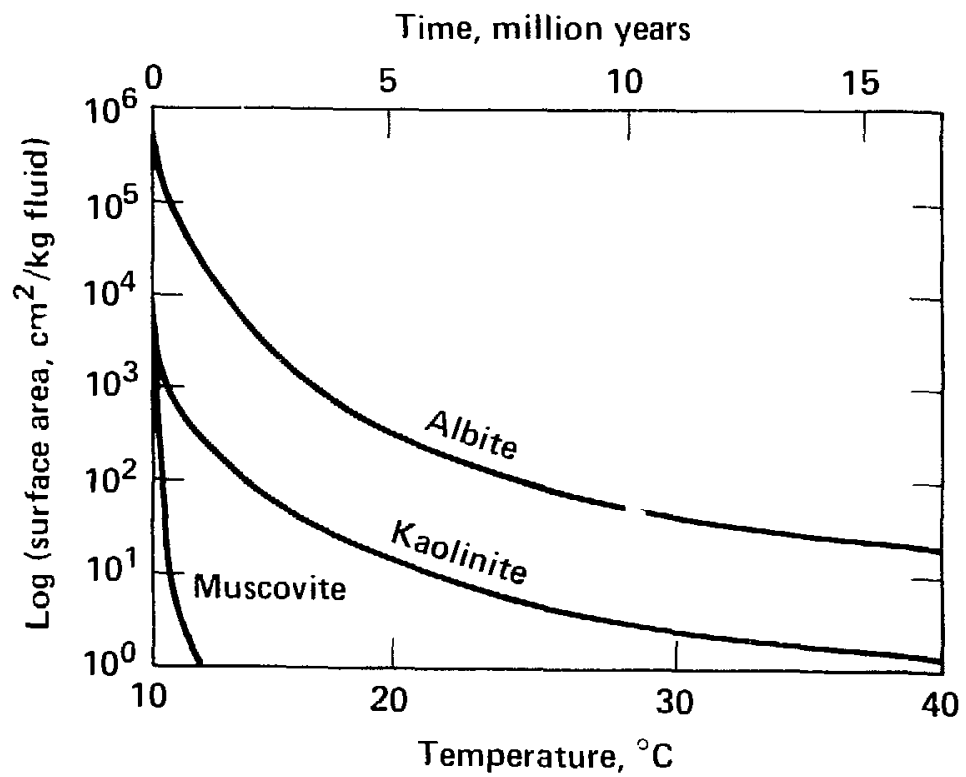

Figure 4. Temperature and timing of mineral equilibration as a funciion of the logarithm of surface area (in $\mathrm{cm}^{2} / \mathrm{kg}$ ) for reaction of quartzose sandstone with river water assuming zeroth order kinetics.

Assuming that total surface area equals effective surface area, albite precipitation occurs at less than $11^{\circ} \mathrm{C}$ in a sandstone with $1 \mathrm{~mm}$ grains and a surface area of $10^{5.15} \mathrm{~cm}^{2} / \mathrm{kg}$ fluid. Significant reductions in effective surface area are required to generate albitization at $100^{\circ} \mathrm{C}$, as is commonly reported in natural sequences. 
Synthetic diagenetic sequences for reaction between quartzose sandstone and river water calculated using transition state theory are shown in Figures 5 and 6 assuming surface areas of $10^{5.15}$ and $10^{3.15} \mathrm{~cm}^{2} / \mathrm{kg}$ fluid, respectively. Note the same strong dependence of the timing of diagenetic events on the choice of surface area a; otserved using a zeroth order rate law.

The above calculations suggest that either effective surface areas are many orders of magnitude smaller than total surface area, or phenomena in

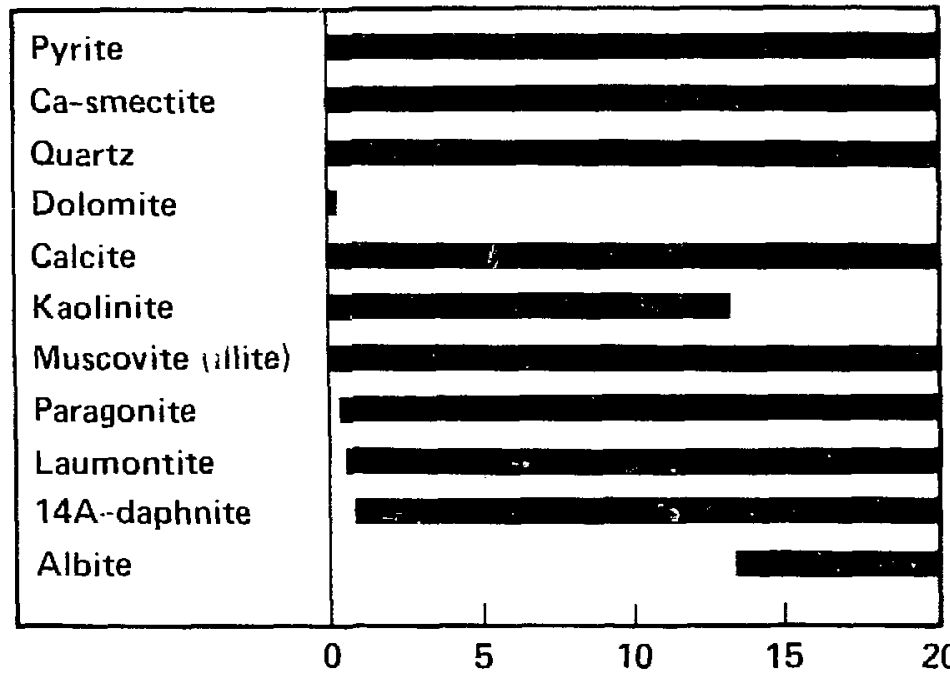

Time, million years

Figure 5. Synthetic diagenetic sequence for reaction between quartzose sandstone and river water assuming transition state theory reaction kinetics and a surface area of $10^{5.15} \mathrm{~cm}^{5} / \mathrm{kg} \mathrm{fluid}$.

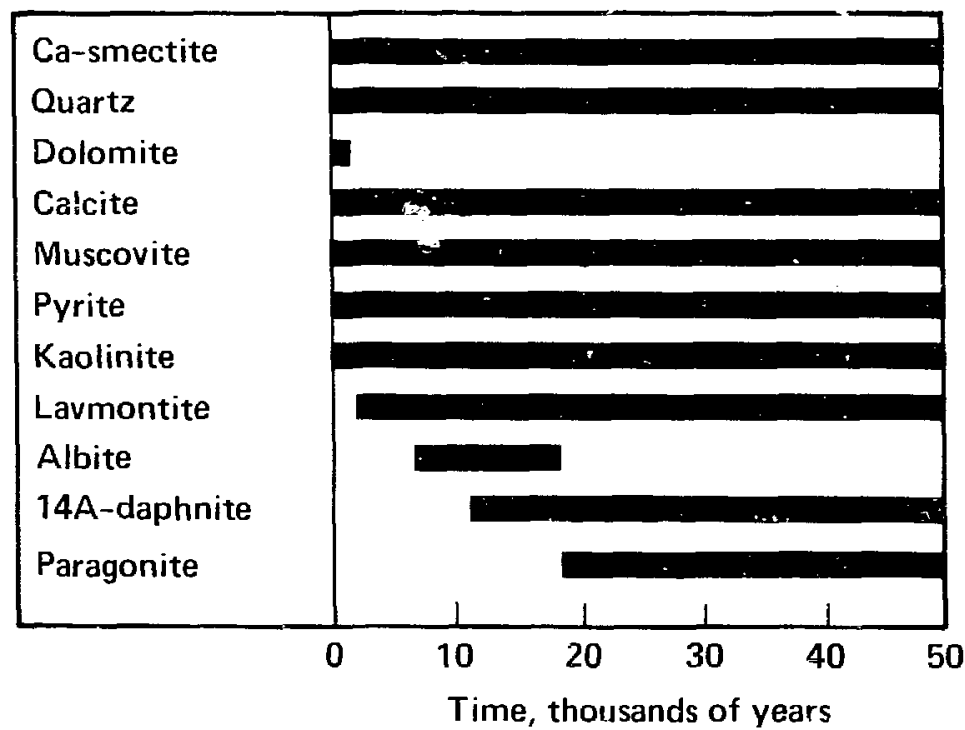

Figure 6. Synthetic diagenetic sequence for reaction between quartzose sandstone and river water assuming transition state theory reaction kinetics and a surface area of $10^{3,15} \mathrm{~cm}^{2} / \mathrm{kg}$ fluid. 
addition to the density of reactive surface sites affect rates of mineral dissolution. Precipitation kinetics, in particular, must be considered as a prime factor in the timing of diagenetic events. Phenomena whose effec's may have been implicitly included in the surface area term when matching observation with simulation results include poisoning of mineral surfaces by aqueous species, and armoring effects of pore-lining mineral precipitates. Effective application of kinetic models to the study of diagenetic processes requires explicit provision for precipitation kinetics and other potential ratecontrolling phenomena.

\section{Conclusion}

Synthetic diagenetic sequences correspond reasonably well with observed diagenetic sequences in natural systems. The interactions of various rock types and fluid compositions during burial can therefore be synthesizeu to produce alteration sequences that serve as a general guide to diagenetic changes with depth as a function of source terrane, depositional environment and burial history. The sequence of diagenetic events for reaction between a given rock and fluid is largely independent of the rate law used to describe mineral dissolution. Calculation of the absolute timing of diagenetic events, however, appears to depend not only on estimates of the reactive surface area of minerals but also on other rate-controlling phenomena.

\section{References}

DELANY, J. M., PUIGDOMENECH, I., and WOLERY, T. J. (1986) Precipitation Kinetics Option for the EO6 Geochemical Reaction Path Code, Lawrence Livermore National Laboratory, UCRL-53642.

HELGESON, H. C., MURFAY, W. M., and AAGAARD, P. (1984) Thermodynamic and kinetic constraints on reaction rates among minerals and aqueous solutions. II. Rate constants, effective surface area, and the hydrolysis of feldspar. Geochim. et Cosmochim. Acta, 48, p. 2405-2432.

KNAUSS, K. G., and WOLERY, T. J. (1986) Dependence of albite dissolution kinetics on $\mathrm{pH}$ and time at $25^{\circ} \mathrm{C}$ and $70^{\circ} \mathrm{C}$. Geochim. et Cosmochim. Acta, 50, p. 2481-2498.

LIVINGSTONE, D. A. (1963) Chemical Composition of Rivers and Lakes. U.S. Geol. Survey Paper, 440G.

MCBRIDE, E. F. (1983) Sandstone Diagenesis: Principles useful in exploration. New Orleans Geological Society Short Course, Nov. 17, 1983.

PETTIJOHN, F. J. (1975) Sedimentary Rocks. Harper and Row.

RIMSTIDT, J. D., and BARNES, H. L. (1980) The kinetics of silica-water reactions. Geochim. et Cosmochim. Acta, 44, p. 1683-1699.

WALTHER, J. V., and WOOD, B. J. (1986) Mineral-fluid reaction rates. FluidRock Interactions during Metamorphism. Springer-Verlag.

WOLERY, T. J. (1978) Some aspects of hydrothermal processes at mid-oceanic ridges- a theoretical study. I. Basalt-sea water reaction and chemical cycling between the oceanic crust and the oceans. II. Calculation of chemical equilibrium betwen aqueous solutions and minerals. Ph.D. thesis, Northwestern Univ., Evanston, I1l. 


\title{
MODELLING INTERACTION OF DEEP GROLNDWATERS WITH BENTONITE ${ }^{1}$
}

\author{
Hans llanner \\ OECD Nuclear Energy Agency. IEA Data Bank \\ 91191 Gif-sur-lictte Ceder. France
}

\begin{abstract}
Based on available experimental data on the interaction of sodium bentonite and groundwater. a model has been developed which represents mear; of extrapolation from laboratory data to the conditions in compacted bentonite. The basic reactions betueen sodium bentonite and grounduater are described by on ion-exchange model for sodium. potassium, magnesium and calcium. The model assumes equilibrium with calcite and quartz. All calculations are carried out for two types of granitic groundwater: the Swiss Reference Groundwater $(I=0.24 . M)$ and the Standard Swedish Groundwater $(I=0.0044 M)$. It is calculated that the pore water of compacted sodium bentonite will have a $\mathrm{pH}$ of 9.7 and a carbonate acticity of $8 \cdot 10^{-4} \mathrm{M}$ in the Suiss case, and $\mathrm{pH} \approx 10.2$ and $\left\{\mathrm{CO}_{3}{ }^{2-}\right\}=8 \cdot 10^{-3} \mathrm{M}$ in the Suedish case.

The long-term situation. which is important for nuclear waste disposal. is modelled by the assumption that the near-field of a radioactive waste repository behaves like a mixing tank. In this way, an attempt is made to account for the continuous water exchange between the near-field and the host rock. It is calculated that sodium bentonite will be slowly converted to calcium bentonite. The time period for this transformation is estimated to be in the order of $10^{\epsilon}$ years. deperding on the groundwater flow and composition and the dimensions of the repository.
\end{abstract}

\section{INTRODLCTION}

The understanding of the chemical processes occurring between bentonite and groundwater is very important for the safety assessments of final repositories for nuclear waste. because the extent of radionuclide release from a high-level waste reposit ory to the geosphere depends strongly on the solubility of these nuclides in the available groundwater. Deep repositories are preferrably envisaged to be backfilled with bentonite due to its considerable swelling capacity and low permeability. Hence. the solubility limits of the radionuclides in the bentonite pore water can be taken as upper limits for the radionuclide release from a repository into the geosphere. Based on available experimental data. this work describes a thermodynamic model which can be used to estimate the chemical composition of the pore water in compacted sodium bentonite. The modelled pore water composition can serve as a basis for the calculation of radionuclide speciation and solubility limits in the near-field of a deep repository (WANER 1986).

\footnotetext{
:This work has teen carrjed out at the Swiss Federal Institute for Reactor Research (EIR) in collaboration with the Vational Conperative for the Storage of Radiuacive Waste: (NAGRA).
} 


\section{THE BENTONITE MODEL}

Among the very few experiments performed to date to study the consequences of bentonite reaction with groundwater. only one deals with the gradual change of the chemical composition of groundwater when brought into contact with bentonite (SNELLMAN 1984). The results of a replication of this experiment (SNELLMA $\ 1985$ ) are listed in Table 1. showing

- no evidence that an equilibrium state is reached between the groundwater and the bentonite after 90 days.

- an increase of the sodium concentration in the liquid phase, accompanied by a decrease of the concentrations of calcium, magnesium and potassium.

- a marked increase of the alkalinity.

- a significant rise in $p \mathrm{H}$ during the first $\bar{i}$ days of contact followed by a surprising decrease during the subsequent time period, probably due to inadequate sampling (dissolution of $\mathrm{CO}_{2}$ from the air).

- the concentration of silicic acid remains more or less unchanged.

Tabie 1: Interaction experiments between $1500 \mathrm{~cm}^{3}$ of synthetic Standard Swedish Groundwater and $40 \mathrm{~g}$ of sodium bentonite MX-80 (SNELLMAN 1984 and 1985).

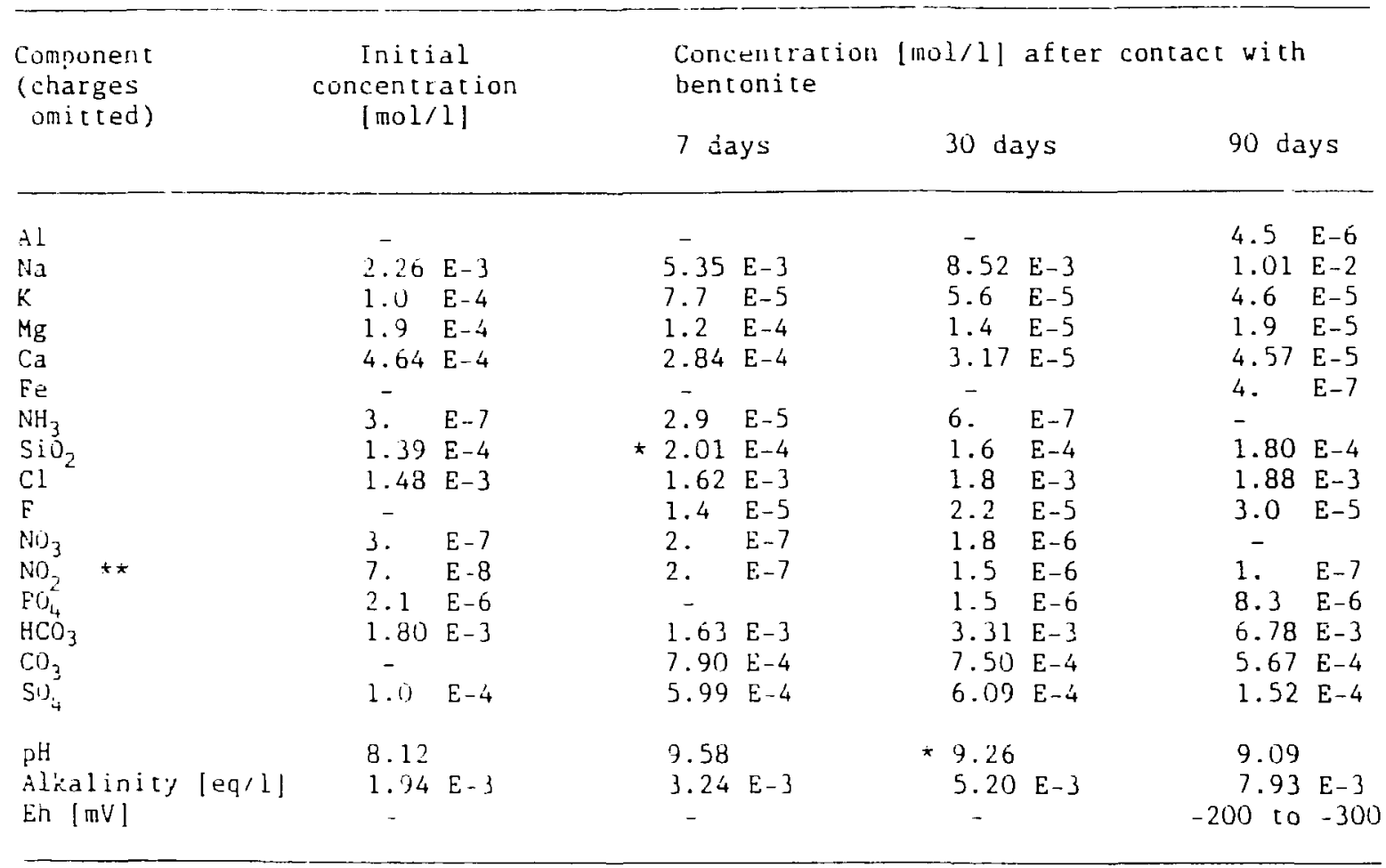

* Large differences in replicate samples

* Nitrite is not taken into consideration in the bentonite model. 
Assuming ion-diffusion reactions between the liquid in the packed bentonite powder and the bulk solution to be the rate deiermining processes (neglecting the possible occurrence of mineral transformation) and therefore the species in the analysed samples to be in thermodynamic equilibrium with each other. allows the use of the code MINEQL:EIR (SCHWEINGRLBER 1982 and 1984) to check the consistency of the experimental analyses. The results are shown in Table $2 a$ and reveil that the charge balance is not satisfactory for the $i$-days and especially the 30 -days analysis. which indicates some experimental inadequacy. Further. the bentonite solutions are found to be oversaturated with respect to calcite. Since the turbid samples had not been filtered before analysis (SNELLMAN 1985), it is possible that part of the turbidity consisted of precipitated calcium carbonate. Therefore, the speciation calculations are repeated, allowing calcium carbonate to precipitate as calcite. In this way, the total concentration of calcium, which is an important parameter for the development of the bentonite model discussed below, can be corrected for the amount of calcite precipitate. The results of these evaluations are listed in Table 2b. From these experimental results, the main reactions between sodium bentonite and groundwater can be described in the following way: Sodium ions in the bentonite exchange for calcium ions from the groundwater, which leads to a considerable decrease of the calcium concentration in the aqueous solution. The subsequent dissolution of carbonates from the sodium bentonite (limited by the solubility product of calcite) is the reason for the increase of the alkalinity (see Table 1) and of $p \mathrm{H}$ :

$$
2 \mathrm{Na}(\mathrm{ex})+\mathrm{CaCO}_{3}(\mathrm{c})-\mathrm{H}_{2} \mathrm{O} \rightleftharpoons \mathrm{Ca}(\mathrm{ex})+2 \mathrm{Na}^{-}+\mathrm{HCO}_{3}^{-}+\mathrm{OH}^{-}
$$

It is important to realize that a model of the chemical composition of pore water in compacted bentonite involves more than interpretation of laboratory data and qualitative extrapolation to the possible situation in a deep repository. Qualitative extrapolations are very difficult, especially if the dominating processes are ion-exchange reactions affecting key parameters such as the carbonate activity which is indirectly influenced by the calcium activity through the saturation equilibrium of calcite. The whole system is thus very sensitive to the proportion of calcium reacting with the bentonite and, since ion-exchange reactions are concerned, is very sensitive to the clay/water ratio. In the experiments performed to date, the clay, water ratio lies between 0.02 and 0.2 , whereas in compacted and water-saturated bentonite the ratio is around 5, i.e., one to two orders of magnitude higher. The chemical composition of the water in compacted sodium bentonite could therefore considerably deviate from that measured in the laboratory.

\section{Model Assumptions}

The model developed here. which can be applied to predict the pore water chemical composition in compacted sodium bentonite. involves a number of assumptions:

- It is assumed that thermodynamic models can be applied 10 describe the chemical processes occurring in water-saturated. compacted sodium bentonite.

- Sodium. potascium. magnesium and calcium are assumed to be the only ions participating in ion-exchange reactions between the sodium bentonite and the aqueous phase. The ion-exchange processes modelled are based on complex formation equilibria involving ion-exchange siies (represented as $Z^{-}$) of the montmorillonite and 
Table :- Specification of the water analyses listed in Tuble 1 by means of the code MINEQL EIR. assuming thernodynamic equilibrium between the dissolved species.

\section{Initial 7 days 30 days 90 days}

a) No precipitation assumed:

$\begin{array}{lcccc}\text { Charge balance }(\%) \star & +2.0 & +3.7 & +9.6 & +1.4 \\ \mathrm{pH} \text { calculated } & 8.15 & 9.66 & 9.45 & 9.02 \\ \log \mathrm{p}\left(\mathrm{CO}_{2}\right) & -3.09 & -4.63 & -4.14 & -3.41 \\ \log \mathrm{SI} \star \star \text { of calcite } & -0.03 & 1.06 & 0.14 & 0.20 \\ \text { log SI } \star \star \text { of dolomite } & -0.17 & 2.09 & 0.26 & 0.34 \\ \text { log SI } \star \star \text { of quartz } & 0.10 & 0.03 & 0.01 & 0.15 \\ \text { Ionic strength [mol/1] } & 0.004 .4 & 0.0073 & 0.0094 & 0.0108\end{array}$

b) Calcite Precipitation:

$\begin{array}{llccc}\text { Charge balance }(\%) \star & 2.0 & 3.9 & 9.6 & 1.4 \\ \mathrm{pH} \mathrm{calculated} & 8.15 & 9.53 & 9.44 & 9.01 \\ \log \mathrm{p}\left(\mathrm{CO}_{2}\right) & -3.09 & -4.51 & -4.14 & -3.40 \\ \mathrm{CaCO}_{3} \text { precipitated [mol/l] } & - & 2.53 \mathrm{E}-4 & 8.41 \mathrm{E}-6 & 1.60 \mathrm{E}-5 \\ \mathrm{Calc} \text {. calcium conc. [mol/1] } & 4.64 \mathrm{E}-4 & 3.09 \mathrm{E}-5 & 2.33 \mathrm{E}-5 & 2.97 \mathrm{E}-5 \\ \log \mathrm{SI} \star \star \text { of dolomite } & -0.17 & 0.92 & 0.12 & 0.14 \\ \log \mathrm{SI} \star \star \text { of quartz } & 0.10 & 0.09 & 0.01 & 0.16 \\ \text { Ionic strength [mol/I] } & 0.0044 & 0.0066 & 0.0094 & 0.0108\end{array}$

* Percentage difference between the total positive and the total negative charge, referred to the total positive charge.

$\star \star \quad S I=$ saturation index. SI is defined as the quotient of the ion activity product of the potentially dissolved free components of the solid, and the solubility product, Kso, of the solid. SI $>1$ $(\log \mathrm{SI}>0)$ represents oversaturation.

$\mathrm{SI}($ Calcite $)=\frac{\left\{\mathrm{Ca}^{2+}\right\} \cdot\left\{\mathrm{CO}_{3}{ }^{2-}\right\}}{\mathrm{Kso}\left(\mathrm{CaCO}_{3}\right)}$ 
the cations mentioned, as shown in the picture below. The ion-exchange sites are theoretically treated as simple ligands dissolved in the pore water. All sites are considered equivalent. carrying one negative charge and being capable of coordinating sodium. potassium. magnesium and calcium only. The energetics of the coordination reactions are described by equilibrium constants derived from the corrected andytical data of groundwater having been in conlact with sodium bentonite for 90 days at a temperature of $20 \mathrm{C}$ (Tables 1 and 26 ). and from data on the exchangeable cations of sodium bentorite $\mathrm{MX}-80$. From these data absolute values of the formation constants cannot be extracted. but they are chosen so high $(\log K(1)=20.0$, by definition) that virtually no uncoordinated sites. $Z^{-}$. exist. The derivation of these constants is described in detail elsewhere (WANNER 1986). The estimated constants are listed in Table 3.

- The pore water in compacted sodium bentonite is assumed to be saturated with respect to calcite and quartz. This assumption is not unreasonable as iong as enough carbonates are available in the bentonite. since most groundwaters are found to be ir equilibrium with these two minerals.

- Long-time extrapolations (which are of interest for safety analyses of nuclear waste repositories) are modelled for the dimensions of a potential Swiss high-level waste repository (NAGRA 1985). In the Swiss case. the main components of the near-field are the glass waste-matrix, a thick steel canister horizontally stored in a drift. and a backfill of highly compacted bentonite. The long-lerm beliaviour is modelled considering the near-field as a box or mixing tank. The groundwater which flows past the repository is modelled to mix with the near-field water and to leave the repository area with an altered composition resulting from the equilibrium with sodium bentonite. In this way, account is taken for the leaching of the bentonite.

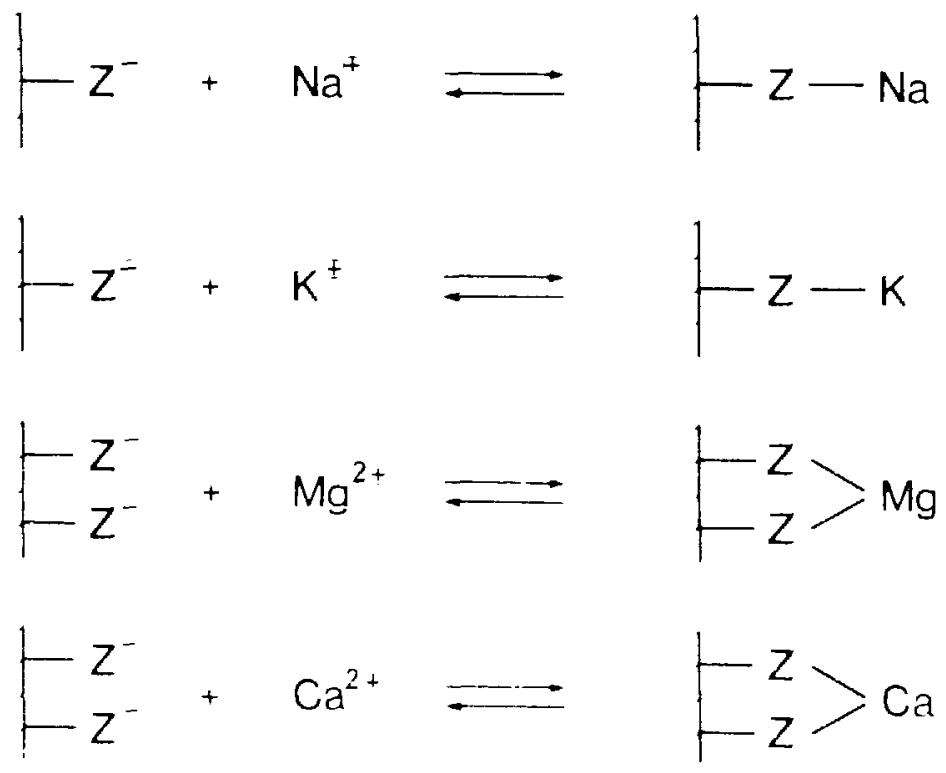


Table 8: Equilibrium constants calculated for the 4 fundamental reactions involved in the ion-cxchange processes considered: (1). (2). (3) and (4), and those derived for the ion-exchange reactions.

\begin{tabular}{|c|c|c|c|c|c|c|c|c|c|c|c|}
\hline (1) & & $z^{-}$ & - & $\mathrm{Na}_{\mathrm{a}^{-}}$ & $\therefore$ & $2 \mathrm{Na}$ & : & & & $\log k(1)$ & $=20.0$ (b) def.) \\
\hline$(2)$ & & $Z^{-}$ & - & $\mathrm{K}^{-}$ & $=$ & $\mathrm{ZK}$ & : & & & $\log K(2)$ & $=20.4$ \\
\hline (3) & 2 & $\mathrm{Z}^{-}$ & - & $1 \mathrm{Ig}^{2-}$ & $=$ & $\mathrm{Z}_{2} \mathrm{Mg}$ & : & & & $\log K(3)$ & $=41.7$ \\
\hline$(4)$ & 2 & $Z^{-}$ & - & $\mathrm{Ca}^{2-}$ & $=$ & $\mathrm{Z}_{2} \mathrm{Ca}$ & : & & & $\log K(4)$ & $=42.4$ \\
\hline (5) & & $\mathrm{ZNa}$ & - & $\mathrm{K}^{-}$ & $\rightleftharpoons$ & $\mathrm{ZH}$ & - & & $\mathrm{Na}^{+}$ & $: \log K(5)$ & $=0.4$ \\
\hline$(6)$ & 2 & $\mathrm{ZNa}$ & - & $\mathrm{Mg}^{2-}$ & $=$ & $\mathrm{Z}_{2} \mathrm{Mg}$ & - & 2 & $\mathrm{Na}^{-}$ & $; \quad \log \mathrm{K}(6)$ & $=1.7$ \\
\hline$(i)$ & 2 & $\mathrm{ZNa}$ & - & $\mathrm{Ca}^{2-}$ & $\Longrightarrow$ & $\mathrm{Z}_{2} \mathrm{Ca}$ & - & 2 & $\mathrm{Na}^{-}$ & $; \quad \log K(i)$ & $=2.4$ \\
\hline (8) & 2 & $\mathrm{Zh}$ & - & $\operatorname{Mg}^{2-}$ & $=$ & $\mathrm{Z}_{2} \mathrm{Mg}$ & - & 2 & $\mathrm{~K}^{-}$ & $: \log \mathrm{K}(8)$ & $=0.9$ \\
\hline (9) & 2 & $\mathrm{ZK}$ & - & $\mathrm{Ca}^{2}-$ & $\rightleftharpoons$ & $\mathrm{Z}_{2} \mathrm{Ca}$ & - & 2 & $\mathrm{~K}^{+}$ & $: \quad \log \mathrm{K}(9)$ & $=1.6$ \\
\hline$(10)$ & & $\mathrm{Z}_{2} \mathrm{Mg}$ & - & $\mathrm{Ca}^{2-}$ & $\rightleftharpoons$ & $\mathrm{Z}_{2} \mathrm{Ca}$ & - & & $\mathrm{Mg}^{2-}$ & $; \quad \log \mathrm{K}(10)$ & $=0 . \bar{i}$ \\
\hline
\end{tabular}

The Extrapolation Model

Two different types of groundwater are used for the application of the bentonite model. The Swiss Reference Groundwater is a deep-crystalline groundwater sampled in the granitic basement of northern Switzerland, at a depth of 1326 meters below the surface. The water is characterized by a relatively high degree of mineralization $(\mathrm{I}=0.24 \mathrm{M})$ and a calcium concentration of $21.7 \mathrm{mM}$ (WANNER 1986). The Standard Swedish Groundwater is a poorly mineralized granitic groundwater with $I=0.0044 \mathrm{M}$. Its composition is listed in Table 1 .

The extrapolation from the experimental conditions to those in compacted sodium bentonite. is modelled as a titration experiment. where the water is titrated with bentonite (represented by $\mathrm{Z}$ ) by increasing $\mathrm{Z}$ tot from $10^{-4} \mathrm{M}$ to $10 \mathrm{M}$. As counter-ions to $\mathrm{Z}^{-}$, the cations $\mathrm{Na}^{-}, \mathrm{K}^{-} . \mathrm{Mg}^{2-}$ and $\mathrm{Ca}^{2-}$ are introduced according to their proportional contribution to the ion-exchange capacity of sodium bentonite (see WANNER 1986). The changes of some parameters during the extrapolation process are presented in Figure 1 for both types of groundwater. The dotted vertical intersection at $Z_{\text {tot }}=3.35 \mathrm{M}$ gives the chemical composition of the pore water in saturated. compacted sodium bentonite. Although the pore water compositions given by these vertical intersections are similar for both types of groundwater. the buffering effect of the highly mineralized Swiss Reference Groundwater is obvious. Contrary to the Standard Swedish Groundwater. no major changes in the water composition would be expected if the experiment by Snellnian (SNELLMAN 1984 and 1985 , where $Z_{t o t}=1.95 \cdot 10^{-2} M$ ) were carried out with Swiss Reference Gioundwater. The assumption of calcite and quartz saturation leads to a tot al dissolution of $7.5 \cdot 10^{-3}$ mol $\mathrm{CaCO}_{3}$ and $9.3 \cdot 10^{-4}$ mol $\mathrm{SiO}_{2}$ per litre of swiss Reference Groundwater or $3.5 \cdot 10^{-2}$ mol $\mathrm{CaCO}_{3}$ and $6.9 \cdot 10^{\circ}$ mol $\mathrm{SiO}_{2}$ per litre of standard iwedish (iroundwater for $\mathrm{Z}_{t, *}$ $3.35 \mathrm{M}$. 
a: Swiss Reference Groundwater

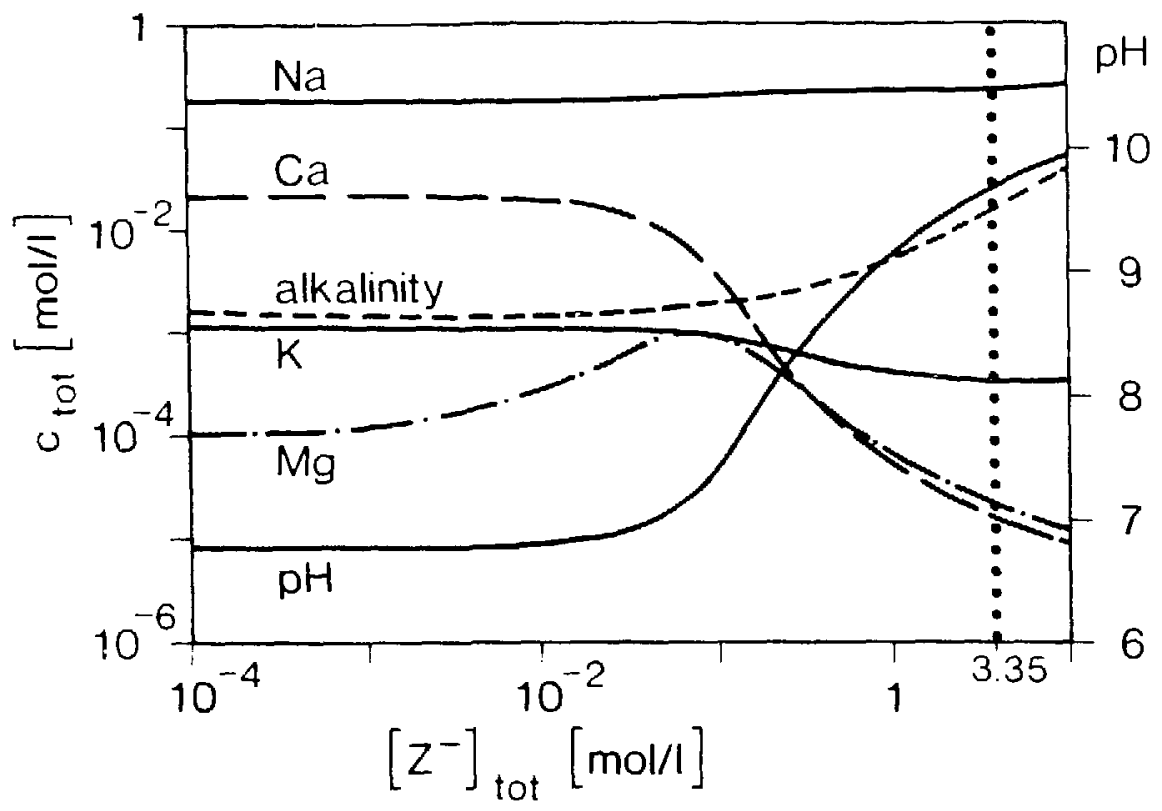

b: Standard Swedish Groundwater

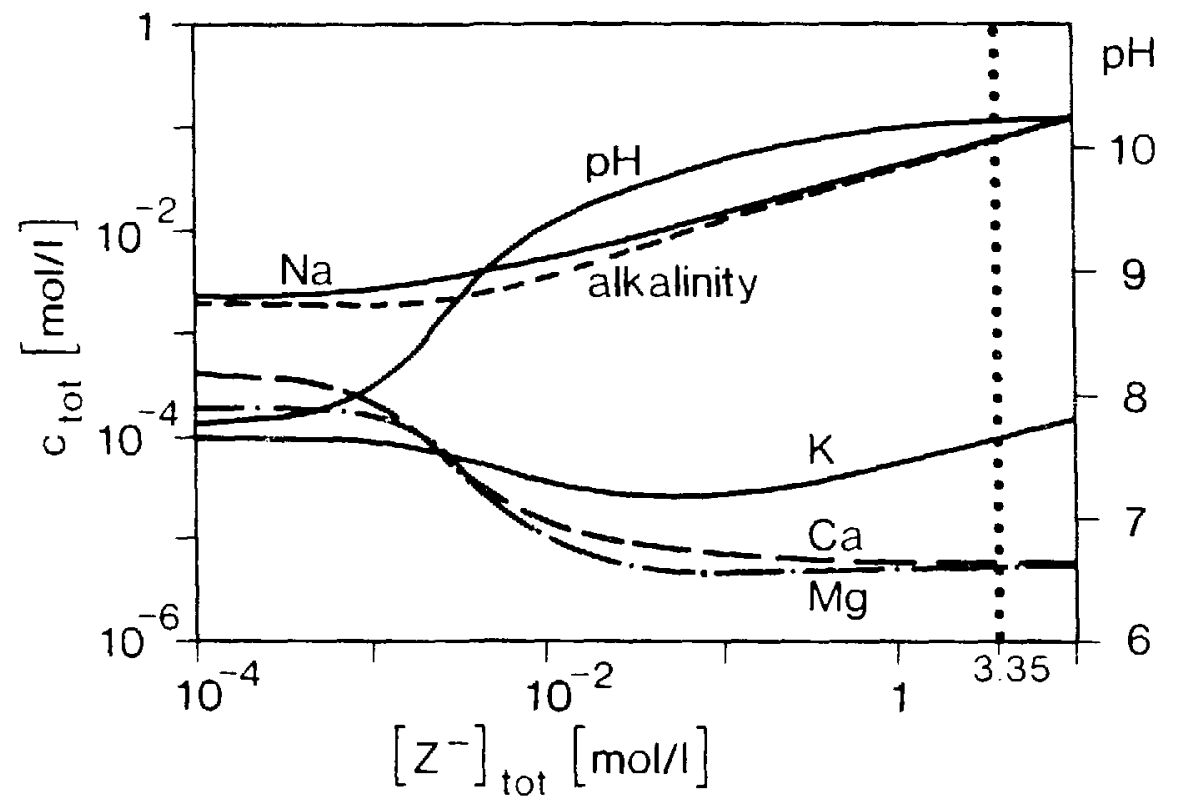

Figure 1: Nodelied change in the composition of Swiss Reference Groundwater (a) and Standard Swedish Groundwater (b) when brought into contact with an increasing quantity of sodium bentonite (represented by the tctal concentration of ion-exchange sites. $\mathrm{Z}^{-}$). Alkalinity is expressed in eq $\ell$. The dotted vertical line represents the predicted conditions in water saturated compacted sodium bentonite. 
In a final nuclear waste repository. the compositions of the bentonite backfill and the bentonite pore water will not remain constant. but will slowly change with time because diffusion of ions between the near-field and the host rock will take place. As it is important to know more about these long-time alterations, a very simple model is applied in order to yield information on trends of variation in the composition of the bentonite pore water in the very far future. The following calculations are based on the assumption that the near-field behaves like a mixing tank: Within a certain time period. the total volume of the equilibrated bentonite pore water is replaced by fresh groundwattr. which then contacts the new distribution of exchangeable ions in the bentonite. Again. the equilibrium state is calculated. This water exchange procedure is repeated a number of times $(\mathbb{N})$ for both types of groundwater. The total number of available ion-exchange sites. $\mathrm{Z}^{-}$. in the bentonite is assumed to remain constant. Taking the dimensions of a potential Swiss high-level waste repository (NAGRA 1985) and assuming a constant annual water flow of $0.71 \ell$ past each canister (containing $52.8 \mathrm{~m}^{3}$ bentonite. see WANNER 1986), the time period for one water exchange cycle $(N=1)$ is estimated to be roughly 30,000 years. The results of these calculations are presented in Figures 2 and 3 . In the case of Standard Swedish Groundwater, the available carbonates in the bentonite (initially $1.4 \%$, calculated as $\mathrm{CaCO}_{3}$ ) will be dissolved after about 35 water exchange cycles, which causes the $p \mathrm{H}$ to drop to that of the initial groundwater $(p H \approx 8)$. At this point, the pore water will be only poorly buffered with respect to $p \mathrm{H}$, and ion-exchange reactions involving $\mathrm{H}^{+}$will become important. In the case of Swiss Reference Groundwater, less than one sixth of the carbonate pool will be dissolved by this mechanism and be carried away. The $p \mathrm{H}$ of the near-field water will have returned to that of the host rock water after 60 to 70 water exchange cycles, indicating exhaustion of the ion-exchange capacity relative to the groundwater chemical composition. Figure 3 shows that the sodium bentonite will convert to calcium bentonite during this water exchange process.

\section{CONCLUSIONS}

The model presented here should be considered as a first attempt to quantitatively describe the most important short-and long-term chemical processes expected between groundwater and compacted sodium bentonite in a deep repository. Refinement and exterision of the model seems sensible only if an extended and consistent experimental data set on the bentonite-groundwater interaction is available. Although uncertainties in the ch.sen parameters. such as ion-exchange constants. are estimated to have no principal influence on the model predictions. it would be helpful to know more about the ranges of uncertainty and to reduce them as far as possible. The performance of a number of experiments under completely anaerobic conditions with systematic paraneter variations is suggested. e.g. variation of temperature. alteration of the bentonite-mass-to-water-volume ratio. and the use of a number of distinctly different groundwatcrs. Further developments should also try to model the slow effects of clay mineral alteration. 
a: Available carbonate
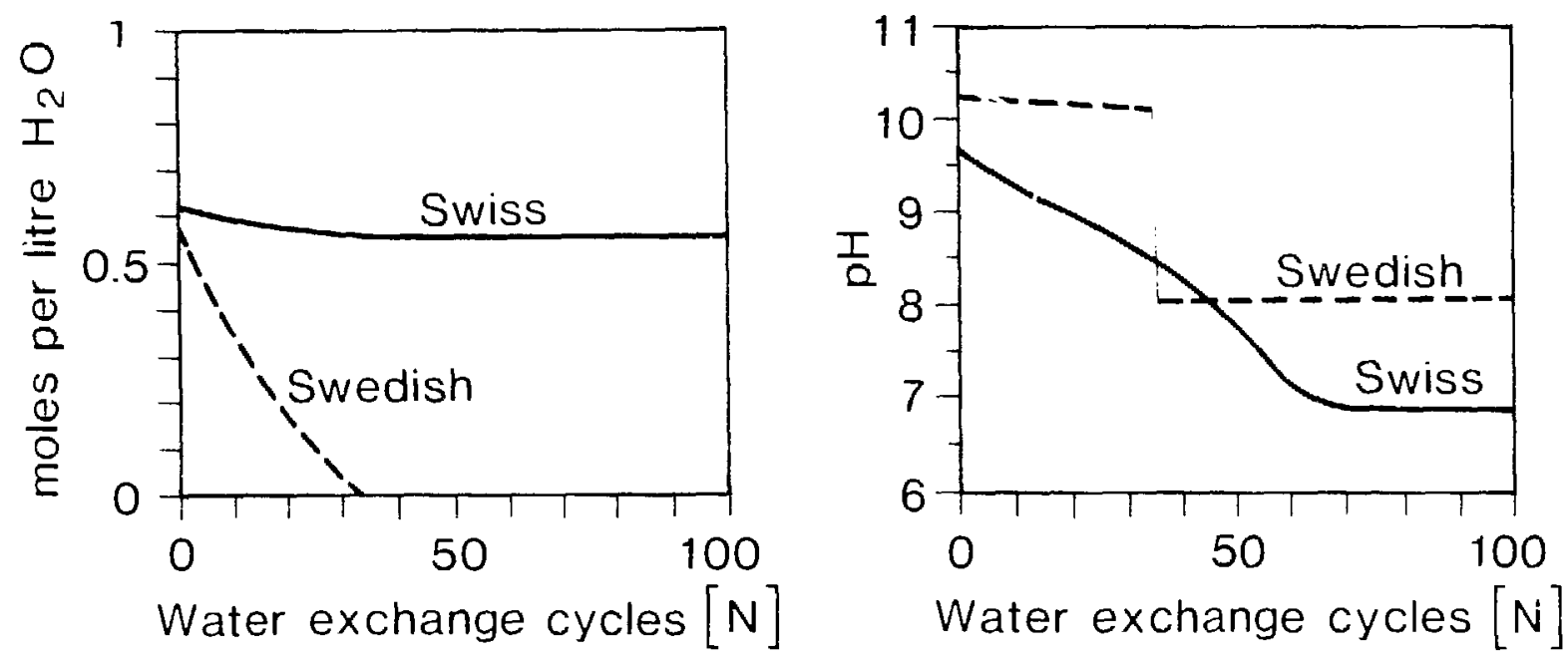

Figure 2: Long-term change in the carbonate reservoir (calculated as calcium carbonate available for 1 litre of water) present in sodium bentonite (a), as well as in the $\mathrm{pH}$ of the near-field pore water (b), calcula ed by application of the mixing tank model to the Swiss Reference Groundwater and to the Standard Swedish Groundwater (dashed).
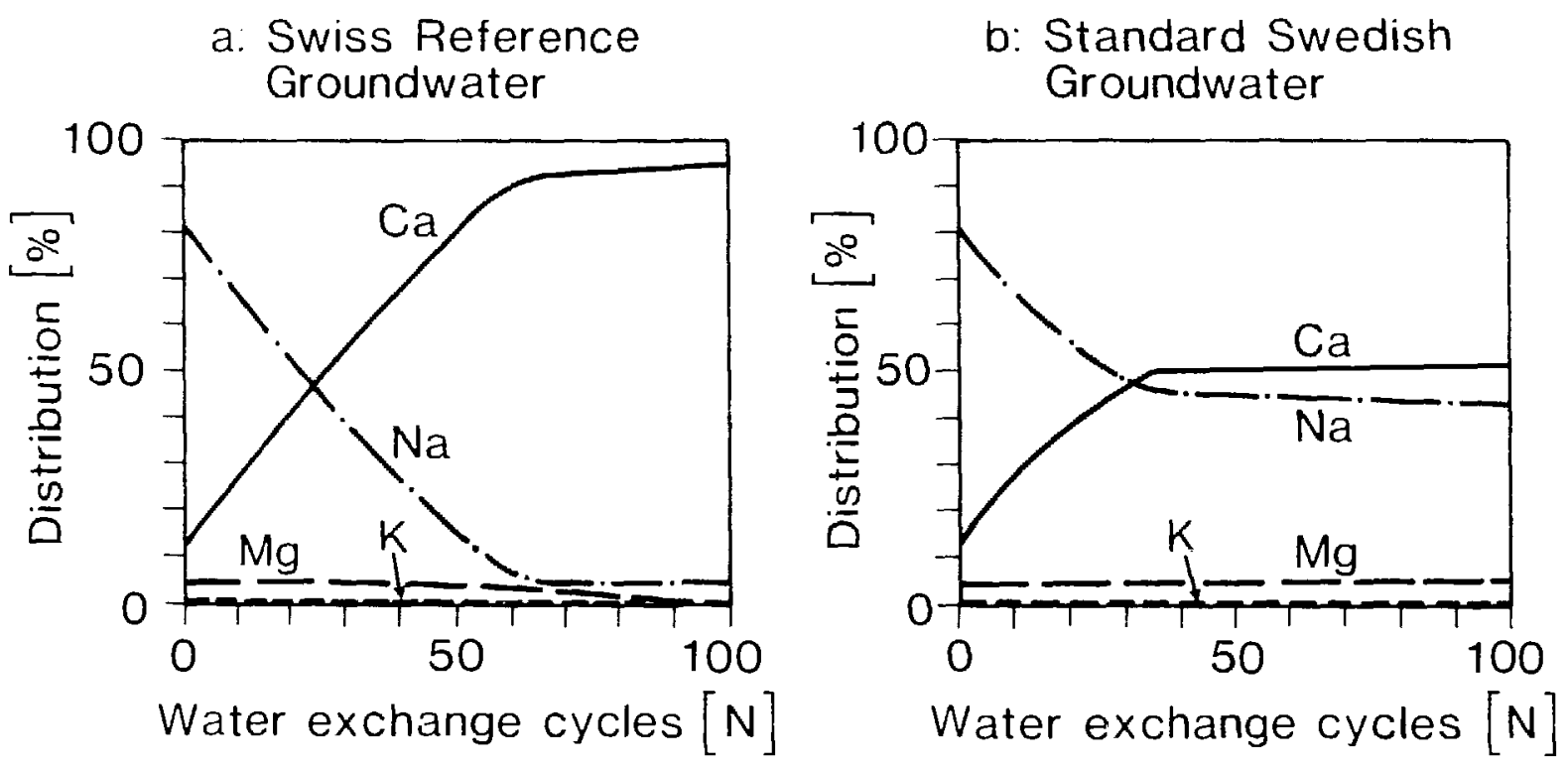

Figure 3: Alteration of the percentage distribution of exch cations in sodium bentonite as a function of exchange cycles by swiss Reference Groundwater (a) and Standard Swedish Groundwater(b). 


\section{REFERENC'ES}

XAGR (1985). Nuclear llaste Management in switzerland: Fasibility itudy and rafet!

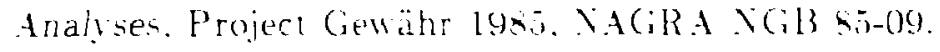

SCHWEINGRLBER M. (1982). (ser's Guide for Extended MNLEL (EHR version) -.. Standard Subroutine Data Library Package. EIR Internal Rejor TM-45-82-38.

SCHWEINGRLBER M. (1984). Rerision 1 of: L'ser's Guide for Extended MINEQL (EIR version) - Standard Subroutine Data Library Package. EIR Internal Report TM-45-8439.

SNELLMAN M. $(198+1)$. Chemical Conditions in a Repository for Spent Fuel. Report YJT$84-08.98 \mathrm{p}$.

SNELLMAN M. (1985), private communication.

WANER H. (1986). Modelling Interaction of Deep Groundwaters with Bentonite and Radionuclide speciation. EIR Report No. 589 and NAGRA ITB 86-21, 103p. 
EVALIIATION OF AN FOIILIBRIIIM SPECIATION MONEL. FOR THE ACID AOUEOIS IRON SILFATE SYSTEM AT $25^{\circ} \mathrm{C}$

\author{
Susan L. Stipn, \\ Environmental Fngineering, Stanford llniversity \\ Stanford, Calif., 94305
}

\title{
Abstract
}

A series ot solutions with known concentrations of $\mathrm{Fe}$ (II), Fe(III), and $\mathrm{SO}_{4}$ were prepared to cover the chemical composition and $\mathrm{pH}_{3}$ range common 1 y encountered in acid mine waters: $10^{-5}<\mathrm{Fe}_{\mathrm{T}}<10^{-2} \mathrm{~m}, 10^{-3}<\mathrm{SO}_{4} \mathrm{~T}<10^{-1} \mathrm{~m}$, $1<\mathrm{pH}<4$ and ionic strength $<0.35 \mathrm{~m}$. An ion speciation model was designed to calculate the roncentrations of all species from the total concentrations of solute and $\mathrm{H}^{+}$(derived from $\mathrm{pH}$ ) and the thermodynamic constants. From the species concentrations it was possible to calculate pe and the charge balance error. This provided two independent parameters with which to test the consistency of the model.

The model was found to be effective in predicting laboratory results for all waters. Slight discrepancies result from error in pH electrode measurements and from model parameter uncertainties such as activity coefficient estimations and equilibrium constants. Conditioning and calibration of the pH electrode in a buffer of similar concentration to tha unknown proves necessary for measuring solutions with $\mathrm{pH}<2 . n$. The model results are most sensitive to the method of calculating single-ion activity coefficients. Hse of the Truesdell-Jones equation yields the closest agreement for measured and predicted pe. Model predictions are less sensitive to equilihrium constant uncertainties for the various iron, hydroxide, sulfate and hisulfate pairs. Of these, the uncertainty in the dissociation constant for $\mathrm{FeSO}_{4}{ }^{r}$ has the greatest effect.

\section{Int roduction}

Waters in contact with non-carhonaze, pyrite-hearing rocks typically have low $\mathrm{pH}$, high concentrations of iron and sulfate and are capable of mohilizing toxic concentrations of heavy metals and rationuclides. Safe management of coal, base metal, and uranium mining and milling sites is facilitated by an ability to simulate and predict the chemical evolution of the ground and surface waters in these environments. NORDSTROM et al (1979) Eound that mineral solubility predictions in acid effluent may be limited by the uncertainty in ion activity coefficients at lower $\mathrm{pH}$, and by a lack of thermodynamic data for iron-bisulfate ion pairs, rendering speciation tenuous for waters with $\mathrm{pH}<2.5$. The purpose of this Daper is to test the predictive ability of an equilibrium speciation model for iron-sulfate waters with $\mathrm{pH}$ hetween $\mathrm{l}$ and 4 . 
Model Development

The equilihrium speciation model makes use of measured pH and known solution concentrations for input into mass halance equations, along with mass action expressions for acid/base and ion-ion association reactions. A Literature review was conducted to determine the uncertainty in the equilihrium constants. The retails are nresented in STIPP (19R3) and the species incorporated in the model are Listed in Table 1, along with their respective constants and the uncertainty associater with each.

When $\mathrm{pH}$ is moderately low and Fe( ILI) concentration is high, $\mathrm{Fe}(\mathrm{OH})^{2+}$ and $\mathrm{Fe}(\mathrm{OH})_{2}^{+}$are maior soecies. If sulfate is also nresent, ferric hydroxide complexes with $\mathrm{SO}_{4}^{2-}$ probably form. No data is renorted for these species, but comparison of $p K$ values for similar complexes indicates that constants for $\mathrm{Fe}(\mathrm{OH}) \mathrm{SO}_{4}{ }^{\mathrm{O}}$ and $\mathrm{Fe}(\mathrm{OH})_{2} \mathrm{SO}_{4}{ }^{-}$would be about 2.3 and $0.8,{ }_{4}+$ respectively. In waters with $\mathrm{pH}<2$, constants for FeHSO 4 and FeHSO; have heen measured but with considerable uncertainty. Constants for these four snecies were included in the model, one at a time, in order to test their effect on speciation. Pairing of $\mathrm{ClO}_{4}^{-}$with iron was found to have a negligible effect on speciation when tested with $\mathrm{pK}=0.9$ for dissociation of $\mathrm{FeClO}_{4}^{+}$(BEUKENKAMP and HERRINGTON, 1960) and $\mathrm{pK}=1.15$, for $\mathrm{FeClO}_{4}{ }^{2+}$ (SMITH and MARTELL, 1976).

The computational procedure applies an iterative approach in which each single-ion activity coefficient $(\gamma)$ is estimated and subsequently refined until convergence is attained. Three different equations for estimating $Y$, Debye-Hückel, Davies, (STUMM and MORGAN, 1981) and TRUESDELL-JONES (1974) were uset. The nebye-Huckel equation is:

$$
\log \gamma_{i}=\frac{-A z_{i}^{2} \sqrt{I}}{1+B_{i} \sqrt{I}}
$$

where I represents innic strength; $z_{i}$, the charge on species $i$; $a_{i}$, the parameter of closest approach (KIFII,ANN, 1937; RIITLF.D, 1964) and A and $\mathrm{p}$ are parameters dependent on temperature and pressure (HFLGESON and KLRKHAM, 1974). The navies equation is:

$$
\log \gamma_{i}=\frac{-A z_{i}^{2} \sqrt{T}}{1+\sqrt{\mathrm{I}}}+0.3 \mathrm{I}
$$

and the Truesdell-. Jones equation is:

$$
\operatorname{lng} Y_{i}=\frac{-A z_{i}^{2} \sqrt{I}}{L+B a_{i} \sqrt{T}}+0.3 L
$$

The dissociation constants for all reactions and the total concentrations of all dissolved constituents are specified in the speciation model, so $\mathrm{pH}$ may be independently calculated. However, by using measured $\mathrm{pH}$, pe may be predictel from the $\mathrm{Fe}^{3+} / \mathrm{Fe}^{2+}$ ratin with the Nernst equation. 


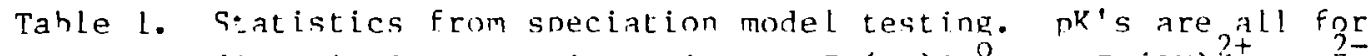
dissociation reactions, i.e., $\mathrm{Fe}(\mathrm{OH}) \mathrm{SO}_{4}^{\circ} \mathrm{Fe}(\mathrm{OH})^{2+}+\mathrm{SO}_{4}^{2-}$

Test for effect of:

pH Measurement Frror (calculations made using listed $\mathrm{pK}^{\prime} \mathrm{s}$ and $T-. \mathrm{I}$ model for $\gamma$ )

i T,iquid Junction Potential (L.JP) corrections matie for $\mathrm{nH}$ anit th measurements.

i i I.TP corrections onilled.

iii -0.1 adjustment made to $\mathrm{pH}<\mathrm{L} .7$ to partially compensate for electrode memory effect *

$\begin{array}{llll}0.94 & 0.97 & 0.45 & 0.74\end{array}$

$0.95 \quad 0.95 \quad 0.41 \quad 1.32$

$\begin{array}{llll}0.94 & 0.98 & 0.29 & 0.37\end{array}$

Model for $\gamma$ Estimation (calculations made using $\mathrm{pH}$ corrected for LJP and listed $\mathrm{pK}^{\prime} \mathrm{s}$ )

Ref

$\begin{array}{rlr}\text { i } & \text { Truesdell-.Jones } & 17 \\ \text { ii } & \text { Davies } & 16 \\ \text { i ii } & \text { Debye-Hückel } & 16\end{array}$

$\begin{array}{lll}0.94 & 0.97 & 0.45\end{array}$

0.74

i i Debye-Hückel

16

$0.94 \quad 0.82 \quad 2.15$

1.75

$0.93 \quad 0.88 \quad 1.45 \quad 2.09$

\begin{tabular}{|c|c|c|c|c|c|c|c|}
\hline \multicolumn{4}{|c|}{$\begin{array}{l}\text { Uncertainty in Equilibrium Constants } \\
\text { (with pH corrected Eor L.JP and T-J for } \gamma \text { ) }\end{array}$} & \multirow[b]{3}{*}{$n .94$} & \multirow[b]{3}{*}{0.97} & \multirow[b]{3}{*}{0.45} & \multirow[b]{3}{*}{0.74} \\
\hline Snecies & $\operatorname{Re} t \star \star$ & pK & Adiustment & & & & \\
\hline $\mathrm{H}_{2} \mathrm{n}$ & 15 & 13.997 & -0.003 & & & & \\
\hline $\mathrm{HSO}_{4}^{-}$ & 15 & 1.99 & -0.02 & 0.94 & 0.97 & 0.47 & 0.70 \\
\hline $\mathrm{KSO}_{4}^{-}$ & $1 ?$ & 0.85 & -0.02 & 0.94 & 0.97 & 1). 48 & 0.74 \\
\hline $\mathrm{Fe}(\cap \mathrm{H})^{2+}$ & 1,15 & 11.81 & -0.02 & 0.94 & 0.97 & 0.43 & 0.74 \\
\hline $\mathrm{Fe}(\mathrm{OH})_{2}^{+}$ & $i, 15$ & 22.3 & -0.1 & 0.94 & 0.97 & 0.43 & 0.74 \\
\hline $\mathrm{FeSO}_{4}^{\circ}$ & 15 & 2.2 & $\begin{array}{l}-0.1 \\
+0.1\end{array}$ & 0.94 & 1.0 & 0.09 & $\begin{array}{l}0.49 \\
1.03\end{array}$ \\
\hline $\mathrm{FeSO}_{4}^{+}$ & 15 & 4.04 & $\begin{array}{l}-0.1 \\
+0.1\end{array}$ & $\begin{array}{l}0.94 \\
0.94\end{array}$ & $\begin{array}{l}0.9 / 4 \\
1.0\end{array}$ & $\begin{array}{l}0.87 \\
0.00\end{array}$ & $\begin{array}{l}1.49 \\
0.00\end{array}$ \\
\hline $\mathrm{Fe}(\mathrm{SO},)_{2}^{-}$ & 15 & 5.38 & $\begin{array}{l}-1.0 \\
-7.1\end{array}$ & $\begin{array}{l}0.93 \\
0.94\end{array}$ & $\begin{array}{l}0.90 \\
0.95\end{array}$ & $\begin{array}{l}1.34 \\
0.67\end{array}$ & $\begin{array}{l}1.18 \\
0.84\end{array}$ \\
\hline $\mathrm{FeHSO}_{4}^{+}$ & 7 & n & $\begin{array}{l}+1.08 \\
+1.5\end{array}$ & $\begin{array}{l}0.95 \\
0.94\end{array}$ & $\begin{array}{l}0.96 \\
0.97\end{array}$ & $\begin{array}{l}0.53 \\
0.48\end{array}$ & $\begin{array}{l}0.20 \\
2.83\end{array}$ \\
\hline FeHSO & 7 & 0 & $\begin{array}{l}+2.47 \\
+1.5\end{array}$ & $\begin{array}{l}0.95 \\
0.94\end{array}$ & $\begin{array}{l}0.97 \\
0.97\end{array}$ & $\begin{array}{l}0.36 \\
0.44\end{array}$ & $\begin{array}{l}0.69 \\
0.57\end{array}$ \\
\hline $\mathrm{Fe}(\mathrm{OH}) \mathrm{SO}_{4}^{\circ}$ & esitimate & 0 & $+2 . ;$ & 11.94 & 0.98 & 0.28 & 0.73 \\
\hline $\mathrm{Fe}(\mathrm{OH})_{2} \mathrm{SO}_{4}^{-}$ & estimate & $n$ & +7.8 & 0.94 & $n .97$ & 11.45 & 0.74 \\
\hline
\end{tabular}

* maximim chare halance error improved fom $\pm 40 \%$ to $\pm 5 \%$ with lhis change. * fur more thorough literalire review see ftipn, 1983. 
Comparison of measured with predicted pe provides one check for testing reliability, and the calculated charge halance yields another. Speciation wis influenced bv the choice for $Y$ estimation, hy uncertainties in the equilihrium constants, and hy errors in $\mathrm{pH}$ measuremrnt. To study the effert of each source of uncertainty, the deviation factor was determined,

$$
\sigma_{E}=\frac{\Sigma\left(p e_{c}-p e_{T}\right)^{2}}{D F} \times 100
$$

where DF represents the degrees of freedom for the popitizion. If correlation hetween predicted and measured pe values is ideal, $\sigma_{f}=n \%$.

Fxperimental Method

The solutions for this stydy were prepared with total iron concentration ranging from $10^{-5} \mathrm{~m}(0.56 \mathrm{ppm})$ to $10^{-2} \mathrm{~m}(558 \mathrm{ppm})$ with $\mathrm{Fe}(\mathrm{III}) / \mathrm{Fe}$ (II) equal to 1 . The $\mathrm{pH}$ ranged from 1 to an upper limit determined by $\mathrm{Fe}(\mathrm{OH}) 3(\mathrm{~s})$ safuration. Sulfate concentration varied Erom $10^{-3} \mathrm{~m}(9 \mathrm{f} \mathrm{Dpm}) \mathrm{so}^{3} 10^{-1} \mathrm{~m}(9600 \mathrm{ppm})$. Although acid mine drainage waters have been found to contain more than $17,000 \mathrm{ppm}$ total iron, three times as much sulfate and $\mathrm{pH}$ as low as 0.55 (DUBROVSKY, I985; NORDSTROM, $19 ? 7$ and 1985), most waters from mine sites fall in the above concentration range. A more detailed description of the experimental procedure is presented in STIPP (1983).

The $\mathrm{pH}$ and Fh electrodes, huffers and test solutions were maintained at $25^{\circ} \mathrm{C}\left( \pm 0.1^{\circ}\right)$ in a water hath. The 0 -ion-Ross combination glass electrode was calihrated before and after each series of measurements with the 4.01 NBS buffer and a standardized $2.095 \mathrm{pH} \mathrm{H}_{2} \mathrm{SO}_{4}$ solution and checked with 1.68 $\mathrm{pH}$ tetroxalate and $1.0 \mathrm{nH} \mathrm{HCl}+\mathrm{KCl}$ buffers. The Markson 1202 platimun F.h electrode was polished periodically with very fine emery paper to remove surface alteration prodicts (WHITFIELn, 1971) and was calihrated in 7oBell solution (NORDSTROM, 1977). All measurements were corrected for drift of potential with time, and for liquid iunction potentials using the Henderson equation (PLIMMER and BUSENBERG (1982). Reproducibility for pH measurements was $\pm \cap .02 \mathrm{pH}$ units and for $\mathrm{Th}$, was hetter than \pm 0.025 pe units $( \pm 1.48 \mathrm{mV})$ except for samples where iron concentration was $\leq 10^{-5} \mathrm{~m}$.

Results

The full data set is rresented in STIPP (1983). Figure 1 shows all data for predicted pe plotted as a function of measured pe. The pe calculations were made with Truesdell-Jones $\gamma$ estimates and the equilibrium constants listed in Table 1 . For ideal correlation, the line of hest fit would have a coefficient of determination $\left(r^{2}\right)$ and slope $(\beta)$ of $1 . n$, and a $y$-intercept $(\alpha)$ and deviation factor $\left(\sigma_{f}\right)$ of $n \%$. For the actual iata, $r^{2}$ was 0.94 for a population size $(\pi)$ of 130 points; $\beta=0.97$ was not siqnificantly different than 1.0 at the $95 \%$ confidence 1 imit; $\alpha$ was $0.45 ; \sigma_{F}$ was $0.74 \%$. The significant rortelation of the data and the closeness of the line of hest $f i t$ to the ideal line demonstrate the effectiveness of the conventional model in tescribing speciation in acid mine waters. 


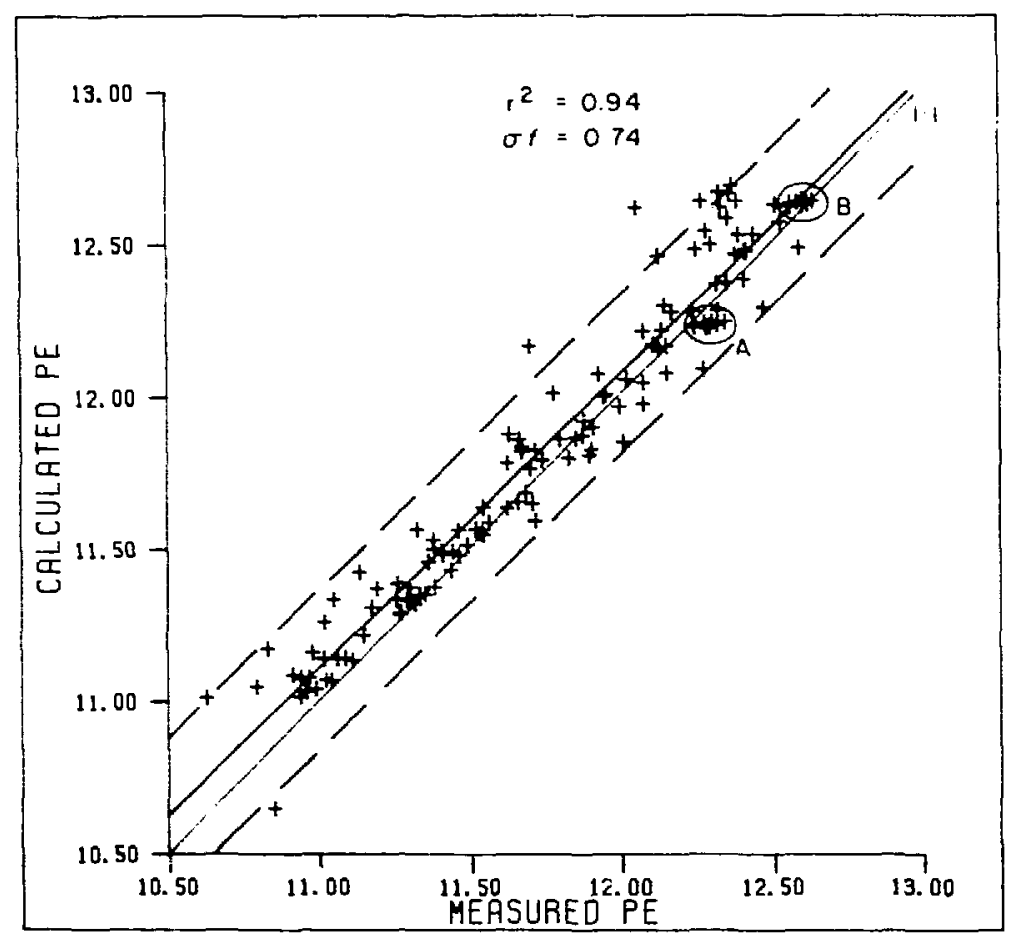

Figure 1. Plot of pe predicted by the speciation model versus measured pe for all data. Single-ion activity coefficients were determined with the Truesdell-Jones equation. The line of hest fit for this data is not significantly different than the $1: 1$ line. The $95 \%$ confidence 1 imits are shown by dashed lines $( \pm 0.27$ De units or $16 \mathrm{mV})$. The points marked $A$ and $B$ represent solutions containing only iron and perchloric acid, no sulfate.

\section{Discussion}

Although the morel predicts pe without significant deviation at the $95 \%$ confidence limit, systematic differences in the data do exist. The degree of discrepency varies, depending on the $\mathrm{pH}$ and the composition of the test solution. These differences are attributed to the following sources:

1) uncertainties in electrode measurement,

2) the method for estimation of single-ion activity coefficients, and

3) the uncertainties in equilibrium constants and/or the existance of ion pairs not accounted for in the speciation morlel. The $\mathbf{I}$ : Lative effects of these sources of uncertainty are evaluated and discussed in the following paragraphs.

Electrode Response. The uncertainty in the electrode measurements was evaluated by an analysis of $\mathrm{pH}$ measurement error and by a test of the imfortance of the liquid junction potential correction for both $\mathrm{pH}$ and $\mathrm{Fh}$ electrodes. The charge balance error showed an increase in anion excess with decreasing $\mathrm{pH}$ and an imbalance of as much as $40 \%$ in solutions with $\mathrm{pH}$ below $1 . n$. The input concentrations of all major constituents except $\mathrm{H}^{+}$ 
were known with less than $2 \%$ uncertainty. The $\mathrm{H}^{+}$concentrations, however, were derived from measured $\mathrm{pH}$. The logarithmic nature of $\mathrm{pH}$ and the dominance of $\mathrm{H}^{+}$as a cation in acid solutions result in magnification of the uncertainties derived from errors in the $\mathrm{\gamma}_{H^{+}}$estimate and the $\mathrm{pH}$ electrode readings. Fstimated $Y_{H}+$ varies, depending on the morlel selected. Large negative charge imbalances were calculated for solutions with $\mathrm{pH} \leq 1.5$ by all models, so error in $\gamma_{H^{+}}$estimation could be only part of the cause for the large apparent $\mathrm{H}^{+}$deficit.

For this study, the $\mathrm{pH}$ electrode was stored in $4.01 \mathrm{pH}$ NBS buffer. Measurements were reproducible $( \pm 0.02 \mathrm{pH}$ units) but where $\mathrm{pH}$ was less than 1.7 , slight and prolonged downward drift of potential was observed. Additional experiments were performed in pure $\mathrm{H}_{2} \mathrm{SO}_{4}$ ranging in concentration from 0.05 to $5 \mathrm{M}$ to test electrode performance with different methods of conditioning and calibration. Measurements made with an electrode that was conditioned in the $1.0 \mathrm{pH}$ huffer for several hours, then calibrated with 4.01 and 1.00 buffers, were remarkably stable. They reflected no memorv effect when compared with pH calculated by speciation nrograms using both Pitzer and Truesdell-.Iones models for $Y$ estimation. Readings for the $\mathrm{Fe}^{-}$ $\mathrm{SO}_{4}-\mathrm{H}_{2} \mathrm{O}$ test solutions with $\mathrm{pH}<1.7$ were adjusted by -0.1 pH units; the maximum charge halance was reduced to $\pm 5 \%$ and predicted pe was much closer to the experimental data (Table 1). It is recommended that electrores for use in solutions where $\mathrm{pH} \leq 2$, he conditioned for several hours hefore use and calibrated with a huffer of acid similar in composition and pH to the solution to be measured.

Liquid iunction potential corrections (less than 0.03 pe or pH units of $2 \mathrm{mV}$ ) are within the reproducibility of the readings. Although correction with this systematic error significantly improved the correlation for experimental data, it need not be considered in routine field measurements.

Activity Coefficients. Single-ion activity coefficients form one set of speciation model parameters. Substantially different $Y^{\prime} s$ result, depending on which estimation method is chosen. For example, at $\mathrm{I}=0.05 \mathrm{~m}$, the $\gamma^{\prime} \mathrm{s}$ for the di- and tervalent species vary by 15 and $50 \%$, respectively. At the maximum ionic strength of the study solutions ( $I=0.36 \mathrm{~m}$ ), $Y^{\prime}$ 's vary by as much as $20 \%$ for the monovalent species, and by $92 \%$ for $\mathrm{Fe}^{3+}$. This contributes significantly to the uncertainty of the morel results for I $>0.05 \mathrm{~m}$ (Table 1$)$.

Estimations made with the Debye-Hückel equation do not include a correction for the ion interaction effect, so $\gamma$ uncertainty increases with ionic scrength. As a result, the predicted pe for solutions with high sulfate, high iron, or low $\mathrm{pH}$ are consistently higher than the measurements. With Davies morlel estimations, predicted ne was significantly rifferent than measured pe at the $95 \%$ confidence limit. Comparison of the statistics for the three models suggests that for this system, Yestimations are suhstantially improved hy the inclusion of both the hydrated size parameter ( $a_{i}$ ) and the ion interaction term $(n .3 I)$ with the Trusdell-innes equation.

Equilibrium Constants. Speciation was tested for sensitivity to the uncertaintv in each of the eruilihrium constants. The statistics are tabulated in Table $\mathrm{l}$. The $\mathrm{Fe}-\mathrm{H}_{2}$ n system has heen investigated more fullv 
than the one containing $90_{4}$ and there $i s$ less uncertainty in the data. The uncertainty effect is further minimized hy the low relative concentration of iron hydroxide species in acid, high sulfate waters. Large pk uncertaintv thes not necessarilv result in larger differences in predicted coilcentrations. Fesn ${ }_{4}^{+}$is often an ahumiant snecies in acitt mine ant tailings water; a small change of 0.1 to the $\mathrm{pK}^{\mathrm{k}}$ resulted in a shift of $o_{f}$ for the test solutions from 0.74 to $1.49 \%$, whereas the much larger adjustinent $n f$. $n$ to the $\mathrm{pK}$ for $\mathrm{Fe}\left(\mathrm{SO}_{4}\right)_{2}$ - resulted in a change in of from 0.74 to $1.18 \%$. The model results were tested for the effect of inclusion of the uncertain pK's for $\mathrm{Fe}(\mathrm{OH}) \mathrm{Sn}_{4}{ }^{2}, \mathrm{Fe}(\mathrm{OH})_{2} \mathrm{SO}_{4}{ }^{-}$. FeHSO ${ }_{4}^{+}$and $\mathrm{FeHSO}_{4}{ }^{+}$. Predicted concentrations were not significantly affected hy the constants for the ferric hudroxidesulfate complexes. Inclusion of constants for the iron-bisulfate nairs slightly improved the relationship hetween measured and predicted pe.

Conclusions

Equilihria in the aqueous acid iron-sulfate system at $25^{\circ} \mathrm{C}$ can reliablv he predicted using a speciation program which incorporates presently accepted equilihrium constants. If the $\mathrm{pH}$ and solute concentrations are known, the model is effective in predicting pe within \pm 0.26 pe units ( \pm ! $\mathrm{mV}$ ) at the $95 \%$ confidence level, over the typical range of composition for acid mine and tailings water. Uncertainties in the predictions result from error associated with $\mathrm{pH}$ electrode measurements and from uncertainty in the two main sets of model parameters: single-ion activity coefficients and the equilibrium constants.

For solutions where $\mathrm{DH}$ is less than 1.7 , large charge imhalance is caused hy error in calculated $\mathrm{H}^{+}$concentration. This imbalance partly results from uncertainty in $\gamma_{\mathrm{H}}{ }^{+}$estinates, but mostly is a function of the technique adopted for conditioning and calihrating the $\mathrm{pH}$ electrode. The model predictions are slightly sensitive to the correction for the liquid junction potential for all measurements with the th and $\mathrm{pH}$ electrodes. Speciation is most sensitive to uncertainties in the estimates for activity coefficients. Of the three methods used, the Truesdell-Jones equation produced the least difference hetween measured and nredicted ne values. The model resilts are not sensitive to changes in $\mathrm{pk}$. for any of the ironhyrroxite complexes. They are sensitive to uncertainties in equilibrium constants for iron-sulfate pairs, particularly Fesn ${ }_{4}^{+}$. Predictions are affected hy inclusion in the model of approximated constants for $\mathrm{FeHSO}_{4}^{+}$and $\mathrm{FeHSO}_{4}^{2+}$

In summary, the equilibrium speciation model for the aqueous acid ironsulfate system, as outlined in this paper, is satisfactory for predicting species concentrations at ionic strengths less than $0.4 \mathrm{~m}$ in the pH range of 1 to 4. To insure accurate predictions using the model in application to real field data where $\mathrm{pH}<2.0$, care must he taken to condition and calibrate the pH electrode in a buffer of similar acid concentration to the unknown. Aside from difficulty in pH wasurement helow 2.0 , the greatest source of uncertainty in model predictions lies with the method of calculating single-ion activity coefficients. Incertainties in the equilibrium constants of the species invrived appear to be of secondary imnortance. 
I wish to thank FRIC I. REARDON for guidance and sunport and D. KIRK VORDSTROM for discussion and encouragement. Financial support was provited hy the vatural Sciences and fingineering Research Council of Canada at the University of Waterlon, nntario.

\section{References}

L. BAES C.F. IR. and MESMER R. F. (1976) The Hydrolysis of Cations. Wiley.

2. BEUKENKAMP .I. and HERRINGTON K.D. (1960) Lon-exchange investigation of the nature of iron (II) in sulfuric and perchloric acid. I. Amer. Chem. Soc. $82,3022-3025$.

3. RUTLER. N. (1964) Ionic Fquilihrium. Addison Wesley.

4. DIRROVSKY N. (1985) Ph.n. Thesis, Iniversity of Waterloo.

5. HELGESON H.C. and KIRKHAM N.H. (1974) Theoretical prediction of the thermodynamic hehavior of aqueous electrolytes at high pressures and Lemperatures: Part I I. Amer. I. Sci. 274, 1199-126l.

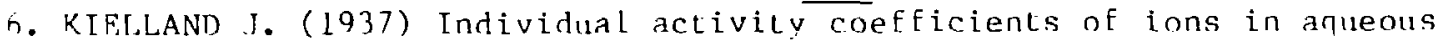
solutions. T. Am. Chem. Soc. 59, L675-1678.

7. MATTIGOD S.V. and SPOSETO 6. ( $\overline{1977)}$ Fstimated association constanls for some complexes of trace metals with inorganic ligands. Soil Science Soc. of Amer. J. 41, 1092-1097.

8. NORNSTROM N.K. ( $19 \overrightarrow{77})$ Thermochemical redox equilibria of 7oRell's solution. Fnechim. Cosmochim. A. 41, 1835-1941.

9 VORDSTROM ח.K., JFNNE F.A. and RAI.L.J.W. (1979) Rerox equilibria of iron in acid mine waters. In: Chemical Modeling in Aqueous Systems. IFNNE E.A. (ed), ACS Sumposium Series $03,51-79$

10. NORDSTROM, ח.K. (1985) The formation of acid mine waters: $\beta$ review. In: RONNFR A.T. (ed). Proc sertings of the Hazardous Materials Management Conference/West, Long Beach, Cálif. Dec. 3-5, 1995, 453-457.

11. PIITMMFR, L.N. and BISFFRFRG F. ( 1982$)$ The solubilities of calcite, aragonite and vaterite in $\mathrm{CO}_{2}-\mathrm{H}_{2} \mathrm{O}$ solutions between $n$ and $90^{\circ} \mathrm{C}$, and an evaluation of the aqueors model for the system $\mathrm{CaCO}_{3}-\mathrm{CO}_{2}-\mathrm{H}_{2} \mathrm{O}$. Fenchim. Cosmochim. A. 4h, 1011-1040.

12. REARDON F..J. ( $\overline{1975})$ Dissociation constants of some monovalent sulfate ion pairs at $25^{\circ} \mathrm{C}$ from stoichiometric activity coefficients. J. Phys. Chem. $79,422-425$.

13. RORINSON R.A. and STOKES R.H. (1970) Electrolyte Solutions. Butterworths.

14. SAPIESZKO R.S., PATFI, R.C. and MATIJEVIC, E. (197\%) Ferric hydrous oxide sols: 2. Thermodynamics of aqueous hydroxo-and sulfato ferric complexes. J. Phys. Chem. 81, 106L-1068.

15. SMITH, R.M. and MARTELL A.E. (1976) Critical Stability Constants. Plenim.

Lh. STIPP S.I. ( 1983$)$ Evaluation of an equilibrium speciation model for the aqueous iron-sulfate system at $25^{\circ} \mathrm{C}$. MSc Thesis, Iniversily of Waterloo.

17. STIMM W. and MORSAN .J.I. (19RL) Aquatic Chemistry, Wilev.

18. TRIIESDEIL A.H. and JONFS B.F. ( 1974$)$ WATFO, A computer program for calculating chemical equilibria of natural waters. I. Pes. IIScs 2 , 233-248.

19. WHITFIFLn 4. (197L) Inn Selective Filectrodes for the Analysis of Vatural waters. Aust. Mar. Sci. Assoc., Handbonk ?, Sydnev. 


\title{
THERMODYNAMIC AND KINETIC MODELING OF GLASS LEACHING IN A WASTE PACKAGE ENVIRONMENT
}

\author{
B. Grambow \\ Hahn-Meitner-Institut Berlin, \\ Glienicker Str.100, 1000 Berlin 39, FRG
}

\section{Abstract}

Modeling of the aqueous dissolution of nuclear waste forms is a necessary step for extrapoiating short term laboratory results to the long-term performance in a repository. For nuclear waste borosilicate glasses a dissolution model (GLASSOL $[1,2]$ ) is proposed, which combines thermodynamic reaction path calculations (PHREEQE code [3]) with kinetic constraints. The model was developed in the frame of the JSS-project (joint Japanese, Swedish, Swiss Project) to allow interpretation of leach data from a radioactive glass delivered from COGEMA ("JSS-A" glass) [4]. Experimental conditions include leach tests in static and flowing solutions, variations of temperature, $\mathrm{pH}$ and S/V (sample surface area-to-solution volume ratio) and the presence of various waste package components (i.e. bentonite or steel corrosion products). The ongoing validation of the model is performed by a description of all major experimental results and by its application to natural analogue systems $[2,5,6]$. This papei gives an overview of the key ideas in the model, and, for some experimental conditions, the results of computer simulations are compared with laboratory data.

Mechanism of glass corrosion

The release of glass constituents is controlled either by matrix dissolution, by solubility, or by sorption processes. Selective extracation of alkali ions from the glass matrix plays only a minor role in the overall mass balance of the reaction [7]. During reaction, surface layers of sparingly soluble glass constituents are formed. Solid reaction products include both crystalline and amorphous products. The actual reaction occurs at the interface (reaction zone thickness $<0.1$ um) between the pristine glass and the surface layer.

At high dilution (i.e. high flow rates) and in the absence of low permeable surface layers matrix corrosion proceeds with constant rate ("forward rate $k+"$ ). If dissolved silica accumulates in solution (static or slow flow rate leach tests), the rate decreases substantially due to saturation effects. The glass phase will never be in equilibrium with the bulk solution, but at saturation condensation of surface silanol groups stabilizes the glass [1]. A residual affinity of reaction remains at silica saturation and the reaction proceeds at a slow rate until the glass has completely reacted in the long term. In the presence of low permeable surface layers a gradient of silicic acid may be established and the rate of reaction may slow down faster than predicted from solution concentration alone [8].

Both the initial rate and the saturation concentration of total silica depend on the solution $\mathrm{pH}$, which usually changes with reaction progress. 
means of changing $\mathrm{pH}$ and silica concentration, waste package components can influence the release of radionuclides. For example, in the presence of cast iron corrosion products, silica is removed from solution by sorption onto the $\mathrm{Fe}$-corrosion product and the dissolution rate of the glass is increased [9].

\section{Rate Equation}

A general rate equation is proposed [1] based on equilibrium and irreversible thermodynamics and on transition state theory. In its simplest form, this equation may be given as

$r_{m}=k+\star\left(1-a_{s} j / a_{s a t}\right)$

where $r_{m}$ is the dissolution rate, $k+$ is the rate constant for the forward reaction, asi is the actual activity of ortho silicic acid in solution and asat is the corresponding activity at saturation. The values of $k+$ and asat can be derived from the experimental data [5]. Alternatively, within a factor of three of uncertainty, $k+c a n$ be calculated from the free energy of reaction $d G_{R}[1]$ using the equation:

$k_{+}=x * \exp \left(-d G_{R} / R T\right) * \exp \left(-E_{A} / R T\right)$

where $x$ is a proportionality constant and $E_{A}$ is the activation energy (ca. $50-120 \mathrm{~kJ} / \mathrm{mol}$ ). The free energy dG depends both on glass composition and on $\mathrm{pH}$. Calculation of $d G$ is based on a solid solution model for the glass phase $[10,1]$. The final rate of reaction $\left(r_{m}=r_{f i n}\right)$ is achieved, when $a_{s i}$ is close to saturation. The final affinity of reaction keeps a certain small difierence between $a_{s i}$ and asat.

The transport of silicic acid through the surface layer are described by Eq. 3 [2] (where the rate of transport is assumed to be equal to the rate of dissolution):

$r_{m}=k+*\left(1-a_{s i, s} / a_{s a t}\right)=0 / L\left(a_{s i, s}-a_{s i, b}\right)+r_{f i n}$

Eq. 1 is included into Eq. 3, but it no longer refers to bulk values (subscript b) of ortho silicic acid but to its activity at the surface (subscript s). The diffusion coefficient for silicic acid is $D$, and $L$ is the thickness of the growing surface layer, rfin, the final rate of reaction describes the dissolution process at saturated conditions, when there is no diffusion gradient for silicic acid.

Solving Eq. 3 first for $\mathrm{a}_{\mathrm{si}}$, s and then for $r_{\mathrm{m}}$ yields a rate equation, which is applicable to tie glass/water reaction both with and without transport control:

$r_{m}=k+*\left(\left(D^{\star}\left(a_{s a t}-a_{s i}, t\right) / L+r_{f i n}\right) /\left(D^{\star} a_{s a t} / L+k+\right)\right)$

The term $D^{\star}$ asat/ $L$ is the maximum transport rate for a given layer thickness $L$, i.e. the transport rate when the solution concentration is zero and the surface concentration is at saturation. If this transport rate is much higher than the forward rate of reaction, then $\mathrm{Eq} .4$ equals $\mathrm{Eq} .1$ (rate 
control by surface reaction). If the maximum transport rate is much lower than $k_{+}$, then under certain conditions, the rate may decrease with the square root of time.

\section{Computer Code "GLASSOL"}

Based on Eq. 4 the code GLASSOL was developed. The effects of S/V, flow rate, temperature, time, solution chemistry, and of waste package components (bentonite and iron corrosion products) are considered.

The constants $k_{r}, a_{s a t}, D$ and $r_{f i n}$ were derived from the experimental results [2]. For leaching JSS-A glass at $90^{\circ} \mathrm{C}$, the constants are included in Table 1. The saturation concentration for silicic acid asat is replaced by the stability constant $\mathrm{K}_{\mathrm{SiO} 2}$ for the reaction $\mathrm{SiO}_{2}+$ $2 \mathrm{H}_{2} \mathrm{O} \mathrm{H}_{4} \mathrm{SiO}_{4}\left(\mathrm{~K}_{\mathrm{SiO} 2}=\mathrm{a}_{\mathrm{sat}}\right.$ for $\left.\mathrm{a}_{2} \mathrm{O}=1\right)$.

Table 1: Constants for JSS-A glass modeling with GLASSOL at $90^{\circ} \mathrm{C}$

$\begin{array}{lll}k+ & 1.5 & \mathrm{~g} /\left(\mathrm{m}^{2} . \mathrm{d}\right) \\ r_{\text {fin }} & 0.0025 \mathrm{~g} /\left(\mathrm{m}^{2} . \mathrm{d}\right) \\ D & 10^{-9} & \mathrm{~cm}^{2} / \mathrm{sec} \\ \log K_{\mathrm{SiO} 2} & -2.934 & \end{array}$

The variables $L$ and $a_{s} i, b$ depend on the reaction progress $\xi$. The dependence of $a_{s i}, b$ on $\xi$ is calculated with the geochemical code PHREEQE, because secondary reactions may be considered, such as hydrolysis of silicic acid, precipitation of silicates, dissolution of bentonite backfill or sorption on iron hydroxide, etc.

The PHREEQE code simulates the stepwise addition of glass to solution. The calculations yield the distribution of glass constituents among solution and solid alteration products. The solid reaction products constitute a replacement surface layer on the glass. There are various options to modify a reaction path by considering additional reactions with waste package ccmponents, such as bentonite or steel corrosion products.

The GLASSOL code uses the output from PHREEQE as input to calculate the resulting activity of silicic acid and Eq. 4 to calculate the time interval between two steps in the PHREEQE model and the total time of experiment. From Eq. 1 and 4 , the activity of silicic acid at the glass surface is calculated. The corresponding surface $\mathrm{pH}$ and surface solution composition is derived from the PHREEQE reaction path model.

The effect of flow rate $F$ (volumetric units), has been included in the GLASSOL code using Eq. 5:

$d C_{G} / d t=S / V * r_{m}-F / V * C_{G}$

where $C_{G}:$ the amount of glass reacted, in units of concentration $[\mathrm{mg} / \mathrm{L}]$. 


\section{Application of the model}

For the reaction of JSS-A glass with deionized water the results from the PHREEQE reaction path calculations are shown in Fig. 1. The solution concentrations are normalized to the glass composition and are plotted versus the amount uf glass reacted per unit volume of solution.

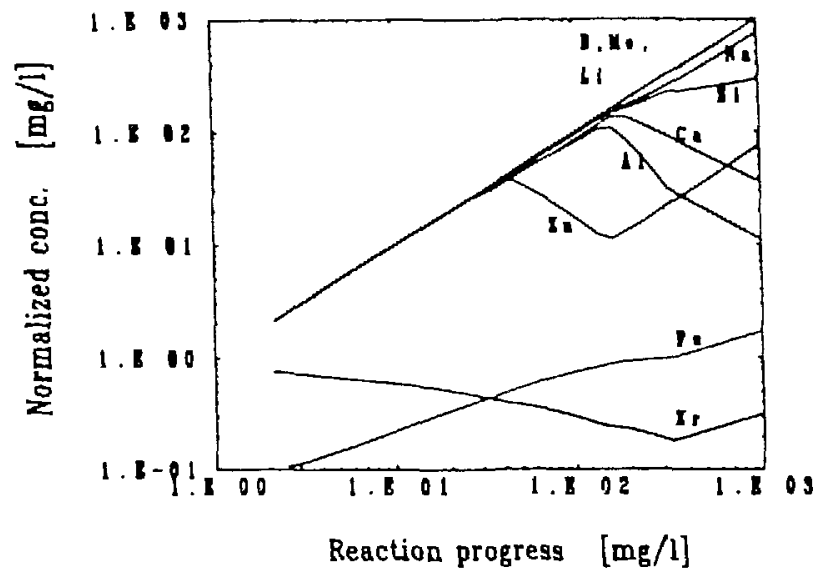

$\begin{array}{lr}\text { Glass composition } \\ & \begin{array}{r}\text { (wt } \%) \\ \text { Si02 }\end{array} \\ \text { Al203 } & 4.15 \\ \mathrm{~B} 203 & 14.47 \\ \mathrm{Na} 20 & 9.79 \\ \mathrm{CaO} & 4.01 \\ \mathrm{Li} 20 & 1.97 \\ \mathrm{ZnO} & 2.52 \\ \mathrm{ZrO} 2 & 0.99\end{array}$

The renlainder is waste oxides

Fig. 1. Reaction path model for JSS-A glass and glass composition.

Fig. $2 a$ and $b$ show two quite different examples for the time dinendence of leaching as calculated from the same reaction path ( $F i g .1$ ). In Fig. $2 a$, the experimental results from static leaching are compared with the calculated curves for various glass constituents, and Fig. $2 \mathrm{~b}$ shows for a dynamic leach test the calculated and observed boron releases. The only difference is the GLASSOL input parameters between the two plots is the flow rate, e.g. $0 \mathrm{ml} / \mathrm{d}$ and $2.9 \mathrm{ml} / \mathrm{d}$.
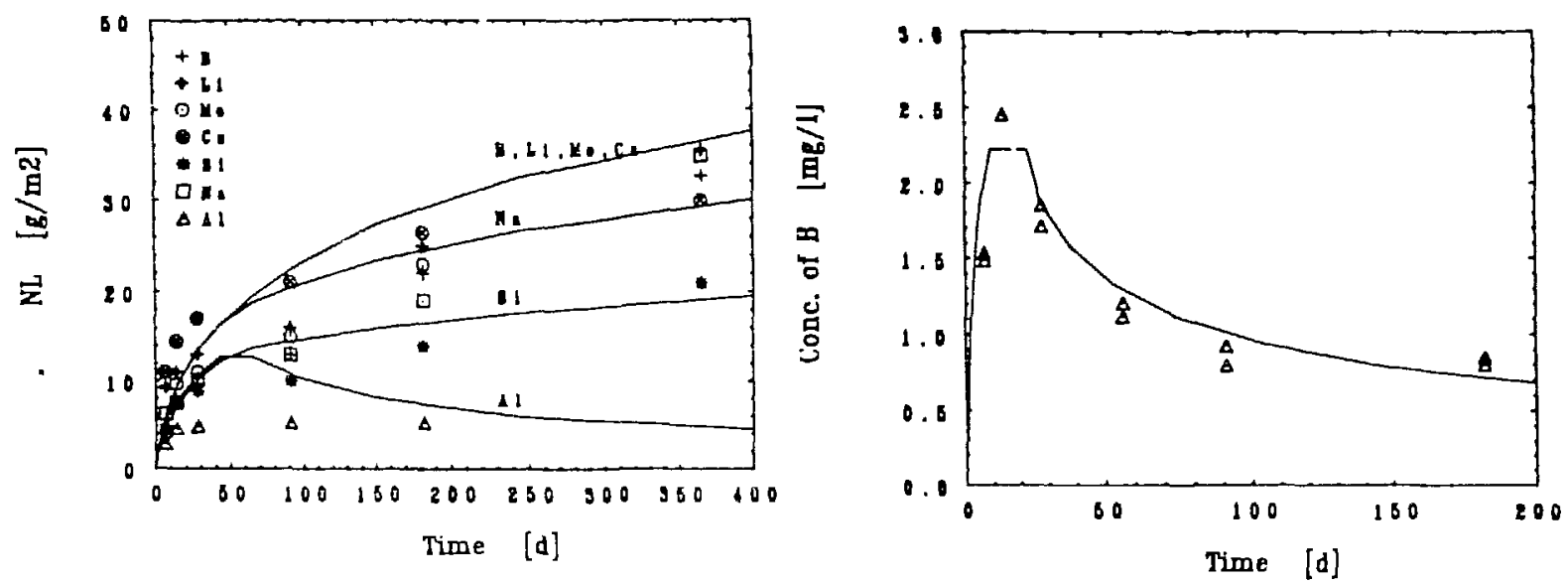

Fig. 2. Time dependence of JSS-A glass dissolution at $90^{\circ} \mathrm{C}$ calculated using GLASSOL for a) static test $\left(10 \mathrm{~m}^{-1}\right)$ and b) dynamic test $(2.9 \mathrm{ml} / \mathrm{d})$ 
The agreement between the calculated and observed values verifies the proposed dissolution mechanism. In iie flow test, the decrease in solution concentration and reaction rate results from slow transport of silicic acid in the growing surface layer. In the surface layer, the silica concentration increased with growing layer thickness and, hence, the reaction rate decreases. In bulk solution the content of silicic acid decreases due to the decreasing rate.

\section{Model for Glass Dissolution in the Presence of Bentonite}

Fig. 3 shows schematically the reactions in the overall glass/bentonite/water system.

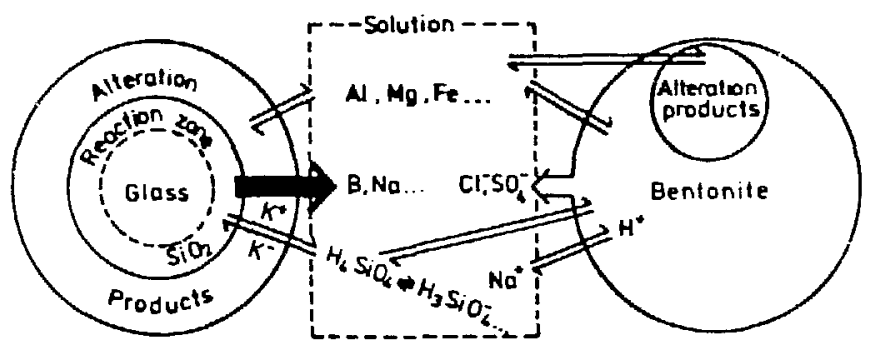

Fig. 3: Scheme of the glass/bentonite/water model

The bentonite/water model describes the effect of bentonite on solution chemistry using equilibrium thermodynamics. The active component of bentonite is montmorillonite, the formula, which for this study, is [11]:

$\mathrm{Na}_{0.3}\left(\mathrm{Si}_{3.96^{\mathrm{Al}}} 0.04\right)\left(\mathrm{Al} 1.55^{\mathrm{Fe}} \mathrm{III}_{0.2} \mathrm{Fe} \mathrm{II}_{0.01} \mathrm{Mg}_{0.24}\right)_{10}(\mathrm{OH})_{2}$

It is assumed that the solution is in equilibrium with montmorillonite. Solubility and ion exchange equilibria are considered in the PHREEQE reaction path model. The formal description for ion exchange is used from the model of Wanner [11]:

$n Z_{-}+M^{n+} \quad M Z_{n}$

$K_{M}=a_{M Z} /\left(a_{Z}{ }^{n} * a_{M}\right)$

The exchange sites are denoted as $Z^{-}$. In addition to the metal ions $\left(\mathrm{M}=\mathrm{Na}^{+}, \mathrm{Ca}^{2}+, \mathrm{K}^{+}, \mathrm{Mg}^{2}+\right)$ in Wanner's model, the present model also uses $\mathrm{H}^{+}$for exchange.

As in the simple glass/water system, the reaction path for glass dissolution is calculated depends on the precipitation of alteration products. The dependence of the silicic acid concentration on reaction progress is used by GLASSOL to compute the time dependence of the reaction. 
For the corrosion of JSS-A glass in the presence of $1 \mathrm{~g}$ of bentonite in $40 \mathrm{ml}$ solution with a $S / V=10 \mathrm{~m}^{-1}$ at a temperature of $90^{\circ} \mathrm{C}$. Fig. 4 a shows the comparison of calculated and experimental results and Fig. 4 b shows the calculated effect of the bentonite water ratio on glass corrosion.
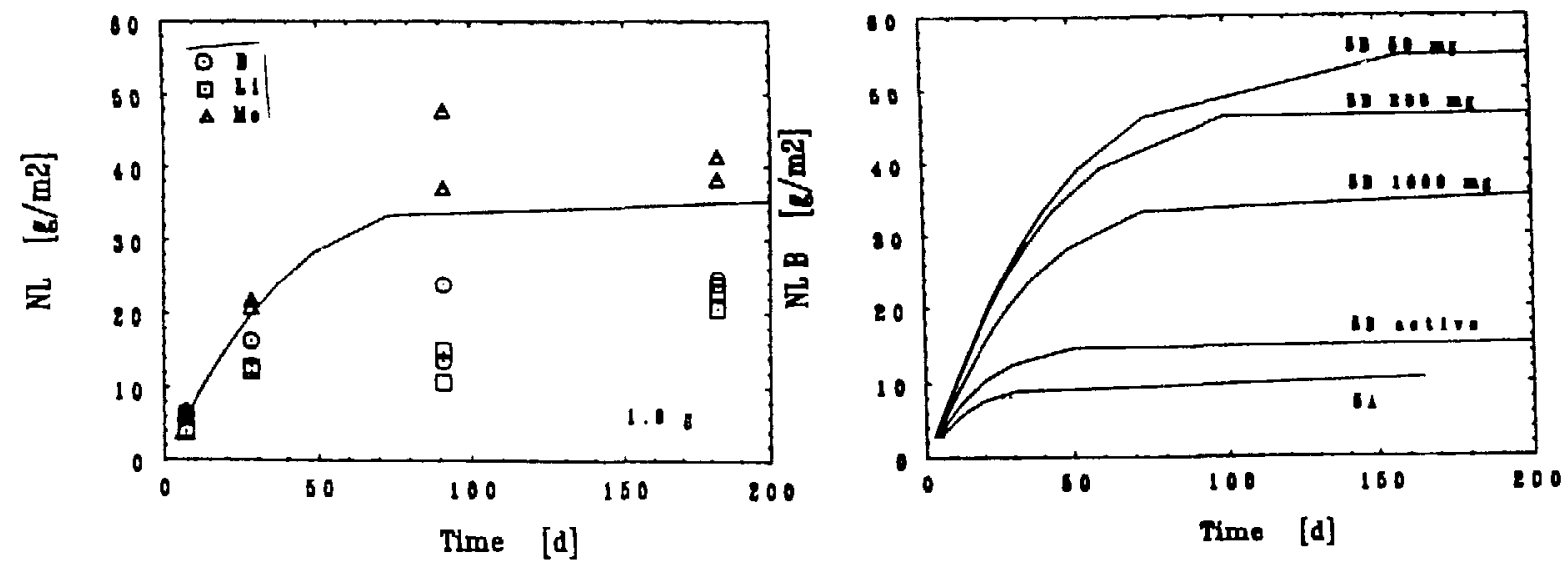

Fig. 4: Glass corrosion in presence of bentonite at $90^{\circ} \mathrm{C}$ -

a) comparison of experimental results with the computer simulations ( $40 \mathrm{ml}$ solution, $1 \mathrm{~g}$ bentonite, $S / \mathrm{V}=10 \mathrm{~m}^{-1}$ )

b) dependence of glass corrosion on the amount of bentonite present

There is reasonable agreement between observed and calculated results. This is also true for most experiments performed at other bentonite/water ratios. The decrease of glass corrosion with increasing amount of bentonite is due to the decrease in solution $\mathrm{pH}$ which decreases the silica solubility. The decrease in solution $\mathrm{pH}$ with increasing amount of bentonite is confirmed experimentally [13].

\section{Final Remarks}

The kinetic parameters of the model provide a means to evaluate nuclear waste forms. The constants are also meaningful in other areas of research. For example, the value of the diffusion coefficient for silicic acid in the surface layer is similar to diffusion coefficients in clay.

The agreement of model and experiment increases the confidence level for short-term predictions. Long-term predictions require detailed understanding of the factors which influence the final affinity of reaction. Nevertheless, the application of the model to natural analogue systems [6] is promising for future reliable long-term predictions. 
1 GRAMBOW, B. (1985) "A General Rate Equation for Nuclear Waste Glass Corrosion." In Scientific Basis for Nuclear Waste Management VIII, eds. C. M. Jantzen, J. A. Stone, R. C. Ewing, North-Holl and, New York, pp. $15-24$

2 GRAMBOW, B., HERMANNSON, H. P., BJOERNER, I. K., CHRISTENSEN, H., WERME, $L$. ( 1986 ) "Reaction of Nuclear Waste Glass with Slowly Flowing Solutions", paper presented at the 88th Annual Meeting of the American Ceramic Society, Inc., Chicago, I11., USA April 27 - May 1

3 PARKHURST, D. L., THORSTENSEN, D. C., PLUMMER, L. N. (1984) Water-Resources Investigations 80-96, U.S. Geological Survey, Reston, Virginia, USA, (1980) extension to run precipitation controlled reactions by $P$. Offermann, Hahn-Meitner-Institute, Berlin, FRG (1983), updated with the MINTEQ data base by W. Howden and K. Kruppka, Pacific Northwest Laboratories, Richland, Washington, USA

4 "JSS-Project Phase I (1984) : A Summary of Work Performed at Studsvik Energiteknik $A B$ and at Swiss Federal Institute for Reactor Research (EIR)." JSS-Project Technical Report 83-03, SKB, Stockholm, Sweden

5 GRAMBOW, B., HERMANSSON, H. P., BJOERNER, I. K., WERME, L. (1986) "Glass/Water Reaction with and without Bentonite Present - Experiment and Model" In Scientific Basis for Nuclear Waste Management, ed. L. Werme, North-Holland, New York, in press

6 GRAMBOW, B., JERCINOVIC, M. J., EWING, R. C., BYERS, C. D. (1985) "Weathered Basalt Glass: A Natural Analogue for the Effect of Reaction Progress on Nuclear Waste Glass Alteration", Mat. Res. Soc. Symp. Proc., Vol. 50, pp. 263-272, Materials Research Society

7 MENDEL, J.E., et al. (1984) Final Report of the Defense High-Leve? Waste Leaching Mechanism Program, PNL-5157, Richland, WA 99352

8 WALLACE, R. M. and WICKS, G. G. (1983) "Leaching Chemistry of Defense Borosilicate Glass." In Scientific Basis for Nuclear Waste Management, Vol. VI, D. G. Brookins, ed., North-Holland, New York, pp. 23-28

9 MCVAY, G. L. and BUCKWALTER, C. Q. (1983) "Effect of Iron on Waste-Glass Leaching" J.Am. Cer. Soc., Vol. 66, No. 3, pp. 170-174

10 PLODINEC, M. J., JANTZEN C. M., and WICKS, G. G. (1982) A Thermodynamic Approach to Prediction of the Stability of Proposed Radwaste Glasses. DP-MS-82-66, Savannah River Laboratory, Savannah, Georgia

11 VONMOOS, M. M. and KAHR, G. (1983) Technischer Bericht 83-12, Nagra, Baden, Switzerland

12 WANNER, H. (1986) "Modelling Radionuclide Speciation and Solubility Limits in the Near-Field of a Deep Repository." In Scientific Basis for Nuclear Waste Management IX, ed. L. Werme, North-Holland, New York, in press 
13 LANZA, F. and RONSECCO, C. (1982) "Influence of a Backfilling Material on Borosilicate Glass Leaching." In Scientific Basis for Nuclear Waste Management $V$, ed. W. Lutze, North-Holland, New York, pp. 173-180 


\title{
COMPUTER MODELING OF THE AQUEOUS GEOCHEMISTRY OF THE ARCHEAN HYDROSPHERE AND THE FORMATION OF BANDED IRON FORMATIONS*
}

\author{
William E. Glassley. Kenneth J. Jackson, and William L. Bourcier \\ Lawrence Livermore National Laboratory \\ Livermore. CA 94550
}

\section{INTRODUCTION}

Constraints on the composition of the hydrosphere during the Archean and early Proterozoic have been difficult to establish because of the lack of an unmetamorphosed sedimentary record. However, it may be possible to significantly restrict the range of possible values for the redox state and concentrations for some of the major components of the Archean hydrosphere by combining key observations from banded iron formations, evaporites, fluid inclusions, and paleosols. Recent developments in the capabilities of geochemical modeling codes have made it possible to accurately model such complex s!stems. Preliminary modeling efforts have concentrated on the geochemistry of the formation of Archean banded iron formations and their implications for the composition of the Archean hyclrosphere.

From the earliest Archean to the early Proterozoic. banded iron formations are a common and persistent lithology in the sedimentary record. These rock units, although diverse in their petrologic detail, consistently preserve several similar mineralogi features that include the prevalence of iron oxide phases (hematite and magnetite), alternating silica-rich and iron oxicle-rich layers, the presence of a siderite or ankerite carbonate phase, and the association of minor amounts of iron-rich clay phases (James, 1966; Holland, 1984). Additional geologic evidence suggests that banded iron formations of the Algoman type, common in the Archean, were deposited in shallow basins, in close proximity to volcanic centers (Gross. 1980).

\section{MODELING APPROACH}

Our approach has been to model the chemical interaction between an acidic, volcanically clerived fluid with a hypothetical Archean ocean water in order to determine whether mixing these solutions will result in precipitation of an iron-rich chemical sediment The EQ3,6 geochemical modeling codes (Wolery. 1979. 1983) were used to perform the simulation. The first step (Figure la) was (1) constrain the composition of the Archean ocean as follows: The $\left(\mathrm{O}_{2}\right.$ fugacil was ansumed to be fixed at a: :-

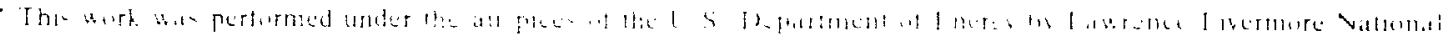

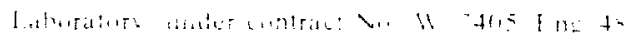


hars hy equilitrium among the aqueous solution and siderite, hematite. and magnetite. whih is a common assemblage in banded iron formations. Likewise, the oxigen fusacit! was assumed to be frated by the presence of hematite and magnetite at $11 \%$ : bars. The initial silica activit! was set at amorphous silica saturation, and major cation abundances and $\mathrm{pH}$ were set equal to those of modern seawater (Figure 2). Chloride was fixed by adjusting the concentration to achieve charge balance. EQ6 was used to precipitate all supersaturated phases. which comprised dolomite. magnesite and talc. The resulting compusition is similar to modern ocean water in sodium, potassium, and chloride concentrations as show $n$ in Figure 2. Calcium and magnesium concentrations are reduced somewhat due to equilibrium precipitation of dolomite and talc. and the $\mathrm{pH}$ drops from 8.1 to 7.5 . Because of the low oxidation state ferrous iron is predominant relative to ferric iron, and the total iron concentration in solutions is relatively high labout $1 ! \mathrm{fpm}$. Modern oceans contain dissolved iron concentrations that var! by a factur of two to four orders of magnitude smaller. Aluminum activity is fixed h! assuming equilibrium with smotite In summary. We have taken modern sea water. reduced the exdation state to correspond to the hematite+magnetitc huffer. saturated it with respect to the iron oxides. and presipitated all supersaturated phases in order to estimate the composition of Archean ocean water.

In addition. We have assumed that the salinity of the Archean ocean was roughly similar to that of modern oceans. Recent datio on the salınities of fluid inclusions in 34 billion year old harite from a massive sulfide-type mineral deposit in the Pilharra block of western lustralia support this ascumption (Bourcier et al. 1954). Although mos of the flud inclusions presersed in these harites have been affected by a lowergreenschist fawes metamorphism. there is a population of presumably primary incluson having consisent phase relations that give freezing temperatures of $-2:$ th

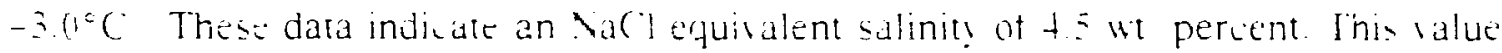
is similar to fluid indusion salinities measured in Phanerozoio massive sulfide deposits The increase in salinit! above that of seawater $(3.5$ wt percent $)$ is most likely due to water-rock interactions in the hydrothermal s! stems that gave rise to the deposits. The smilarity in the salinities of the ancient fluid inclusion. to those of derived seawater trapped in fluid inclusions in modern equiratente of Archean subnarine gecothermal systems strongly suggests a salinity of Archean oxtans similar to that of the present ocean-

Step I involed a determination of the compositun of the rolcanically derived acidh water that was reacted with the cetean water (Figure $2 \mathrm{~h}$ ). It was determined hy using EQh w react water. komatilte and arhitrars amounts of acidic rolcanic component(e.g. $\mathrm{HCl}$ or $\mathrm{HVO}_{3}$ ). In this case. we hale reacted homatite with an $\mathrm{HCl}$ soluticin and allused the reaction path to proceed trom an instial ph of -0 to a ph of 3.5 . The resuled in a reduced. acidic solutun rich in magnestum and aron. Silica. aluminum. and culcium activities tere hmoted to values in eyulibrum with the product rinate: 
Step \#1: Initial constraints for seawater composition

- $\mathrm{CO} 2$ fugacity set by mineral assemblage siderite+magnetite +hematite bulfer.

- O2 fugacity and total iron set by hematite+magnetite buffer.

- SiO2 set by amorphous silica saluration.

- Major element concentrations of seawater from modern seawater.

- Chloride concentration from charge balance

- Precipitate all supersaturated phases.

Step \#2: Generation of acid iron-rich water

Initial compositional constraints

- React komatiite with acidic solution $(\mathrm{HCl})$.

- Precipitate out all supersaturated phases.

Results

- Oxygen fugacity fixed by $\mathrm{Fe}_{++} \mathrm{Fe}+++$ ratio of komatiite

- Reaction stopped arbitrarily at pH ct 3.5.

- Total Mg and total Fe of .001 molal

\section{Step \#3: Mix river basin into ocean basin}

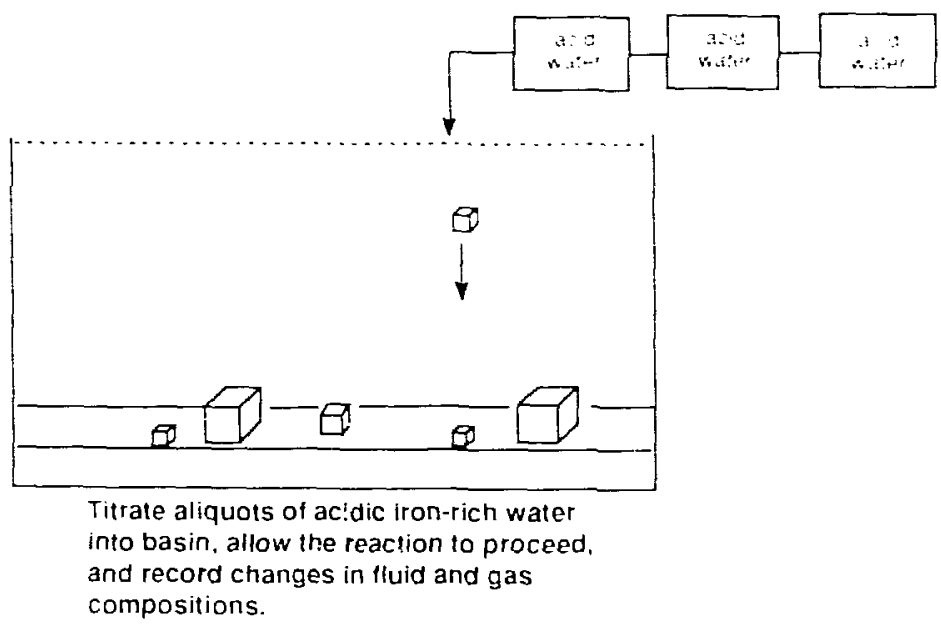

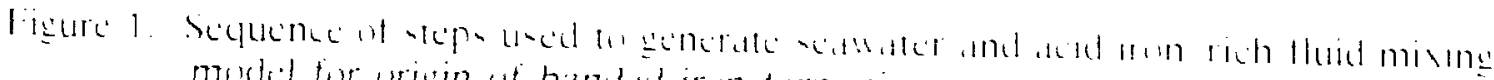
medel for artign of handed iron tormestion- 


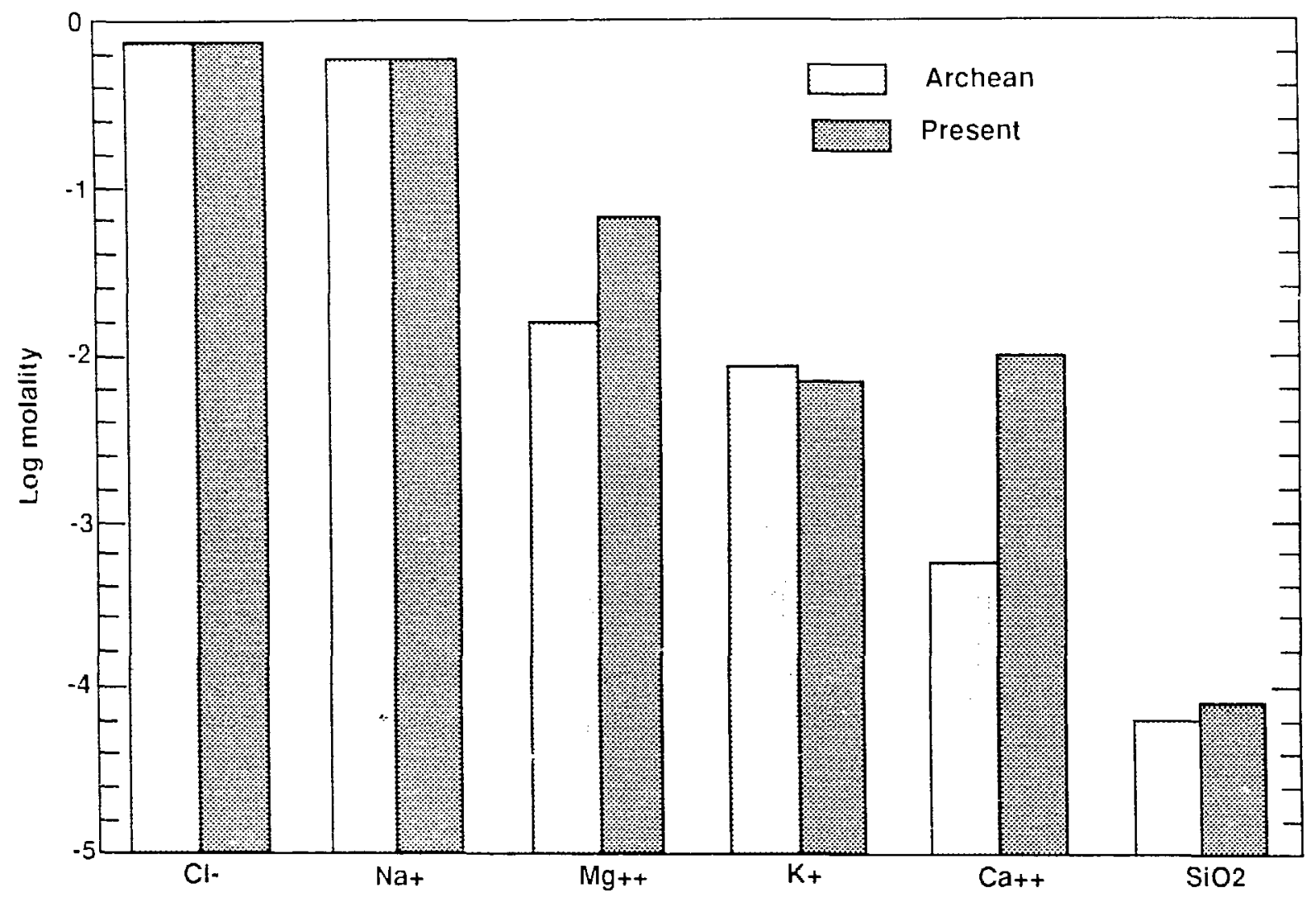

Figure 2. Histogram comparing hypothetical Archean and present-day ocean compositions. The iron concentration (not shown) of Archean seawater is assumed to be 10 ppm. wo to four orders of magnitude higher than in the present aceins

-mestite. Shlorite and katolinite. that precipitated during the reaction process. The whution wa highly reduced becaluse of the low ferrous ferric ratio of the komatiite with which it wa- reacted.

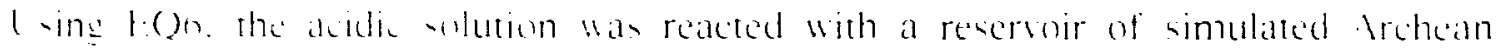

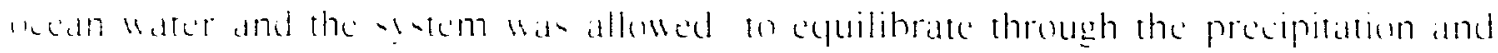

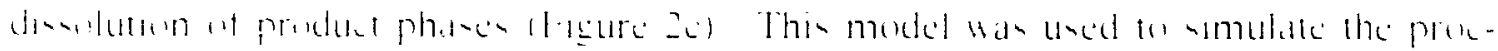

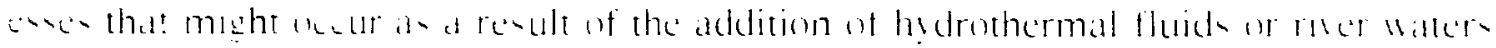
[1. an acaln biam 


\section{RESLLTS}

Initial modeling results indicated that mixing the wo hypothetical solutions discussed above produced no product phase other than a magnesium-rich smectite clay. This was because the $\mathrm{pH}$ dropped rapidly as a function of reaction progress. In order to prevent the $\mathrm{pH}$ from dropping too rapidly and diverging from the iron-oxide and iron aluminosilicare stability fields, it was necessary to maintain the system in equilibrium with a $\mathrm{pH}$ buffering mineral phase. By assuming that the system remained in equilibrium with a carbonate phase (such as calcite or siderite), the mineralogy typical of banded iron formations was predicted by the modeling runs. Geologically. this is a reasonable assumption that is equivalent to allowing some dissolution of carbonate phases present on the seafloor during the initial stages of influx of acid water into the ocean basin.

The minerats calculated to precipitate and dissolve in the reaction path modeling are shown in rigure 3. Reaction progress. plotted on the $x$ axis indicates the log of the number of milliliter of acid water added to one kilogram of the ocean water. The $y$ anis gives the log of the number of moles of product phases that EQ6 predicted would form. The first phase precipitated was hematite. followed by cronstedite (an iron-rich hydroxy-silicate). dolomite. magnesite, and saponite (a sodium smectite component). As more of the reduced acidic fluid is added. the oxidation state of the system. initially: at the hematite+magnetite boundary. drifts downward and ends up in the magnetite ficld. This causes the early formed hematite to redissolve and be replaced by magnetite in the mineralogic sequence. Biotite and siderite appear as reaction products late in the reation. The sequence of mineral products predicted to be stable include assemhlage of hematite plus magnetite. and magnetite plus siderite. Hematite and siderite are not predicted to coexist in the model. and this mineral pair is seldom seen to coexist on a fine scale in nature.

Rerunning the same model using the solid solution option (Bourcier. 1985) in the most recent version of EQ3 6 produced similar results. The main difference was that the phase's dolomite. magnesite and siderite were replaced by an ankeritic carbonate solid solution composed mainly of the iron and magnesium components. The carbonate solid solution composition fell in the range of measured ankerites in Algoman-type banded iron formations in western Australia (Klein and Gole, 1981).

It hould be noted that the sequence of precipitate mincrals predicted to form was relativel! insenvitive to the $\mathrm{pH}$ chosen for the aciclic fluid. Simitar results were obtained with the acidic component having an initial pll of 4.5 although smaller amounts at eath of the irom minerate were produced.

fren at adsanced tages of this reaction. only a small amount of the acid solution had heen added. It a reaction progeress cyuivalent wa adding one gram of acid water to one 


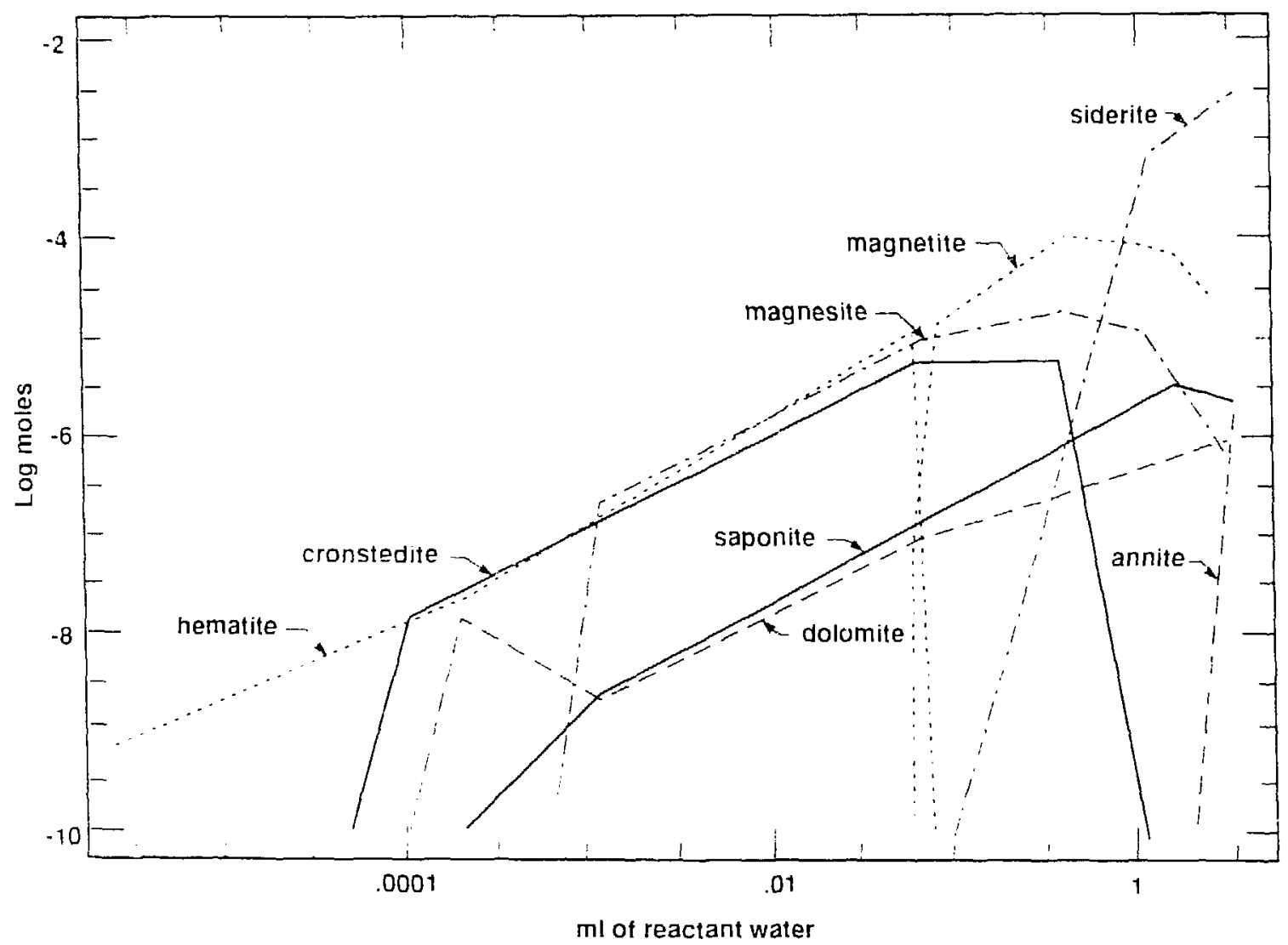

Figure 3. Sequence and amounts of mincral precipitites that form as a consequence of mixing 1 kilogram of Archean seawater with the reactant acidic iron-rich fluid using EQ6.

kilogram of ocean water. approximately $11^{4}$ moles of magnetite was precipitated from the mixture. This would correspund to about $0.05 \mathrm{~mm}$ of iron-rich chemical sediment precipitating from a water column 100 meters deep. In addition, although rather severe changes took place in the sequence of mineral precipitants, only minor changes in major element concentrations and $\mathrm{pH}$ were evident. For example, the $\mathrm{pH}$ of the mixture dropped by onl: $19.1 \mathrm{pH}$ units during the racton. and magnesium. calcium, and bicarbonate actisities were essentially unchanged.

These resule cain explatin the major iron-rich accumulation of banded iron formations. The mechanism for pouducing the microbanding ut iron abd silical-rich layering often

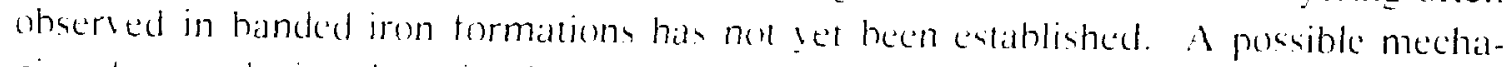
nim tor producing the microhanding that has heen propued is that of seasonal tem- 
perature changes affecting iron and silica solubilities in so as 60 callse allernalting deposition of iron and silica-rich lavers. Initial results indiculte that this mechanism is consistent with calculations of the soluthilie of iron in cyptilithium with the assemblage hematite plus magnetite plus siderite in our hypothetical Archean ocean water. However, more modeling work is necessary to determine whother these temperature dependencies hold for the metastable precipitates such as amorphous iron hydroxides that likely control iron concentrations during precipitation in natural waters.

\section{CONCLUSION}

In conclusion. the results of our $\mathrm{EQZ}$ 6 modeling effort suggest that inorganic chemical processes can result in the precipitation of phases that closely mimic the mineralogey of the iron-rich portions of banded iron formations. Mixing of ocean water with an acidic fluid that has been equilibrated with a hasalt or homatite results in a pll change and subsequent precipitation of iron-rich chemical sediment. A more neutral fluid cannot dissolve a high enough concentration of iron wo contribute significantly to the formation of iron-rich sediments.

The generation of acid waters responsible for banded iron formation may result either from terrestrial volcanic input into runoff or active seafloor vents in the banded iron formation basin. These mechanisms require no change in the oxygen fugacity of the local hydrosphere. and do not require biologicail activity.

Future efforts will be directed at more critically exaluating the predictions of our model. the sensitivity of model results to input constraints. and consparison of modeling resulss to detailed field obiersation

\section{REFERENCES}

Bourcier. W' 1.. (1985) Improrements in the Solid Solution Modeling Capabilities of the EQ3i6 Geochemical Cole. UCII)-21)587. L awrence Livermore National Laboratory. Livermore. CA.

Bourcier. H. L.. E.K. (jibson. Ir.. and R. K. Kotra (1984) Characterization and gas analsis of fluid inclusion: in harites from the Warrawoona Group. Northwestern Australia. In Lumar and Planetary Sitono XV. p. $82-83$.

Ciross. (i. A. (1980) A classification of iron formations hased an deponitional environments. Canadian Min. 18. Г. 215-222.

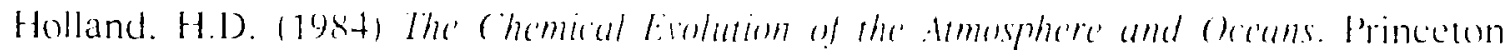
University Prese. Princeton. Vell Ieres.

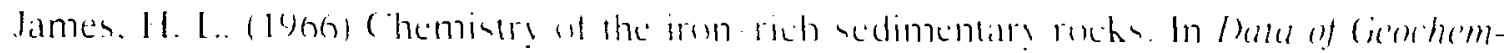

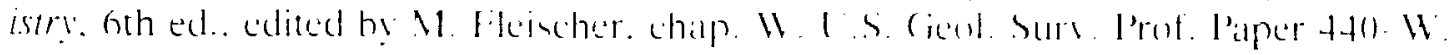

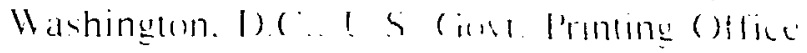




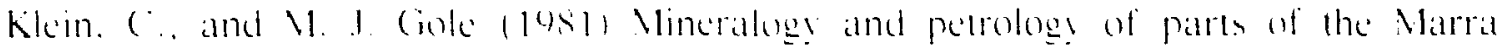

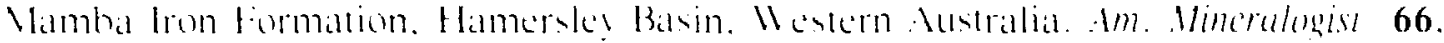
p. $30-235$

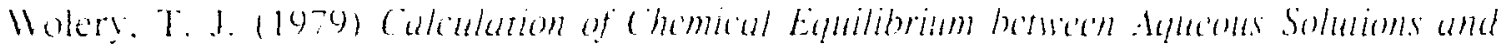

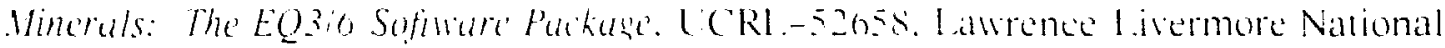
Laboratory. Livermore. C A.

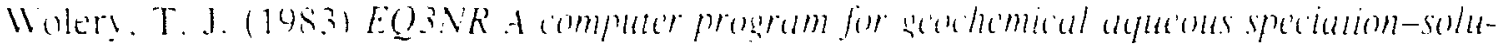

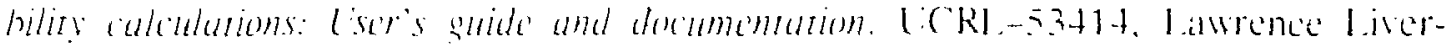
more Xational I aboratory. I ivermore. $(\because$. 
Database Development 


\author{
Hans Wanner \\ OECD Vuclear Energy Agency. NEA I ata Bank \\ 91191 Gij-sur-Yvette Ciedex, France
}

\title{
ABSTRACT
}

The OECD Nuclear Energy Agency (NEA) has undertaken the development of a CODATA-compatible chemical thermodynamic data base for a number of elements of interest to various areas of nuclear technology, especially to radioactive waste management research areas such as the safety analysis of nuclear waste repositories. The development of this data base involves not only a compilation of all relevant published thermodynamic data, but also a detailed critical revieu and, finally, the selection of a "best data set" which will be recommended. Each review is being performed by a group of four to five internationally acknowledged experts in chemical thermodynamics. Each expert team has at least one member who is CODATA liaison, to assure compatibility with the CODATA tables. The first 10 elements to be reviewed are: Uranium, neptunium, plutonium, americium, technetium, cesium, strontium, radium, iodine and lead. The thermodynamic data being compiled and reviewed for each species include:

$$
\begin{array}{rll}
\Delta_{f} G^{\mathrm{U}} & \text { the standard Gibbs free energy of formation } & \left(\mathrm{kJ} \cdot \mathrm{mol}^{-1}\right) \\
\Delta_{f} H^{\mathrm{U}} & \text { the standard enthalpy of formation } & \left(\mathrm{kJ} \cdot \mathrm{mol}^{-1}\right) \\
S^{0} & \text { the standard entropy of formation } & \left(\mathrm{J} \cdot \mathrm{mol}^{-1} \cdot \mathrm{K}^{-1}\right) \\
C_{p} & \text { the standard heat capacity (at constant pressure) } & \left(\mathrm{J} \cdot \mathrm{mol}^{-1} \cdot \mathrm{K}^{-1}\right)
\end{array}
$$

together with uncertainties and, if available, the temperature functions. Emphasis is placed on data for $298.15 \mathrm{~K}, 10^{5} \mathrm{~Pa}$ and zero ionic strength.

In addition, an interface program is being developed which makes it possible to extract specific data from the thermodynamic data base and to convert them into a form in which they are readable by geochemical modelling codes, such as PHREEQE, MINEQL and EQS 6 , all of which are widely used geochemical reaction path computer codes. The data could also be made available in a form compatible with other computer codes if there is any demand from users.

\section{INTRODUCTION}

The development of an international chemical thermodynamic data base is a recent activity of the IEA Data Bank carried out jointly with the Division of Kadiation Protection and Waste Management of YE.A. Ir was initiated to account for the increasing need of such data for modelling purposes in safe1y analyses for nuclear waste repositories (MLLLER 198.5!. Although a number of thermodynamic data compilations and reviews have been putblished in recent years. none of them can be used as a complete source data table to study the hehaviour of radioelements in the cnvironment. Some are of a general nature. not giving a comprehensive review of the data. whereas others-c-like the COInATA tables - 
contain critically evaluated thermodynamic data. though not including elements which are of particular interest for nuclear waste mandgement purposes. Consequenty. most modelling groups supporting the performance assessment of radioactive waste disposal. have developed their own data base from the scientific literature. However. the geochemical modellers in different countries may not have the specialized experience in this field to distinguish between good and bad data appearing in the literature. Hence. these individual data bases often differ considerably from each other, especially in the data of the actinides. It is thus not surprising that radionuclide speciation and maximum solubilities calculated by different groups, with different geochemical computer codes and data, but for similar conditions, often turn out to differ by orders of magnitude. It has been recognized that the reason for these discrepancies are not the different codes but the different data bases. The needs for a comprehensive, internally consistent and internationally recognized chemical thermodynamic data base meeting the requirements of the modellers in nuclear fields have thus been acknowledged by a number of technical groups within the NEA Member countries. It is in response to this need that the NEA has undertaken its thermochemical data base development.

\section{STRUCTURE OF THE DATA BASE SYSTEM}

A schematic presentation of NEA s chemical thermodynamic data base development system is given in Figure 1 . The development of the data base includes the compilation of all published thermodynamic data, a critical review of them, and the selection and publication of recommended data. Another important part of the data base system is the retrieval of data requested by users in different countries, as well as the conversion of them into forms compatible with the input formats of geochemical modelling codes, such as PHREEQE. MINEQL and EQ3/6. The heart of the system. the Thermodynamic Data Base (TDB), consists of a number of records, as shown in Figure 2. The DATA record comprises for each species fundamental thermodynamic data at $298.15 \mathrm{~K}$ and $10^{5} \mathrm{~Pa}$ :

$$
\begin{aligned}
\Delta_{f} G^{0} & \text { the standard Gibbs free energy of formation } \\
\Delta_{f} H^{v} & \text { the standard enthalpy of formation } \\
S^{(} & \text {the standard entropy of formation } \\
C_{p} & \text { the standard heat capacity (at constant pressure) }
\end{aligned}
$$

All data are compiled in SI units. As the parameters in this set vary as a function of temperature, provision has been made to include the compilation of empirical temperature functions of $\Delta_{f} G, \Delta_{f} H, S$ and $C_{f}$ data, as well as the temperature ranges over which they are valid. The ELEMENTS record contains all 104 elements of the periodic table, whereas the FORMULAE record contains the chemical formulas of each species compiled in the data base. The FORMEL record contains the elements and chemical formulas and acts as a link between the ELEMENTS and the FORMULAE record. The temperature coefficients are stored in the records G-COEF, H-COEF, S-COEF and C-COEF. The formulas are entered consistent with basic Hill notation to avoid ambiguity arising from the fact that both superscripts and subscripts have to be placed on the same line as the symbols of the elements. The formula is the actual entry point for data retrieval. A special sub-program allows to uecode formulas, so that formation constants for species can be readily calculated for any components or master species. 


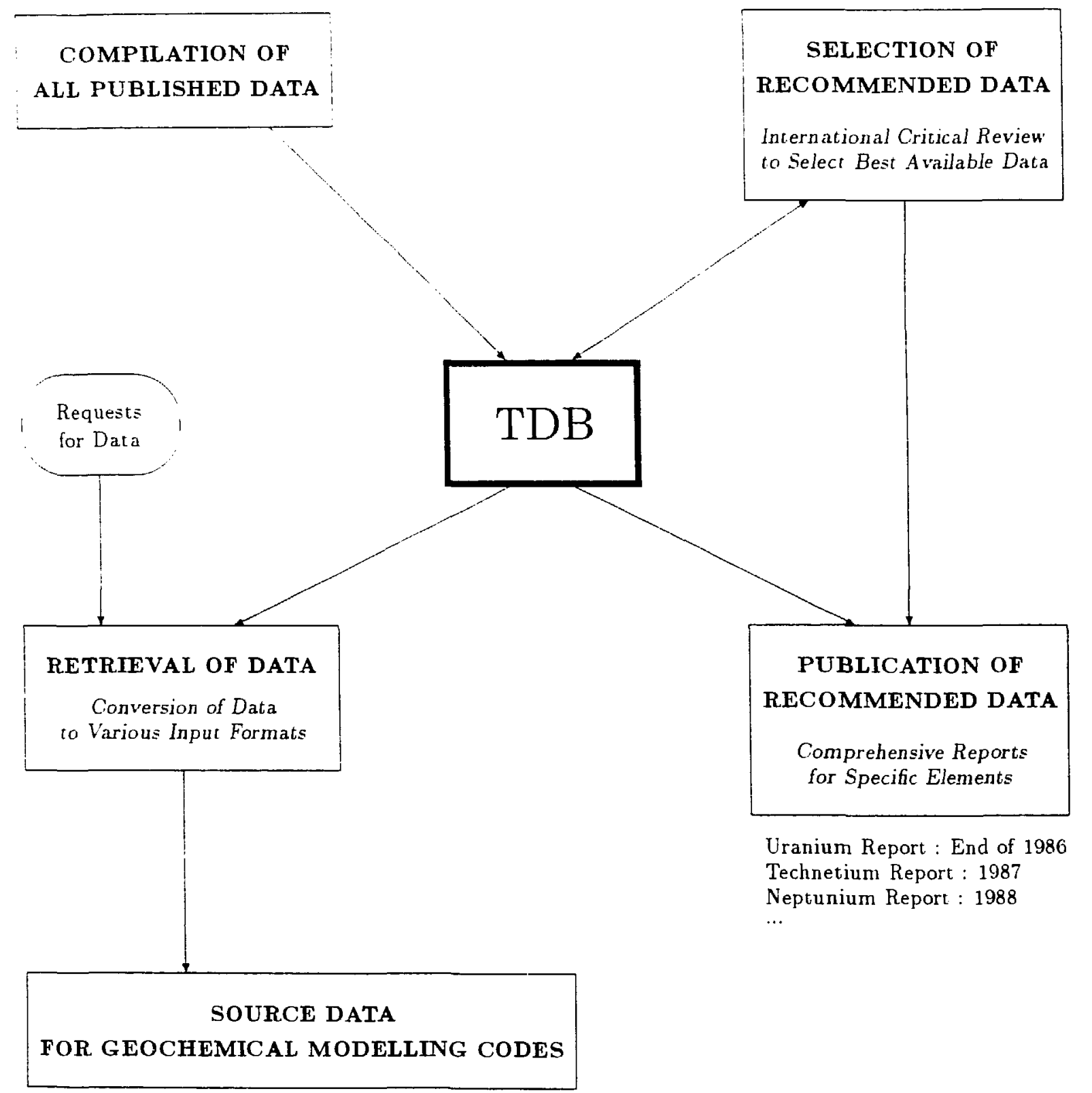

PHREEQE: Aug. 1986

MINEQL : Oct. 1986

EQ3/6 : Jan. 1987

Figure 1: Structure of the NEA Thermochemical Data Base Systern 


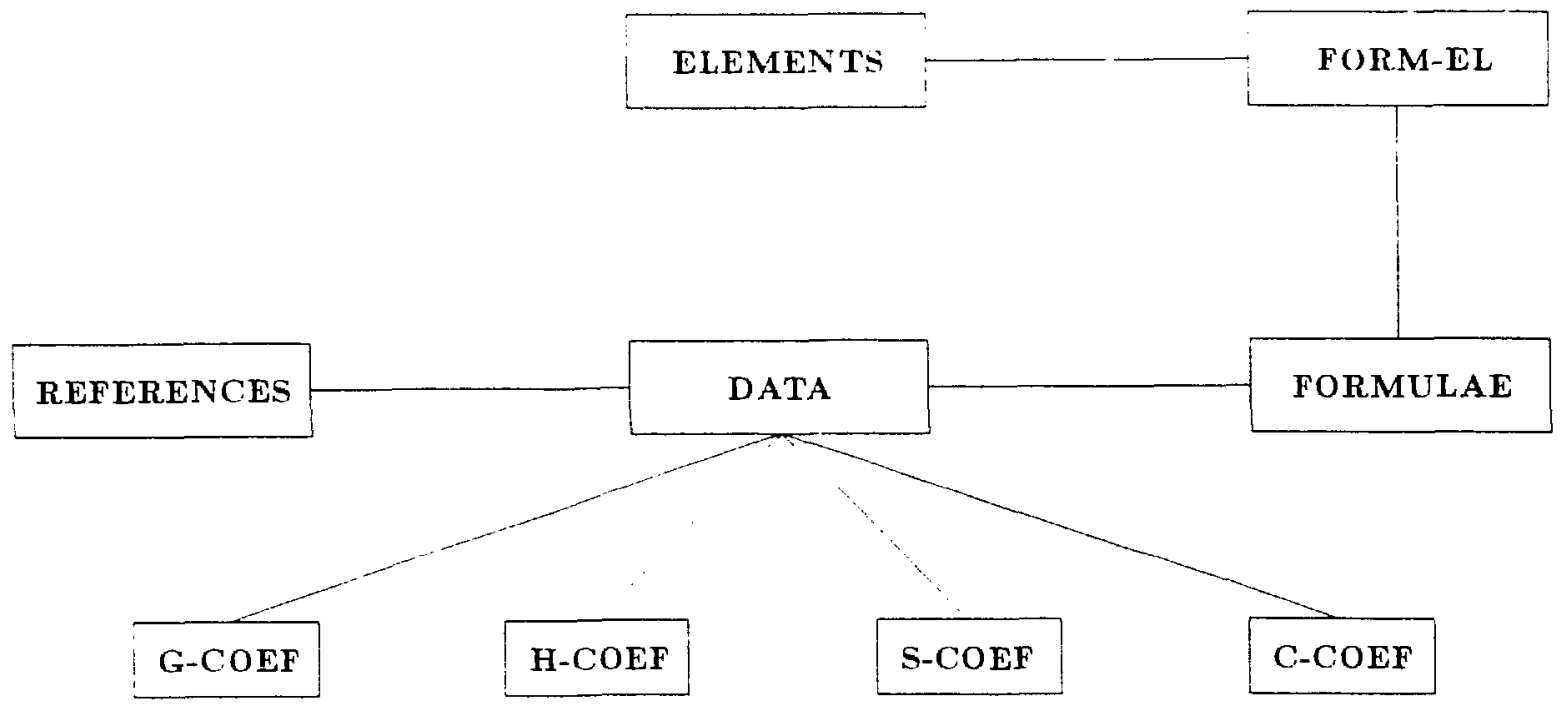

Figure :2: The Thermochemical Data Base Schema

\section{CRITICAL INTERNATIONAL REVIEW OF THERMODYNAMIC DATA}

Generally: all thermodynamic data published in the open literature are compiled by NEA. However, preference is given to data for $298.15 \mathrm{~K}$ and $10^{5} \mathrm{~Pa}$ as well as unit activity (i.e., zero intersolute interactions, $\mathrm{I}=0 \mathrm{M}$ ) in the reviewing process. The selection of best available data is done by a specialist team for each element considered. Data selections already made by other reviewer groups, e.g., the CODATA and IAEA thermodynamic data tables (CODATA 1978 and IAEA), are accepted as selected data in the NEA Thermochemical Data Base. NEA specialist teams have been established for the following elements:
uranium
neptunium
plutonium
americium
technetium
cesium $^{1}$
strontium ${ }^{1}$
radium
iodine $^{1}$
lead ${ }^{1}$

\footnotetext{
${ }^{1}$ The expert team for this element is only partly established.
} 
Each team consists of four to five internationally recognized experts in chemical thermodynamics. One member of each team is selected in consultation with the CODATA Task Group on Chemical Thermodynamic Tables and has the special responsibility to assure that the review is performed consistent with CODATA procedures and recommendations. The critical reviewing work of each leam is coordinated by the NEA Secretariat. A detailed description of the critical reviewing procedure is given elsewhere (MLLLER 1985). The resulting selected data set for each element considered, including uncertainties as well as data found and not selected. will be published by the NEA under the authorship of the specialist teams. These reports will also contain detailed discussions of the scientific rationale used in the reviewing procedure. The first review report, the uranium volume, is planned before the end of 1986. The uranium publication will be followed by one on technetium. and then by a neptunium volume.

\section{DATA RETRIEVAL}

The retrieval of compiled data and selected auxiliary data is an important routine procedure in the critical review of thermodynamic data. On the other hand, the users of thermodynamic data. e.g.. the geochemical modellers. mostly do not use the fundamental Gibbs energy data for each species they consider in their calculations, but rather the formation constants from components or master species. Most geochemical computer codes actually require formation constants. $\log K$ values, as source data. rather than Gibbs energies, $\Delta G^{0}$. For this reason, an interface program has been developed which allows to extract thermodynamic data from the TDB and to convert them into a format in which they can be directly used as source data for the code PHREEQE. The master species can be freely chosen by the requester of data. and the retrieved data can be sent on magnetic tape. A similar version of this interface program is under development for the code MINEQL, and a version for EQ3 6 is planned. Modellers requesting thermodynamic data from the IEA ar. advised to specify the elements or particular species for which data are desired. as well as the master species of the element.

\section{REFERENCES}

CODATA (1978), Recommended Key Values for Thermodynamics 1977, Committee on Data for Science and Technology (CODATA) Bulletin 28, Paris: International Council for Scientific Unions, 16 p.

IAEA. The Chemica! Thermodynamics of Actinide Elements and Compounds, (OETTING F.L., ed.) 14 Parts. Internationsl Awinic Energy Agency, Vienna, in press.

MLLLER A.B. (1985). International Chemical Thermodynamic Data Base for Nuclear Applications, Radio. Waste Manage. Nucl. Fuel Cycle 6(2), 131-141. 


\title{
EQ3/6 DATA BASE - ONGOING DEVELOPMENT
}

AT

\section{LAWRENCE LIVERMORE NATICHAL LABORATORY}

\author{
Joan M. Delany \\ Earth Sciences Department \\ Lawrence Livermore National Laboratory \\ Livermore, CA 94550
}

\section{Abstract}

The EQ3/6 Data Base has been revised and enhanced to meet the maintenance needs of a large continuously evolving data base. Within the last year a rew data-base structure has been developed to manage the manipulation, basic data entry, import/export, retrieval and display features. The data management approach includes visual simplicity, on-line documentation, information management and controls to limit user error, ensure data protection and proper documentaticn of thermodynamic values and their sources.

\section{Introduction}

The goal of this project is to develop a software product responsive to the Scientific and Engineering Software QA Procedure of the Nevada Nuclear Waste Storage Irivestigations Project. (Wolery, 1988)

The new data-base structure is composed of a master data maintenance program (MDAP) that has been developed specifically to accept, reorganize and report thermodynamic data in the EQ3/6 format. This code is menu driven and includes both dynamic and typed command strategies. Support functions such as automatic updating and data reporting capabilities are also available. MDAP runs attachea to a newly created master data file, MDAR. MDAR was designed and constructed to be a data holding bank and records file that can meet the needs of all software quality assurance requirements that are expected to be imposed on the EQ3/6 Task. 
Data evaluation has begun on a single element basis for existing values. Recently completed revisions of thermodynamic data for many aqueous and solid species of $A m, U$, and Pu has demonstrated the need for an EQ3/6 experimental data-base activity. (For example see Kerrisk and Silva. 1988). As a result, a laboratory program has been scarted at LLNL to make necessary experimental measurements and to correct gaps and/or conflicts in the master data file. This activity commenced during the last half of Fir 86 , and is planned over a 5-year period.

\section{Dita Base Structure}

The upcoming release of the EQ3/6 Software Package (version 3z45) will contain several pre-processor codes and data files. A schematic of the data base codes and data files shown in Figure 1. The master or MCRT

Thermodynamic Data File exists in both direct access (MDAR) and sequentiai (MDAS) format. All data maintenance is done by MDAP, a data maintenance code. MDAR also runs attached to MCRT, a data pre-processor code that has been part of the EQ3/6 software package since its inception. Extensive modifications and restructuring have been done to bring MCRT into active status with the new master data file format. MCRT output files are now also completely compatible with DATAO format. DATAO, is the EQ3/6 main thermodynamic data file. A new pre-processor code, DARP, is used to manipulate and maintain the DATAO file. DARP is a companion code to MDAP and runs in a similar menu-driven environment. MCRT is now designed to process all DATAO species in a single run, and DARP can upload this output to the DATAO file also with a single command. The pre-processor codes are describe: in more detail below. (Also see Wolery et al., 1988).

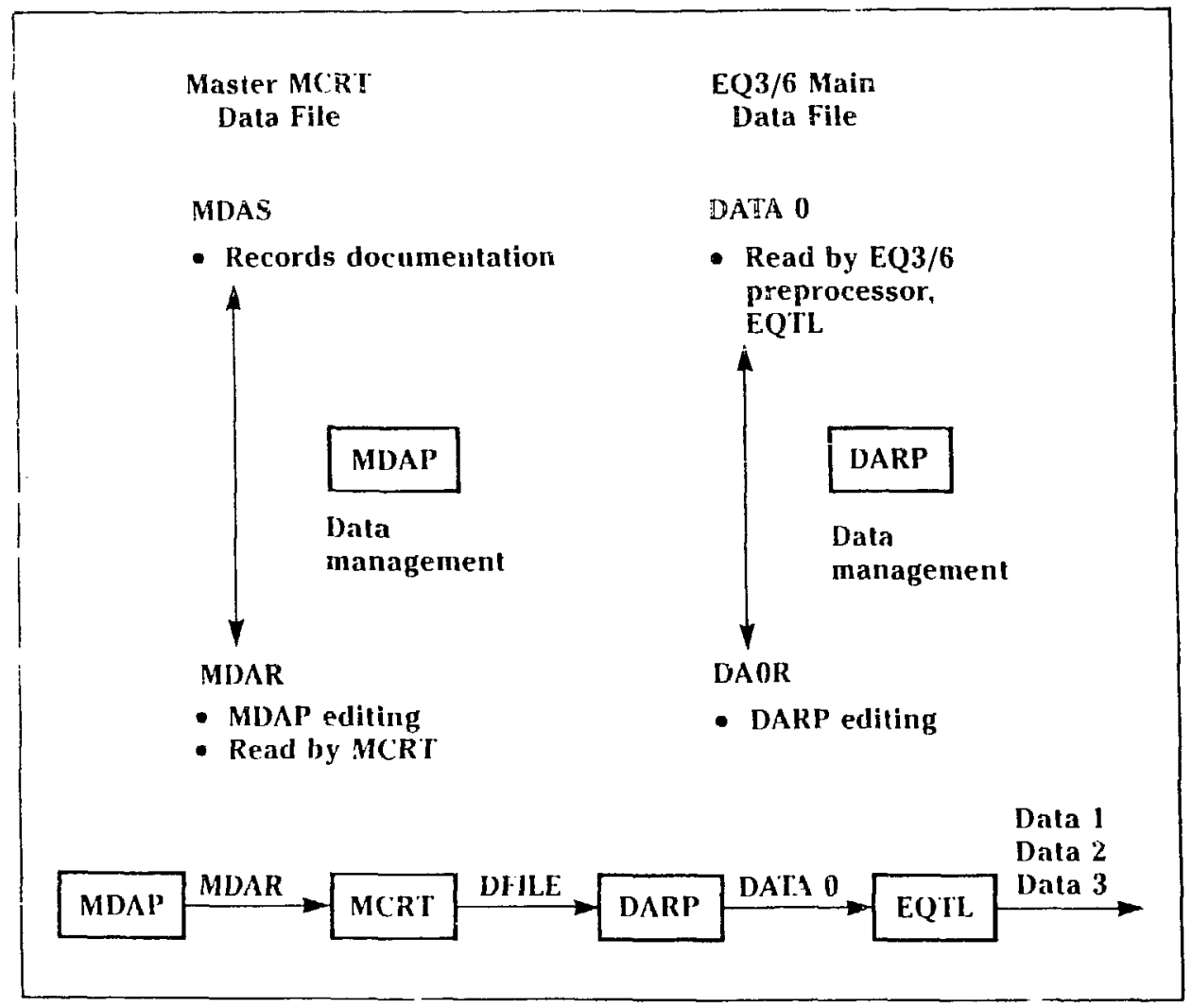

Figure 1. Architecture of the EQ3/6 Data Base. 
MDAP is a menu-driven data management code. The program boots to a main menu of self-explanatory choices that include import, retrieval, replace, and display options to maintain the archival data base of thermodynamic data. Each menu option displays a submenu of additional options. User interface $r$ data entry and revision has been reduced to editing individua! MDAR species plocks. The need for multiple files to be opened and edited has been eliminated. All data import and export functions accept ASCII files. The MCRT code has been restructured and currently runs attached to the master data file. The current default provision is to run all species except those explicitly designated by an internal flag in each species block.

MCRT is a thermodynamic code that is run attached to the master data file, MDAR. It is used to identify active species and ca?culate logk values as a function of temperature. OFILE output can be directly inserted into DATAO through the DARP replace option. The MCRT file structure has been changed, MDELEM and REAC have been eliminated as individual files. The REAC file has been interspersed into MDAR. All DATAO reactions are now located within the appropriate species block. MDELEM has been incorporated into MDAR as a single elements bloci.. All element data can be updated in MDAR and replaced into the header portion of DATAO through MCRT DFILE output.

A second data maintenance program, DARP, has been developed to allow the user to search, view and update the thermodynamic data file, DATAO. This menu-driven code was written as a companion code to MDAR, but, yet it does not contain many of the enhanced support functions available in MDAR. DARP runs attached to the thermodynamic data file in direct access format, DAOR. output from the MCRT code in DFILE format can be used as a replace file to update the entire DATAO file. Structural changes made to the thermodynamic data file, DATAO and the sibsequent EQ3/6 data files, DATAI, DATA2, and DATA3, have been relutively minor.

\section{Work in Progress}

- A customized data entry form is being constructed. This capability will supersede standard ASCII file format and local editing procedures currently used for adding new species to MDAF. The interactive format will provide the user with default values, typed command strategy, and calculated fields where appropriate. This procedure will help eliminate data-editing errors and protect accurate data input.

- Data protection mechanisms are being developed to provide the necessary security for a multi-user data base. Certain core subsets will be protected. All data-base users will be assigned valid passwords. The password utility will provide user interface on three levels; (1) species data and references can be displayed or 
extracted, (2) experierced users can modify thermodynamic values and add or suppress species from the master data file, (3) reserved for the data base administrator, to revise the structure of the data base and control acess to security and password utilities.

- Ail CODATA recommended key values are being adopted. (CODATA, 1978) This change will coincide with a conversion to Sl units. This data set will protected as a key subset. In early 1987, the EQ3/6 Data Base will be fully CODisTA compatible.

- A conversion to SI units will be made for the entire EQ3/6 software package. A utility option will be available in MDAR to allow the user to generate a copy of the master data file thermochemical calories for literature comparisons.

- Thermodynamic data for Np solids and aqueous species are being reviewed and incorporated into MDAR. Major emphasis is being givan to species that may be significant in geochemical applications of radioactive waste disposal.

- The rock-forming minerals data set is under review for revision. The existing thermodynamic data includes the SUPCRT data base for rock-forming minerals (Helgesen et al., 1978). Current plans are to (1) update all minerals for which new experimental data has been reported; (2) expand the heat-capacity fit equation to five parameters.

\section{Laboratory Experiments}

The goal of the EQ3/6 Data Base Program is the thermodynamic characterization of a complete set of solution species and solid phases. Measurements will be made as a function of temperature, ionic and oxidation state as required. Our initial review of the thermodynamic data for Am, $U$, and $\mathrm{Pu}$ has led to the following proposed research FY96-88. (Silva and Delany, 1986)

\section{Americium Laboratory Measurements}

This work is being done as a joint effort with Lawrence Berkeley Laboratory. The free energy of the solubility reactions of amorphous and crystalline $\mathrm{Am}(\mathrm{OH})_{3}$ will be determined. Also under investigation is the nature and characterization of the solid phase that forms in solutions with ph values greater than 9 . We are investigating the carbonate complexation of $\mathrm{Am}^{+++}$to verify the existence of bicarbonate and hydroxycarbonate complexes. If possible, formation constants will be also obtained.

\section{Laser-Induced Pulsed Photo-Acoustic Spectroscopy}

A pulsed photo-acoustic (PA) spectroscopy system using a Nd-YAG pumped dye laser and associated computer-control instrumentation is being developed to 
investigate the capabilities and sensitivity limitations for characterizing waste radionuclide species in aqueous solutions. A completed system would allow detection of corcentrations in the submicromolar region.

\section{Plutonium Laboratory Measurements}

The initial phase of this work involves determining the hydrolysis and carbonate complex formation constants for $\mathrm{PuO}_{2}^{+}$. Synthes is, characterization and solubility product constants will also be determined for $\mathrm{PuO}_{2}(\mathrm{OH}) 2(\mathrm{~s})$ and $\mathrm{PuO}_{2}(\mathrm{OH})(\mathrm{am})$ under this activity.

\section{Uranium Laboratory Measurements}

Synthesis, characterization and the determination of the free energies for the solubility reactions of soddyite, uranophane, na-boltwoodite,

Ca-haiweeite and schoepite are underway. Solubility measurements are to begin in early FY87.

\section{Calorimetric Measurements}

This work is being done as a sub-contract to ANL. Facilities are available to yield complete thermodynamic $p$ operties of material from 0 to $1500 \mathrm{~K}$. Individual techniques include: low-temperature calorimetry, enthalpy of solution or reaction calorimetry, fluorine- and oxygen-bomb calorimetry and high-temperature drop calorimetry. Mineral samples of soddyite, uranophane, and clinontilolite will he measured.

\section{References}

WOLERY, T.J. (1988) EQ3/6 - Status and Future Development. Proceedings from the workshop on Geochemical Modeling; September 14-17, 1986, Fallen Leaf Lake, CA (this volume).

KERRISK, J.F. and SILVA, R.J. (1987) A Consistent Set of Thermodynamic Constants for Americium(III) Species with Hydroxyl and Carbonate. Proceedings from the workshop on Geochemical Modeling; September 14-17, 1986, Fallen Leaf Lake, CA (this volume).

JACKSON, K.J., WOLERY, T.J., BOURCIER, W.L., DELANY, J.M., MOORE, R.M. , CIINNICK. M.L., and LUNDEEN, S.R., (1989) MCRT User's Guide and Documentation. UCRL report (in preparation). Lawrence Livermore National Laboratory, Livermore, CA.

CODATA Task Group on Key Values for Thermodynamics (1978) Recommended Koy Values for Thermodynamics, 1977, J. Chem. Thermo. 10, 903-906.

HEIGGESON, H.C., DELANY, J.M., NESBITT, H.W., and BIRD, D.K., (1978) "Summary \& Critique of the Thermodynamic Properties of Rock Forming Minerals," Amer. J. Sci., 278-a, p. 229.

SILVA, R. and DELANY, J.M. (1986) "The Chemical Behavior of Waste Radionuclides Under Ground Water Conditions" Annual Report of Nuclear Chemistry Division, UCAR-10062-86, p.3-21. 


\author{
Jerry F. Kerrisk and Robert J. Silva \\ Los Alamos National Laboratory, Los Alamos, NM 87545 USA \\ Lawrence Livermore National Laboratory, Livermore, CA 94550 USA
}

\title{
Abstract
}

A consistent set of thermodynamic constants for aqueous species and compounds of Am(III) with hydroxyl and carbonate ligands has been developed. The procedure used to develop these constants involved establishing a value for one formation constant at a time in a sequential order, starting with the hydrolysis products and hydroxide solids, and then proceeding to carbonate species. The EQ3NR chemical-equilibrium model was used to test the constants developed. These constants are consistent with most of the experimental data that form their basis; however, considerable uncertainty still exists in some aspects of the Am(III) data.

\section{Introduction}

Americium is one of the major contributors to the radioactivity of high-level waste that will eventually be stored in geologic repositories. Under natural conditions, only one oxidation state of americium should exist. Am(III). To model the transport of americium in water, information is needed about aqueous species and solids of Am(III) that exist under repository conditions. Although numerous experimental studies have been done that contribute information about aqueous species and solids of americium, these data must be interpreted within a theoretical framework to assure that the data are internally consistent and to allow predictions under conditions that differ from the experiments. Thermodynamics provides the best framework for these data, as long as it is applicable, that is under equilibrium conútions.

This paper describes the development of a consistent set of thermodynamic constants for the formation of Am(III) complexes and solids with hydroxyl and carbonate ions. These anions are important because they form strong complexes with Am(III) and are present in most natural waters. Existing experimental data were used for this analysis. Because of disagreements among the results of some experiments, a set of thermodynamic constants that was consistent with all of the experimental data could not be developed.

\section{Existing Experimental Data}

Experimental data that form the basis for the constants developed here include distribution coefficients between organic and aqueous phases as a furiction of $\mathrm{pH}$ and carbonate content, potentiometric measurements as a function of $\mathrm{pH}$, and solubility measurements as a function of $\mathrm{pH}$ and carbonate content.

\footnotetext{
"This work was supported by the Nevada Nuclear Waste Storage Investigation Project.
} 
Experiments designed to determine hydrolysis constants are generally done in a neutral (noncomplexing) electrolyte to limit complex formation to hydrolysis products only. Two measurements of the distribution of Am(III) between organic and aqueous phases were used here. Lundqvist (1982) measured distribution coefficients in a perchlorate medium $(\mu=1 \mathrm{M})$ at $\mathrm{pH} 4$ to $9(\mu$ is ionic strength and $M$ is concentration in molar units). Caceci and Choppin (1983) measured distribution coefficients in a chloride medium $(\mu=0.7 \mathrm{M})$ at pH 5.9 and 8.1 as a function of oxalate content and determined the first hydrolysis constant from data for oxalate complexes using competing reactions. Another measurement of Am(III) distribution between organic and aqueous phases (Desire et al. 1969) was considered, but not included in the analysis. Data from two potentiometric titrations were also used. Nair et a l. (1982) titrated $A m(I I I)$ in perchlorate $(\mu=1 \mathrm{M})$ fiom $\mathrm{pH} 4$ to 7. Edelstein et al. (1983) titrated two chemical analogs of Am(III) [Cm(III) and $N d(I I I)]$ in a chloride medium $(\mu=0.1 M)$. Hydrolysis constants and solubility-product constants can also be determined from solubility measurements. Four sets of solubility data for Am(III) in neutral electrolytes were considered. They include the measurements of Silva (1982) in perchlorate $(\mu=0.1 M)$ at $\mathrm{pH} 7$ to 9.5 ; Rai et al. (1983) in chloride $(\mu=\sim 0.01)$ at $\mathrm{pH} 7$ to 13; Bernkopf and $\mathrm{Kim}$ (1984) in perchlorate $(\mu=0.1$ to 0.3 ) at $\mathrm{pH}$ 6.5 to 13; and Nitsche and Edelstein (1985) in perchlorate $(\mu=0.1 \mathrm{M})$ at $\mathrm{pH} 7$. Data for crystalline $\left(\mathrm{Am}(\mathrm{OH})_{3}(\mathrm{c})\right.$ ) and amorphous $\left(\mathrm{Am}(\mathrm{OH})_{3}(\mathrm{am})\right.$ ) hydroxide solids were reported. Significant differences among these results are apparent in a number of cases; choices made for this analysis are discussed in the following section.

Four sets of experimental data were used to determine constants for carbonate species with Am(III). Lundqvist (1982) measured Am(III) distribution between organic and aqueous phases in perchlorate $(\mu=1 \mathrm{M})$ at pH 4 to 7.5 under 0.1 and 1 atm $\mathrm{CO}_{2}$ pressure. Bidoglio (1982) measured distribution coefficients in perchlorate $(\mu=0.2 \mathrm{M})$ at $\mathrm{pH} 8$ to 9 and fixed total carbonate concentrations ( 1 to $6 \mathrm{mM}$ ); equilibrium $\mathrm{CO}_{2}$ pressures were calculated to be 0.0001 to $0.001 \mathrm{~atm}$. Silva and Nitsche (1983) measured the solubility of $\mathrm{Am}$ (III) in a carbonate solution under 0.008 atm $\mathrm{CO}_{2}$ pressure at $\mathrm{pH} 6(\mu=0.1 \mathrm{M}$ in perchlorate $)$ and identified $\mathrm{AmOHCO}_{3}(\mathrm{c})$ as the solid. Bernkopf and Kim (1984) measured Am(III) solubility in carbonate solutions controlled by a $\mathrm{CO}_{2}$ pressure of $0.00032 \mathrm{~atm}(\mu=0.1$ to $0.3 \mathrm{M}$ in perchiorate) at $\mathrm{pH} 6$ to 10 .

\section{Procedure}

A variety of procedures can be used to determine one or more formation constants from a set of experimental data (Rossotti and Rossotti 1961). In the situation described here, where a large variety of data from different kinds of experiments was used, the procedure of employing a least-squares method or some equivalent technique to determine all the constants of a model in a single step did not seem practical. Instead, we tried to determine formation constants for one species at a time, in each case using only the experimental data that are sensitive to that species and previously determined formation constants. The EQ3NR chemical equilibrium model (Wolery 1983) was used to calculate experimentally observable parameters such as the distribution of Am(III) between organic and aqueous phases or the solubility of Am(III) under conditions applicable to the various experiments; these calculated values were compared with experimental data as a means of testing the formation constants. 
The process started with the first hydrolysis constant of $A_{m}$ (III), which can be determined in a neutral electrolyte in a pH range where other nydrolysis products are not. present in significant quantities. The formation constant for $4 \mathrm{mOH}^{2}+$ was taken as the average of values reported by Lundqvist (1982), Caceri and Choppin (1983), Nair et al. (1982), and Edelstein et al. (1983). corrected to $\mu=0$. The resulting loak is 7.41 (see Table I). EQ3NR calculations of the distribution experiments were done by defining fictitious species to simulate $A m(I I I)$ in an organic phase and by estimating a logk for these species from the experimental distribution coefficients. Calculations of Am(III) distribution and average ligand number (for the potentiometric titrations) showed good agreement with the data of Lundquist (1982) and Caceci and Choppin (1983), but underpredicted the average ligand number of Nair et al. (1982) over the pH range of 4 to 8.

Next, the availability of solubility data for $\operatorname{Am}(\mathrm{OH})_{3}(\mathrm{c})$ and $\mathrm{Am}(\mathrm{OH})_{3}(\mathrm{am})$ at pH 7 allowed solubility product constants for these solids to be determined in a pH range in which the first hydrolysis constant is the only important complex. Using the measured solubilities of Silva (1982) for $\mathrm{Am}(\mathrm{OH})_{3}(\mathrm{C})$ at $\mathrm{pH} 7$, and of Rai et al. (1983) and Nitsche and Edelstein (1985) for $A m(O H)_{3}(a m)$ at $p H 7$, values of $\log K(\mu=0)$ for the formation of these solids were calculated to be 26.60 and 25.10 , respectively (see Table I).

Solubility data for $\mathrm{Am}(\mathrm{OH})_{3}(\mathrm{C})$ and $\mathrm{Am}(\mathrm{OH})_{3}(\mathrm{am})$ show that the solubility beccmes constant for sufficiently high $\mathrm{pH}$ (see Fig. 1). This indicates that $A m(O H)^{\circ} 3$ is an important aqueous species but that $A m(O H) 4^{-}$is not present in significant amounts because formation of $\mathrm{Am}(\mathrm{OH})_{4}^{-}$would increase solubility at high pH. Solubility data at high pH for either solid could be used to determine the formation constant of $\mathrm{Am}(\mathrm{OH})^{\circ} 3$, which is the only aqueous species present in significant quantity in the $\mathrm{pH}$ range where the solubility is constant; we used the solubility of $\mathrm{Am}(\mathrm{OH})_{3}(\mathrm{C})$ at $\mathrm{pH} 9.5$ (Silva 1982) to determine logk for formation of $\operatorname{Am}(\mathrm{OH})^{\circ} 3$ as 18.20 at $\mu=0$ (see Table I).

TABLE I

FORMATION CONSTANTS OF AM(III) SPECIES AT ZERO IONIC STRENGTH

Reaction

$$
\begin{aligned}
& \mathrm{Am}^{3+}+\mathrm{OH}^{-}=\mathrm{AmOH}^{2+} \\
& \mathrm{Am}^{3+}+2 \mathrm{OH}^{-}=\mathrm{Am}(\mathrm{OH})_{2}{ }^{+} \\
& \mathrm{Am}^{3+}+3 \mathrm{OH}^{-}=\mathrm{Am}(\mathrm{OH})_{3}{ }^{\circ} \\
& \mathrm{Am}^{3+}+3 \mathrm{OH}^{-}=\mathrm{Am}(\mathrm{OH})_{3}(\mathrm{c}) \\
& \mathrm{Am}^{3+}+3 \mathrm{OH}^{-}=\mathrm{Am}(\mathrm{OH})_{3}(\mathrm{am}) \\
& \mathrm{Am}^{3+}+\mathrm{CO}_{3}^{2-}=\mathrm{AmCO}_{3}^{+} \\
& \mathrm{Am}^{3+}+2 \mathrm{CO}_{3}^{2-}=\mathrm{Am}^{2-\mathrm{CO} 3)_{2}-} \\
& \mathrm{Am}^{3+}+3 \mathrm{CO}_{3}^{2-}=\mathrm{Am}(\mathrm{CO} 3)_{3}{ }_{3-} \\
& \mathrm{Am}^{3+}+\mathrm{OH}^{-}+\mathrm{CO}_{3}^{2-}=\mathrm{AmOHCO}_{3}(\mathrm{c})
\end{aligned}
$$$$
\underline{\log K}
$$ 
The formation constant for the second hydrolysis product. Am(OH) $2^{+}$, was determined by comparing the calculated solubilities with measurements taken by Rai et al. (1983) and Silva (1982) in the pH range of 8 to 9 . This gave a value of logk for the formation of $\operatorname{Am}(\mathrm{OH}) 2^{+}$as $\leq 12.00$ at $\mu=0$ (see Table I).

Figure 1 shows the calculated solubility of $\operatorname{Am}(\mathrm{OH}) 3(\mathrm{C})$ and $\operatorname{Am}(\mathrm{OH}) 3(\mathrm{am})$ based on these constants (using EQ3NR) compared with experimental data. The data of Rai et al. (1983) are for amorphous material at low pH and crystalline at higher pH. Below pH 9.5, generally good agreement exists among the experiment comparisons, other than Bernkopf and Kim (1984), and between calculated and observed solubilities. Above pH 9.5, the calculated curve for crystalline material is about two orders of magnitude above that for the data from Rai et al. (1983). The data of Bernkopf and Kim (1984) are for amorphous material but have a lower solubility than either the crystalline or amorphous solids of other experiments. These data were not lised in this analysis because they disagree with the generally consistant data of other experimenters and because the solid phase used in their work was not identified. Figure 2 shows a plot of the distribution of aqueous species in a neutral electrolyte calculated using the data in Table I.

After formation constants for Am(III) species in a neutral electrolyte were established, species with carbonate were considered next. The species $\mathrm{AmCO}_{3}{ }^{+}$and $\mathrm{Am}\left(\mathrm{CO}_{3}\right)_{2}-$ were considered first because they were identified by

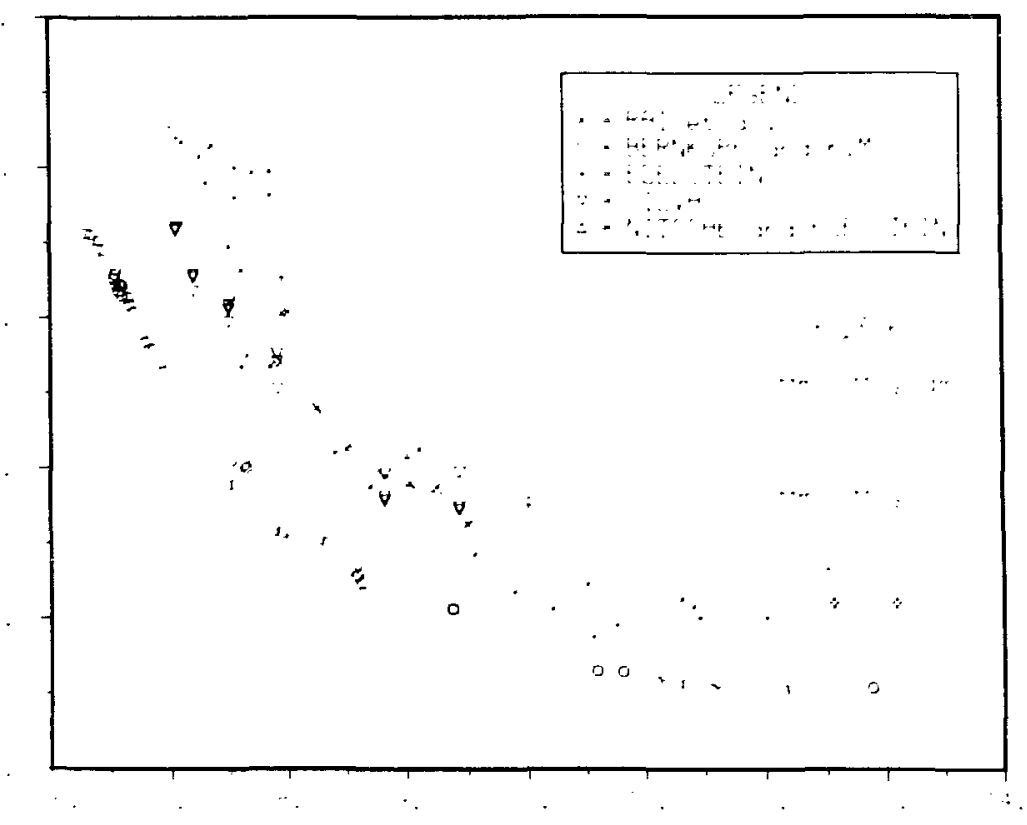

Fig. 1. Am(III) solubility in a neutral electrolyte at $25^{\circ} \mathrm{C}$. 
Lurdquist ('982) as reing present under the condit'jns of his expeiments. $4 m\left(60_{3}\right)^{-}$was also identified by Bidoj!io $(1982)$ as the most important carcrite comolex in his experiments. These species have also oeen identified for trivalent rare earths (Ferri et al. 1933: Lurgquist 1982). The vaive of logk for the formation of $\mathrm{AmCO}_{3}{ }^{+}$was taken from Lundarist (1982) and corected to $\mu=9$, giving a corrected value of 3.26 . the walue for

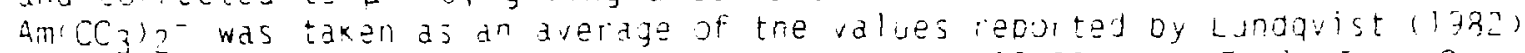
and Bidoglio (1982), corlected to $\mu=0$, to give 13.30 (see Tabie I). Comparisons of experimental data with the calculated (with EQS IR) districution of Am(III) between organic and aqueous phases under the conditions of these two experiments zave generally gord agreement using only these two carbonate species; it was not nezessary to include the bicarbonate or hydroxy-carbonate complexes postulated oy Bidogio (1982) ano by Bernkopf and Kim (1984).

These two Am(III)-carbonate complexes and the solubility data of Silva and Nitsche (1983) at $\mathrm{pH} 6$ were used to calculate logk for $\mathrm{AmOHCO}_{3}(\mathrm{c})$ at $\mu=0$, giving a value of 22.60 (see Table $I$ ). Because these measurements were made at only one $\mathrm{OH}$, the one used to determine the formation constant, further comparisons between calculated and measured data could not be made. However, the solubility measurements of Bernkopf and Kim (1984) in carbonate solution also involved $\mathrm{AmOHCO}_{3}(\mathrm{c})$. EQ3NR calculations of the solubility of AmOHCO$_{3}(\mathrm{C})$ under the conditions of the Bernkopf and $\mathrm{kin}$ (1984) exper:ment compared well with measurements up to about pH 8 ; above that pH however, the calculated solubility dropped below the measured data. By analogy with rare-earth carbonates, the presence of $\mathrm{Am}\left(\mathrm{CO}_{3}\right)_{3} 3^{3-}$ was postulated (Ferri at al. 1983), and a value of logk of 14.95 for formation of this species at

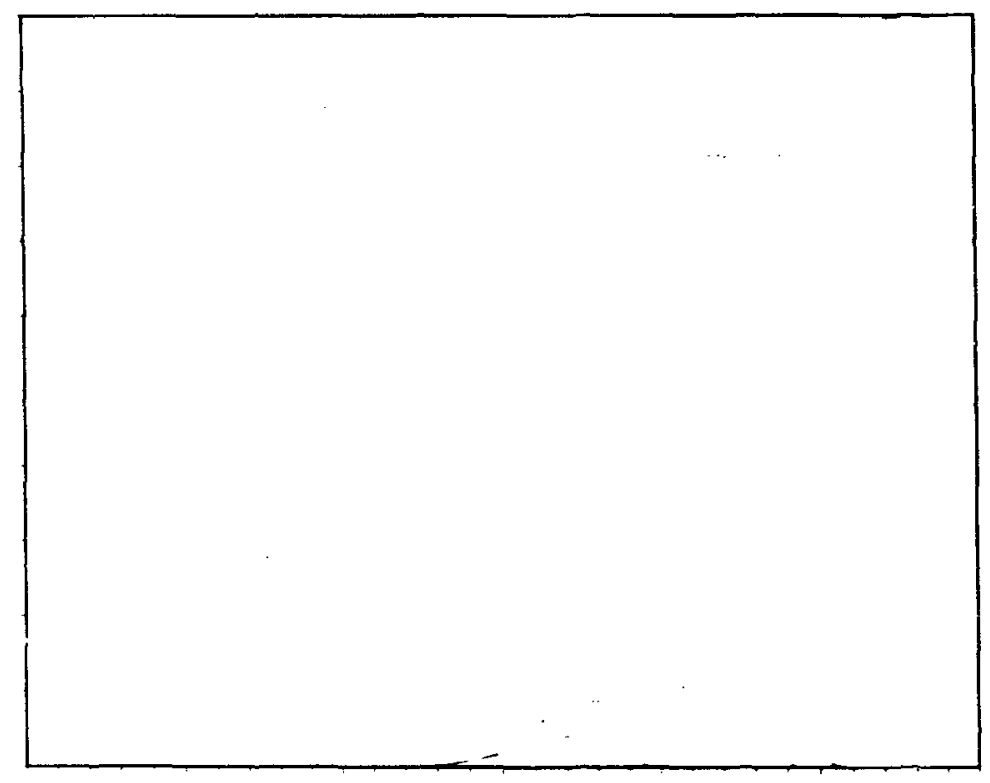

Fig. 2. Am(II) speciation in a neutral electrolyte dt $25^{\circ} \mathrm{C}$. 


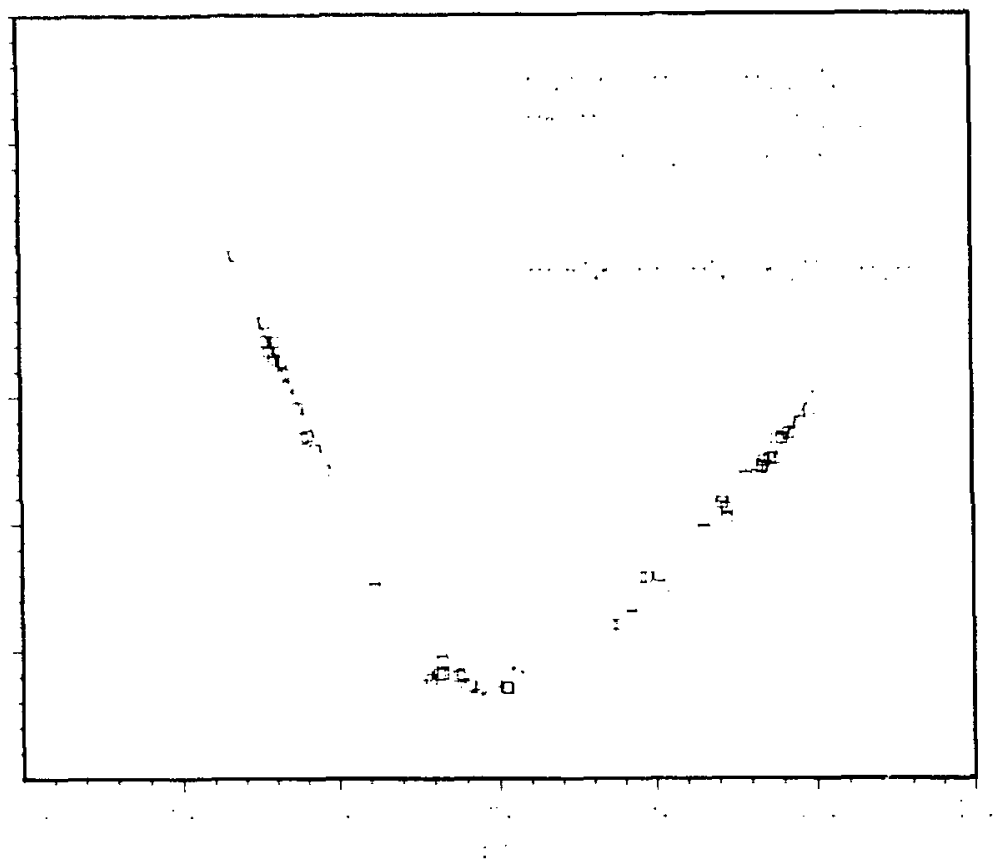

Fig. 3. Am(III) solubility in a carbonate solution with 0.000316 atm $\mathrm{CO}_{2}$ pressure.

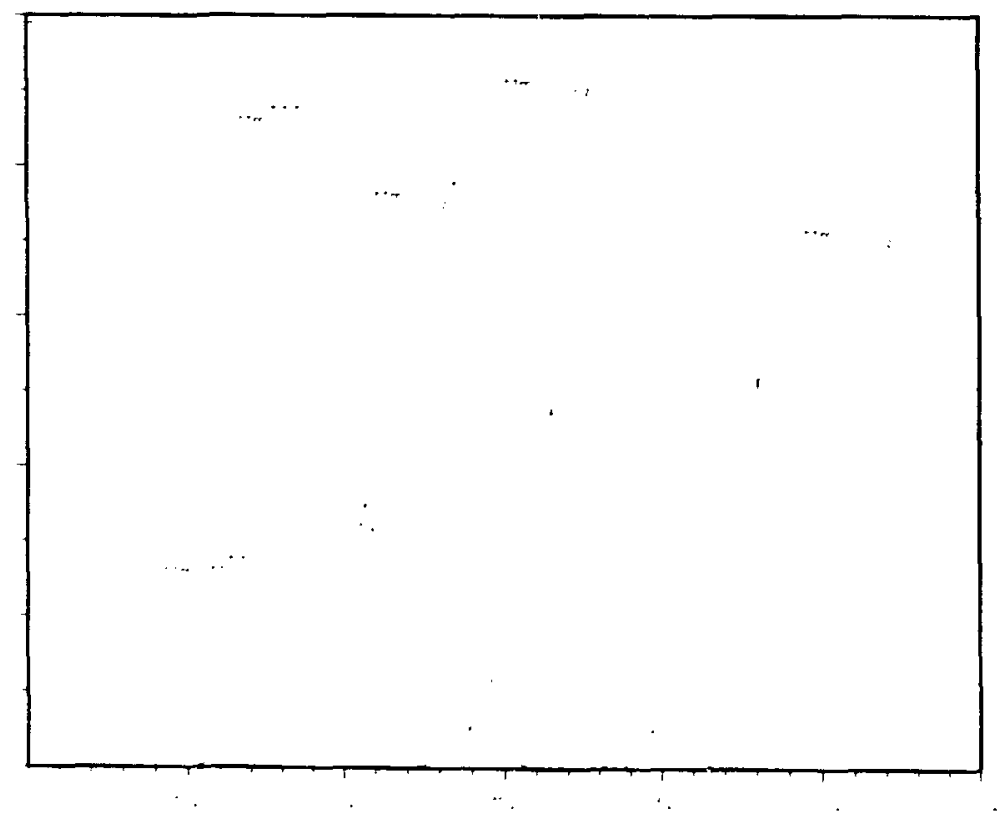

Fig. 4. Am(III) speciation in a carbonate solution with $0.000316 \mathrm{~atm} \mathrm{CO}_{2}$ pressure. 
$\mu=0$ was determined (see Tabie I). Use of this species along with the other two carbonate complexes gave generally good agreement between the calculated solubility and the measured data of Bernkopf and kim (1984) (see cig. 3). Figure 4 shows a distribution of species under the conditions of the Bernkopf and kim (1984) solubility experiments; it aiffers significartly From that proposed by Bernkopf and kim (1984). On?y one hydrolysis praduct, anoH ${ }^{2}+$ is present in significant quantities; the importance of this soecies would be reduced at higher carbonate contents (higher equilibrium $\mathrm{CO}_{2}$ pressures).

Problem Areas

Considerable uncertaility still exists in some aspects of Am(III) chemistry under natural conditions. One of the major areas of uncertainty is caused by disagreement among various experimenters about the identity of ajueous species present under the conditions of their experiments. Kerrisk (1984) pointed out that Lundqvist (1982) should have seen evidence of some of the Am(III) carbonate species reported by Bidoglio (1982); and likewise, Bidoglio (1982) should have seen some of the species reported by Lundquist (1982). This situation occurs because the species used in these models have not been identified by some technique such as spectroscopy, but are inferred from the data. This situation will not be remedied until higher-sensitivity instruments, such as a photoacoustic spectrometer, are used to identify aqueous species.

A second problem area results from the disagreement among the various experiments about the solubility of Am(III) in a neutral electrolyte. Disagreemencs exist over the entire pH range ( 7 to 13) of the measurements (see Fig. 1). Part or all of these disagreements may have been caused by the different solid species controlling solubility in these experiments. Bernkopf and Kim (1984) did not report any identification of their solid: cnly a preparation techirique. Silva (1982) identified his starting material as $\mathrm{Am}(\mathrm{OH})_{3}(\mathrm{C})$ using $x$-ray data, but only visually compared the final solid to the starting material. Rai et al. (1983) saw evidence of an amorphous solid (probably $\mathrm{Am}(\mathrm{OH})_{3}(\mathrm{am})$ ) at low $\mathrm{pH}$ and $\mathrm{Am}(\mathrm{OH})_{3}(\mathrm{c})$ at high $\mathrm{pH}$ in the final material. Plots of the solubility data as a function of $p H$, taken from the experiments of Bernkopf and Kim (1984) and of Rai et al. (1983), show a break arourd $\mathrm{pH} 8.5$ to 3.5 , with a drop to lower solubilities at higher pH: tnis may be a sigrial of a change in the identity of the solid controlling solubility. This problem requires additional experimental work, giving strong emphasis to the ideritification of the solid phase or phases that control solubility under these conditions.

A final problem affecting the results reported here is the ionic-strength corrections to measured logk values. Many of the experiments discussed here were done at $\mu=1 \mathrm{M}$; others ranged from $\mu=0.7$ down to $\mu<0.1$. Thermodyriamic models such as EQ3NR use logk values at $\mu=0$ and provide their own ionic-strength corrections. Experimentally derived activity coefficients were used to correct the measured values of logk to $\mu=0$ (Robinson and Stokes 1359; Pitzer and Peiper 1980; Khoo et al. 1981; and Peiper and Pitzer $1982 ;$. Eecause of the high charge on $\mathrm{Am}^{3+}$, activity coefficients of about 0.02 aoply for this species at $\mu=1 \mathrm{M}$. In comparing these activity coefficient; with the values calculated by EQ3NR, the EQ3NR activity coefficients ware found to be significantly different in a number of cases. For the EQ3NR 
Calculations discussed here, values of the a parameter used in the activitycoefficient calculation (Wolery 1983) were modified so that the calculated activity coefficients were comparable to experimentally derived values. This involved changing à as follows: from $8.0 \AA$ to $5.0 \AA$ for $\mathrm{Am}^{3+}$, from $9.0 \AA$ to $5.0 \AA$ for $\mathrm{H}^{+}$, from $4.5 \AA$ to $3.5 \AA$ for $\mathrm{CO}_{3}{ }^{2-}$, from $4.5 \AA$ to $4.0 \AA$ for $\mathrm{HCO}_{3}^{-}$, and from $3.0 \AA$ to $4.0 \AA$ for $\mathrm{Cl}^{-}$. This type of correction, which is needed to adjust data measured over a range of ionic strengths to some common value, adds additional uncertainty to the results.

\section{References}

BERNKOPF, M. F. and J. I. KIM (1984) Hydrolysereaktionen und Karbonatkomplexierung von Driwertigen Americium imi Naturlichen Aquatischen System. Institut fur Radiochenie der Technischen Universitat report RCM-02884, Munchen; see a!so KIM, J. I., M. BERNKOPF, C. LIERSE, and F. KOPPOLD (1983a) Hydrolysis Reactions of Am(III) and Pu(VI) Ions in Near Neutral Solutions. Paper presented at the 185th Americal Chemical Society Meeting, Seattle, Wa., March, 1983, paper No. 91.

BIDOGLIO, G. (1982) Characterization of Am(III) Complexes with Bicarbonate and Carbonate Ions at Groundwater Concentration Levels. Radiochemical and Radioanalytical Letters, 53, 45-60; see also BIDOGLIO, G., A. DEPLANO, and A. CHATT (1983) Studies on Speciation of Americium, Technecium, and Neptunium in Simulated Vitrified-Waste Leachates. In Scientific Basis for Nuclear Waste Management, Materials Research Societ, Symposium Proceedings, Vol. 15, G. Brookins, (ed.), North Holland Publishing Co., Inc., pp. 373-382.

CACECI, M. and G. R. CHOPPIN (1983) The Determination of the First Hydrolysis Constant of Eu(III) and Am(III). Radiochimica Acta, 33, 101-104.

DESIRE, B., M. HUSSONNIOS, and R. GUILLAUMONT (1969) Determination de la premiere constante d'hydrolyse de l'americium, du curium, du berkelium et dL cai ifornium," C. R. Acad. Sc. Paris, 269, 448-451.

EDELSTEIN, N., J. BUCHER, R. SILVA, and H. NITSCHE (1983) Thermodynamic Properties of Chemical Species in Nuclear Waste. Lawrence Berkeley Laboratory report LBL-14325.

FERRI, D., I. GRENTHE, F. HIETANEN, and F. SALVATORE (1983) Studies on Metal Carbonate Equilibria. 5. The Cerium(III) Carbonate Complexes in Aqueous Perchlorate Media. Acta Chemica Scan., A37, 359-365.

KERRISK, J. F. (1984) Americium Thermodynamic Data for the EQ3/6 Database. LoS Alamos National Laboratory report LA-10040-MS.

KHOO, H. K., T. K. LIM, and C. Y. CHAN (1981) Activity Coefficients in Aqueous Mixtures of Hydrochloric Acid and Lanthanum Chloride at $25^{\circ} \mathrm{C}$. Jour. Solution Chem., 10, 683-691.

LUNDQVIST, R. (1982) Pyarophilic Complexes of the Actinides. I. Carbonates of Trivalent Americium and Europium. Acta Chemica Scand., 36, 741-750.

NAIR, G. M., K. CHANDER, and J. K. JOSHI (1982) Hydrolysis Constants of Plutonium (III) and Americium(III). Radiochimica Acta, 30, 37-40.

NITSCHE, H. and N. M. EDELSTEIN (1985) Solubilities and Speciation of Selected Transuranium Ions. A Comparason of a Non-Complexing Solution with a Groundwater from the Nevada Tuff Site. Radiochimica Acta, 39, 23-33.

PEIPER, J. C. and K. S. PITZER (1982) Thermodynamics of Aqueous Carbonate Solutions Including mixtures of Sodium Carbonate, Bicarbonate, and Chloride. Jour. Chem. Thermodynamics, 14, 613-638.

PITZER, K. S. and J. C. PEIPER (1980) Activity Coefficients of Aqueous $\mathrm{NaHCO}_{3}$. Jour. Phys. Chem., 84, 2396-2398. 
RAI, D., R. G. STRICKERT, D. A. MOORE, and J. L. RYAN (1983) Am(III) Hydrolysis Constants and Solubility of Am(III) Hydroxide. Radiochemica Acta, 33, 201-206.

RUBINSON, R. A. and R. H. STOKES (1959) Electrolytic Solutions, Academic Press.

ROSSOTTI, F. J. and H. ROSSOTTI (1961) The Determination of Stability Constants, McGraw-Hill Book Co.

SILVA, R. J. (1982) The Solubilities of Crystalline Neodymium and Americium Trihydroxides. Lawrence Berkeley Laboratory report LBL-15055.

SILVA, R. J. and H. NITSCHE (1983) Thermodynamic Properties of Chemicil Species of Waste Radionuclides. In NRC Nuclear Waste Geochemistry '83, U. S. Nuclear Regulatory Commission report NUREG/CP-0052, pp. 70-93.

WOLERY T. (1983) EQ3NR, A Computer Frogram for Geochemical Aqueous Speciation-Solubility Calculations: User's Guide and Documentation. Lawre.ce Livermore National Laboratory report UCRL-53414. 
software for the ('omputation and (imaphical Displat

of

Intensive lariable Phase Diagrame

\author{
E.Il. Pertins \\ Alberta Research (ouncil. Oil sands Rescarch Department. \\ P'O Box 8330. Postal siation l:. \\ Fidmonton. Alberta. Canada. TGill $5 \times 2$ \\ R. Berman and T.H. Brown \\ lepartment of Cicological siciences. l'be: \\ Vanconver. B.('. camada. $16 \mathrm{~T} 2 \mathrm{BA}$
}

Atsiract

The use of intensive variable diagrams to portray the stability relationships of minerals. aqueous species and gases is one of the most critical tools available to evalwate the stability of natural assemblages. With the increasing accuracy and size of thermodynamic databases for minerals. gases and aqueous species. and the continually increasing speed and power of modern computers. it is now possible to interactively and quickly calculate diagrams relating all possible stability relationships for a given ststern.

P’-SYTEM and its derivatives (TX-SYSTEM. PX-SYYTEM. THO2-SYSTE.M. PA-SYSTEN. TA-SYSTEM and AA-SYSTEMI) allow ti, calculation of phase diagrams as functions of pressure verus iemperature. temperature verus fluid composition. pressure verus fluid composition. temperature verus oxygen fugacity pressure verus activity of a specified component. lemperature verus activity of a specified component. and activity verus activity of two different components. By default, only the stable diagram is calculated and is present in tabular form and as a plot. All curves are labelled with the correct assemblage on cach side of the curve.

The programs are versatile with many different run time options. including: projection from a given phase or assernblage: limiting the calculation of curves to those which contain a given phase or assemblage: inclusion of meta-slable equilibria. and the use of various solid solution models for solids and equations of state for gases. 11 includes equations for disorder. polymorphic transitions as well as extended heat capacity functions and volumetric cquations of state for solids.

The first versioms of the programe were uritem in 1977. and hey have been con-

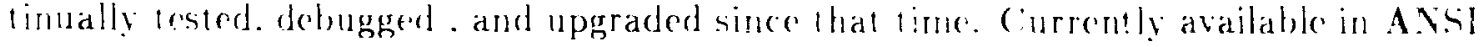
tandard FORTR A T. These progrates are rumning at over 30 sites on a range of machines. including a Cray. almost all of the 113.11 and ('I)C: majuframes. all VAX's, 


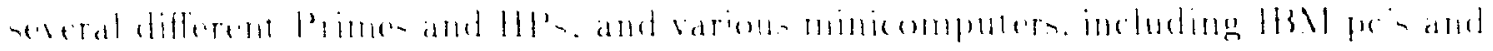
their clomen.

Introturivin

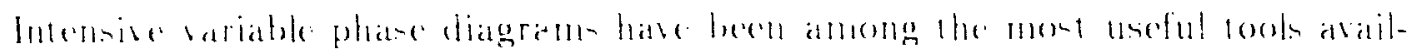

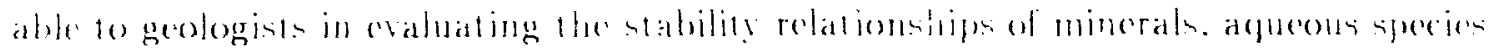

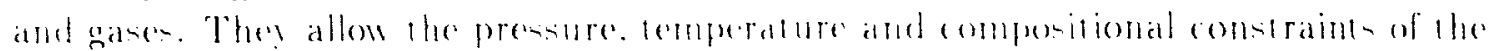

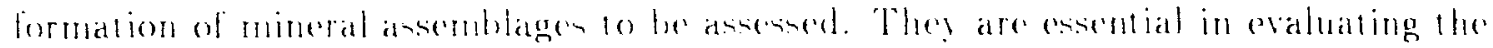

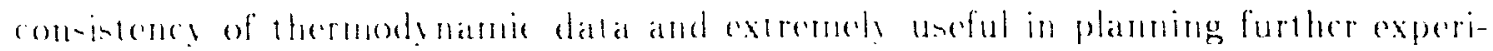

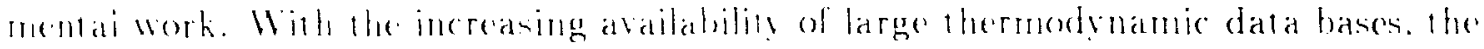

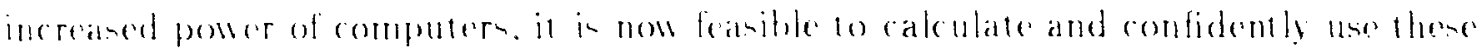
diagratum.

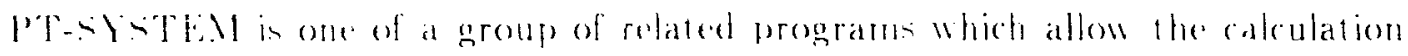

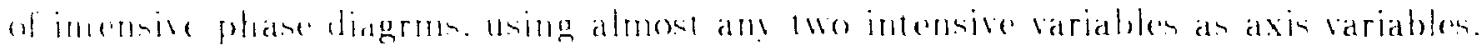

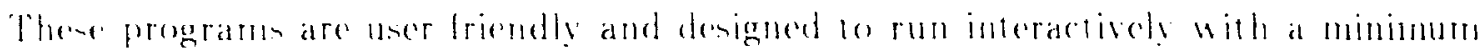

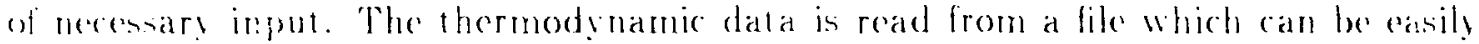
read and tnodifed by any text editor. The output from the programs is given in both labular and graphic formats.

Whenever poseihle. the philosephe betind these programs has been to allow the uner to specify. use and tent diflerem thermodynamie data sets for the phases and spereen. and differeat equations of hate for the gases. and then to compare the re sults. It is thi-procese which builds confidence in the programs. the dataset and any prodictione evaluations made.

Latmples of computed intemsive variathlo diagrams.

In the following figures. We have uned the thermotynamic data base for minerals of Berman. Brown and Cireomood (1985). and either the Hat cquation of state for waler (Hadr. (iallagher. Koll. 19x.1) or a Redlich-hwong (herrich and Jacobs. 1981) lormulations for water-carton dioxide mixumes. All diagrams were plotted on a laser printer. Because of the limberl size awalatale for diagrams. only simple” diagrams wub fow curves have heon shown. Diagrams with libousands of stable reactions have been calculated but it in diflicult to show these.

l. igure ome i a pressure temperature diagram for porlapes the simplest geological

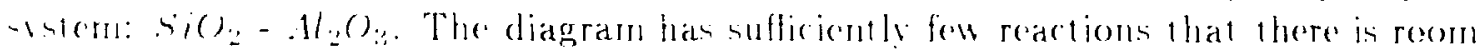
fer the complete mineral name to be used in labeling the curve. At the users option. abturesiations of the names could be mod. 
Fignerelofe and Two
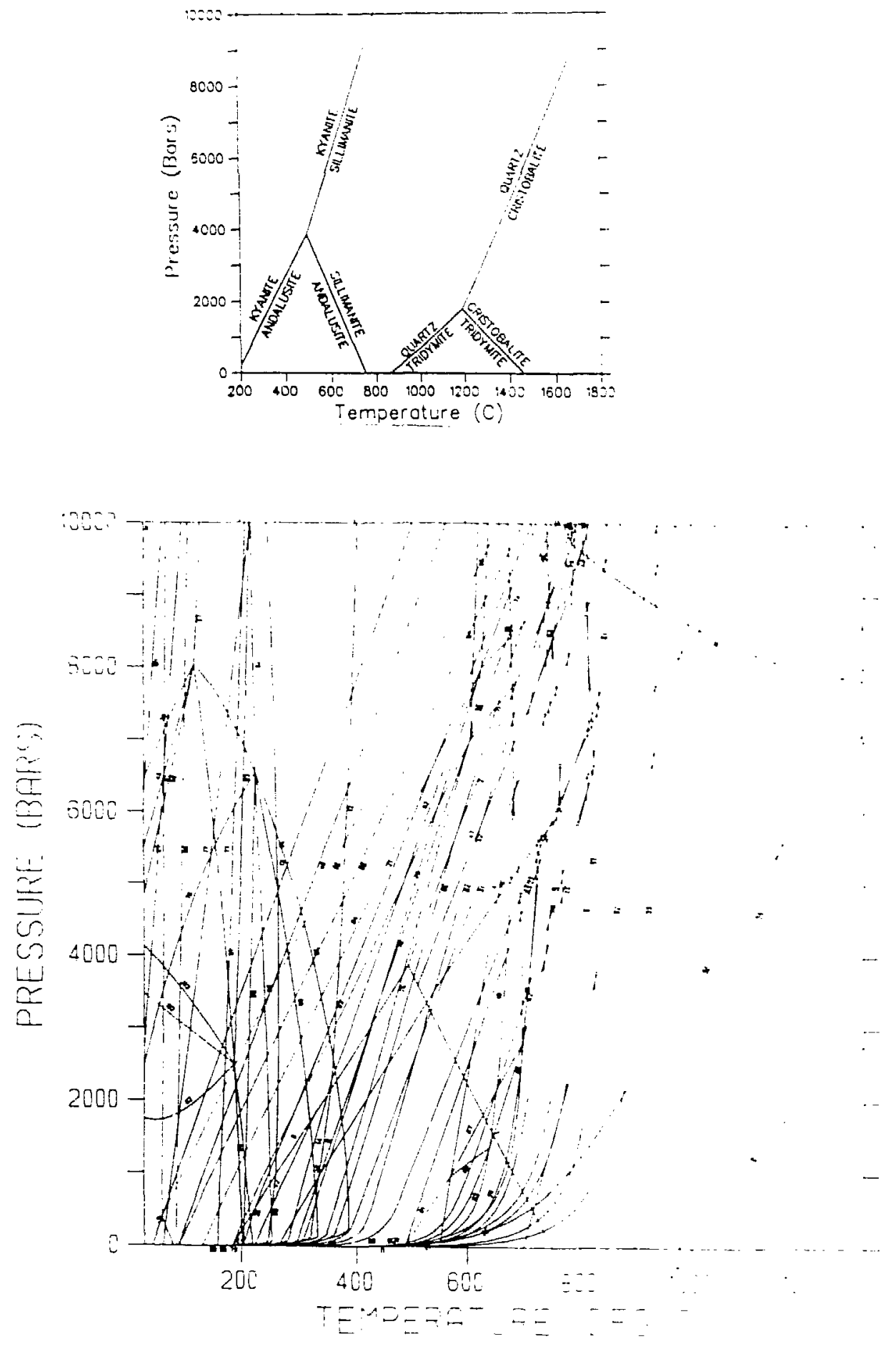
Figure jhere. Four and hine
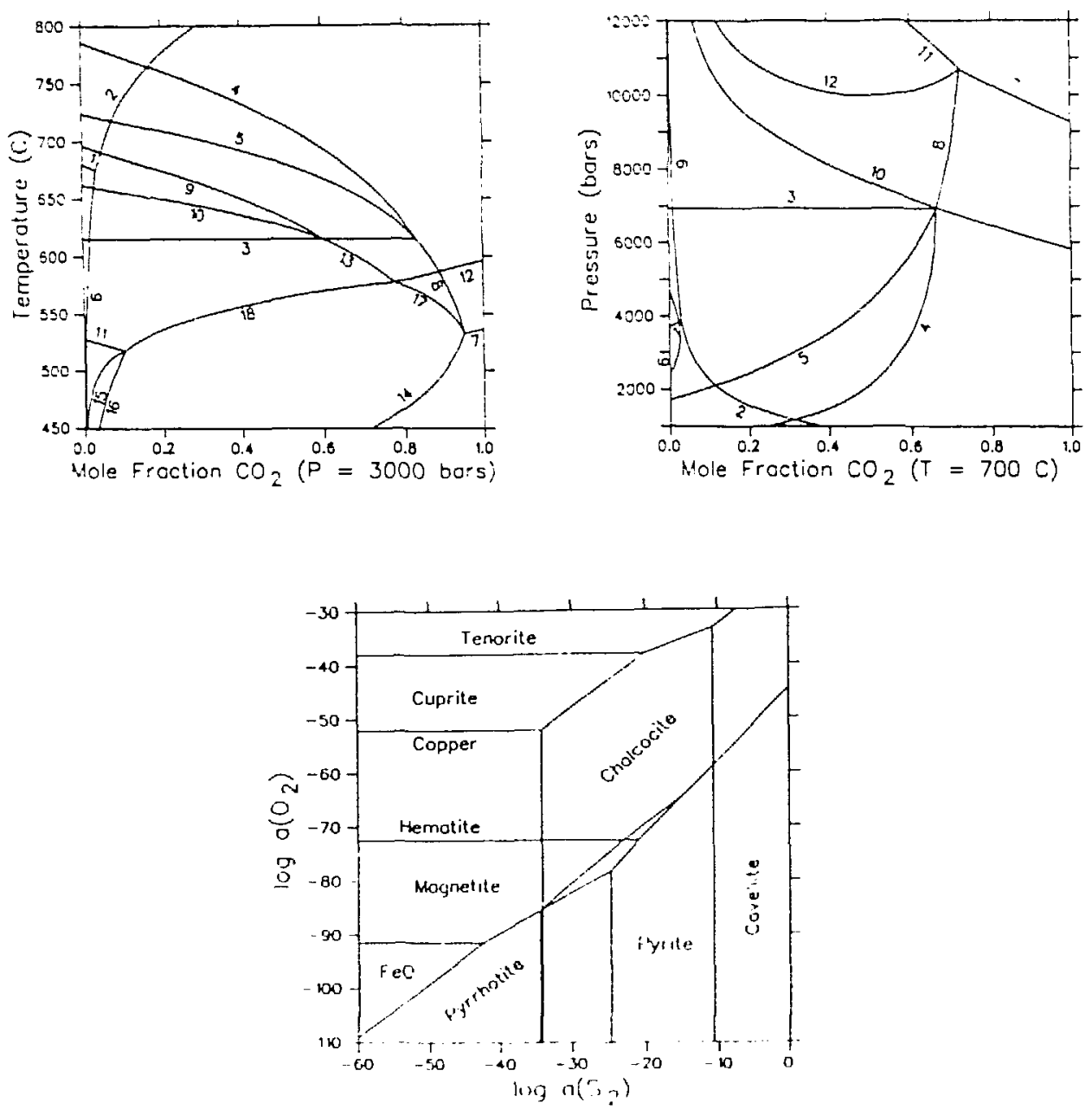

Figure tus in a more complicated P. T diagram. including a fluid phase, which

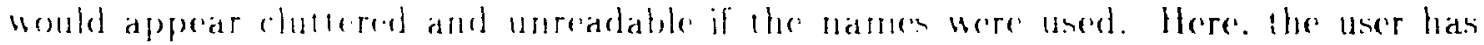
sperified that the cureen be numbered. The pregram prints a separale table with these

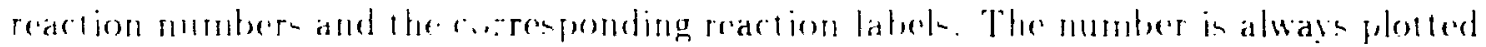
on the produce cide of the equilibria. The Hatar ceplation of state for water was uned.

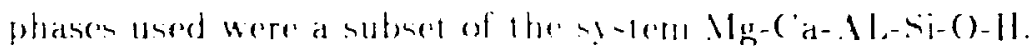

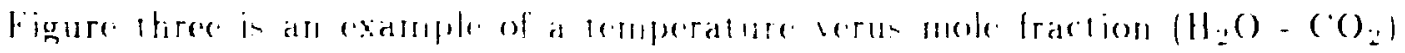
diagrart. calculated at there hiletars. weing the Redlich-hwong equation of state for 


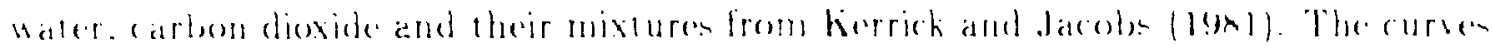
have foren mumbered rather than labelled for elarim.

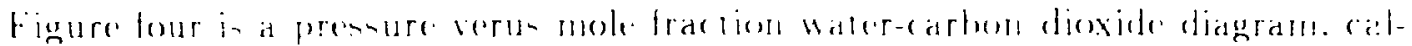

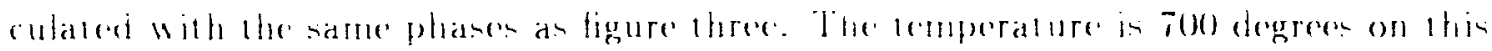
diagratil

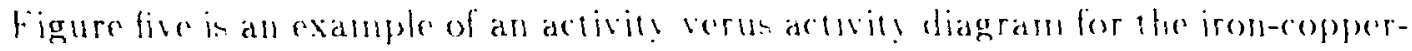

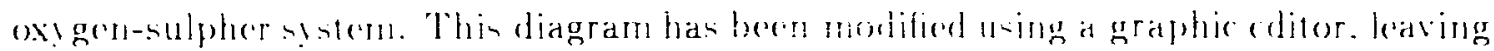
the chalcoperite field untabellod for claring.

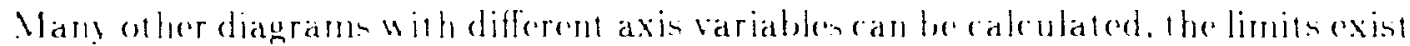
onls in the mind of the user and in the avalablity of the appropriate thermodynamic datas.

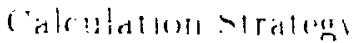

All of the programs follow the same basic strategy for hbe ralculation of phase diagrame. Thene mat he -ummarized as follows:

\section{sispe performed ones}

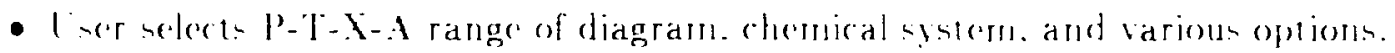

- Program reado thermodynamic databane.

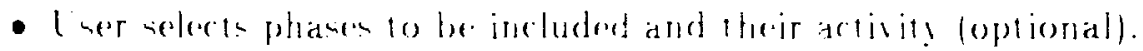

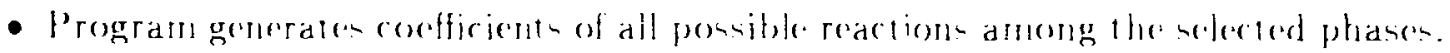
Repeated for cach reaction

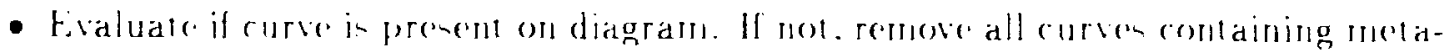
stable assemblage frem the list of remaining curves. then ged nexe curve. If preserte. continue.

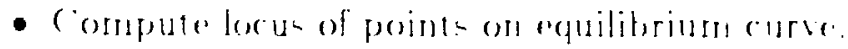

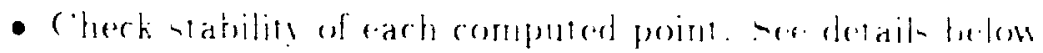

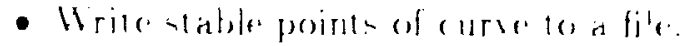

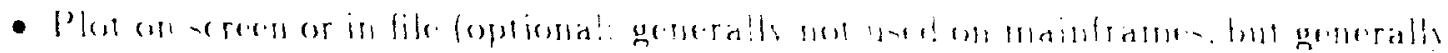
asored he microsel. 

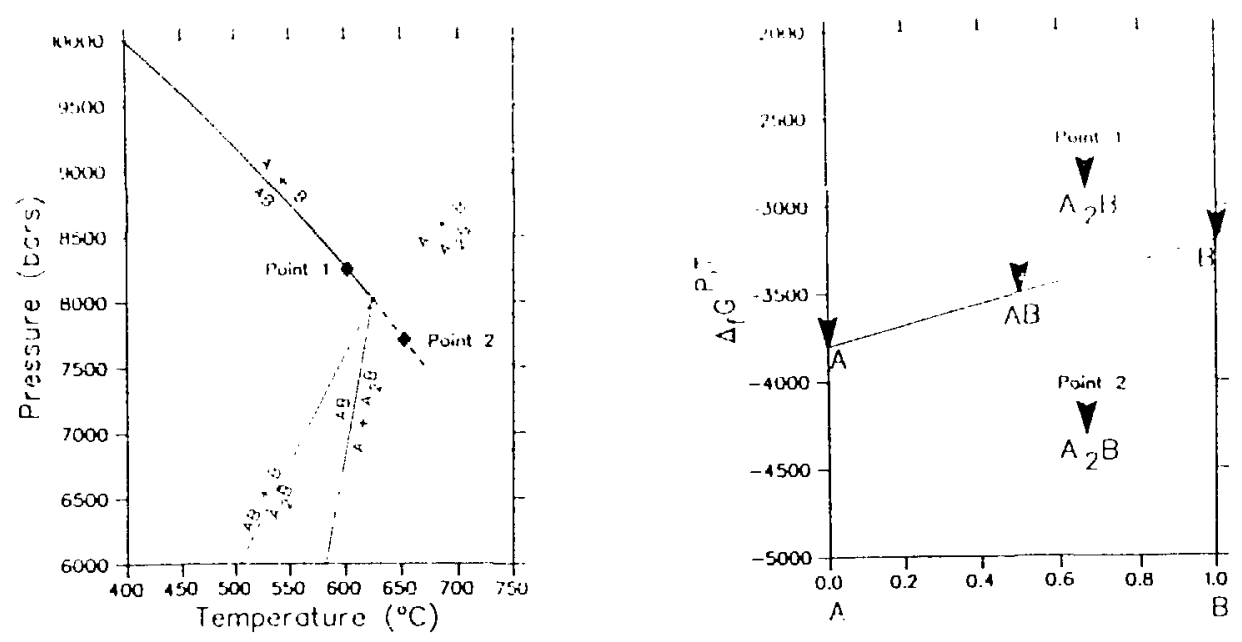

- If all curves have been evaluated. close filen. exil.

P'ost-processing

- P'rint sumenar! file (optional as it is often big).

- Vien edit completed phase diagram. with option of making copies on various output devicen.

Figures six and sesen illustrate the most critical stepe in the calculation procedure. determining the statrility of poirts on the equilibrium curven. Stability ievel is calculated he comparing the position of the component chemacal potential plane with the chemieal potential of every other phase in the system. For example. in figure six at point I. the chemical potential of phase $A_{2} B$ is above that defined th the stable univariant 1-B-assemblage. At point 2. the situation is reversed. indicating that this unitariant assemblage is metastable. The exact location of the 1-phase invariant point is located by interval halving between stable and metastable points on the univariant reaction.

The strong point of the strateg! summarized abowe in that it ensure that all stable

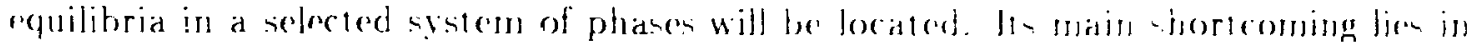
the inefficienes of having 10 compune ment of the equilitoria in ordes to find the wathe oncs.

We are cusently exploring an alereate atrategs that utilize the information re-

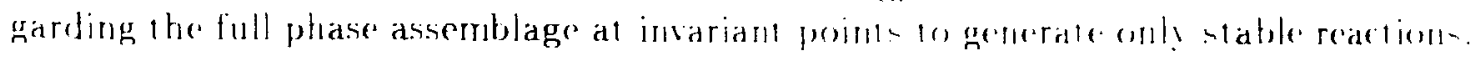




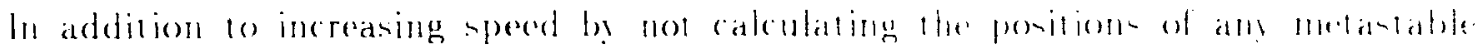

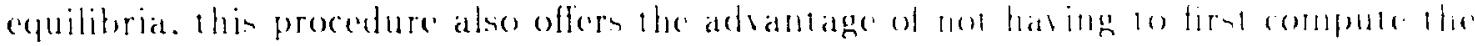

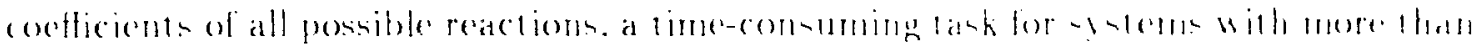

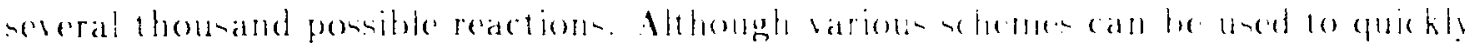

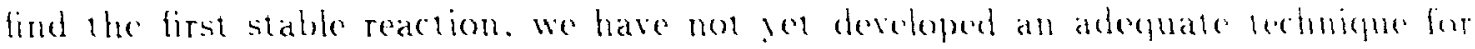
finding reactions that are not connected to the stable nee.

Program detail

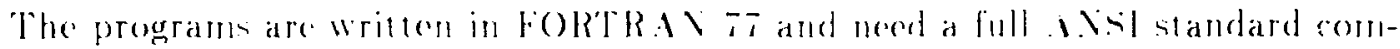

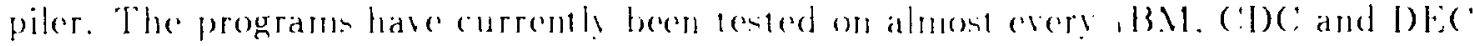
mainframe. as woll as MlleRO-VAXs. varioms of the larger Ho' computers. several PRIALE computers and a CRAY LS. To the best of the authers knouledge. atl main-

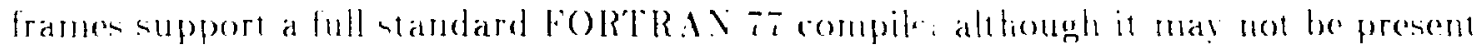
at specifie sites. There are neveral minor differences beween 1 he ba bous compilers. these generally reflece file naming opening rewinding cloming comventions. Areas of the code which might need to be changed are flagged and allormative versions are giv'm.

The sofuare can be run on microcomputers it has heen allecesfull! compilied and run on lHBM-XTs. IHM-ATs, and various of the clones. If the programs are nol

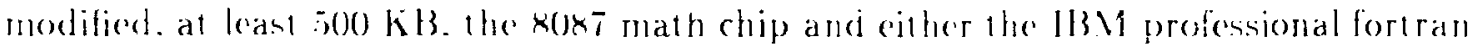
it compiler or the Lahe! fial compiler are required. Various other pe compilers are

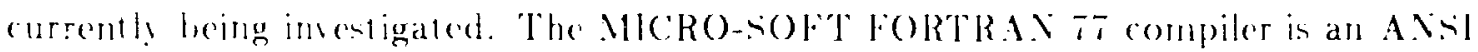
subiamdard lORTR 1.17 compiler and an nol be used withoul major modificalioms in 1 heme prograns

The pregram has a comeiderable mumber of defaults. These range from the defaula answers for the question- the size of labels on the plots and the amouall of information writen to the interactive unit. These are designed to be asily modified by the user to provide at "cmotom" remiont of the programs.

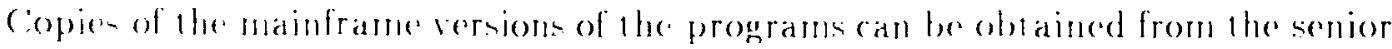

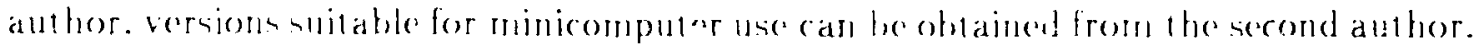
becumentalion. a datatiane. and examples are provided with the programs.

\section{Roferences}

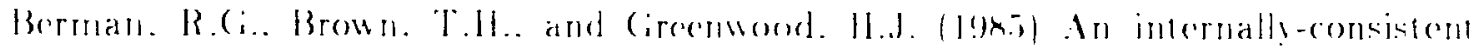

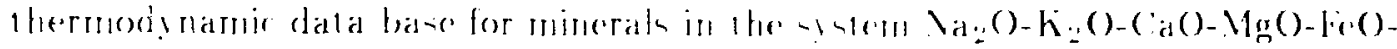

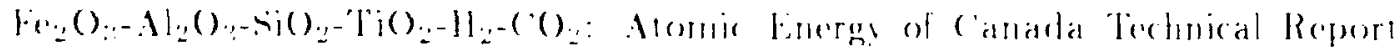
TR-:3TT. TOp).

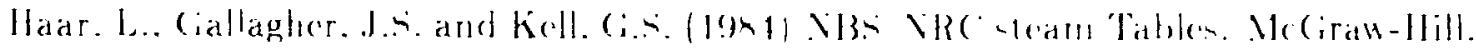




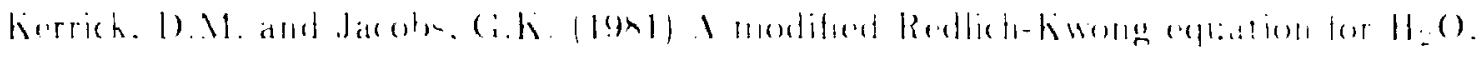

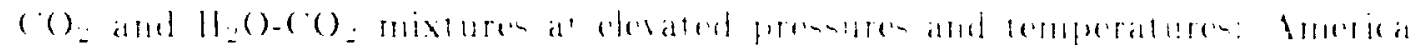

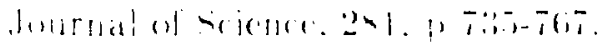




\title{
CHLORITE SOLUBILITY BETWEEN $200^{\circ} \mathrm{C}$ AND $350^{\circ} \mathrm{C}$ : AN EXPERIMENTAL AND TIIEORETICAL MODFLING STUDY
}

\author{
Edward C. Thornton, William E. Seyfried, Jr., and Jeffrey Seewald \\ Dept. of Geology and Geophysics, University of Minnesota, Minneapolis, MN 55455
}

\section{INTRODUCTION}

Computer modeling of rock/water interaction processes can contribute greatly to our understanding of mineral alteration and mass transport in hydrothermal systems. These models, however, may be applied in a quantitative manner only if we have accurate thermodynamic data for the solubilities of common rock-forming minerals. Currently, solubilities of many minerals can only be approximated owing to a lack of experimental data at the appropriate conditions. We present here recently acquired solubility data for chlorite and illustrate how it may be integrated into a computer model for rock/water interaction.

\section{PROCEDURES}

The experiment reported here was conducted in flexible cell hydrothermal equipment for a period of 11 months. A mineral assemblage consisting of Mg-chlorite, kaolinite, gibbsite, magnetite, and hematite was employed to buffer the fluid chemistry with respec: to aluminum. silica, and oxygen fugacity; all dissolved components were measured in the fluid samples obtained during the experiment, however, to test the reliability of these buffers and to provide information for assessing the approach of the system to equilibrium conditions. These minerals were reacted with seawater at an initia! water/rock mass ratio of 5 . The experiment was conducted at $200,250,300$, and $350^{\circ} \mathrm{C}$ at 500 bars to investigate the role of temperature in the alteration process. Temperature was subsequently decreased in a similar manner to evaluate reversibility of the system.

SOLVEQ, a computer prosram developed by Reed (1982), was utilized to assess aqueous speciation and ionic activities at experimental conditions from the fluids analyses. This information permiired calculation of mineral solubilities for comparison with estimates provided by SUPCRT (Helgeson et al., 1978). Alteration of fluid chemistry during rock/water interaction was compared with that predicted by the EQ3/6 software package (Wolery, 1979) as at means of assessing the impact of mineral solubility changes on the theoretical reaction path model.

\section{RESULTS}

Petrographic and $\mathrm{x}$-ray diffraction examination of reactants and products indicated no major changes in the mineral assemblage other than the transformation of gibbsite to boehmite, alteration of a portion of the magnetite to hematite, and the formation of a minor amount of smectite. The chlorite phase (essentially a pure clinochlore) was not significantly altered during the experiment. Kaolinite was present in the products, though its abundance decreased relative to the reactants.

Changes in fluid chemistry included an increase in silica concentration to near ciuartz saturation levels with dissolved aluminum in the range of 0.005 to 0.01 millimoles $/ \mathrm{kg}$ (Table 1). Also observed was the development of moderately acid conditions and decrease of dissolved magnesium in response to precipitation of chlorite. Dissolved iron concentrations subsequently rose in response to the acid state of the fluid. Minor chloride depletions were observed early in the experiment in response to the dehydration of gibbsite to boehmite. This 
Table 1. Concentrations for dissolved components (millimoles/kg) and ph for chlorite solubility experiment.

\begin{tabular}{|c|c|c|c|c|c|}
\hline Temperature & Time (hri) & $\underline{A !}$ & $\underline{\mathrm{SiO}}_{2}$ & $M g$ & $\mathrm{HH}\left(25^{\circ} \mathrm{C}\right)$ \\
\hline scawater, $25^{\circ} \mathrm{C}$ & -- & $<.(10) 2$ & $<(0)$ & 53.4 & 7.9 \\
\hline \multirow[t]{5}{*}{$2000^{\circ} \mathrm{C}$} & 22.0 & 0.005 & 1.91 & 45.5 & 5.00 \\
\hline & 116.5 & 0.004 & 2.20 & 44.2 & 4.26 \\
\hline & 213.0 & 0.006 & 2.26 & 43.6 & 4.15 \\
\hline & 479.0 & - & 2.23 & 43.2 & 4.15 \\
\hline & 1126.5 & 0.008 & 2.33 & 42.8 & 4.06 \\
\hline \multirow[t]{3}{*}{$250^{\circ} \mathrm{C}$} & 44.5 & $0.0(0) 7$ & 5.23 & +3.8 & 2.85 \\
\hline & 212.5 & 0.010 & 5.44 & 42.2 & 2.81 \\
\hline & 761.0 & 0.004 & 5.88 & 42.0 & 2.73 \\
\hline \multirow[t]{4}{*}{$.300^{\circ} \mathrm{C}$} & 23.5 & 0.007 & 11.1 & 38.4 & 2.28 \\
\hline & 170.0 & 0.005 & 11.6 & 38.3 & 2.22 \\
\hline & 456.0 & 0.006 & 11.9 & 37.1 & 2.21 \\
\hline & 1152.0 & 0.006 & 11.8 & 35.0 & 2.15 \\
\hline \multirow[t]{4}{*}{$350^{\circ} \mathrm{C}$} & 22.0 & 0.008 & 19.9 & 27.0 & 1.98 \\
\hline & 165.5 & $0.0(19$ & 18.7 & 24.1 & 1.97 \\
\hline & 453.5 & 0.007 & 18.8 & 22.3 & 1.97 \\
\hline & 934.0 & 0.007 & 18.6 & 20.2 & 1.96 \\
\hline \multirow[t]{2}{*}{$3(x)^{0} \mathrm{C}$} & 332.5 & 0.007 & 13.9 & 30.0 & 2.09 \\
\hline & 837.0 & 0.007 & 13.9 & 30.0 & 2.14 \\
\hline \multirow[t]{3}{*}{$250^{\circ} \mathrm{C}$} & 382.0 & 0.003 & 8.55 & 34.0 & 2.25 \\
\hline & 959.0 & 0.007 & 8.35 & 34.1 & 2.30 \\
\hline & 1727.0 & 0.005 & 8.20 & 34.0 & 2.30 \\
\hline \multirow[t]{2}{*}{$2(x)^{\circ} \mathrm{C}$} & 380.5 & $<.002$ & 4.41 & 37.3 & 2.69 \\
\hline & 1101.0 & $<002$ & 4.33 & 36.3 & 2.73 \\
\hline
\end{tabular}

transformation appears to have gone to completion during the $250^{\circ} \mathrm{C}$ heating stage of the experiment.

\section{DISCUSSION}

The mineral assemblage $\mathrm{Mg}$-chlorite/boehmite kaolinite buffers the activities of the ions $\mathrm{Al}^{3+}$ and $\mathrm{SiO}_{2}$ and the ratio of $\mathrm{Mg}^{2+}$ activity to $\mathrm{H}^{+}$activity at a given pressure and temperature by the following reactions:

$$
\begin{aligned}
& \text { Boehmite }+3 \mathrm{H}^{+}=\mathrm{Al}^{3+}+2 \mathrm{H}_{2} \mathrm{O} \\
& \text { Boehmite }+2 \mathrm{SiO}_{2}+\mathrm{H}_{2} \mathrm{O}=\text { Kiolinite } \\
& \text { Clinochlore }+10 \mathrm{H}^{+}=\text {Boehmite }+5 \mathrm{Mg}^{2+}+3 \mathrm{SiO}_{2}+8 \mathrm{H}_{2} \mathrm{O}
\end{aligned}
$$

Ionic activities may be calculated by using the mineral solubility data from SLPCRT or computed directly using EQ3/6. Alternatively, activities may be computed for the experimental fluid chemistry using SOLVEQ and then utilized to compute mineral solubilities. Comparison of the experimental data and theoretical models may thus be employed to assess the impaci of mineral solubilities on rock/water interaction. This approach may be illustrated by 
considering the fluid data collected at $3000^{\circ} \mathrm{C}$ from the experiment. Reversibility was well demonstrated at this temperature and appears to provide reliable datia on bochnite-clinochlore iolubility.

Examination of the thuid data indicates that dissolved Al concentrations were signilicantly lower than predicted by solubility data for boehmite (reaction 1) from the SUPCRT code. This, in turn, results in lower values for acpeous $\mathrm{SiO}_{2}$ in the theoretical model relative to the experimental data owing to kaolinite dissolution:

$$
\text { Kitolinite }+6 \mathrm{H}^{+}=5 \mathrm{H}_{2} \mathrm{O}+2 \mathrm{Al}^{3+}+3 \mathrm{SiO}_{2}
$$

This is illustrated by the activity diagram shown in Figure 1. Recent bochmite solubility datta provided by Kuyunko et al. (1983) agrees very well with that observed in the experiment and hence was incorporated into the SUPCRT and EQ3/6 data bases. This resulted in a model that agreed reasonably well with the experiment from the standpoint of dissolved Al concentrations. The $\mathrm{SiO}_{2}$ concentrations predicted on the basis of reaction 2, however, then exceed yuartz saturation and render kaolinite unstable. The experimental $\mathrm{SiO}_{2}$ concentrations appear to reflect equilibrium with quartz and, indeed, do correspond very well with quartz solubility data atler correction for salinity effects (Fournier, 1983).

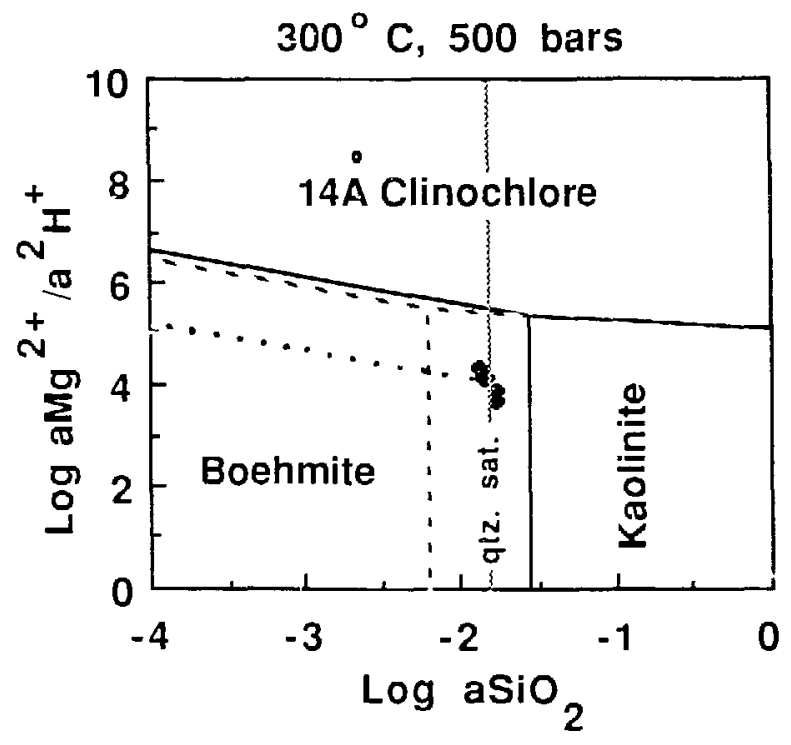

Figure 1. Activity diagram for the system $\mathrm{HCl}-\mathrm{MgO}-\mathrm{SiO} 2-(\mathrm{Al} 2 \mathrm{O} 3$ ) showing phase relationships using original SUPCRT data (dashed lines) and revised boundaries incorporating the solubility data for bochmite of Kuyunko et al (1983) (solid lines). Solid symbols demonstrate reversible approach to equilibrium of experimental fluid chemistry from higher and lower temperatures thus constraining the position or the inferred invarient point and bochmite-clinochlore phase boundary (dotted line).

Fxamination of the fluid data also revealed that the Mg content of the fluids and the in situl pH were considerably lower thin predicted from estimated clinochlore solubility data provided by SLPCRT. This is illustrated in Figure 1, where it can be seen that the clinochlore stability field constructed from the experimental data is considerably larger than the theoretical stability lield. The position of the univarient boundary between clinochlore and boehmite deduced from the experimental data provides a basis for calculating the solubility of clinochlore at $300^{\circ} \mathrm{C}$ and .5()$)$ bars, where clinochlore solubility is expressed in terms of the hydrolysis reaction:

$$
\text { Clinoxhlore }+16 \mathrm{H}^{+}=12 \mathrm{H}_{2} \mathrm{O}+2 \mathrm{Al}^{3+}+5 \mathrm{Mg}^{2+}+3 \mathrm{SiO}_{2}
$$

The activity of $\mathrm{Al}^{3+}$ or this reaction is constrained by boehmite solubility (reactions 1 and 3 ). 
This approich was utilized over the entire temperature range investigated during the experiment to establish the valiation of chlorite solubility with temperature. This is illustratled in Figure 2 where the experimental values of $\log \mathrm{K}$ for reaction 5 are shown and are compalred to those values calculated by SUPCRT at 500 bars. It is apparent from this study that the solubility o " clinochlore is considerably lower than the theoreticill value.

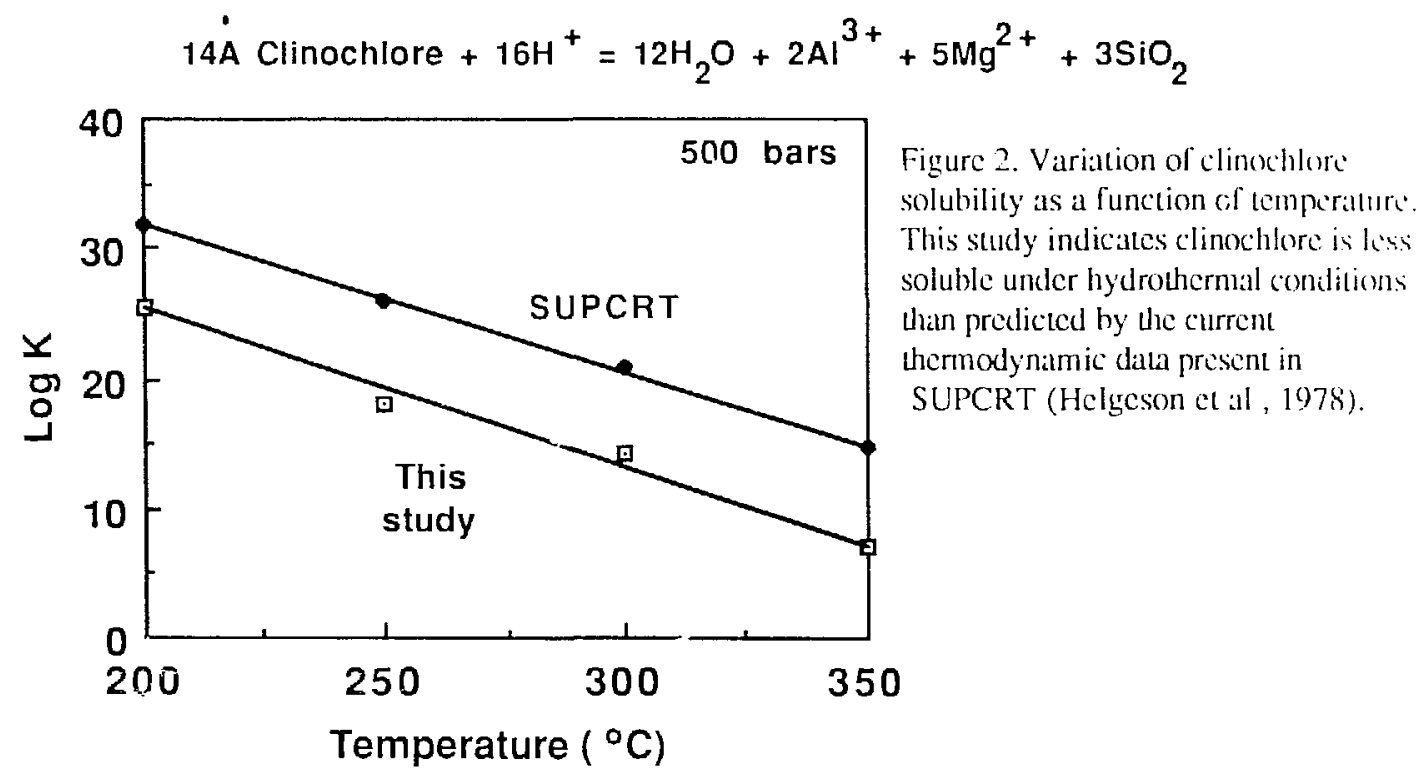

\section{CONCLUSIONS}

The experimental data presented here indicates that the solubility of boehmite is lower than predicted by SUPCRT; our results are in agreement with those of Kuyunko et aㅣ. (1983) and thus clearly indicate a need for updating the SUPCRT data base for this phase. Incorporation of the revised boehmite solubility data into EQ3/6 indicates that kaolinite may not be stable at $300^{\circ} \mathrm{C}$ owing to conversion to quartz. Clinochlore solubility calculated from this study is considerably lower than that predicted by SUPCRT in the temperature range of $200^{\circ} \mathrm{C}$ to $350^{\circ} \mathrm{C}$ at 500 bars.

Further experimental studies should be conducted to evaluate aluminosilicate solubilities under l.ydrothermal conditions. Incorporation of this data into SUPCRT and the EQ3/6 data base may be readily performed as it becomes available. This approach is essential to accurate modeling of mass transport of chemical components during rock/water interaction and will ultimately increase our understanding of hydrothermal alteration processes in a variety of geological environments.

\section{REFERENCES}

Fournier, R.O. (1983) A method of calculating quartz solubilities in aqueous sodium chloride solutions. Geochem. Cosmochim Acta 47, 579-586.

Helgeson, H.C., Delany, J.M., Nesbitt, N.H. and Bird, D.K. (1978) Summary and critique of thermodynamic properties of rock-forming minarals. Amer. I. Sci. 278-A, 229p. 
Kuyunko, N.S., Malinin, S.D. and Khodakovskiy, I.L. (1983) An experimental study of aluminum ion hydrolysis at 150,200 , and $250^{\circ} \mathrm{C}$. Geokhimiya 3, 419-428. [in Russian].

Reed, M.H. (1982) Calculation of multicomponent chemical equilibria and reaction processes in systems involving minerals, gases, and an aqueous phase.Geochim. Cosmochim. Acta $46,513-528$.

Wolery, T.H. (1979) Calculation of chemicai equilibrium between aqueous solution and minerals: the FQ3/6 software package. Lawrence Livermore Laboratory Report UCRL-52658, 41 p. 
Appendices 


\section{Appendix A. Agenda}

\section{Monday, September 15}

Morning S
8:40 a.m.
9:05 a.m.
9:35 a.m.

10:20 a.m.

10:50 a.m.

11:20 a.m.

11:50 a.m.

Evening Session

7:30 p.m.

8:00 p.m.

8:30 p.m.

9:00 p.m.

Morning Session

$8: 30$ a.m
Geochemical Model Development

Session Chairman: William McKenzie

EQ3/6 - Status and Future Development - Tom Wolery

Reduced Basis Method for Calculating Heterogeneous Geochemical Equilibria in Multicomponent Reaction Paths - Craig Bethke

A Theoretical Basis for the Coupling of Chemical Reactions to Open System Processes - Ernie Perkins

Calculations of Geochemical Mass Transfer as a Function of Temperature and Time - William Murphy

Comparison of Reaction Path and Interacting Continua Models of Mass Transfer in Geochemical Systems - Peter Lichtner

Comparison of Measured and Predicted Solubilities of Aluminosilicates in Aqueous Solution - John Apps

Surface Complexes in Geochemical Processes - James Leckie

Ore Deposits

Session Chairman: Ken Jackson

Chlorite Solubility Between 200 and $350^{\circ} \mathrm{C}$ - An Experimental and Theoretical Modeling Study - Edward Thornton, Jeffrey Seewald, and William E. Seyfried, Jr.

Boiling of Geothermal Waters: Base and Precious Metal Precipitation, Arsenic and Antimony Speciation and the Role of Metal Transport in Gas Phase - Nicholas Spycher and M. H. Reed

Chemical Evolution of Oil-Field Brines and the Formation of SedimentHosted Cu-Pb-Zn Sulfide - Dimitri A. Sverjensky

Clay-Carbonate Reactions in Oil Sand Reservoirs During Steam Flooding William Gunter and G. W. Bird

\section{Tuesday, September 16}

Nuclear Waste Disposal

Session Chairman: Virginia Oversíby

Application of Equilibrium Computations to the Geochemical Interpretation of the Deep Granitic Groundwaters at the Stripa Research Sile, Sweden - D. Kirk Nurdstrom 
$9: 00$ a.m.

$9: 30$ a.m.

$10: 15$ a.m.

10:45 a.m.

1 1:15 a.m.

11:45 a.m.

Poster Session
Modeling Interaction of Deop Groundwaters with Bentonite -

Harss Wariner

Reaction-Path Modeling of Interaction Between Basalt and Croundwater in the Columbia Plateau, Washington - Cleve Solomon

A Consistent Set of Thermodynamic Constints tor Americium III Species with Hydroxyl and Carbonate - Jerry Kerrisk and Bob Silva

Thermodynamic and Kinetic Modeling of Glass Leaching in a W..ste Package Environment - Bernd Grambow

Hydrothermal Alteration of the Auriat Granite (Creuse, France):

Comparison of Experimental Observations and Modeling with EQ3/6-

I. C. Petit and 1. C. Parneix

Compatibility of Observed Mineralogy in Borehole Cores, Palo Duro

Basin, Texas, with Coexisting Brines, as Computed by EQ3/6 - Paul Cloke

The NEA Thermochemical Daia Base - Hans Wannier

Variations of $\mathrm{K}_{\mathrm{D}}$ Due to Changes in Solution Chemistry - James Leckie

EQ3,6 Data Base - On-going Development at Lawrence Livermore

National Laboratory - Joan M. Delany

Improvemer:, sis ine Solid Solution Modeling Capabilities of EQ3/6 William L. Bourcier

Models for Activity Coefficients in Brines - Ken Jacksin and Tom Wolcry

Computer Modeling of the Aqueous Geochemistry of the Archean Hydrosphere and the Formation of BIF - William Glassley, Ken jackson, and William L. Bourcier

Progressive Mineral Alteration and Oxygen Isotope Depletions in the Lake City Hydrothermal System (23 Ma), Colorado - Peter Larson

Predicted Reaction Paths During the Hydrothermal Alteration of Columbia River Basalts: Sensitivity Analysis of Variability in the Composition Mesostasis - Randy Arthur

Preliminary Chemical Modeling of Epithermal Processes at Creede, Colorado: The Role of Fluid Mixing as an Ore Deposition Mechanism Geoffrey Plumlee and D. O. Hayba

Software for the Computation and Graphical Display of Intensive Variable Phase Diagrams - Ernie Perkins, T. H. Browni, ind $R$ G. Berman

Mineral and Stable lsotope Evidence for Regin:al Fluid Flow and Rock-Water Interaction in the San locan Basin, New Mexico Gene Whitncy and Roy Northrep 


\begin{tabular}{|c|c|}
\hline Evening Session & $\begin{array}{l}\text { Hydrothermal Systems } \\
\text { Session Chairman: Bill Glassley }\end{array}$ \\
\hline 7:30 p.m. & $\begin{array}{l}\text { Application of EQ3/6 to Modeling the Chemical Evolution in } \\
\text { Hydrothermal Systems: An Example at the Valles Caldrea, N.M. - } \\
\text { Art White and N. Chuma }\end{array}$ \\
\hline 8:00 p.m. & $\begin{array}{l}\text { Chemical Equilibrium and lsotopic Models of Mid-Ocean Ridge } \\
\text { Hot Springs - Teresa S. Bowers }\end{array}$ \\
\hline \multirow[t]{2}{*}{$8: 30$ p.m. } & $\begin{array}{l}\text { Serpentinization Reaction Pathway: Implications for Modeling } \\
\text { Approach - Dave Janecky }\end{array}$ \\
\hline & Wednesday, September 17 \\
\hline Morning Session & $\begin{array}{l}\text { Sedimentary Basins/Groundwater } \\
\text { Session Chairman: Roger Aines }\end{array}$ \\
\hline $8: 30$ a.m. & $\begin{array}{l}\text { Paleohydrologic Analysis of Geopressures and Meteoric Infiltration } \\
\text { in the Gulf Coast Basin - Wendy Harrison and Craig Bethke }\end{array}$ \\
\hline 9:00 a.m. & $\begin{array}{l}\text { Predicting Mineral Dissolution and Precipitation During Burial: } \\
\text { Synthetic Diagenetic Sequences - Carol /. Bruton }\end{array}$ \\
\hline 10:00 a.m. & $\begin{array}{l}\text { Modeling Mass Transfer Reaction Rates: Calcite Precipitation and } \\
\mathrm{CO}_{2} \text { Outgassing in a Karst Stream - Janet Herman }\end{array}$ \\
\hline $10: 30$ a.m. & $\begin{array}{l}\text { Geochemical Modeling of Water-Rock Interactions in High lsland } \\
\text { Oil Field, Offshore Texas - Yousif Kharaka and J. D. Cocker }\end{array}$ \\
\hline 11:00 a.m. & $\begin{array}{l}\text { Evaluation of an Equilibrium Speciation Model for the Aqueous Low } \\
\mathrm{pH} \text { lron-Sulfate System at } 25^{\circ} \mathrm{C} \text { - Susan Stipp }\end{array}$ \\
\hline $11: 30$ a.m. & $\begin{array}{l}\text { Chemical Equilibrium in Mineral Formation and Diagenesis in the } \\
\text { Carbonate Evaporite System - John Weare, Nancy Moller, Jerry } \\
\text { Greenberg, and Andrew Felmy }\end{array}$ \\
\hline
\end{tabular}




\section{Appendix B. List of Attendees}

Hugh Abercrombie, University of Calgary

Pradeep Aggarwal, U. S. Ceological Survey

Roger Aines, Lawrence Livermore National Laboratury

Charlie Alpers, University of Michigan

john A. Apps, Lawrence Berkeley Laboratory

Randy Arthur, Rockwell Haniord Operations

Mark D. Barton, University of California, Los Angeles

Craig Bethke, University of Illinois

Dennis Bird, Stanford University

Mark S. Bloom, Monash University

Jo'ın Karl Bohlke, Argonne National Laboratory

W'illiam Bourcier, Lawrence Livermore National Laboratory

Tiresa S. Bowers, Massachusetts Institute of Technology

fohn Bradbury, U.S. Nuclear Regulatory Commission

Carol Bruton, Lawrence Livermore National Laboratory

Leonel Vaca Castelion, Instituto Costarricense de Electricidad

Paul L. Cloke, Batelle Memorial Institute

Harrison Crecrait, UNOCAL Geothermal

Allan Crowe, University of Alberta

Kenneth Czyscinski, Roy F. Weston lnc.

Joan Delany, Lawrence Livermore National Laboratory

Andrew Dickson, University of California, San Diego

Fiona M. Doyle, University of California, Berkelcy

Kenneth Eggert, Lawrence Livermore National Laboratory

Donald O. Emerson, Lawrence Livermore National Laboratory

Robert Erikson, Battelle Pacific Northwest Laboratory

R. Stephen Fisher, University of Texas at Austin

Mormino Gabricle, AGIP - S. p. A.

Alan Gaines, National Science Foundation

Barbara Gällinatti, UNOCAL Geothermal

William Glassley, Lawrence Livermore National Laboratory

Bernd Grambow, Hahn-Meitner-Institut Berlin GmbH.

William Gunter, Alberta Research Council

Linda Hansen, Lawrence Livermore National Laboratory 
Wendy J. Harrison, Exxon Production Research Co.

Dan Hayba, U. S. Geological Survey

Janet Herman, University of Virginia

C. J. Hostetler, Battelle Pacific Northwest Laboratories

Dwight Hoxie, L. S. Geological Survey

Ken Jackson, Lawrence Livermore National Laboratory

Dave Janecky, Los Alamos National Laboratory

Hamlin Jennings, National Bureau of Standards

Anne Jordan, U. S. Geological Survey

Walt Kelly, U. S. Nuclear Regulatory Commission

Jerry F. Kerrisk, Los Alamos National Laboratory

Yousif Kharaka, U. S. Geological Survey

Deborah Kiraly, Lawrence Livermore National Laboratory

Kevin Knauss, Lawrence Livermore National Laboratory

Brian Koenig, Union Geothermal Division

Linda Kovach, U. S. Nuclear Regulatory Commission

Paul H. Krumrine, PQ Copr.

Ken Krupka, Battelle Pacific Northwest Laboratory

John Y. T. Kwong, B. C. Ministry of Energy, Mines, and Pelroleum Resources

Donald Langmuir, Colorado School of Mines

Peter B. Larson, Washington State University

James $O$. Leckie, Stanford University

Peter Lichtner, University of California, Berkeley

Donald E. Livingston, U.S. Department of Energy

David T. Long, Michigan State University

Bertero Luigi, AGIP S. p. A.

Paul Lundgard, UNOCAL

Rigel Lustwerk, Pennsylvania State University

John J. Mahoney, Battelle Pacific Northwest Laboratory

Steven R. Mattson, Science Applications International Corporation

Arend Meijer, Los Alamos National Laboratory

Indu D. Meshri, Amoco Production Company

Jonathon Meyers, IT Corporation

Kathleen A. Mihm, U. S. Department of Encrgy

Anthony B. Muller, Science Applications International Corporation

Gregory Murphy, Lawrence Livermore National Laboratory 
William M. Murphy, Rockwell Hanford Operations

Ross McCartney, Geoscience 1 td.

William McKenzie, Lawrence Livermore National Laboratory

D. Kirk Nordstrom, U. S. Geological Survey

H. Roy Northrop, L'. S. Geological Survey

Helen Nuckolls, Woodward Clyde Consultants

Virginia Oversby, Lawrence Livermore National Laboratory

Roberto Pabalan, University of California, Berkeley

Edward S. Patera, Jr., U. S. Department of Energy

Steve Paulson, U.S. Burcau of Mines

Ermie H. Perkins, Alberta Research Council

Andrew Peterson, Sandia National Laboratories

Jean-Claude Petit, Commissariat a l'Energie Atomique

Geoffrey Plumlee, U. S. Geological Survey

Heather Ponader, Stanford University

Larry Ramspott, Lawrence Livermore National Laboratory

Richard E. Rice, Butler University

Nicholas M. Rose, Stanford University

Patricia Salter, Rockwell Hanford Operations

Jeffrey Seewald, University of Minnesot:;

Henry Shaw, Lawrence Livermore National Laboratory

Robert J. Silva, Lawrence Livermore National Laboratory

Robert W. Smith, Rockwell Hanford Operations

G. Cleve Solomon, Rockwell Hanford Operations

Sheldon E. Sommer, Mobil

Nicholas Spycher, University of Oregon

Susan Stipp, Stanford University

Denis M. Strachan, Battelle Pacific Northwest Laboratory

Dimitri Sverjensky, The John Hopkins University

Edward C. Thornton, University of Minnesota

Brian E. Viani, Lawrence Livermore National Laboratory

Karen L. Von Damm, Oak Ridge National Laboratory

Jana M. Walker, Amoco Production Co.

Hans Wanner, NEA Data Bank

John H. Weare, University of California, San Diego

David Weill, Aluminum Company of America 
Arthur F. White, Lawrence Berkeley Laboratory

Gene Whitncy, U. S. Geological Survey

Alan Williams, University of California, Riverside

Timothy Wilson, Michigan State University

Thomas J. Wolery, Lawrence Livermore National Laboratory

Ray W. Wuolo, EWA, Inc.

Albert Yang, U. S. Genlogical Survey

George Zandt, Lawrence Livermore National Laboratory 